\title{
SEBASTIAN CRAVERO
}

Desenvolvimento de Procedimentos para Avaliação de Curvas $J-R$ em Espécimes à Fratura SE(T) Utilizando o Método de Flexibilidade

Tese Apresentada à Escola Politécnica da Universidade de São Paulo para a obtenção do Título de Doutor em Engenharia. 


\section{SEBASTIAN CRAVERO}

\section{Desenvolvimento de Procedimentos para Avaliação de Curvas $J-R$ em Espécimes à Fratura SE(T) Utilizando o Método de Flexibilidade}

Tese Apresentada à Escola Politécnica da Universidade de São Paulo para a obtenção do Título de Doutor em Engenharia.

Área de Concentração:

Engenharia Naval e Oceânica

Orientador:

Prof. Livre-Docente

Dr. Claudio Ruggieri 
Este exemplar foi revisado e alterado em relação à versão original, sob responsabilidade única do autor e com a anuência de seu orientador.

São Paulo, de dezembro de 2007.

Assinatura do autor

Assinatura do orientador

FICHA CATALOGRÁFICA

Cravero, Sebastian

Desenvolvimento de procedimentos para avaliação de curvas $\mathrm{J}-\mathrm{R}$ em espécimes à fratura $\mathrm{SE}(\mathrm{T})$ utilizando o método de flexibilidade / S. Cravero. -- ed.rev. -- São Paulo, 2007.

$162 \mathrm{p}$.

Tese (Doutorado) - Escola Politécnica da Universidade de São Paulo. Departamento de Engenharia Naval e Oceânica.

1.Mecânica da fratura I.Universidade de São Paulo. Escola Politécnica. Departamento de Engenharia Naval e Oceânica II.t. 
Ao Felipe, à Fabiana e à minha mãe Raquel... 


\section{AGRADECIMENTOS}

Ao amigo e orientador Prof. Dr. Claudio Ruggieri, pela orientação, constante incentivo e pelo exemplo de profissionalismo;

Ao amigo Prof. Dr. Moyses Szajnbok, pelos úteis conselhos e sabedoria que soube transmitir;

Ao Prof. Dr. Waldek Wladimir Bose Filho, ao Roberto Ramon Piovatto e todo o pessoal da USP São Carlos pela camaradagem e excelente relação profissional.

Ao Dr. Hugo Ernst do Centro de Pesquisas Industriais do Grupo Tenaris (Argentina) pelos úteis conselhos sobre o cálculo dos fatores $\gamma$.

Ao Dr. Eduardo Hippert Jr. da Petrobras pelo material e usinagem dos corpos-de-prova $\mathrm{SE}(\mathrm{T})$.

Aos colegas do NAMEF: Carlos Mojica, Fernando Dotta, Gustavo Bologinesi Donato, Juan Carlos Galindo, Lucas Nobumichi Yshii, Luiz Augusto de Lima e Silva, Mario Sergio Giancoli Schiodo e Mauricio de Carvalho Silva pelo companheirismo e amizade;

À Fundação de Amparo à Pesquisa do Estado de São Paulo (FAPESP) pela bolsa de Doutorado.

Ao Departamento de Engenharia Naval e Oceânica da EP-USP pelo apoio institucional.

Ao Departamento de Engenharia Aeronáutica e de Materiais da EESC que fez possível a realização dos ensaios experimentais contidos neste trabalho. 


\section{RESUMO}

Este trabalho apresenta o desenvolvimento de procedimentos para a medição de curvas de resistência $J-R$ em espécimes $\mathrm{SE}(\mathrm{T})$ usando os métodos de flexibilidade elástica e método $\eta$. Uma descrição da metodologia sobre a qual $J$ e o crescimento de trinca são medidos estabelece o contexto para determinar dados de resistência ao rasgamento dúctil com o emprego de curvas carga vs. deslocamento obtidas experimentalmente. A extensiva matriz de análises em estado plano de deformações de espécimes SE(T) complementada, em algumas geometrias selecionadas, com análises $3 D$ permite a determinação numérica da flexibilidade adimensional, $\mu$, e fatores $\eta_{J} \mathrm{e} \gamma$ para uma grande faixa de proporções geométricas e propriedades de material características de aços estruturais e para dutos. Ensaios laboratoriais de um aço API 5L X60 à temperatura ambiente usando espécimes $\mathrm{SE}(\mathrm{T})$ carregados por pinos com entalhes laterais (side-grooves) fornecem os dados de carga e deslocamento necessários para validar o procedimento para determinar curvas de resistência do material. Os resultados apresentados nesta tese fornecem uma base de soluções para o futuro estabelecimento de norma padronizada para a medição experimental de curvas $J$ - $R$ em corpos de prova $\mathrm{SE}(\mathrm{T})$ mecanicamente similares a dutos com defeitos bidimensionais. 


\begin{abstract}
This work provides an estimation procedure to determine $J$-resistance curves for pinloaded and clamped SE(T) fracture specimens using the unloading compliance technique and the $\eta$-method. A summary of the methodology upon which $J$ and crack extension are derived sets the necessary framework to determine crack resistance data from the measured load $v s$. displacement curves. The extensive plane-strain analyses and key $3 D$ results enable numerical estimates of the nondimensional compliance, $\mu$, and parameters $\eta$ and $\gamma$ for a wide range of specimen geometries and material properties characteristic of structural and pipeline steels. Laboratory testings of an API 5L X60 steel at room temperature using pin-loaded SE(T) specimens with side-grooves provide the load-displacement data needed to validate the estimation procedure for measuring the crack growth resistance curve for the material. The results presented in the this thesis produce a representative set of solutions which lend further support to develop standard test procedures for constraint-designed $\mathrm{SE}(\mathrm{T})$ specimens applicable in measurements of crack growth resistance for pipelines.
\end{abstract}




\section{SUMÁRIO}

\section{LISTA DE FIGURAS}

\section{LISTA DE TABELAS}

\section{LISTA DE SÍMBOLOS}

\section{LISTA DE ABREVIATURAS E SIGLAS}

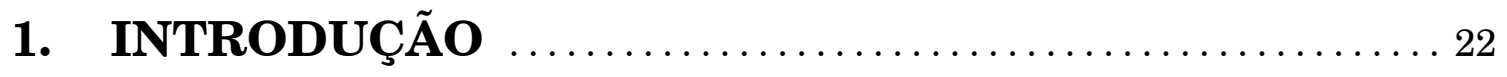

1.1 Cenário Energético Brasileiro $\ldots \ldots \ldots \ldots \ldots \ldots \ldots \ldots \ldots \ldots \ldots \ldots \ldots \ldots$

1.2 Avaliação da Integridade Estrutural em dutos $\ldots \ldots \ldots \ldots \ldots 23$



2. MECÂNICA DA FRATURA ELASTO-PLÁSTICA . . . . . . 29

2.1 Fratura Frágil e Fratura Dúctil $\ldots \ldots \ldots \ldots \ldots \ldots \ldots \ldots \ldots \ldots \ldots$

2.2 Mecânica da Fratura Monoparamétrica . . . . . . . . . . . . . 31

2.3 A Integral $\boldsymbol{J}$ e o Campo de Tensões Elasto-plásticas . . . . . . 33

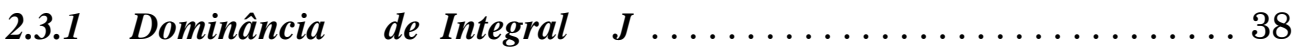

2.3.2 Dominância de Integral J com Crescimento de Trinca . . 40

2.4 Aspectos Fenomenológicos do Rasgamento Dúctil



2.5 Curvas de Resistência ao Rasgamento Dúctil $\ldots . \ldots \ldots \ldots \ldots 45$

3. MEDIÇÃO DE CURVAS DE RESISTÊNCIA

EM ESPÉCIMES SE(T) $\ldots \ldots \ldots \ldots \ldots \ldots \ldots \ldots \ldots \ldots$

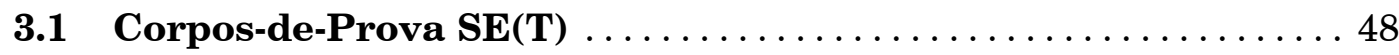

3.2 Método $\eta$ e Método de Flexibilidade no Descarregamento . . . . 49

3.3 Correção por Rotação em Corpos-de-Prova SE(T) . . . . . . . 53

3.4 Medição Experimental de integral $J$ Empregando

Múltiplos Corpos-de-Prova $\ldots \ldots \ldots \ldots \ldots \ldots \ldots \ldots \ldots \ldots \ldots \ldots \ldots \ldots \ldots$

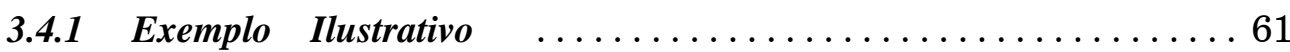

4. MATRIZ DE ANÁLISE E PROCEDIMENTOS

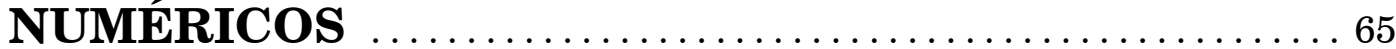

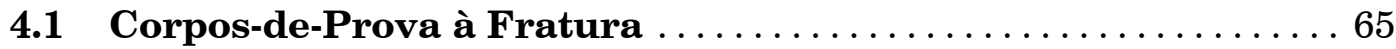

4.1.1 Corpos-de-Prova em Estado Plano de Deformações . . .665

4.1.2 Modelos de Corpos-de-Prova em Contexto 3D ........67

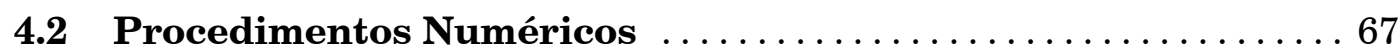

4.2.1 Código de Elementos Finitos $\ldots \ldots \ldots \ldots \ldots \ldots \ldots \ldots \ldots \ldots$ 


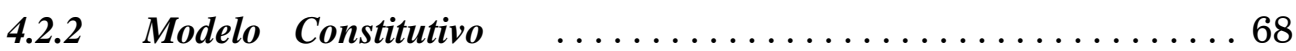

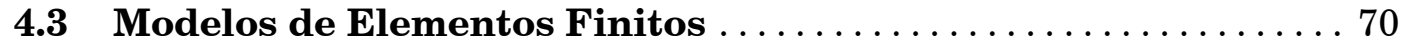

4.4 Modelagem Numérica do Crescimento Dúctil de Defeitos . . . . 72

4.5 Modelos Numéricos para Crescimento Estável de Trinca . . . . . 76

5. PROCEDIMENTOS PARA O CÁlCULO DA FLEXIBILIDADE E FATORES $\eta_{\boldsymbol{J}} \mathbf{E} \boldsymbol{\gamma} \ldots \ldots \ldots \ldots \ldots \ldots$

5.1 Obtenção de Equações de Flexibilidade . . . . . . . . . . . . . 79

5.2 Verificação da Metodologia $\ldots \ldots \ldots \ldots \ldots \ldots \ldots \ldots \ldots \ldots \ldots$

5.3 Obtenção dos Fatores $\eta_{J}$ Plásticos .................. 83



5.5 Medição Experimental de Integral $J$ Empregando o Deslocamento da Boca da Trinca . . . . . . . . . . . . . . . 89

5.6 Relação entre LLD e CMOD $\ldots \ldots \ldots \ldots \ldots \ldots \ldots \ldots \ldots \ldots \ldots$

6. FLEXIBILIDADE PARA ESPÉCIMES SE(T) . . . . . . 96

6.1 Efeitos $3 D$ na Flexibilidade .................... 98

7. FATORES $\eta_{J}, \gamma$ E RAIOS PLÁSTICOS PARA ESPÉCIMES SE(T) CARREGADOS POR PINOS . . . . 100

7.1 Fatores $\eta_{J}$ derivados de CMOD ................... 100



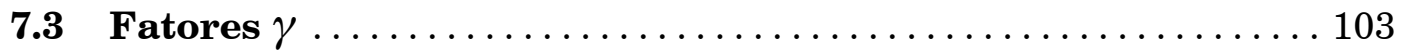

7.4 Comentários Sobre os Resultados do Capítulo ........... 106

7.5 Cálculo do Fator de Rotação Plástica para Espécimes SE(T) . 107

8. FATORES $\eta_{J} \mathbf{E} \gamma$ PARA ESPÉCIMES SE(T) FIXADOS POR GARRAS ..................... 112

8.1 Fatores $\eta_{J}$ derivados de CMOD $\ldots \ldots \ldots \ldots \ldots \ldots \ldots \ldots \ldots \ldots \ldots$

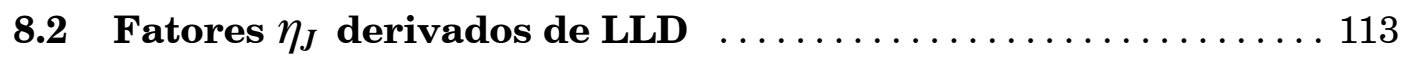

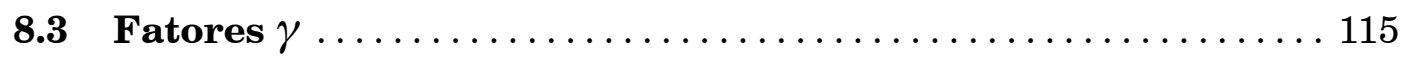

9. COMPARAÇÃO DE RESULTADOS $2 D$ E $3 D \ldots \ldots \ldots 119$

10. CALIBRAÇÃo DOS MODELOS DE CÉLULAS COMPUTACIONAIS E MEDIÇÕES EXPERIMENTAIS

10.1 Calibração dos Parâmetros das Células Computacionais . . . . . 122 
10.2 Medição Experimental de Curvas de Resistência

\section{CONCLUSÕES E SUGESTÕES PARA A}

CONTINUAÇÃO DO TRABALHO .................. 133

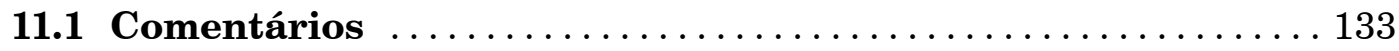

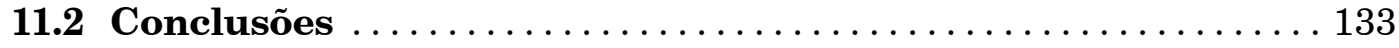

11.3 Sugestões para a Continuação do Trabalho $\ldots \ldots \ldots \ldots \ldots \ldots$



Anexo A: FATORES $\eta$ E $\gamma$ PARA A MEDIÇÃo

EXPERIMENTAL DE INTEGRAL $\boldsymbol{J} \ldots \ldots \ldots \ldots 144$

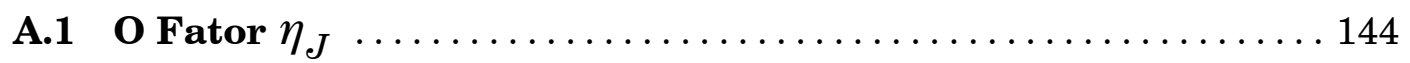

A.2 Medição Experimental de Integral $J$ com Crescimento

Estável de Trinca ............................... 152

Anexo B: SOLUÇÕES PARA O FATOR DE INTENSIDADE DE TENSÓES $K_{I}$ EM ESPÉCIMES SE(T) 


\section{LISTA DE FIGURAS}

Figura 1. Exemplo de colapso catastrófico de gasoduto onde a iniciação e propagação dúctil de um defeito originou uma trinca instável propagando-se por dezenas de metros ................ 23

Figura 2. Zonas plásticas de espécimes $S E(T)$ carregados por pinos, espécimes $S E(B)$ e dutos contendo trincas com diâmetro de $508 \mathrm{~mm}$ (20") e espessura de $12,7 \mathrm{~mm} \ldots \ldots \ldots \ldots \ldots \ldots \ldots . \ldots 28$

Figura 3. Fractografias representativas de fraturamento frágil;

a) Fractografia de superficies de fratura; b) SEM, magnificação de X500. [30]

Figura 4. a) Fractografias representativa de fratura dúctil. Observar a presença do defeito original, a zona com crescimento estável de trinca e finalmente o colapso da estrutura; b) MEV, fratura dúctil com formação de alvéolos nucleados por inclusões [31]. . . . . 32

Figura 5. a) Chapa tracionada representativa de um componente estrutural constituída de material plasticamente deformável contendo uma trinca; b) Corpo de prova convencional $S E(B)$ de 3 Pontos à Flexão; c) Zona de dominância $J$ na região da ponta da trinca indicando a validade da mecânica da fratura

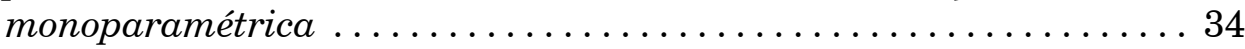

Figura 6. Comparação da curva tensão-deformação para um material não-linear elástico e um elasto-plástico $\ldots \ldots \ldots \ldots \ldots \ldots \ldots \ldots$

Figura 7. Contorno arbitrário em volta da ponta da trinca . . . . . . . . 36

Figura 8. Comparação das tensões de abertura na frente de trinca em espécime $S E(B)$ com a / W=0,5 para diferentes valores de $J$ aplicado e o modelo $B L . . . \ldots \ldots \ldots \ldots \ldots \ldots \ldots \ldots \ldots \ldots . . \ldots 40$

Figura 9. Comparação das tensões de abertura na frente de trinca em espécime $S E(T)$ com a/W=0,5 para diferentes valores de $J$ aplicado e o modelo $B L \ldots \ldots \ldots \ldots \ldots \ldots \ldots \ldots \ldots \ldots \ldots \ldots$

Figura 10. Tensões de abertura na frente de trinca em espécime $S E(T)$ com a / W=0,2 para diferentes valores de $J$ aplicado.

Figura 11. a) Esquema de crescimento de trinca controlado por $J$ [32];

b) Perda de dominância $J$...

Figura 12. a) Formação de trinca (macroscópica) interna na região de estricção em barra cilíndrica submetida a tração uniaxial [39];

b) Crescimento e coalescência de microcavidades nucleadas a partir de inclusões não metálicas . . .................. 44

Figura 13. Micrografias com diferentes níveis de detalhamento mostrando a propagação estável de defeito em aço dúctil .............46

Figura 14. Esquema de curva de resistência indicando os diferentes estágios de crescimento do defeito

Figura 15. a) Descarregamentos parciais durante a evolução do carregamento com a abertura da ponta da trinca (CMOD);

b) Definição da área plástica sob a curva carga-deslocamento 
Figura 16. Corpo-de-prova $S E(T)$ carregado por pinos para as configurações não deformada e deformada ................ 58

Figura 17. Detalhe da medição do CMOD; neste caso o deslocamento à direita do ponto de medição faz com que o valor medido seja diferente ao que seria medido sem rotação ............... 59

Figura 18. Curvas carga vs. deslocamento da linha de carga obtidas de modelos de elementos finitos para corpos-de-prova $S E(T)$ com diferentes profundidades de trinca . . . ...............62

Figura 19. Energias de deformação dos corpos-de-prova $S E(T)$ como função da profundidade de trinca para três níveis de deslocamento da linha de carga ..............................663

Figura 20. Comparação dos valores de integral J obtidos dos modelos numéricos com os valores obtidos empregando a Eq. 33 para três níveis de deslocamento da linha de carga . ............664

Figura 21. Geometrias dos Corpos-de-Prova; a) $S E(T)$ carregado por pino; b) $S E(T)$ fixado por garras; c) $S E(B) \ldots \ldots \ldots \ldots \ldots \ldots \ldots 6$

Figura 22. Curvas tensão-deformação verdadeira dos diferentes materiais considerados

Figura 23. Modelos de elementos finitos empregados nas análises em estado plano de deformações; a) espécime $S E(T)$ carregado por pinos com $a / W=0,5$ e $H / W=6$; b) espécime $S E(T)$ fixado por garras com a $/ W=0,5$ e $H / W=6$; c) Detalhe da ponta da trinca arredondada construída com anéis focais centrados na mesma 71

Figura 24. Modelo de elementos finitos $3 D$ para espécime $S E(T)$ carregado

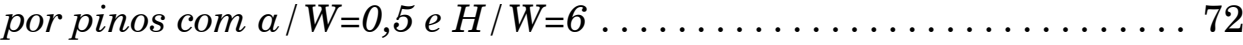

Figura 25. Modelagem da extensão dúctil de trincas utilizando células computacionais; a) Caminho esquemático de crescimento dúctil sob modo I de fratura.; b) Arranjo de células computacionais para a modelagem

Figura 26. Modelo de elementos finitos de espécime $C(T)$ empregado na calibração dos parâmetros numéricos das células computacionais ................................ 77

Figura 27. Modelos de elementos finitos de espécimes $S E(T)$ empregados nas análises de crescimento estável de trinca;

a) $a / W=0,5$; b) $a / W=0,2$

Figura 28. Variação linear da carga por unidade de espessura com a abertura da boca da trinca (CMOD) para espécime $S E(B)-1 T$ e diferentes relações $a / W$

Figura 29. Variação linear da carga por unidade de espessura com a abertura da boca da trinca (CMOD) para espécime $S E(T)$ carregado por pinos com $H / W=6$ e diferentes relações $a / W \ldots \ldots 80$

Figura 30. Variação linear da carga por unidade de espessura com a abertura da boca da trinca (CMOD) para espécime $S E(T)$ fixado por garras com $\mathrm{H} / \mathrm{W}=6$ e diferentes relações $a / W$

Figura 31. Variação da flexibilidade normalizada, $\mu$, em função de $a / W$ para corpos-de-prova $S E(B)$ 
Figura 32. Variação do fator $\eta_{J}$ derivado do CMOD com o incremento do carregamento normalizado para espécimes $S E(T)$ com $H / W=6$ e $n=10$; a) $S E(T)$ carregado por pinos com $a / W=0,1$; b) $S E(T)$ carregado por pinos com a /W=0,7; c) $S E(T)$ fixado por garras com a/W=0,1; d) $S E(T)$ fixado por garras com $a / W=0,7 \ldots 86$

Figura 33. Variação do fator $\eta$ derivado do $L L D$ com o incremento do carregamento normalizado para espécimes $S E(T)$ com $H / W=6$ e $n=10$; a) $S E(T)$ carregado por pinos com $a / W=0,1$; b) $S E(T)$ carregado por pinos com a $/ W=0,7$; c) $S E(T)$ fixado por garras com $a / W=0,1$; d) $S E(T)$ fixado por garras com $a / W=0,7 \ldots 87$

Figura 34. Quociente entre $L L D_{p}$ e $C M O D_{p}$ como função de $J$ normalizado para espécimes $S E(T)$ carregados por pinos com $H / W=6$ e $n=5 \ldots 93$

Figura 35. Quociente entre $L L D_{p}$ e $C M O D_{p}$ como função de $J$ normalizado para espécimes $S E(T)$ carregados por pinos com $H / W=6$ e $n=10 \quad \ldots 93$

Figura 36. Quociente entre $L L D_{p}$ e $C M O D_{p}$ como função de J normalizado para espécimes $S E(T)$ carregados por pinos com $H / W=6$ e $n=20 \quad \ldots 94$

Figura 37. Quociente entre $L L D_{p}$ e $C M O D_{p}$ como função de J normalizado para espécimes $S E(T)$ fixado por garras com $H / W=6$ e $n=5 \ldots \ldots .94$

Figura 38. Quociente entre $L L D_{p}$ e $C M O D_{p}$ como função de J normalizado para espécimes $S E(T)$ fixado por garras com $H / W=6$ e $n=10$. . . . 95

Figura 39. Quociente entre $L L D_{p}$ e $C M O D_{p}$ como função de $J$ normalizado para espécimes $S E(T)$ fixado por garras com $H / W=6$ e $n=20 \ldots \ldots 95$

Figura 40. Variação da flexibilidade, $\mu$, com a relação a / W para espécimes $S E(T)$ carregados por pino e diferentes relações $H / W \ldots \ldots \ldots . . .97$

Figura 41. Variação da flexibilidade, $\mu$, com a relação a/W para espécimes $S E(T)$ fixados por garras com diferentes relações $H / W \ldots \ldots \ldots . . .98$

Figura 42. Variação dos fatores $\eta_{J}$ derivados de CMOD com a profundidade de trinca a / W para espécimes $S E(T)$ carregados por pinos $e$

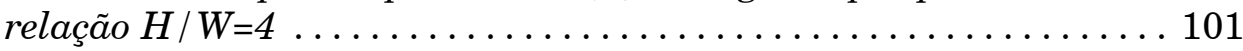

Figura 43. Variação dos fatores $\eta_{J}$ derivados de CMOD com a profundidade de trinca a / W para espécimes $S E(T)$ carregados por pinos e relação $H / W=6$

Figura 44. Variação dos fatores $\eta_{J}$ derivados de CMOD com a profundidade de trinca a / W para espécimes $S E(T)$ carregados por pinos e

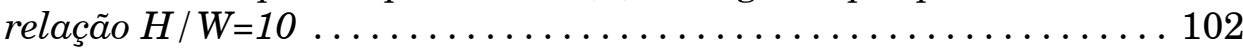

Figura 45. Variação dos fatores $\eta_{J}$ derivados de LLD com a profundidade de trinca a/W para espécimes $S E(T)$ carregados por pinos $e$ relação $H / W=4$. . . . . . . . . . . . . . . . . . . . . . . . . . . . . 104

Figura 46. Variação dos fatores $\eta_{J}$ derivados de $L L D$ com a profundidade de trinca a/W para espécimes $S E(T)$ carregados por pinos $e$

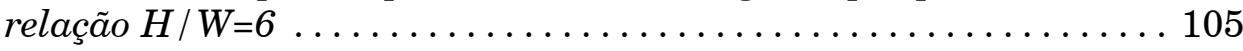

Figura 47. Variação dos fatores $\eta_{J}$ derivados de LLD com a profundidade de trinca a / W para espécimes $S E(T)$ carregados por pinos $e$

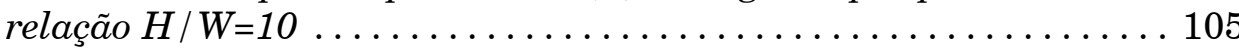

Figura 48. Variação do fator $\gamma$ com a relação a / W para espécime $S E(T)$ carregado por pinos com $H / W=6$ e diferentes propriedade de material . ................................ 106 
Figura 49. Variação do fator de rotação plástico com o CMOD normalizado para espécimes $S E(T)_{P}$ com a $/ W=0,2$, diferentes propriedades de material e $H / W=4$ e 6 . . . . . . . . . . . . . . . . . . . . . . . . . . . 109

Figura 50. Variação do fator de rotação plástico com o CMOD para espécime $S E(T)_{P}$ com a / W=0,3; $H / W=6$ e diferentes propriedades de material ....................................... 109

Figura 51. Variação do fator de rotação plástico com o CMOD para espécime $S E(T)_{P}$ com $a / W=0,4 ; H / W=6$ e diferentes propriedades

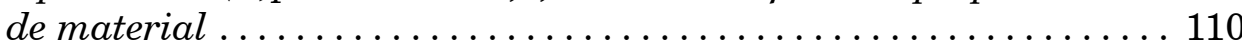

Figura 52. Variação do fator de rotação plástico com o CMOD normalizado para espécimes $S E(T)_{P}$ com a $W=0,5$, diferentes propriedades

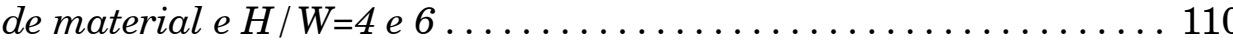

Figura 53. Variação do fator de rotação plástico com o CMOD para espécime $\mathrm{SE}(\mathrm{T})_{P}$ com a $/ \mathrm{W}=0,6 ; \mathrm{H} / \mathrm{W}=6$ e diferentes propriedades de material .................................... 111

Figura 54. Variação do fator de rotação plástico com o CMOD para espécime $S E(T)_{P}$ com a / W $=0,7 ; H / W=6$ e diferentes propriedades de material ...................................... 111

Figura 55. Variação dos fatores $\eta_{J}$ derivados de CMOD com a profundidade de trinca a /W para espécimes $S E(T)$ fixados por garras $e$ relação $H / W=4$

Figura 56. Variação dos fatores $\eta_{J}$ derivados de CMOD com a profundidade de trinca a / W para espécimes $S E(T)$ fixados por garras e relação $H / W=6$

Figura 57. Variação dos fatores $\eta_{J}$ derivados de CMOD com a profundidade de trinca a / W para espécimes $S E(T)$ fixados por garras e relação $H / W=10$

Figura 58. Variação dos fatores $\eta_{J}$ derivados de LLD com a profundidade de trinca a /W para espécimes $S E(T)$ fixados por garras $e$

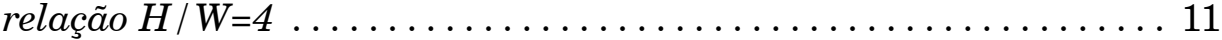

Figura 59. Variação dos fatores $\eta_{J}$ derivados de $L L D$ com a profundidade de trinca a / W para espécimes $S E(T)$ fixados por garras $e$ relação $H / W=6$

Figura 60. Variação dos fatores $\eta_{J}$ derivados de $L L D$ com a profundidade de trinca a / W para espécimes $S E(T)$ fixados por garras $e$ relação $H / W=10$

Figura 61. Variação do fator $\gamma$ com a relação a / $W$ derivado do $L L D$ para espécime $S E(T)$ fixado por garras com $H / W=6$ e diferentes propriedade de material

Figura 62. Comparação entre fatores $\eta_{J}$ derivados do CMOD para diferentes relações a / W obtidos de modelos em estado plano de deformações e modelos $3 D$ de corpos-de-prova $S E(T)$ carregados por pinos com $H / W=6$ e $n=10$. . . . . . . . . . . . . 12

Figura 63. Comparação entre fatores $\eta_{J}$ derivados de LLD para diferentes relações a / W obtidos de modelos em estado plano de deformações e modelos $3 D$ de corpos-de-prova $S E(T)$ carregados por pinos com $H / W=6$ e $n=10$ 
Figura 64. Comparação entre fatores $\eta_{J}$ derivados de CMOD para diferentes relações a/W obtidos de modelos em estado plano de deformações e modelos $3 D$ de corpos-de-prova $S E(T)$ fixados por garras com $H / W=6$ e $n=10$

Figura 65. Comparação entre fatores $\eta_{J}$ derivados de LLD para diferentes relações a / W obtidos de modelos em estado plano de deformações e modelos $3 D$ de corpos-de-prova $S E(T)$ fixados por garras



Figura 66. Comparação entre as curvas $R$ medidas experimentalmente em espécimes $C(T)$ e as obtidas numericamente com o modelo de células computacionais (aço API 5 L X60) ................. 123

Figura 67. Comparação entre curvas $R$ obtidas dos modelos de células computacionais de espécimes $S E(T)$ com diferentes profundidades de trinca

Figura 68. a) Máquina de ensaios MTS com o corpo-de-prova $S E(T)$ montado;

b) Detalhe de montagem do corpo-de-prova com o extensômetro (clip gage); c) Corpo-de-prova com trinca profunda após o ensaio ................................. 125

Figura 69. Curva carga vs. CMOD medida experimentalmente correspondente

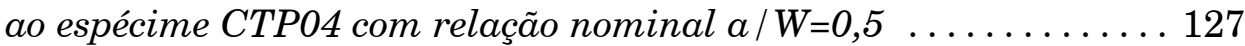

Figura 70. Curva carga vs. CMOD medida experimentalmente correspondente ao espécime CTR04 com a /W-nominal=0,2 . . . 127

Figura 71. Curvas $R$ correspondentes aos espécimes com relação nominal a / W=0,5 obtidas usando os resultados apresentados noscapítulos precedentes . .......................... 131

Figura 72. Curvas $R$ correspondentes aos espécimes com relação nominal a / W=0,2 obtidas usando os resultados apresentados nos capítulos precedentes

Figura 73. Comparação de faixas de resultados entre espécimes com relação nominal a $/ W$-nominal $=0,5$ e a $/ W$-nominal $=0,2 \ldots \ldots \ldots \ldots \ldots 132$

Figura A.1. Curvas carga vs. deslocamento com crescimento de trinca controlado por deslocamento ou por força . ................. 146

Figura A.2. Corpo-de-prova com entalhe lateral submetido a flexão pura; a) Sem deformar; b) Deformado ........................ 147

Figura A.3. Corpo-de-prova à flexão em 3 pontos $\ldots \ldots \ldots \ldots \ldots \ldots \ldots \ldots \ldots$

Figura A.4. Curva esquemática carga vs. deslocamento plástico com crescimento estável de trinca . . . . . . . . . . . . . . . . . . . . . . 153

Figura B.1. Variação do fator de intensidade de tensões adimensional em função de a / W e diferentes valores de $H$ / W para o espécime $S E(T)$ carregado por pino. ........................ 160

Figura B.2. Variação do fator de intensidade de tensões adimensional em função de a / W e diferentes valores de $H / W$ para o espécime $S E(T)$ carregado por garra. . . . . . . . . . . . . . . . . . . . . . 160 


\section{LISTA DE TABELAS}

Tabela 1: Comparação dos valores de $J$ obtidos da derivada da

energia de deformação com os valores obtidos por elementos finitos 64

Tabela 2: Dimensões dos espécimes 1-T estudados 66

Tabela 3: Coeficientes para o ajuste polinomial da Eq. (60) . . . . . . . . 97

Tabela 4: Coeficientes para os ajustes polinomiais das Eqs. (62) e (63) . . . . 107

Tabela 5: Coeficientes para os ajustes polinomiais das Eqs. (65) e (66) . . . . . 118

Tabela 6: Propriedades mecânicas do aço API 5L X60 usado no ensaio

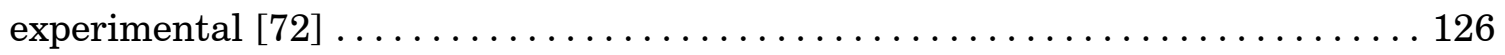

Tabela 7: Características dos corpos-de-prova ensaiados [73] . . . . . . . . 128

Tabela B.1: Valores dos coeficientes $\xi$ para o cálculo dos SIFs de

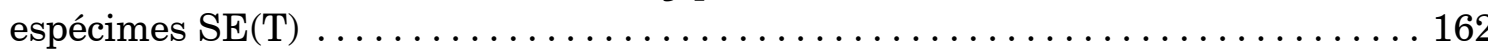




\section{LISTA DE SÍMBOLOS}

$a$ : comprimento de trinca.

$a_{0}$ : comprimento inicial de trinca.

A: área sob a curva carga vs. deslocamento.

$A_{e}$ : área elástica sob a curva carga vs. deslocamento.

$A_{p}$ : área plástica sob a curva carga vs. deslocamento.

$A_{p}^{\mathrm{CMOD}}$ : área plástica sob a curva $P$-CMOD.

$A_{p}^{\mathrm{LLD}}$ : área plástica sob a curva $P$-LLD.

$b$ : ligamento remanescente $(b=W-a)$.

$b_{0}$ : ligamento remanescente inicial.

$B$ : espessura do espécime.

$B_{N}$ : espessura do corpo-de-prova considerando a redução causada pelos entalhes laterais.

$B_{e f}$ : espessura efetiva do corpo-de-prova $\left(B_{e f}=B-\left(B-B_{N}\right)^{2} / B\right)$.

$c$ : excentricidade da carga em espécimes $\mathrm{SE}(\mathrm{T})$ carregado por pinos.

$\mathrm{C}_{c}^{\text {CMOD }}$ : flexibilidade no CMOD corrigida.

$\mathrm{e}_{m}^{\text {CMOD }}$ : flexibilidade medida no CMOD.

$\mathrm{C}_{c}^{\mathrm{LLD}}$ : flexibilidade na LLD corrigida

$\mathrm{C}_{m}^{\mathrm{LLD}}$ : flexibilidade medida na LLD.

$d s$ : elemento do contorno $\Gamma$.

$E$ : modulo de elasticidade.

$D$ : distância vertical entre o ponto de fixação do extensômetro e a linha de simetria do espécime (Capítulo 3); espessura da camada de células computacionais (Capítulos 4 e 10).

$\mathcal{F}\left(a_{k} / W\right)$ : fator adimensional de intensidade de tensões.

$f$ : porosidade corrente no modelos GT.

$f_{0}$ : porosidade inicial no modelos GT.

$f_{E}$ : valor crítico de porosidade no modelos GT.

G: taxa de liberação de energia de Griffith. 
$H$ : comprimento do corpo-de-prova.

$I_{n}$ : constante de integração na solução do campo $H R R$.

$J$ : integral $J$.

$J_{2}$ : teoria de plasticidade de Von Mises.

$J_{e}$ : componente elástica da Integral $J$.

$J_{p}$ : componente plástica da Integral $J$.

$J_{\mathrm{Ic}}:$ valor de integral $J$ que produz a iniciação de crescimento de trinca.

$K_{\mathrm{I}}$ : fator de intensidade de tensões

$K_{\mathrm{Ic}}$ : valor de $K_{\mathrm{I}}$ que produz a iniciação de crescimento de trinca.

$M$ : constante que determina o valor de dominância $J$ (Capítulo 2); momento aplicado (Anexo A).

$n$ : coeficiente de encruamento.

$O$ : centro de rotação.

$P$ : força aplicada.

$P_{m}$ : força medida.

$P_{c}$ : força corrigida por rotação.

$q_{i}$ : fatores de ajuste da função de escoamento no modelo de GT $(i=1,2,3)$.

Q: parâmetro para quantificar o nível de restrição plástica.

$r$ : distância à ponta da trinca (coordenadas polares).

$r_{1}$ : distância horizontal entre a linha de carga e o centro de rotação no espécime sem deformar.

$r_{2}$ : distância horizontal entre a linha de carga e o centro de rotação no espécime deformado.

$R_{C}$ : posição horizontal do centro de rotação.

$r_{p}$ : fator de rotação plástico.

$T_{i}$ : vetor de tração $(i=1,2)$.

$u_{i}$ : vetor de deslocamento $(i=1,2)$.

$U$ : energia de deformação.

$U_{p}$ : componente plástica da energia de deformação. 
$U^{*}$ : energia de deformação complementar.

$V$ : deslocamento da boca da trinca (CMOD).

$V_{m}$ : deslocamento da boca da trinca medido.

$V_{c}$ : deslocamento da boca da trinca corrigido por rotação.

$V_{p}$ : componente plástica do deslocamento da boca da trinca $\left(\mathrm{CMOD}_{p}\right)$.

W: largura do corpo-de-prova.

W: densidade de energia de deformação.

$z$ : espessura das lâminas de fixação do extensômetro.

Z: terceira direção em sistema de coordenadas ortogonal.

$\alpha$ : constante da equação de Ramberg-Osgood

$\gamma$ : fator adimensional para corrigir a integral $J$ devido aos efeitos de crescimento de trinca.

$\gamma_{C}$ : fator adimensional para corrigir a integral $J$ devido aos efeitos de crescimento de trinca em espécimes $\mathrm{SE}(\mathrm{T})_{C}$.

$\gamma_{P}$ : fator adimensional para corrigir a integral $J$ devido aos efeitos de crescimento de trinca em espécimes $\mathrm{SE}(\mathrm{T})_{P}$.

$\Gamma$ : caminho de integração usado para a obtenção de $J$.

$\delta$ : abertura da ponta da trinca (do inglês: Crack Tip Opening Displacement).

$\Delta$ : deslocamento da linha de carga (LLD).

$\Delta_{e}$ : deslocamento elástico da linha de carga $\left(\mathrm{LLD}_{e}\right)$.

$\Delta_{p}$ : deslocamento plástico da linha de carga $\left(\operatorname{LLD}_{p}\right)$.

$\varepsilon$ : deformação uniaxial.

$\varepsilon_{t}$ : deformação máxima à ruptura.

$\varepsilon_{0}$ : deformação de referência (geralmente igual á deformação de escoamento).

$\widetilde{\varepsilon}_{i j}$ : Função adimensional na solução do campo $H R R$.

$\eta_{J}=\eta_{J}^{\mathrm{LLD}}$ : fator adimensional derivado da curva $P$-LLD para calcular $J$. Notar

que, em alguns casos, é suprimido o sobrescrito LLD para simplificar a notação.

$\eta_{J, C}^{\mathrm{LLD}}$ : fator $\eta_{J}^{\mathrm{LLD}}$ para corpos-de-prova $\mathrm{SE}(\mathrm{T})$ fixados por garras.

$\eta_{J, P}^{\mathrm{LLD}}$ : fator $\eta_{J}^{\mathrm{LLD}}$ para corpos-de-prova $\mathrm{SE}(\mathrm{T})$ carregados por pinos.

$\eta_{J}^{\mathrm{CMOD}}$ : fator adimensional derivado da curva $P$-CMOD para calcular $J$. 
$\eta_{J, C}^{\mathrm{CMOD}}$ : fator $\eta_{J}^{\mathrm{CMOD}}$ para corpos-de-prova $\mathrm{SE}(\mathrm{T})$ fixados por garras.

$\eta_{J, P}^{\mathrm{CMOD}}$ : fator $\eta_{J}^{\mathrm{CMOD}}$ para corpos-de-prova $\mathrm{SE}(\mathrm{T})$ carregados por pinos.

$\theta$ : ângulo de rotação.

$\theta_{c}$ : ângulo de rotação devido à presença da trinca.

$\theta_{n c}$ : ângulo de rotação correspondente ao corpo sem trinca.

$\mu$ : flexibilidade adimensional.

$\rho$ : arredondamento inicial da ponta da trinca nos modelos numéricos.

$\sigma$ : tensão uniaxial.

$\bar{\sigma}$ : tensão plástica corrente.

$\sigma_{0}$ : tensão de referência (geralmente igual á tensão de escoamento).

$\sigma_{e}:$ tensão de Von Mises.

$\sigma_{f}$ : tensão de referência (geralmente: $\sigma_{f}=\left(\sigma_{y s}+\sigma_{u}\right) / 2$ ).

$\sigma_{m}:$ tensão hidrostática.

$\sigma_{u}$ : limite de resistência.

$\sigma_{y s}:$ tensão de escoamento.

$\sigma_{i j}$ : tensor de tensões.

$\widetilde{\sigma}_{i j}$ : função adimensional na solução do campo $H R R$.

$v$ : coeficiente de Poisson

$\phi$ : ângulo inicial entre o ponto de fixação do extensômetro e o centro de rotação do espécimes medido com a horizontal. 


\section{LISTA DE ABREVIATURAS E SIGLAS}

$2 D$ : contexto bidimensional.

$3 D$ : contexto tridimensional.

API: Instituto americano de petróleo (do inglês: American Petroleum Institute).

ASTM: Sociedade americana de ensaios e materiais (do inglês: American Society for Testing and Materials).

BS: padrão Britânico (do inglês: British standard).

CMOD: abertura da boca da trinca (do inglês: crack mouth opening displacement).

$\mathrm{CMOD}_{e}$ : componente elástica da abertura da boca da trinca.

CTOD: abertura da ponta da trinca (do inglês: Crack Tip Opening Displacement).

Curva $R$ : curva de resistência à propagação estável de trinca.

FAD: curva de avaliação de falha (do inglês: failure assessment diagram).

GT: modelo constitutivo de Gurson - Tvergaard.

$H R R$ : solução analítica para o campo de tensões e deformações na frente de trinca dada pela integral $J$.

LLD: deslocamento da linha de carga (do inglês: load line displacement).

MFEL: mecânica da fratura elástica linear.

MFEP: mecânica da fratura elasto-plástica.

$\mathrm{SE}(\mathrm{B})$ : espécime submetido a flexão com entalhe lateral.

$\mathrm{SE}(\mathrm{T})$ : espécime submetido a tração com entalhe lateral.

$\mathrm{SE}(\mathrm{T})_{P}$ : espécime $\mathrm{SE}(\mathrm{T})$ carregado por pinos.

$\mathrm{SE}(\mathrm{T})_{C}$ : espécime $\mathrm{SE}(\mathrm{T})$ fixado por garras.

SEM: microscopia eletrônica de varredura (do inglês: Scanning Electron Microscopy).

SSY: escoamento em pequena escala (do inglês: small scale yielding). 


\section{INTRODUÇÃO}

\subsection{O Cenário Energético Brasileiro}

O fornecimento energético no território brasileiro deve-se principalmente ao petróleo. Efetivamente, quase $40 \%$ da energia é fornecida por este produto e seus derivados [1]. Adicionalmente, a contribuição do gás natural passou de 4,7\% em 2000 a $8 \%$ em 2005 com perspectivas de incrementar esta contribuição a 12\% em futuro próximo [2]. Evidentemente, uma das questões centrais no cenário energético no médio e longo prazo é o transporte adequado e eficiente destes recursos naturais, particularmente o gás natural. As linhas dutoviárias constituem uma das alternativas mais viáveis, confiáveis e econômicas para o escoamento da produção de gás e petróleo. Desta forma, antecipa-se um significativo aumento da malha de dutos nos próximos anos.

Uma significativa expansão da malha dutoviária para transporte de petróleo, derivados leves/claros e gás natural requer níveis de segurança e confiabilidade operacional cada vez mais elevados objetivando a redução de custos, aumento da eficiência operacional e, mais importante, a eliminação de acidentes causadores de danos ambientais e acidentes potencialmente perigosos em áreas densamente urbanizadas. Este cenário é particularmente importante quando se considera que cerca de $40 \%$ da malha atual de dutos já ultrapassou a vida útil de projeto (comumente 20 anos) ao mesmo tempo que existe uma forte tendência em estender a vida operacional de estruturas antigas. Sob uma ótica voltada ao problema específico de avaliação de integridade estrutural de dutos, o setor industrial identifica algumas necessidades fundamentais tais como aumentar a confiabilidade operacional e a vida útil da malha de dutos já existente, minimizar riscos de vazamento, reduzir o impacto de vazamentos no meio ambiente e reduzir o tempo de reparo melhorando a tecnologia de reabilitação de dutos. Como exemplo, a Fig. 
1 ilustra a severidade do colapso catastrófico em gasoduto originado a partir do crescimento estável (subcrítico) de defeitos, tais como trincas originadas a partir de corrosão localizada (e.g. stress corrosion cracking), falhas em juntas soldadas, etc. [3]. Durante o carregamento da estrutura, o defeito propaga-se de forma estável até que um tamanho crítico seja atingido quando ocorre a falha catastrófica por mecanismo de fratura frágil ou colapso plástico. Para o caso apresentado na Fig. 1, as condições de operação associadas à grande energia armazenada pelo gás provocou a fratura instável da estrutura. Isto evidencia a importância e necessidade de desenvolvimento de tecnologias adequadas à avaliação robusta do comportamento mecânico destas estruturas e do impacto de defeitos sobre a integridade do material.

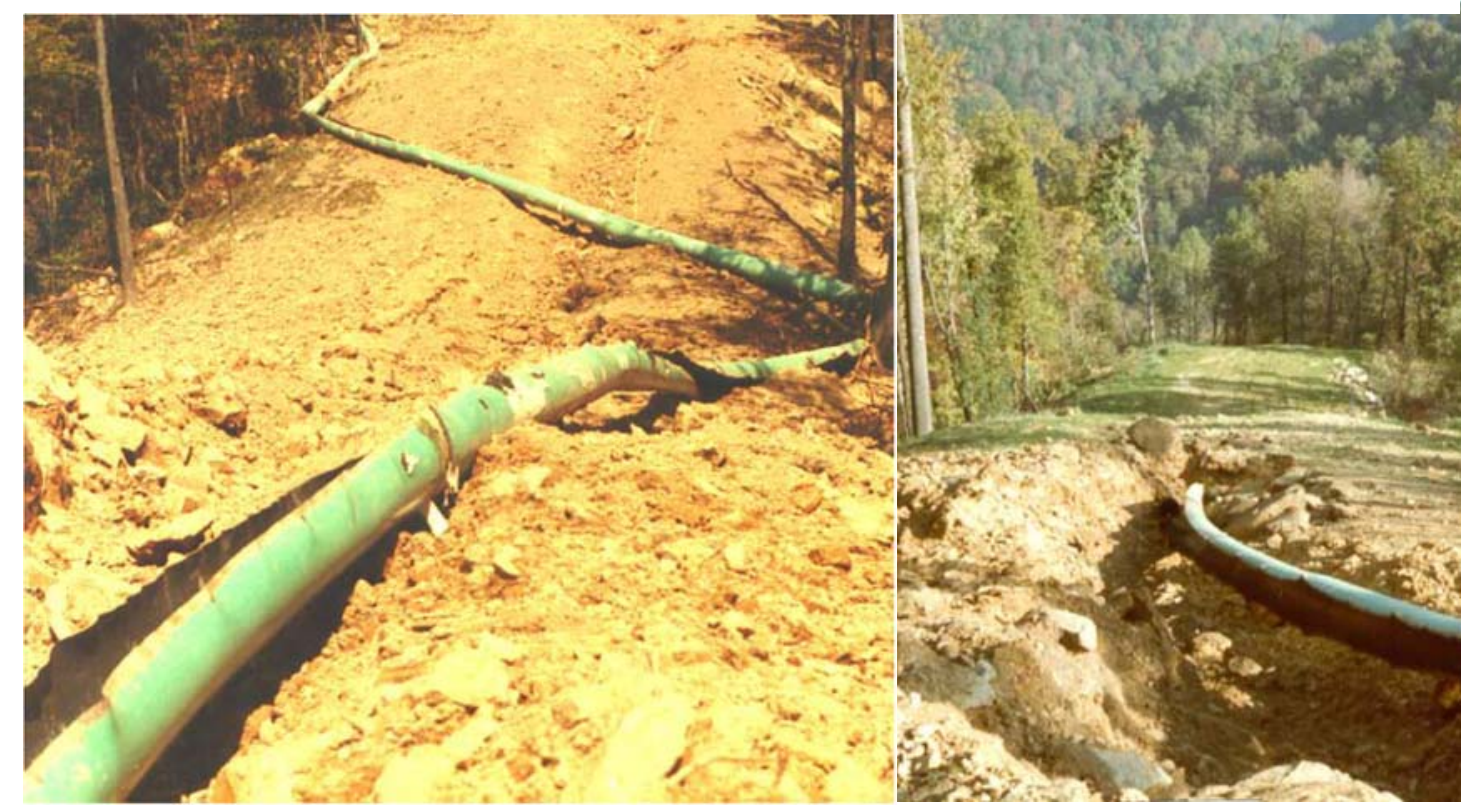

Figura 1 Exemplo de colapso catastrófico de gasoduto onde a iniciação e propagação dúctil de um defeito originou uma trinca instável propagando-se por dezenas de metros. [3]

\subsection{Avaliação da Integridade Estrutural em dutos}

Procedimentos convencionais utilizados para a avaliação da integridade estrutural de dutos geralmente utilizam critérios simplificados incorporando 
mecanismos de colapso plástico e as propriedades mecânicas (tensão de escoamento e limite de resistência) do material [4]. Adicionalmente, estes métodos simplificados estabelecem critérios de aceitação de defeitos baseados em dados experimentais limitados a aços estruturais de baixa resistência, os quais não refletem necessariamente o mecanismo de falha real (e.g., crescimento estável do defeito macroscópico antes do colapso do duto) nem consideram requisitos específicos para aços estruturais de alta resistência correntemente em uso. Procedimentos mais recentes incluem as curvas de avaliação de falhas (do inglês, failure assessment diagram ou $\mathrm{FAD}$ ), as quais definem dois critérios de avaliação para a incorporação da interação entre a falha por fratura e o colapso plástico. Entre estes procedimentos os mais conhecidos e utilizados são API 579 [5] e BS 7910 [6]. O ponto central dos procedimentos FAD está no uso de dados de tenacidade obtidos de corpos-de-prova à fratura com trinca profunda e carregados por flexão para garantir o conservadorismo no procedimento. Entretanto, os dados experimentais de tenacidade utilizados para a construção destas curvas FAD não representam as condições existentes em estruturas com defeitos superficiais, tais como dutos e vasos de pressão cilíndricos (com carregamento predominante de tração e grande plastificação precedente à falha).

Aços estruturais e em particular aços para vasos de pressão geralmente exibem substancial aumento de tenacidade à fratura, caracterizada pela integral $J$ [7], sobre os milímetros iniciais de propagação estável (extensão dúctil) de uma trinca. Este crescimento de trinca é freqüentemente acompanhado por grande aumento da plasticidade do material em relação a uma trinca estacionária. As implicações práticas deste fenômeno sobre o comportamento e integridade de estruturas contendo defeitos são enormes. O aumento da zona plástica na região da trinca com o aumento de carregamento da estrutura representa, em termos mais genéricos, a dissipação do trabalho das forças externas na forma de energia de deformação plástica. Conseqüentemente, uma estrutura constituída de material dúctil contendo um defeito continua a suportar elevados níveis de carga mesmo após a iniciação e propagação estável da fratura. Adicionalmente, filosofias de projeto 
recentes advogam a operação de estruturas sob regime plástico, uma vez que a propagação estável de defeitos contribui para a redistribuição de esforços e sua detecção em operações posteriores de inspeção e manutenção.

Procedimentos avançados para avaliação de defeitos estruturais objetivam incorporar quantitativamente o aumento de tenacidade do material durante a extensão dúctil de trincas através da utilização de curvas de resistência à propagação da fratura (curvas $R$ ). Estas curvas, caracterizadas pela integral $J[7]$ nos primeiros milímetros de crescimento estável do defeito $(\Delta a)$, são medidas experimentalmente por meio de corpos-de-prova laboratoriais (dimensões e configurações reduzidas em relação ao componente estrutural real). Entretanto, a avaliação de defeitos superficiais em dutos e vasos de pressão, por exemplo, requer uma metodologia robusta e verificada para transferir os dados experimentais à estrutura em serviço. A metodologia deve, necessariamente, incorporar o forte efeito do nível de restrição plástica da ponta da trinca (constraint effects) sobre as curvas de resistência ao rasgamento. No entanto, ensaios laboratoriais padronizados para a medição de curvas de resistência indicam um forte efeito das dimensões do espécime, geometria, profundidade relativa de trinca $(a / W)$ e modo de carregamento (tração vs. flexão) sobre a tenacidade para valores similares de crescimento do defeito (veja Joyce e Link [8] para maiores detalhes).

Os efeitos geométricos e de carregamento observados em curvas $R$ têm grandes implicações práticas na avaliação de falhas e decisões de reparo em estruturas com baixo nível de restrição plástica. Componentes estruturais que se enquadram nesta categoria incluem sistemas dutoviários de pressão com defeitos superficiais formados durante a fabricação ou operação (ex., corrosão, inclusões de escórias ou não metálicas, trincas em soldas, etc.) [9-11]. Tais defeitos geralmente desenvolvem níveis baixos de tensões triaxiais (devido aos carregamentos trativos e esforços de membrana associados à pressão interna) deste modo contrastando significativamente com as condições presentes em corpos-de-provas $\mathrm{SE}(\mathrm{B})$ ou $\mathrm{C}(\mathrm{T})$ com trinca profunda utilizados comumente pelas normas correntes [12]. 
Conseqüentemente, a avaliação de defeitos em dutos pressurizados baseada em espécimes padronizados com trinca profunda pode ser excessivamente conservadora. Embora este conservadorismo represente um fator de segurança adicional, um elevado pessimismo na avaliação de defeitos pode levar a reparos desnecessários de dutos em serviço com grande custo operacional.

\subsection{Motivação e Objetivos do Trabalho}

As observações mencionadas anteriormente estimulam esforços sobre o desenvolvimento do uso de espécimes mecanicamente similares em procedimentos de avaliação de defeitos de estruturas com baixo nível de restrição plástica. Particularmente para dutos e vasos cilíndricos, há grande interesse na predição do comportamento à fratura baseada em corpos-de-prova à tração com entalhe lateral - SE(T) single edge notched specimens under tension (veja [13,14]). A principal motivação para o uso de espécimes à fratura $\mathrm{SE}(\mathrm{T})$ na avaliação de defeitos em dutos é a forte similaridade dos campos de tensões e de deformações que determinam a fratura para ambas configurações. Enquanto que os trabalhos das referências $[13,14]$ baseiam-se no estudo das similaridades entre corpos-de-prova SE(T) e dutos com trincas circunferênciais, trabalhos prévios de Cravero e Ruggieri $[15,16]$ utilizaram procedimentos da mecânica da fratura biparamétrica $J-Q[17,18]$ para estabelecer as similitudes entre estas geometrias no caso de defeitos longitudinais. Adicionalmente, a Fig. 2 [19] apresenta a distribuição de tensões de Von Mises obtida por análises de elementos finitos na zona de existência de defeito para dutos com trinca longitudinal externa, espécimes $\mathrm{SE}(\mathrm{T})$ e espécimes $\mathrm{SE}(\mathrm{B})$ padrão, com profundidades relativas de trinca similares. Como pode ser observado, as zonas plásticas entre espécimes $\mathrm{SE}(\mathrm{T})$ e dutos são essencialmente similares o que é um indicativo das condições de fratura similares entre eles. Em contraste, os espécimes à flexão de 3 pontos, $\mathrm{SE}(\mathrm{B})$, apresentam zonas plásticas bastante diferentes para níveis de carregamento similares. Estes resultados sugerem aplicações promissoras de espécimes de fratura $\mathrm{SE}(\mathrm{T})$ em procedimentos de engenharia para a avaliação 
de defeitos em dutos. Entretanto, um completo entendimento do comportamento à fratura de corpos-de-prova $\mathrm{SE}(\mathrm{T})$ para suportar o desenvolvimento de procedimento padronizado de ensaios permanece uma questão em aberto.

Como um passo nesta direção, esta tese de doutorado apresenta o desenvolvimento metodológico de um procedimento para medição de curvas de resistência (curvas $R$ ) em espécimes $\mathrm{SE}(\mathrm{T})$ baseado sobre a técnica de flexibilidade elástica e método $\eta$. Investigações colaborativas, experimentais e computacionais [20] suportam o desenvolvimento de um procedimento padronizado para ensaios desta configuração de corpo-de-prova. No presente estudo, são analisadas geometrias $\mathrm{SE}(\mathrm{T})$ com diferentes proporções geométricas, profundidades de trinca e modos de carregamento. A metodologia sobre a qual $J$ e $\Delta a$ são obtidos estabelece o contexto para a determinação das curvas de resistência à fratura baseadas em dados de carregamento e deslocamentos. Extensivas análises numéricas $2 D$ e $3 D$ permitem a medição da flexibilidade adimensional, $\mu$, e dos fatores $\eta$ e $\gamma$ para uma grande faixa de proporções geométricas de espécimes e propriedades de material representativas de aços estruturais e para dutos de pressão. Ensaios laboratoriais de um aço API 5L X60 à temperatura ambiente usando espécimes SE(T) carregados por pinos fornecem os dados de carga vs. deslocamento para a validação do procedimento de medição de curvas de resistência deste material. A fundamentação analítica dos fatores $\eta$ e $\gamma$ e a justificativa para o emprego de medições CMOD para a obtenção de curvas de resistência são também apresentados em anexo a este trabalho. Os resultados apresentados neste trabalho fornecem uma base de soluções que suportam o futuro estabelecimento de procedimento padronizado para a medição de curvas de resistência em dutos pressurizados empregando espécimes à fratura $\mathrm{SE}(\mathrm{T})$. 
Duto $20 "-a / t=0.1$

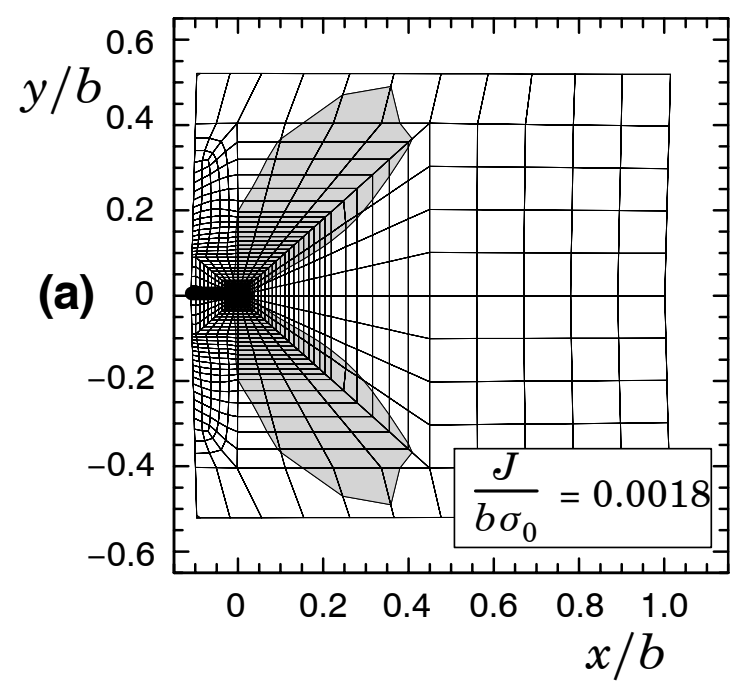

Duto $20 "-a / t=0.5$

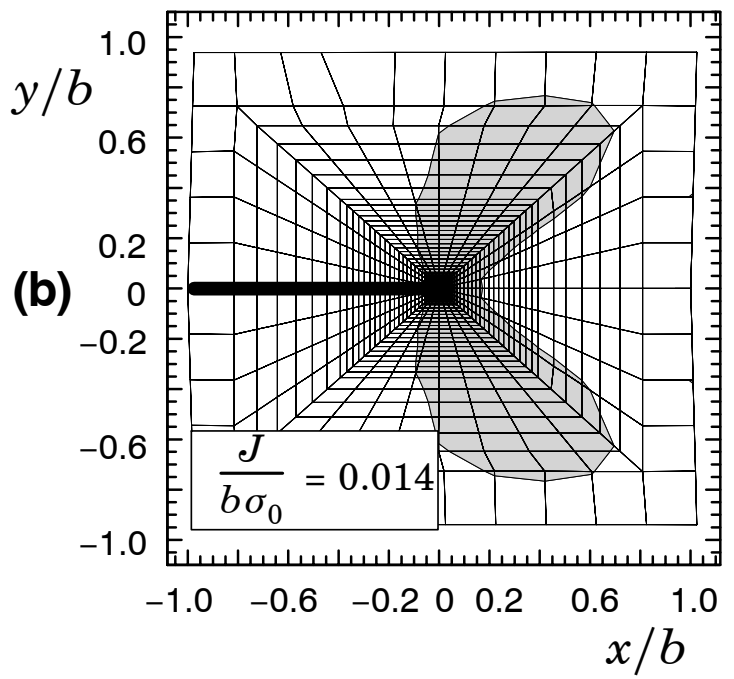

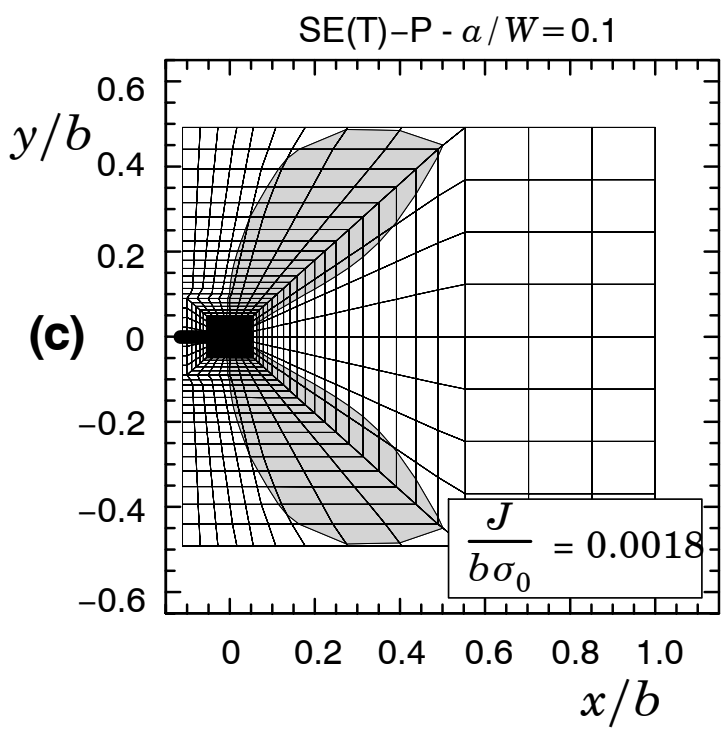
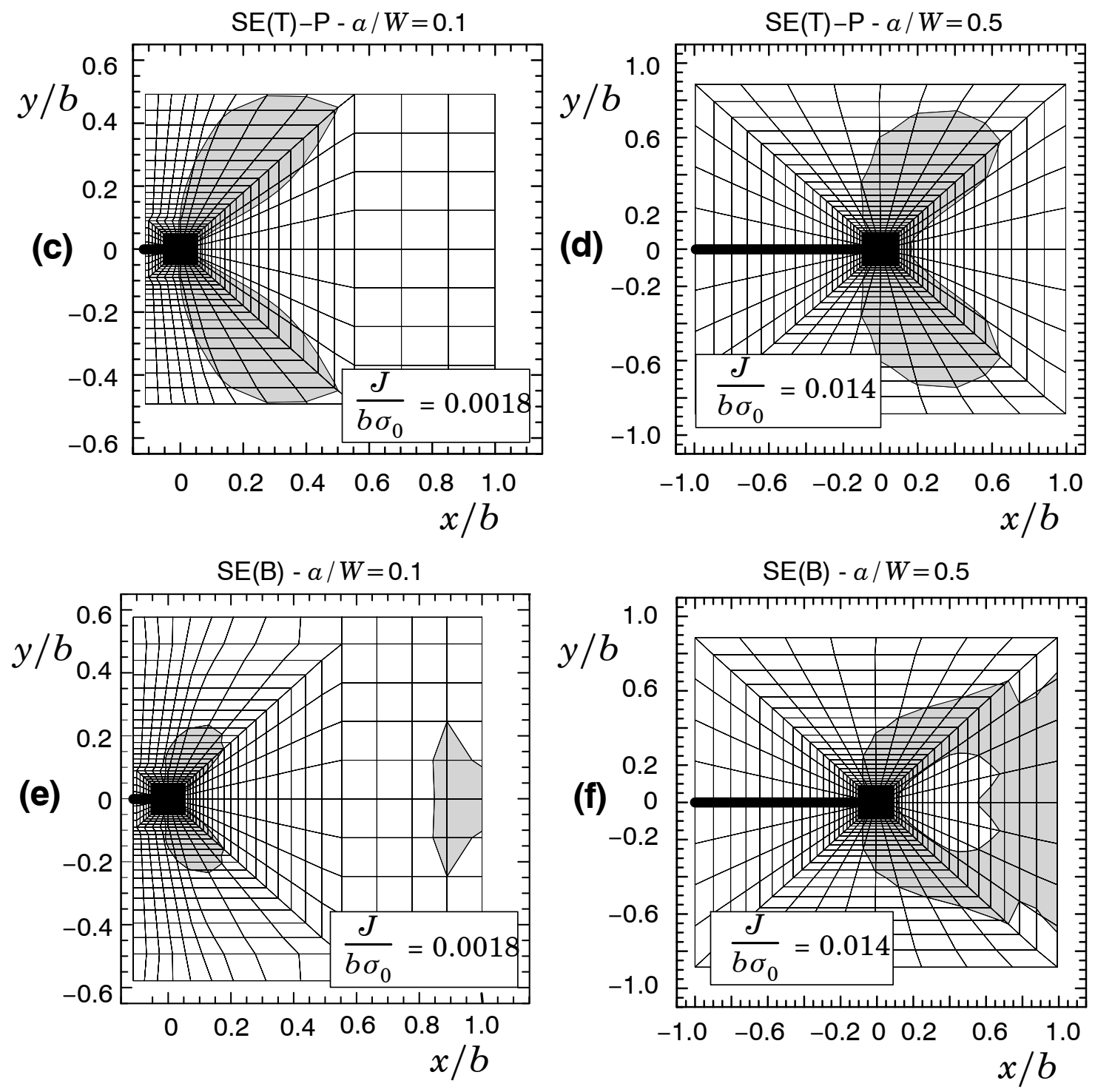

Figura 2 Zonas plásticas de espécimes $S E(T)$ carregados por pinos, espécimes $S E(B)$ e dutos contendo trincas com diâmetro de $508 \mathrm{~mm}$ (20") e espessura de $12,7 \mathrm{~mm}$ [19]. 


\section{MECÂNICA DA FRATURA ELASTO-PLÁSTICA}

O desenvolvimento da mecânica da fratura elasto-plástica (MFEP) [7, 21 - 24] foi motivado pelas limitações da mecânica da fratura elástica linear (MFEL) [25 - 29] em representar o comportamento à fratura de materiais estruturais com grande ductilidade. Sob condições de escoamento e plasticidade limitados, a mecânica da fratura elástica linear permite descrever o comportamento à fratura de diversos materiais e ligas metálicas. Entretanto, com o desenvolvimento de aços de grande resistência e ductilidade, os quais desenvolvem grande plasticidade antes do colapso total, a MFEL encontrou sérias dificuldades na sua aplicabilidade. Os requisitos dimensionais da MFEL para estes tipos de aços requerem tamanhos de corpos-de-prova excessivamente grandes para obter valores válidos de tenacidade à fratura o que torna os ensaios proibitivos. Ainda assim, mesmo sendo possível a sua obtenção, estes não são aplicáveis a estruturas com espessura ou dimensões reduzidas.

Este capítulo apresenta uma breve revisão dos principais conceitos mecânicos associados ao tratamento da fratura em sólidos com comportamento elasto-plástico. O enfoque é dado sob um ponto de vista mecânico sem aprofundar em fenômenos metalúrgicos. É introduzido o parâmetro $J$ para caracterizar as condições à fratura de sólidos elasto-plásticos. Também são discutidas as condições para a aplicabilidade de $J$ tanto para o caso de trinca estacionária como no caso de crescimento estável da mesma. Finalmente, são apresentadas a descrição fenomenológica do crescimento estável de defeitos em materiais dúcteis e a ferramenta empregada para a quantificação deste processo.

\subsection{Fratura Frágil e Fratura Dúctil}

Há dois modos principais de fratura em materiais estruturais. A primeira delas é a fratura frágil, caracterizada pela súbita separação das faces do defeito e pelo 
aspecto granular e plano da superfície de fratura como mostrado na Fig. 3. Este tipo de fratura pode produzir falhas catastróficas em estruturas em operação porque a velocidade de propagação do defeito é muito elevada (muitas vezes ultrapassando a velocidade do som). A fratura frágil pode ser transgranular (clivagem), a qual é a mais comum em aços ferríticos onde, o crescimento do defeito ocorre devido à separação do material de acordo com os planos cristalográficos preferenciais. Outro tipo de fratura frágil (bastante menos comum em aplicações típicas de aços) é a fratura intergranular na qual o defeito cresce devido à separação do material nos contornos de grãos. A segunda forma de fratura é dúctil, característica de aços de alta tenacidade. Este tipo de fratura apresenta grande deformação plástica na frente de trinca antes da propagação do defeito o qual, inicialmente, cresce de forma estável. A Fig. 4 (a) apresenta uma macrografia de um corpo-de-prova C(T) na qual pode ser observado o processo de rasgamento dúctil e a Fig. 4 (b) apresenta uma imagem obtida por microscopia eletrônica de varredura onde pode ser observada a formação de alvéolos nucleados por inclusões.

A temperatura de operação, características metalúrgicas e o estado tensional são os principais fatores que determinam a forma de propagação de um defeito (dúctil ou frágil). A fratura frágil é característica de um elevado nível de tensões hidrostáticas na zona de processo de fratura ${ }^{1}$. Entretanto, a fratura dúctil é associada a um estado triaxial menor e elevadas deformações plásticas as quais produzem o crescimento de microcavidades e conseqüente coalescência das mesmas devido ao deslizamento e ruptura dos planos cristalográficos. As condições existentes em defeitos planares contidos em dutos e vasos de pressão (carregamentos trativos e trincas rasas) favorecem o crescimento dúctil do defeito antes da ruptura. Efetivamente, observações experimentais revelam que tais estruturas com trincas superficiais apresentam colapso geralmente precedido por um significativo crescimento estável do defeito. O processo de rasgamento dúctil

1) Zona de processo de fratura é a denominação dada à região na frente da trinca que apresenta elevado nível de tensões (tensões e deformações no caso de fratura dúctil) as quais são responsáveis pelo crescimento (estável ou não) do defeito. 


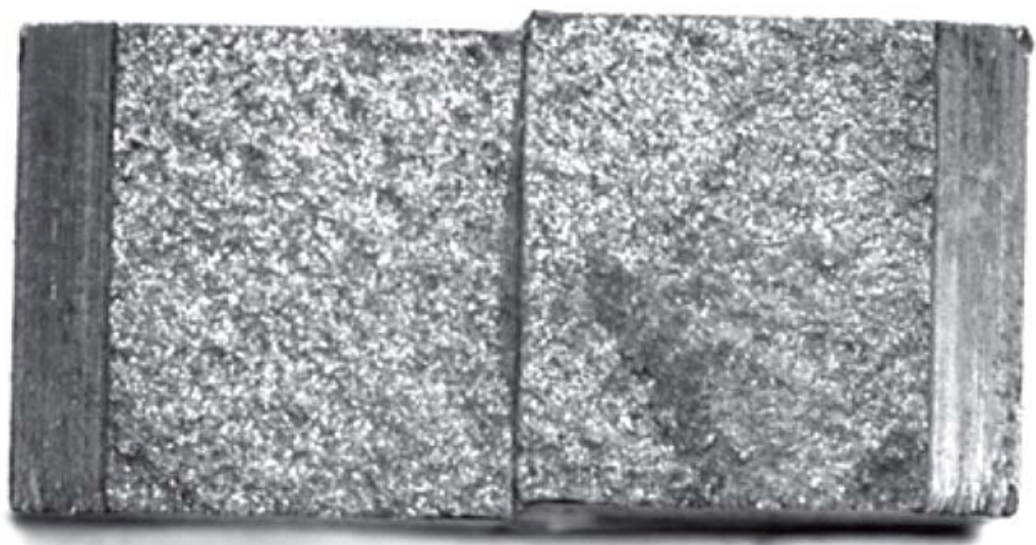

(a)

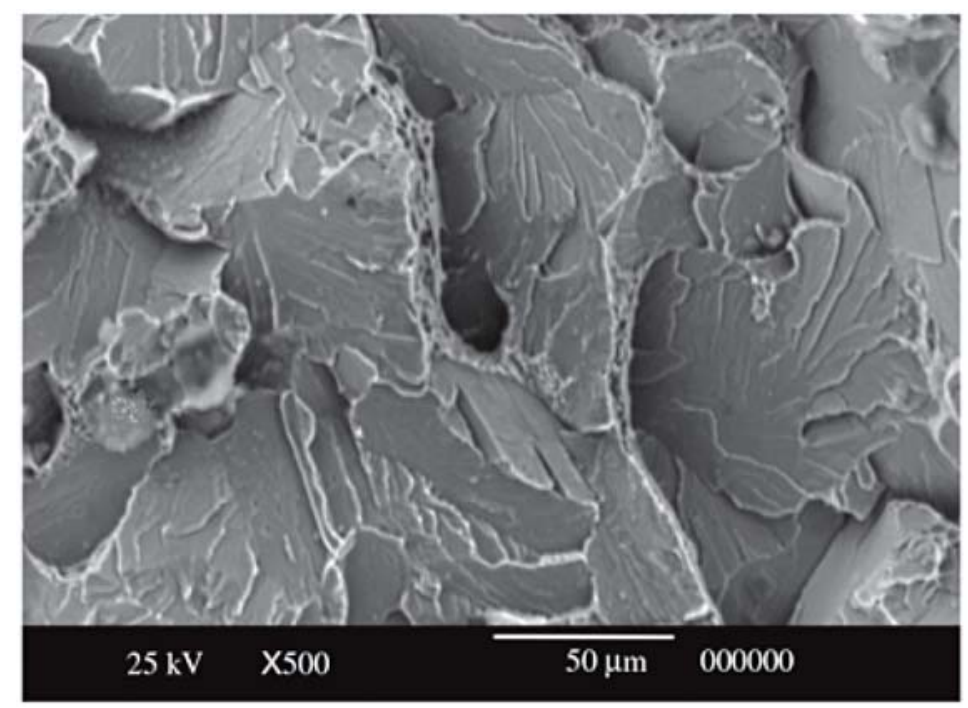

(b)

Figura 3 Fractografias representativas de fratura frágil; a) Fractografia de superficies de fratura; b) MEV, magnificação de X500. [30].

assim como sua caracterização mecânica por intermédio de curvas de resistência (curvas $R$ ) será explicado com maior detalhamento nas seções 2.4 e 2.5.

\subsection{Mecânica da Fratura Monoparamétrica}

A mecânica da fratura monoparamétrica ou clássica emprega um parâmetro único para descrever as condições de propagação instável da fratura [24]. Sob condições de plasticidade restrita nas vizinhanças da trinca ou fissura (i.e., escoamento em 


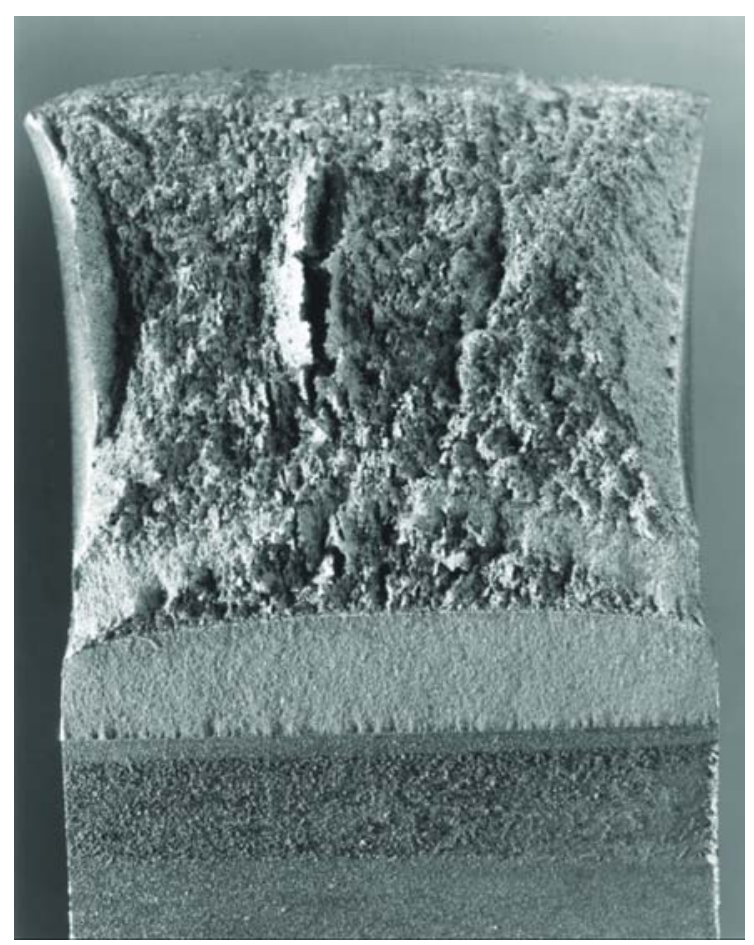

(a)

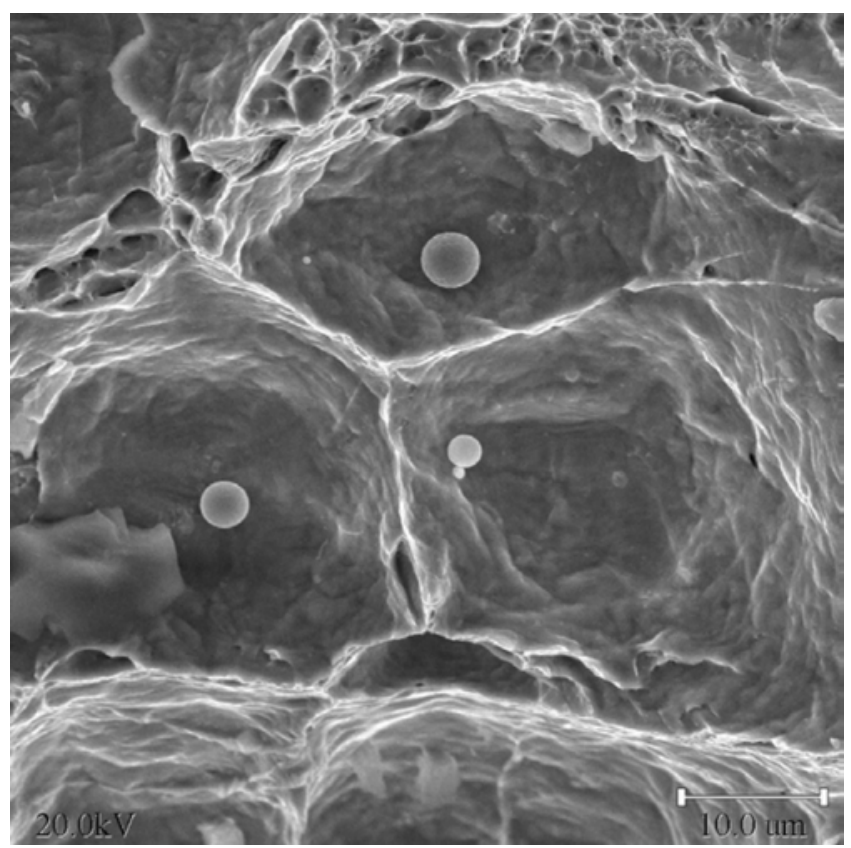

(b)

Figura 4 a) Fractografia representativa de fratura dúctil. Observar a presença do defeito original, a zona com crescimento estável de trinca e finalmente o colapso da estrutura; b) MEV, fratura dúctil com formação de alvéolos nucleados por inclusões [31].

pequena escala ou, como é usualmente conhecido na literatura, small scale yielding (SSY) conditions), estabelece uma correlação direta entre valores de tenacidade 
medidos experimentalmente $\left(K_{\mathrm{Ic}}, J_{\mathrm{c}}\right)$ e o comportamento à fratura de um componente estrutural em serviço. $\mathrm{O}$ conceito fundamental que permite o emprego deste procedimento (mecânica da fratura correlativa) é a existência de similaridade dos campos de tensões entre corpos-de-prova (i.e., com dimensões reduzidas) e o componente estrutural em serviço [32].

A Fig. 5 representa esquematicamente as condições de similaridade de tensões para validade da mecânica da fratura monoparamétrica. As condições à fratura devem ser iguais no componente estrutural (Fig. 5 (a)) e no corpo-de-provas (Fig. 5 (b)); a condição de similaridade implica que a zona plástica deve ser pequena. Para caracterizar as condições à fratura no caso monoparamétrico, podem ser empregados diversos parâmetros, sendo os mais conhecidos os parâmetros $K_{\mathrm{I}}$ [28], CTOD [21] e $J$ [7]. O parâmetro $K_{\mathrm{I}}$ é baseado em considerações elásticas lineares, o que limita muito a sua aplicação. Os parâmetros CTOD e $J$ são baseados em considerações não-lineares elásticas e elasto-plásticas e tem um campo de aplicação maior. Uma vez que a utilização de $J$ é de interesse central neste trabalho, a seção seguinte apresentará uma descrição detalhada deste parâmetro.

\subsection{A Integral $J$ e o Campo de Tensões Elasto-plásticas}

A mecânica da fratura linear elástica (MFLE) e a correspondente descrição das tensões nas vizinhanças de uma trinca somente são válidas em materiais que apresentam baixa plastificação no momento que a fratura acontece. No caso de materiais com grande tenacidade, os efeitos das deformações plásticas não podem ser desconsiderados e o emprego do parâmetro da MFLE torna-se questionável e mesmo incorreto. Esta limitação motivou o desenvolvimento da mecânica da fratura elasto-plástica.

Um dos passos mais importantes no desenvolvimento da mecânica da fratura elasto-plástica foi dado por Rice em 1968 [7] que introduziu a integral $J$ como uma taxa de liberação de energia para caracterizar a fratura em materiais com 


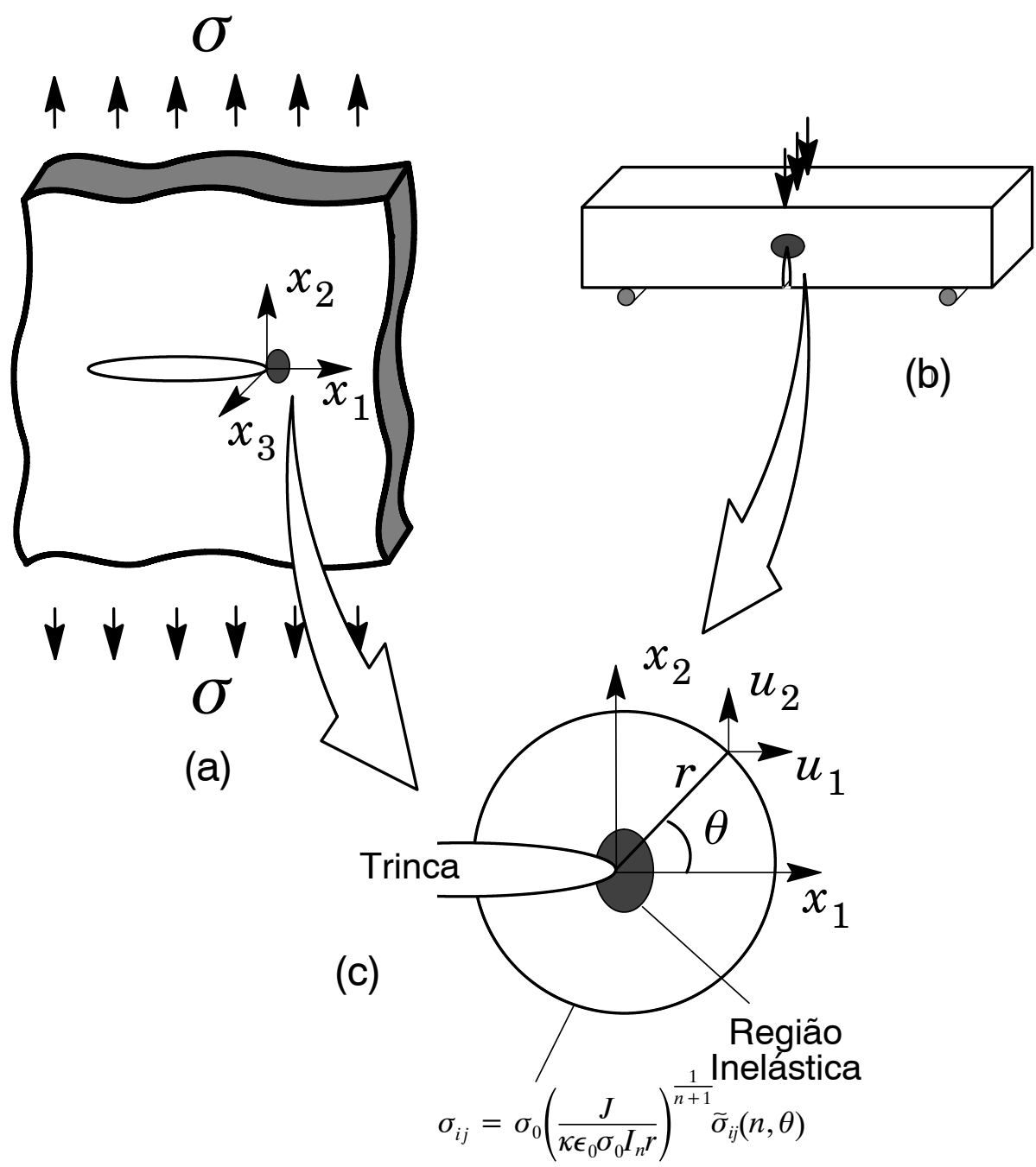

Figura 5 a) Chapa tracionada representativa de um componente estrutural constituida de material plasticamente deformável contendo uma trinca; b) Corpo de prova convencional SE(B) em 3 Pontos à Flexão; c) Zona de dominância J na região da ponta da trinca indicando a validade da mecânica da fratura monoparamétrica.

comportamento não-linear elástico. Utilizando uma hipótese de elasticidade não linear (ver Fig. 6) para analisar uma trinca em materiais elasto-plásticos, Rice mostrou que a taxa de liberação de energia, denotada $J$, em sólido com comportamento não linear elástico pode ser descrita por uma integral de linha independente do caminho de integração (veja Fig. 7). Para um contorno arbitrário e anti-horário, a integral $J$ é definida como 


$$
J=\int_{\Gamma}\left[W n_{1}-P_{j i} \frac{\partial u_{i}}{\partial X_{1}} n_{j}\right] d \Gamma
$$

onde $\Gamma$ denota um contorno fechado definido sobre um plano normal à frente da trinca, iniciando na face inferior da trinca e terminando na sua face superior, $n_{j}$ é o vetor normal exterior ao contorno $\Gamma$, $W$ denota a energia de deformação por unidade de volume indeformado, $P_{i j}$ e $u_{i}$ são as componentes cartesianas do tensor de tensões (assimétricas) de Piola-Kirchoff e dos deslocamentos no sistema de coordenadas localizado na frente da trinca. Para o caso especial de material com comportamento linear elástico, $J$ é equivalente à taxa de liberação de energia de Griffith [33], isto é, $J=$ G. Portanto, esta equivalência permite obter a seguinte relação entre o fator de intensidade de tensões elásticas lineares e a integral $J$ (Veja Kanninen e Popelar, [34] para maiores detalhes).

$$
J=\frac{K_{\mathrm{I}}^{2}}{E^{\prime}}
$$

com

$$
E^{\prime}=E ; \text { para estado plano de tensões }
$$

$\mathrm{e}$

$$
E^{\prime}=\frac{E}{1-v^{2}} ; \text { para estado plano de deformações }
$$

onde $E$ é o módulo de elasticidade longitudinal do material e v é o coeficiente de Poisson.

Estudos posteriores mostraram que a hipótese de elasticidade não linear é válida em muitos casos de interese. Também, é importante mencionar que a definição para a integral $J$ da Eq. (1), somente é independente do caminho de integração no caso em que a lei constitutiva do material seja elástica não-linear [7]. 
Entretanto, para carregamento monotônico e lei constitutiva elasto-plástica, (Ex.: teoria incremental de plasticidade) a independência do caminho de integração ainda é observada de forma aproximada em regiões suficientemente distantes da ponta da trinca.

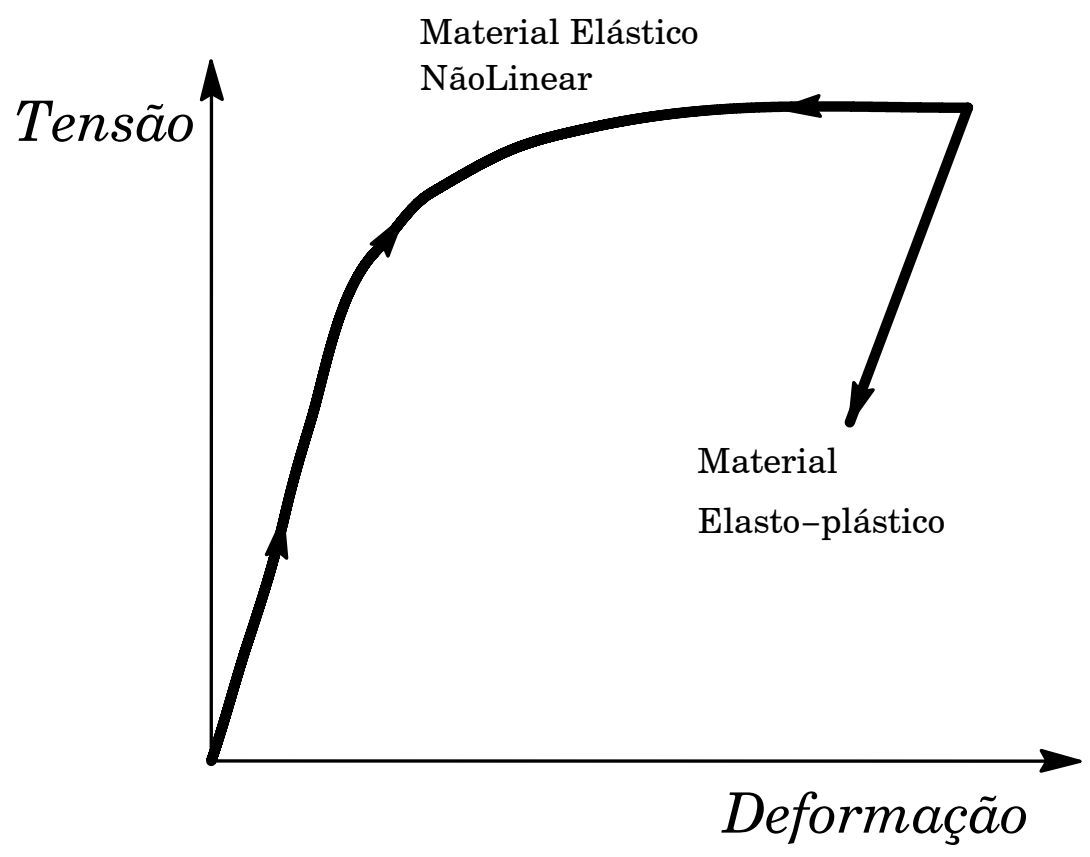

Figura 6 Comparação da curva tensão-deformação para um material elástico não-linear e um elasto-plástico.



Figura 7 Contorno arbitrário em volta da ponta da trinca.

Estudos subseqüentes de Rice e Rosengren [22] e, paralelamente, Hutchinson [23] deduziram a relação unívoca entre o campo de tensões e deformações atuante 
nas vizinhanças de uma trinca contida em sólido elástico não-linear e a integral $J$. Os autores mencionados mostraram que $J$ caracteriza as tensões e deformações em material elástico não linear com resposta tensão-deformação obedecendo a uma lei de potência na forma

$$
\frac{\varepsilon}{\varepsilon_{0}}=\frac{\sigma}{\sigma_{0}}+\alpha\left(\frac{\sigma}{\sigma_{0}}\right)^{n}
$$

$\mathrm{Na}$ Eq. (5), $\sigma$ e $\varepsilon$ são a tensão e a deformação verdadeiras respectivamente, $\alpha$ é uma constante adimensional e $n$ é o expoente de encruamento. Ainda na Eq. (5) o subscrito "0" indica valores de referência, os quais são usualmente adotados os valores da tensão e deformação de escoamento. Hutchinson e Rice e Rosengren mostraram que para manter a integral de linha independente do caminho de integração é preciso que as tensões nas vizinhanças da ponta da trinca variem com $(1 / r)^{\frac{1}{n+1}}$. Aplicando condições de contorno apropriadas, eles obtiveram a seguinte forma para os campos de tensões e deformações

$$
\begin{gathered}
\sigma_{i j}=\sigma_{0}\left(\frac{E J}{\alpha \sigma_{0}^{2} I_{n} r}\right)^{\frac{1}{n+1}} \tilde{\sigma}_{i j}(n, \theta) \\
\varepsilon_{i j}=\frac{\alpha \sigma_{0}}{E}\left(\frac{E J}{\alpha \sigma_{0}^{2} I_{n} r}\right)^{\frac{1}{n+1}} \tilde{\varepsilon}_{i j}(n, \theta)
\end{gathered}
$$

Nas Eqs. (6) e (7) anteriores, $I_{n}$ é uma constante de integração que depende do expoente de encruamento $n$, $\tilde{\sigma}_{i j}$ e $\tilde{\varepsilon}_{i j}$ são funções adimensionais de $\theta, n$ e do estado de tensões (estado plano de tensões ou estado plano de deformações). No caso elástico linear, $n=1$ e as tensões variam com $\sqrt{1 / r}$, recuperando-se a singularidade caracterizada por $K_{\mathrm{I}}$. As Eqs. (6) e (7) são conhecidas como solução $H R R$ (iniciais de Hutchinson, Rice e Rosengren).

Desta forma a integral $J$ pode ser interpretada como um parâmetro de variação de energia e também como um parâmetro de intensidade de tensões. Esta integral 
é completamente consistente com o parâmetro $K_{\mathrm{I}}$ porque, no caso particular de sólido com comportamento elástico linear, fornece resultados equivalentes. Nesta seção é importante mencionar que, paralelamente ao trabalho de Rice em 1968 [7], Cherepanov, no ano 1967 [35] na antiga União Soviética, também apresentou uma formulação de uma integral similar à integral $J$ obtida por Rice.

\subsubsection{Dominância da Integral J}

A integral $J$ estendeu grandemente o campo de aplicabilidade da mecânica da fratura, pois tornou possível a descrição dos campos de tensões e deformações em sólidos elasto-plásticos contendo trincas. Embora menos severas que as limitações do parâmetro $K_{\mathrm{I}}$, a integral $J$ também tem limitações para descrever os campos de tensões e deformações.

Shih e German (S\&G) [36] foram os primeiros a estabelecer limites para a dominância $J$. Por intermédio de modelos de elementos finitos representativos de diferentes corpos-de-provas, S\&G obtiveram os campos de tensões e deformações na frente de trinca para diferentes níveis de carregamento. A seguir, compararam estes campos com os campos dados pela solução $H R R[22,23]$ e observaram que a solução de elementos finitos se afasta da solução $H R R$ à medida que o carregamento aumenta. O qual indica que a integral $J$ não descreve os campos de tensões e deformações em situações com carregamentos elevados e plasticidade generalizada. Desta forma, os autores propuseram o parâmetro $M$ para estabelecer o limite de validade da integral $J$ na caracterização dos campos de tensões e deformações em sólido contendo defeito,

$$
M \leq \frac{b \sigma_{f}}{J} \quad e \quad M \leq \frac{B \sigma_{f}}{J}
$$

onde $b$ é o ligamento remanescente $(W-a), B$ é a largura do corpo-de-provas e $\sigma_{f}$ é uma tensão de referência geralmente definida como a tensão de escoamento, $\sigma_{y s}$, ou a média entre a tensão de escoamento e a tensão de ruptura e.g. $\sigma_{f}=\left(\sigma_{y s}+\sigma_{u}\right) / 2$. 
Finalmente, $M$ é um parâmetro que depende da geometria do corpo-de-prova cujo valor é definido em função das tensões que se desenvolvem na ponta da trinca do mesmo e do desvio destas em relação às tensões do campo HRR [36]. Como exemplo, para que $J$ caracterize adequadamente os campos de tensões e deformações, em corpos-de-prova C(T) e SE(B) com trinca profunda o valor de $M$ é 20 [12] e para um corpo-de-prova à tração com entalhe central $\mathrm{M}(\mathrm{T})$ o valor de $M$ é 200 [36].

No caso dos espécimes $\mathrm{SE}(\mathrm{T})$ em estudo neste trabalho, foram comparadas as tensões que se desenvolvem na frente da trinca para diferentes valores de integral $J$ aplicada com as tensões dadas pela solução numérica de uma placa com dimensões infinitas. Este modelo numérico é conhecido como Camada de Contorno Limite ou Boundary Layer (BL) [37] do inglês e a solução dos campos de tensões e deformações dada pelo modelo $B L$ é conhecida como solução SSY (do inglês, small scale yielding). A solução $S S Y$ é equivalente à solução $H R R$ no sentido de gerar campos com alta triaxialidade sem efeito das dimensões finitas do sólido e pode ser avaliado de forma numérica. Os modelos de elementos finitos empregados para obter as tensões à frente da trinca são descritos no capítulo 4. Primeiramente, foram obtidas as tensões de abertura de espécime $\mathrm{SE}(\mathrm{B})-1 \mathrm{~T}$ com trinca profunda $(W=50.8 \mathrm{~mm}$ e relação $a / W=0,5)$ para diferentes valores de $J$ aplicado. A seguir, foram comparadas estas tensões com as tensões dadas pela solução do modelo $B L$ como apresentado na Fig. 8. Nesta figura pode ser observado que, para valores baixos de $J$ aplicado, as tensões são bastante próximas à solução $B L$ e se afastam progressivamente da mesma à medida que $J$ aumenta. Também, observa-se que para $J \cong 520 \mathrm{~kJ} / \mathrm{m}^{2}$ (correspondente a $M \cong 20$ estabelecido por norma [12]) as tensões do espécime $\mathrm{SE}(\mathrm{B})$ são $15 \%$ menores às tensões SSY para um raio adimensional, $r \sigma_{0} / J=2$. Dado que este valor do raio adimensional é considerado um ponto dentro da zona de processo de fratura, o critério adotado para determinar o valor de $M$ nos espécimes $\mathrm{SE}(\mathrm{T})$ baseou-se na determinação do valor de $J$ aplicado que produz uma queda nas tensões de $15 \%$ em relação à solução do modelo $B L$ em $r \sigma_{0} / \mathrm{J}=2$. 
A Fig. 9 compara a solução do modelo $B L$ com as tensões de abertura para diferentes valores de $J$ aplicado de um espécime $\mathrm{SE}(\mathrm{T})$ com trinca profunda $(a / W=0,5)$. Como pode ser observado, o valor de $J$ que produz um desvio de $15 \%$ em $r \sigma_{0} / J=2$, corresponde a um valor de $M$ de aproximadamente 19. Entretanto, a Fig. 10 apresenta a comparação com a solução $B L$ das tensões geradas em espécimes $\mathrm{SE}(\mathrm{T})$ com trinca rasa $(a / W=0,2)$ onde pode é observado que o valor de $J$ que produz um desvio de $15 \%$ da solução $H R R$, corresponde a $M \cong 470$. Da discussão prévia, é possível concluir que o parâmetro $M$ depende fortemente da profundidade de trinca. No caso de espécimes $\mathrm{SE}(\mathrm{T})$ com trinca profunda, o valor deste parâmetro é próximo a 20. Enquanto que para espécimes $\mathrm{SE}(\mathrm{T})$ com trinca rasa este valor sobe a 470 .

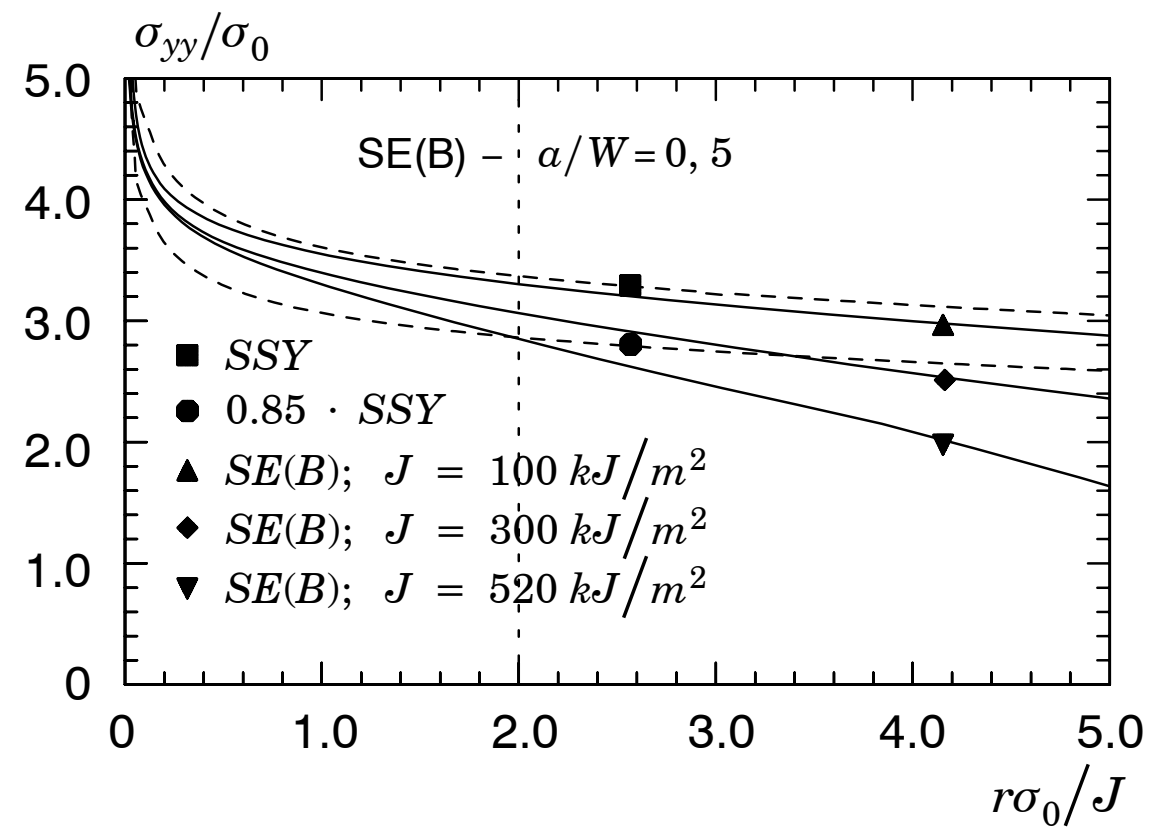

Figura 8 Comparação das tensões de abertura na frente de trinca em espécime $S E(B)$ com a / W=0,5 para diferentes valores de J aplicado e o modelo $B L$.

\subsubsection{Dominância da Integral J com Crescimento de Trinca}

A integral $J$ é válida para trincas estacionárias com zona de grandes deformações relativamente pequena quando comparada às dimensões características do corpo-de-prova. Entretanto, quando a trinca cresce de forma estável, é introduzida outra dimensão ao problema de dominância J. Como pode ser observado na Fig. 


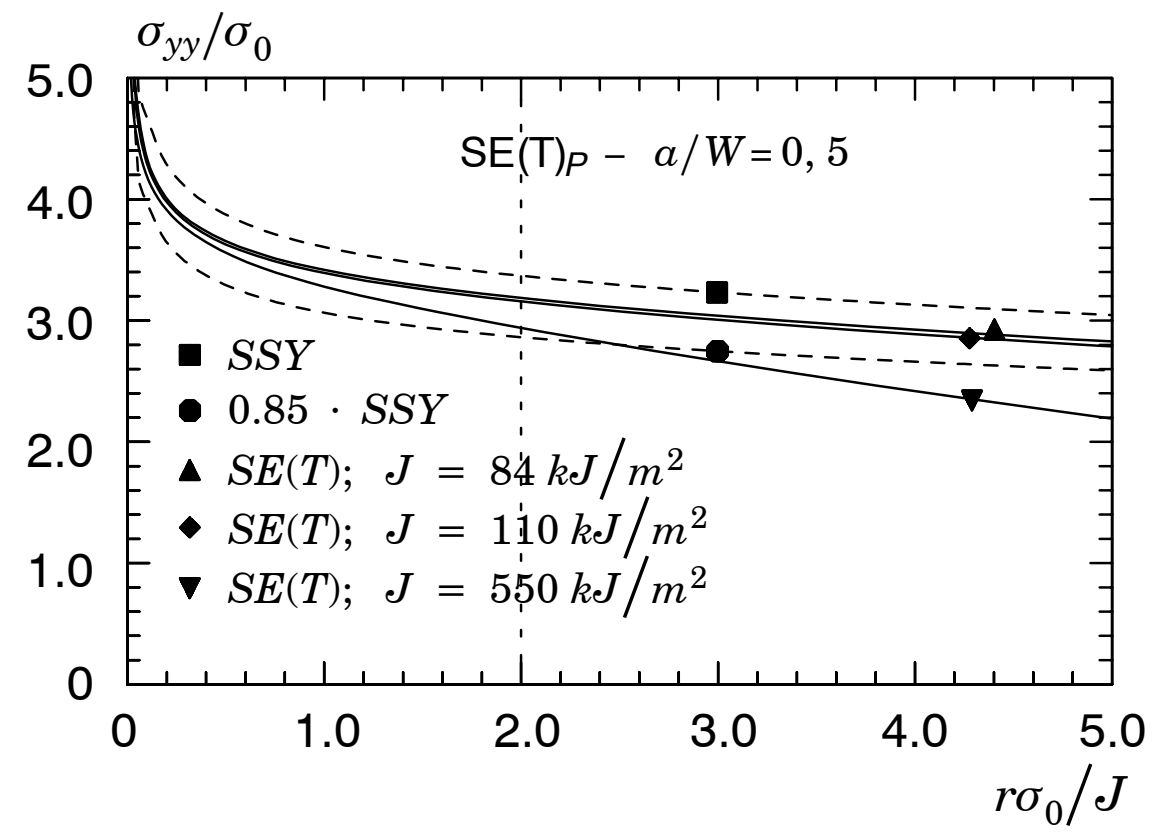

Figura 9 Comparação das tensões de abertura na frente de trinca em espécime $S E(T)$ com a $/ W=0,5$ para diferentes valores de $J$ aplicado e o modelo $B L$.

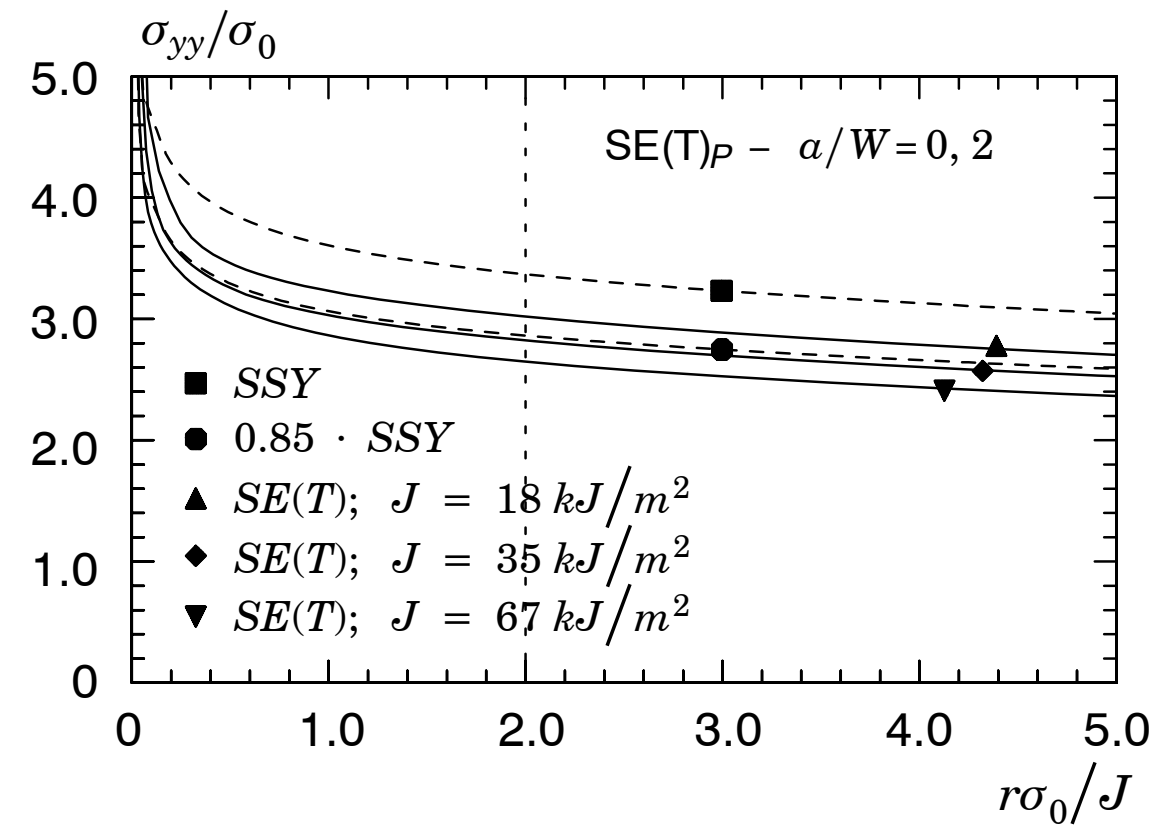

Figura 10 Tensões de abertura na frente de trinca em espécime $S E(T)$ com $a / W=0,2$ para diferentes valores de J aplicado.

11-(a), enquanto a trinca propaga dentro da zona de dominância $J$, a zona de descarregamentos elásticos produzida pelo crescimento da trinca e de grandes deformações estão contidas pela mesma. Portanto, o parâmetro $J$ ainda continua caracterizando as condições de fratura mesmo para trinca com crescimento estável. 
Entretanto, quando a extensão da trinca é considerável (veja Fig. 11-(b)) ou a zona de grandes deformações é muito grande (plasticidade generalizada), a integral $J$ não consegue caracterizar os campos de tensões e deformações que regem a fratura. Desta forma o parâmetro $J$ não pode ser considerado como descritor absoluto das condições de fratura do espécime.

\subsection{Aspectos Fenomenológicos do Rasgamento Dúctil em Aços Estruturais}

A fratura dúctil ocorre quando cavidades, previamente existentes na matriz do material ou que nuclearam durante o carregamento, crescem até coalescer e formar uma fratura macroscópica. Efetivamente, um dos passos mais importantes no entendimento dos aspectos microestruturais da fratura dúctil foi o descobrimento de que as cavidades nucleiam a partir de inclusões e partículas de segunda fase. Em trabalho publicado em 1948, Tipper [38] sugeriu que a fratura durante o carregamento tractivo uniaxial surge do crescimento de cavidades iniciadas pela decoesão da matriz ao redor de inclusões não metálicas. Isto foi corroborado por Puttick em 1957 [39].

O trabalho experimental de Puttick mostrou que barras cilíndricas de cobre e aço submetidas à tração apresentam, na sua seção transversal, pontos com maior intensidade de tensões devido às heterogeneidades microscópicas das diferentes fases do material constituinte e às inclusões presentes. Estes pontos são os causadores do início da falha do material. Desta forma, uma microcavidade é formada quando um campo de tensões suficientemente intenso é aplicado ao redor de uma inclusão o que ocasiona a ruptura da inclusão ou a decoesão da união interfacial entre a matriz metálica e a inclusão. $\mathrm{O}$ aumento nas tensões atuantes ao redor da microcavidade produz o crescimento desta e a conseqüente coalescência com microcavidades vizinhas. Na Fig. 12 [39] são apresentadas macrografias de ensaio à tração interrompido antes do colapso total da barra cilíndrica. Nesta figura pode ser observada a nucleação e coalescência de cavidades. 

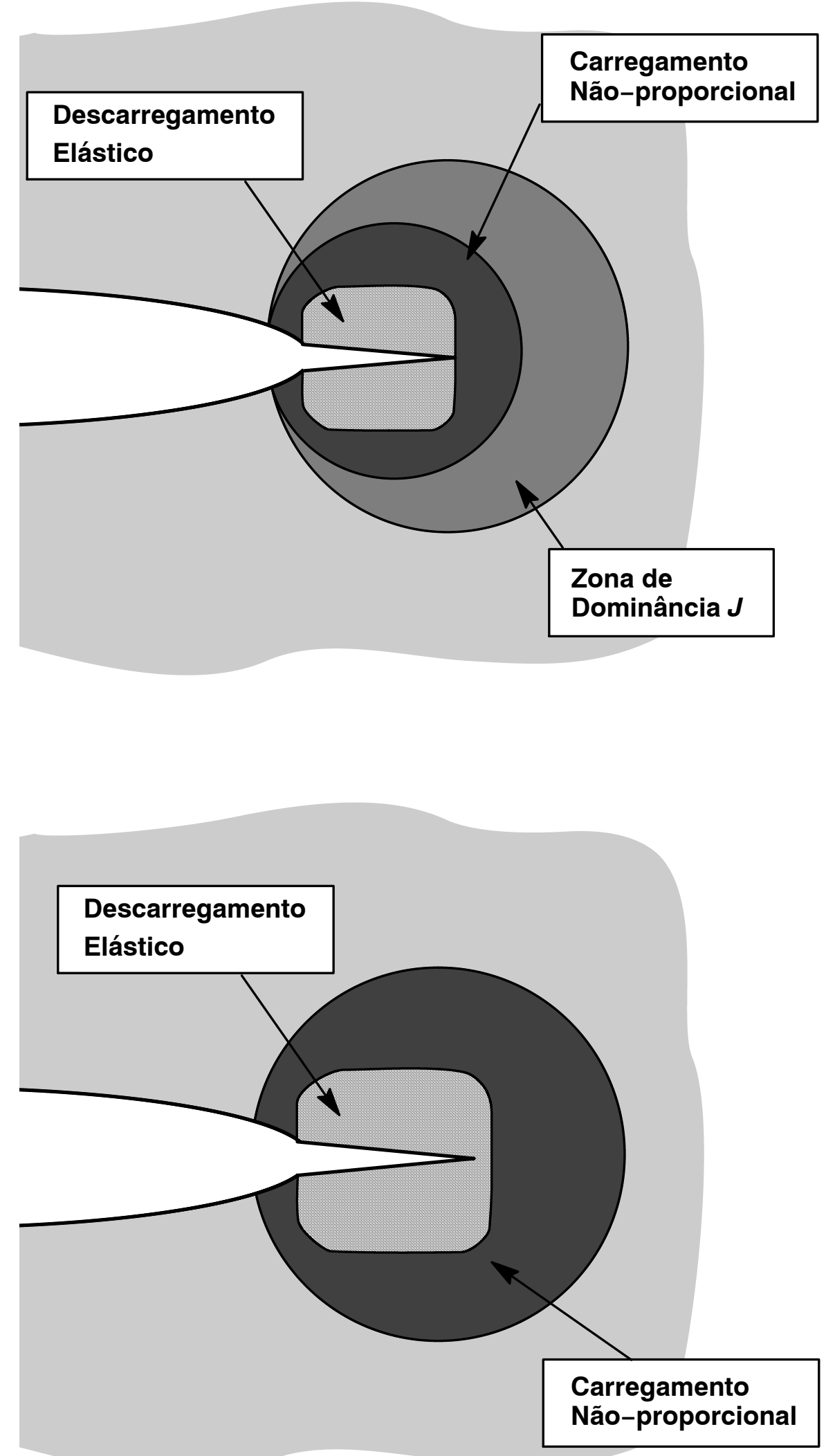

Figura 11 a) Esquema de crescimento de trinca controlado por J [32]; b) Perda de dominância J. 


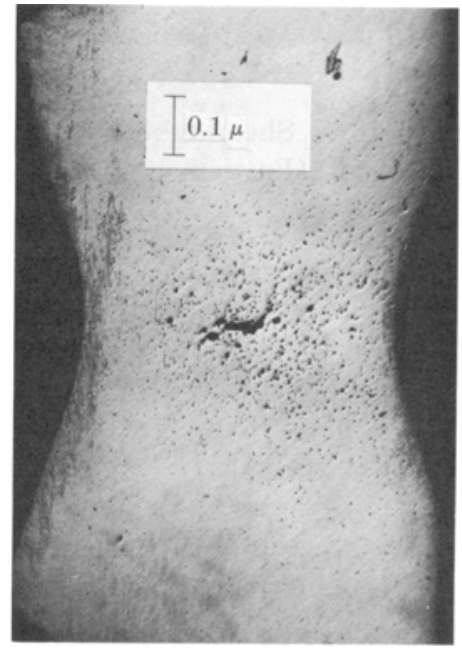

(a)

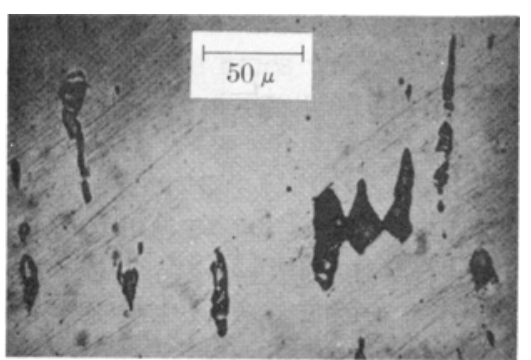

(b)

Figura 12 a) Formação de trinca (macroscópica) interna na região de estricção em barra cilíndrica submetida a tração uniaxial [39]; b) Crescimento e coalescência de microcavidades nucleadas a partir de inclusões não metálicas [39].

Os trabalhos mencionados anteriormente em adição a outros $[40,41]$ permitiram estabelecer 3 estágios principais do processo de fratura dúctil [42]: 1) nucleação de microcavidades, 2) crescimento de microcavidades e 3) coalescência das mesmas. É importante destacar que, em materiais reais, os 3 estágios acontecem simultaneamente (e.g.: nucleação de novas microcavidades durante o crescimento de outras previamente formadas). A combinação destes processos depende fortemente do estado tensional do sólido e do material constituinte. Para maiores detalhes o leitor pode referir-se ao trabalho de Garrison e Moody [42].

Quando existe uma trinca macroscópica em material dúctil, como é o caso de corpo-de-prova de fratura ou estrutura com defeito planar, a geometria do defeito faz com que a região de maior intensidade de tensões se localize à frente desta ocasionando (quando as tensões são suficientemente elevadas) o crescimento estável do defeito. Efetivamente, as máximas tensões de abertura desenvolvem-se a uma distância de aproximadamente 2 a 3 CTODs [24] à frente da ponta da trinca 
sendo que nesta região ocorre a nucleação de microcavidades. As microcavidades crescem com o aumento da carga e eventualmente coalescem com a trinca macroscópica produzindo o incremento no seu tamanho. Isto gera uma nova frente de trinca e, conseqüentemente, o deslocamento do ponto com máximas tensões produzindo a nucleação de novas microcavidades.

Evidências experimentais do processo de rasgamento dúctil em aços ferríticos para vasos de pressão com a presença de trincas foram apresentadas por Isacsson e Narstroöm [43]. Neste trabalho foram executados ensaios de fratura dúctil pelos quais os autores obtiveram evidências concretas do processo de nucleação de cavidades. Além disto, eles puderam observar o caminho preferencial de propagação de trinca. Uma primeira observação da superfície de fratura de um corpo-de-prova após o ensaio aparenta ser plana. Entretanto, um estudo mais detalhado desta revela que a propagação estável segue um caminho alternado (zig-zag, Veja Fig. 13). $\mathrm{O}$ caminho alternado pode estar associado às direções de maiores tensões de cisalhamento $\left( \pm 45^{\circ}\right)$ em relação ao plano de propagação quando a trinca macroscópica está submetida a modo I de carregamento.

\subsection{Curvas de Resistência ao Rasgamento Dúctil}

Uma vez que uma trinca em sólido elasto-plástico pode propagar de forma estável, é importante uma metodologia ou procedimento para quantificar essa propagação. A metodologia empregada para descrever o crescimento estável de trincas é a curva de resistência ao rasgamento dúctil (curva $J-\Delta a$ ou curva $R$ ). Esta curva representa, no eixo das abscissas, o crescimento de trinca $(\Delta a)$ e, no eixo das ordenadas, o carregamento aplicado para este crescimento. Normalmente o eixo das ordenadas é representado em valores de integral $J$ ou de CTOD (ठ) [21].

A Fig. 14 apresenta de forma esquemática uma curva de resistência ao rasgamento dúctil. Nesta figura é indicado o ponto de iniciação de crescimento $\left(J_{\mathrm{Ic}}\right)$; até este ponto, o incremento de trinca $\Delta a$ é aparentemente devido ao 


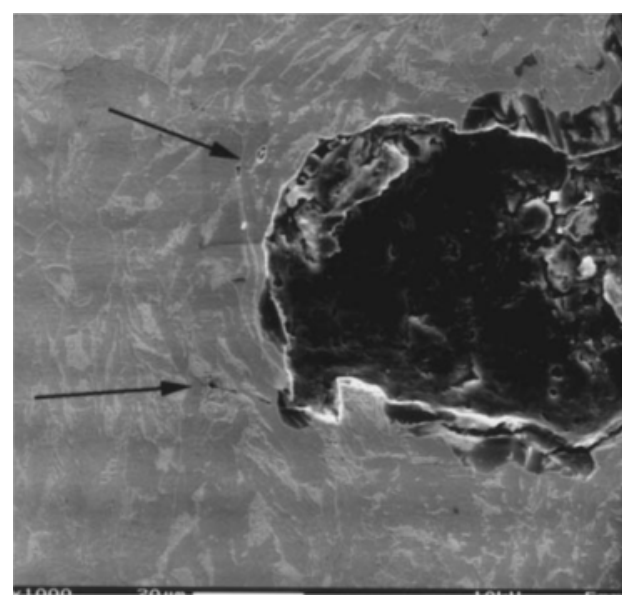

(a)

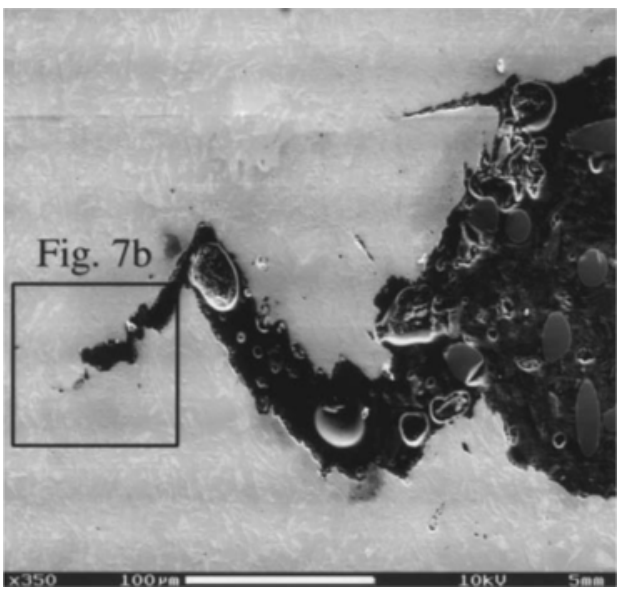

(c)

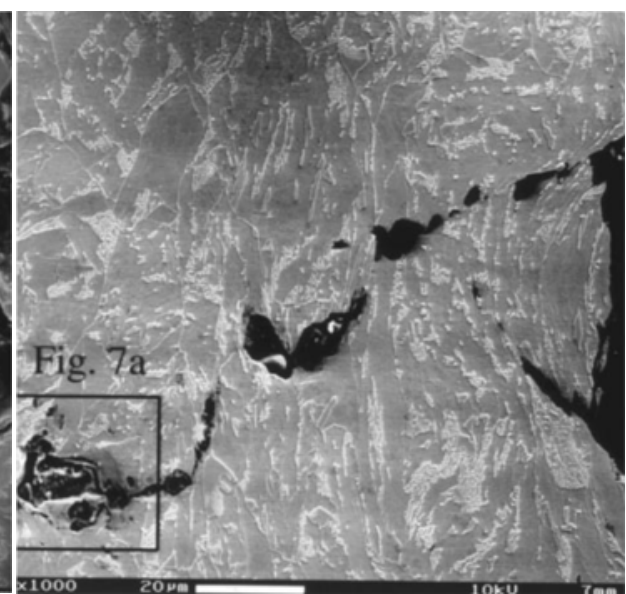

(b)

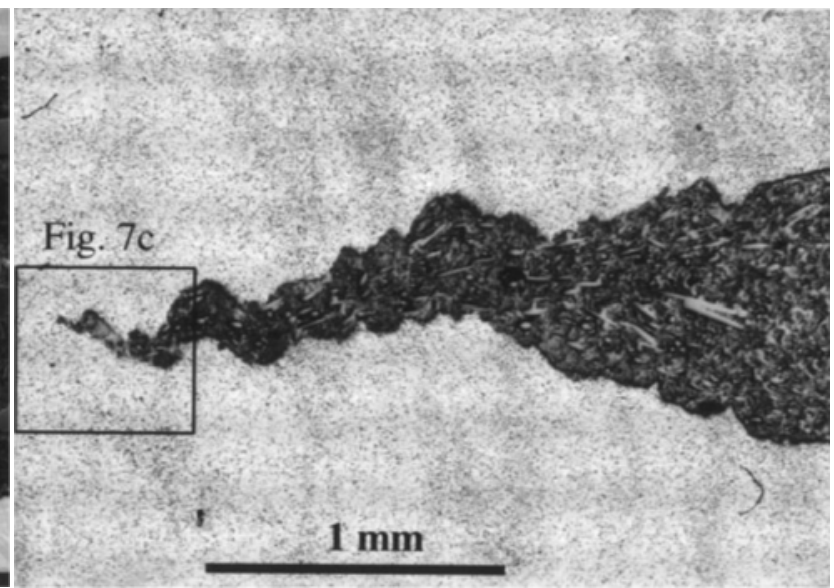

(d)

Figura 13 Micrografias com diferentes níveis de detalhamento mostrando a propagação estável de defeito em aço dúctil [43].

arredondamento inicial da mesma. Entretanto, é praticamente impossível determinar exatamente o valor de $J$ que inicia o crescimento do defeito $\left(J_{\mathrm{Ic}}\right)$ e, dependendo do procedimento, podem ser obtidos resultados muito diferentes. Desta forma, foram estabelecidos critérios padronizados para determinar este valor [32, 12]. Por exemplo, o critério empregado pela norma ASTM E1820 [12], de alguma forma, é análogo ao critério de $0,2 \%$ de deformação plástica para determinar a tensão de escoamento em ensaios à tração.

Embora $J_{\text {Ic }}$ forneça alguns dados sobre o comportamento à fratura do material, este valor isolado não caracteriza a fratura após o início do crescimento (fase de 
propagação da trinca). Portanto, a curva $R$ completa fornece uma descrição mais geral do comportamento do material. Por exemplo, a inclinação da curva (após o início de crescimento) fornece uma idéia da estabilidade relativa ao crescimento da trinca. Curvas $R$ com inclinação maior indicam uma estabilidade maior. [44]

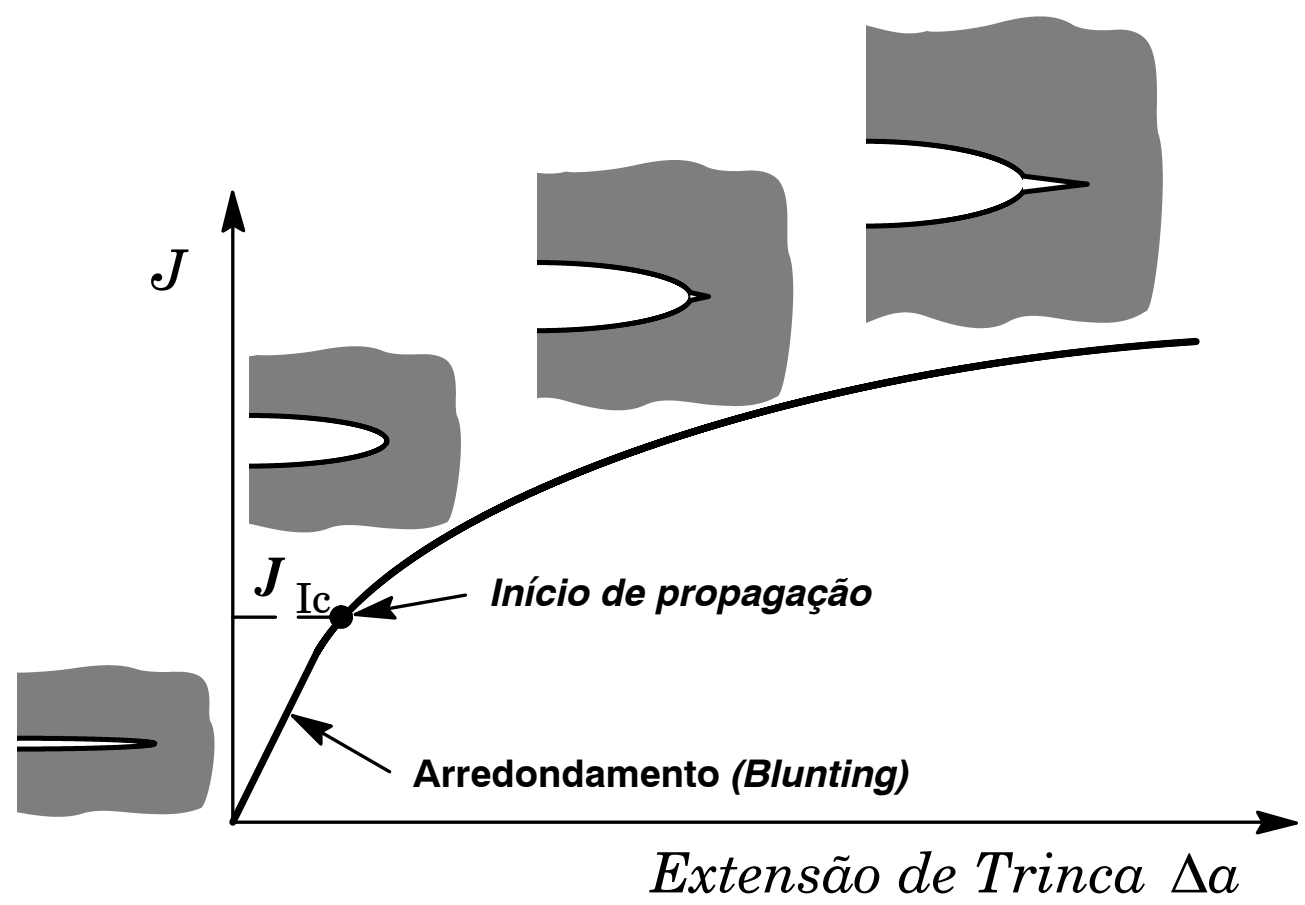

Figura 14 Esquema de curva de resistência indicando os diferentes estágios de crescimento do defeito [32]. 


\section{MEDIÇÃO DE CURVAS DE RESISTÊNCIA EM ESPÉCIMES SE(T)}

Como foi apresentado no capítulo anterior, a metodologia empregada para descrever o crescimento estável de trinca é a curva de resistência ao rasgamento dúctil (curva $J-\Delta a$ ou curva $R$ ). Neste capítulo é descrito o método $\eta$ e o método de flexibilidade no descarregamento para a medição de curvas $R$, os quais são aplicáveis em uma grande variedade de geometrias de corpos-de-prova. Entretanto, este capítulo visará a aplicação deste método em espécimes $\mathrm{SE}(\mathrm{T})$. Desta forma, na seção 3.3 é descrito o procedimento para a correção por rotação necessária para a aplicação acurada do método de flexibilidade no descarregamento em espécimes $\mathrm{SE}(\mathrm{T})$ carregados por pinos. Finalmente, a seção 3.4 apresenta um exemplo ilustrativo sobre a metodologia usada nos primeiros ensaios experimentais [45, 46] nos quais eram empregados múltiplos espécimes.

\subsection{Corpos-de-Prova SE(T)}

Como foi mencionado na seção 1.2, a aplicação de curvas $R$ obtidas de corpos-de-prova padronizados ( $\mathrm{SE}(\mathrm{B})$ ou $\mathrm{C}(\mathrm{T})$ com trinca profunda) na avaliação de defeitos superficiais em dutos ou vasos de pressão vem sendo questionada devido aos efeitos de restrição plástica ou triaxialidade sobre as curvas de resistência. Ensaios experimentais em espécimes com diferentes geometrias, profundidades relativas de trinca e modos de carregamento (flexão vs. tração) demonstraram esses efeitos [8]. Desta forma, há uma tendência no emprego de corpos-de-prova com condições de restrição similares às presentes na estrutura sendo avaliada em procedimentos de avaliação de defeitos.

No caso particular de dutos e vasos cilíndricos, há interesse na predição do comportamento à fratura baseado em corpos-de-prova à tração com entalhe lateral - SE(T) [13,14]. A principal motivação para o uso de espécimes SE(T) na avaliação 
de defeitos em dutos é a forte similaridade dos campos de tensões e de deformações que determinam a fratura para ambas configurações. Enquanto que os trabalhos das referências [13,14] baseiam-se no estudo das similaridades entre corpos-de-prova SE(T) e dutos com trincas circunferenciais, este trabalho se focaliza no desenvolvimento de espécimes $\mathrm{SE}(\mathrm{T})$ para a avaliação de defeitos longitudinais. Embora estudos sobre a aplicabilidade de espécimes de fratura $\mathrm{SE}(\mathrm{T})$ em procedimentos de engenharia para a avaliação de defeitos neste tipo de estrutura demonstrem que este tipo de espécime apresenta grande plastificação durante a evolução do carregamento o qual potencialmente invalida as condições de dominância $J$ apresentadas no capítulo 2 , a semelhança dos campos de tensões e de deformações entre esta geometria e dutos contendo defeitos superficiais justificam o uso dos resultados obtidos $[15,16]$.

\subsection{Método $\eta$ e Método de Flexibilidade no Descarregamento}

Os primeiros procedimentos para a medição de curvas $J-R$ empregavam múltiplos espécimes de dimensões similares e diferentes comprimentos iniciais de trinca (veja seção 3.4). Tal estratégia demanda uma maior quantidade de material o qual nem sempre está disponível. Outra desvantagem do emprego de múltiplos corpos-de-prova é que os custos para a execução de um ensaio são maiores porque exigem maior trabalho de usinagem e maior tempo de ocupação do equipamento de ensaios. Isto motivou o desenvolvimento de procedimentos experimentais nos quais somente é empregado um corpo-de-prova para a obtenção da curva de resistência. Dentre os trabalhos pioneiros no emprego de um espécime único para a determinação destas curvas podem ser mencionados os trabalhos de Clarke e colaboradores [47] e de Joyce e Gudas [48]. Especificamente, a metodologia proposta por Joyce e Gudas é amplamente usada pela economia de material e simplicidade (quando corretamente estabelecida) na sua execução e forma a base da norma ASTM E1820 [12]. 
Uma das metodologias para a medição experimental de curvas $J-R$ com o emprego de um espécime único utiliza o conceito de flexibilidade no descarregamento. Nesta metodologia, o comprimento de trinca é relacionado com a flexibilidade instantânea do corpo-de-prova. Durante o ensaio experimental são executados descarregamentos elásticos a intervalos regulares (veja Fig.15(a)) os quais, para cada um destes, é associado um valor de flexibilidade correspondente à extensão da trinca. $\mathrm{O}$ uso de uma função que relaciona os valores de flexibilidade C com o comprimento de trinca do espécime permite obter os valores de crescimento $(\Delta a)$ correspondentes a cada um dos descarregamentos parciais.

Uma vez obtidos os valores de crescimento de trinca, resta determinar a integral $J$ para cada um destes descarregamentos. Interpretando a integral $J$ como a taxa de liberação de energia e separando-a em suas partes elástica e plástica, $J$ pode ser definida como (veja Anexo A.1)

$$
J=J_{e}+J_{p}=\frac{K_{\mathrm{I}}^{2}}{E^{\prime}}+\frac{\eta_{J} A_{p}}{B_{N} b_{0}}
$$

onde $K_{\mathrm{I}}$ é o fator elástico de intensidade de tensões no modo I de carregamento, $A_{p}$ é a área sob a curva carga-deslocamento, $B_{N}$ é a espessura efetiva do espécime (considerando a sua redução se houver entalhes laterais (side groove)) e $b_{0}=W-a_{0}$ é o ligamento remanescente no início do ensaio. A Eq. (9) considera estado plano de deformações e, portanto, $E^{\prime}=E /\left(1-v^{2}\right)$. O fator $\eta_{J}$ introduzido por Sumpter e Turner [49] e Paris e colaboradores [50] representa um parâmetro adimensional que correlaciona a energia de deformação plástica com a porção plástica da integral $J$. A Fig. 15(b) esquematiza o procedimento para obter $J_{p}$. Como pode ser observado nesta figura, a área utilizada para estimar a componente plástica de $J$ pode ser obtida usando o deslocamento da linha de carga (LLD ou $\Delta$ ) ou a abertura da boca da trinca (CMOD ou $V$ ). Embora estas duas áreas sirvam para o mesmo propósito (obter a componente plástica de $J$ ), os fatores $\eta_{J}$ correspondentes 


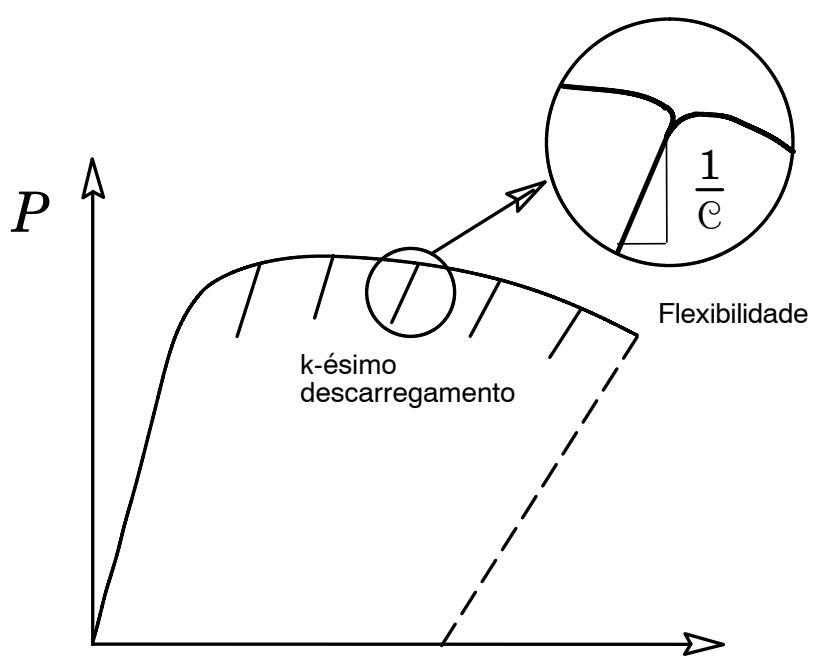

(a)

$C M O D$

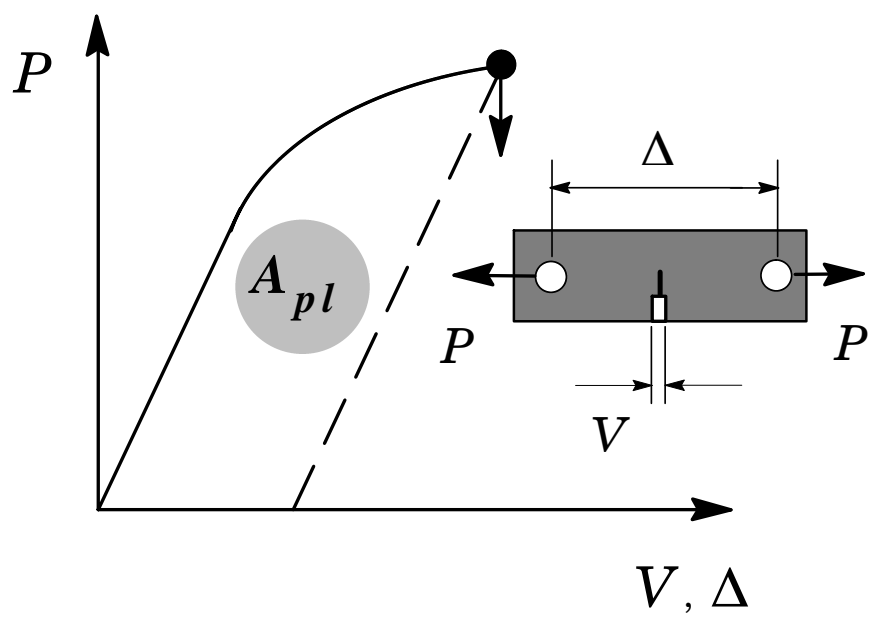

(b)

Figura 15 a)Descarregamentos parciais durante a evolução do carregamento com a abertura da ponta da trinca (CMOD); b) Definição da área plástica sob a curva carga-deslocamento.

são diferentes e possuem características distintas que serão discutidas nas seções seguintes.

A expressão anterior define a correlação entre a área plástica e $J_{p}$ para uma trinca estacionária. No caso de extensão estável da trinca, a curva carregamento-deslocamento difere significativamente da correspondente à trinca estacionária (veja Anexo A). Conseqüentemente, a obtenção de valores acurados de integral $J$ necessita de uma modificação da Eq. (9) que leve em conta as mudanças 
da curva carga vs. deslocamento conforme a trinca avança. Ernst e colaboradores [51] propuseram um procedimento muito usado (inclusive pela ASTM E1820 [12]) para avaliar $J$ com crescimento de trinca. O procedimento atualiza os valores de $J_{e}$ e $J_{p}$ a cada um dos descarregamentos parciais durante o ensaio na forma

$$
J_{k}=J_{e}^{k}+J_{p}^{k}
$$

Com este procedimento, o $k$-ésimo termo elástico é diretamente calculado do correspondente $k$-ésimo $K_{\mathrm{I}}$ usando o primeiro termo da Eq. (9)

$$
J_{e}^{k}=\frac{\left(K_{\mathrm{I}}^{k}\right)^{2}}{E^{\prime}}
$$

Para espécime SE(T), o fator de intensidade de tensões $K_{\mathrm{I}}$ é avaliado usando a carga aplicada no ponto do início do descarregamento, $P_{k}$ como

$$
K_{\mathrm{I}}^{k}=\frac{P_{k}}{B_{N} \sqrt{W}} \mathcal{F}\left(a_{k} / W\right)
$$

onde $\mathcal{F}\left(a_{k} / W\right)$ define o fator de intensidade de tensões adimensional o qual depende da geometria do espécime, comprimento de trinca e condições de carregamento. Para os espécimes $\mathrm{SE}(\mathrm{T})$ analisados neste trabalho foram usadas as soluções para $K_{\mathrm{I}}$ dadas por Chiodo e colaboradores [52] as quais são reproduzidas no Anexo B.

Similarmente, a $k$-ésima componente plástica de $J$ é dada por

$$
J_{p}^{k}=\left[J_{p}^{k-1}+\frac{\eta_{k-1}}{b_{k-1} B_{N}}\left(A_{p}^{k}-A_{p}^{k-1}\right)\right]\left[1-\frac{\gamma_{k-1}}{b_{k-1}}\left(a_{k}-a_{k-1}\right)\right]
$$

Na equação acima, o fator $\gamma$ é dado pela seguinte expressão [51] (veja Anexo A.2)

$$
\gamma_{k-1}=\left[\eta_{k-1}-1-\left(\frac{b_{k-1}}{W} \frac{\eta_{k-1}^{\prime}}{\eta_{k-1}}\right)\right]
$$


onde

$$
\eta_{k-1}^{\prime}=W \frac{d \eta_{k-1}}{d a_{k-1}}
$$

A aplicação do procedimento apresentado anteriormente requer o conhecimento dos fatores $\eta_{J}$ e $\gamma$ assim como dos valores de flexibilidade da geometria considerada. As normas atuais fornecem dados de $\eta_{J}, \gamma$ e flexibilidade $C$ para espécimes $\mathrm{SE}(\mathrm{B}) \mathrm{e}$ $\mathrm{C}(\mathrm{T})$ com trinca profunda $(a / W \geq 0.45)$. Entretanto, existem dados relativamente escassos para espécimes SE(T) indicando a necessidade de estudos aprofundados desta geometria. As referências [53] e [54] são representativas da literatura disponível sobre flexibilidade e fatores $\eta_{J}$ em espécimes $\mathrm{SE}(\mathrm{T})$.

\subsection{Correção por Rotação em Corpos-de-Prova SE(T)}

A medição de curvas de resistência requer a correta determinação do comprimento de trinca conforme esta cresce e da área plástica sob a curva carga vs. deslocamento ( $P$-LLD ou $P$-CMOD). Quando é empregado o método de flexibilidade no descarregamento, o comprimento de trinca é determinado em intervalos regulares por intermédio da medição da flexibilidade do corpo-de-prova. Adicionalmente, a área plástica é determinada subtraindo-se a área elástica da área total sob a curva carga vs. deslocamento. No entanto, os espécimes $\mathrm{SE}(\mathrm{T})$ carregados por pinos apresentam uma importante rotação durante o ensaio experimental como apresentado na Fig. 16. Esta rotação do corpo-de-prova faz com que os valores de carregamento e de deslocamento medidos na boca da trinca (CMOD) durante o ensaio tenham que ser corrigidos para aplicar as formulações de integral $J$ e flexibilidade. As razões para isto são ilustradas nas Figs. 16 e 17 e descritas a seguir.

As equações de flexibilidade e fatores $\eta_{J}$ são derivadas de modelos analíticos ou de elementos finitos sob hipótese de pequenas deformações. Desta forma, os valores de carga e reações obtidas destes modelos referem-se à geometria sem deformar. Por 
exemplo, é possível observar na Fig. 16 que a carga $P_{c}$ aplicada na geometria sem deformar produz um momento em relação ao centro de rotação dado por $P_{c} \cdot r_{1}$. No entanto, a carga na geometria deformada produz outro momento dado por $P_{m} \cdot r_{2}$ (notar que os subscritos $m$ e $c$ indicam valores medidos e valores corrigidos respectivamente). Desta forma o efeito que a carga produz na geometria sem deformar é diferente do efeito que produz na geometria deformada. Isto é diretamente capturado pela flexibilidade medida experimentalmente. Outro efeito da rotação do corpo-deprova pode ser observado na Fig. 17, onde é evidente que o valor de CMOD $\left(V_{m}\right)$ medido diretamente pelo extensômetro é inferior ao deslocamento que seria medido se não houvesse rotação do corpo-de-prova $\left(V_{c}\right)$. A seguir é apresentado o procedimento de correção para estes efeitos de rotação, o qual baseia-se em trabalho prévio de Joyce e Link [8]. Entretanto, é considerada uma dimensão geométrica adicional para incluir o efeito da espessura $(z)$ das lâminas de fixação do extensômetro (veja Fig. 17).

Primeiramente será apresentada a correção por rotação do deslocamento CMOD. Empregando as dimensões e relações trigonométricas observadas na Fig. 17 pode ser obtida a seguinte relação

$$
\tan (\theta+\phi)=\frac{\left(V_{c} / 2\right)+D}{R_{C}+z}
$$

onde $\theta$ define o ângulo de rotação do espécime, $R_{C}$ é a distância da borda do espécime até o seu centro de rotação, $z$ é a espessura das lâminas de fixação do extensômetro, $D$ é a metade da distância inicial entre os pontos de medição de deslocamento. $\mathrm{O}$ ângulo $\phi$ é dado por

$$
\phi=\arctan \left(\frac{D}{R_{C}+z}\right)
$$

Considerando a seguinte relação trigonométrica

$$
\tan (\alpha+\beta)=\frac{\tan \alpha+\tan \beta}{1-\tan \alpha \cdot \tan \beta}
$$


e substituindo na Eq. (16) obtém-se,

$$
\frac{V_{c} / 2+D}{R_{C}+z}=\frac{\tan \theta+\tan \phi}{1-\tan \theta \cdot \tan \phi}
$$

Assumindo $D \ll R_{C}$, é possível eliminar o termo de ordem superior no denominador da equação precedente. Reordenando e simplificando obtém-se

$$
V_{c} \approx 2\left(R_{C}+z\right) \tan \theta
$$

Ainda na Fig. 17, podem ser obtidas as seguintes relações

$$
\theta=\operatorname{arcsen}\left(\frac{V_{m} / 2+D}{\sqrt{D^{2}+\left(R_{C}+z\right)^{2}}}\right)-\phi
$$

e

$$
\operatorname{sen}(\theta+\phi)=\frac{V_{m} / 2+D}{\sqrt{D^{2}+\left(R_{C}+z\right)^{2}}}
$$

Utilizando a relação trigonométrica $\operatorname{sen}(\alpha+\beta)=\operatorname{sen} \alpha \cdot \cos \beta+\cos \alpha \cdot \operatorname{sen} \beta$ na equação acima e simplificando, obtém-se

$$
V_{m}=2\left[\left(R_{C}+z\right) \sin \theta+D(\cos \theta-1)\right] .
$$

Finalmente, combinando as Eqs. (20) e (23) pode-se obter a correção para o deslocamento CMOD devido à rotação na forma

$$
V_{c}=\frac{V_{m}}{\cos \theta-\frac{D \tan \theta}{2\left(R_{C}+z\right)}} .
$$


Como foi mencionado anteriormente, além da correção do deslocamento também é importante corrigir a carga aplicada ao corpo-de-prova. Quando há rotação, o momento produzido pela força medida experimentalmente é diferente do momento que produziria a mesma força no corpo-de-prova sem deformar. Portanto, observando a Fig. 16 pode ser estabelecida a seguinte relação de momentos

$$
P_{c} \cdot r_{1}=P_{m} \cdot r_{2}
$$

onde $P_{c}$ é a força corrigida, $r_{1}$ é a distância da linha de carga até o centro de rotação para o espécime não deformado $\left(r_{1}=R_{C}-W / 2\right), P_{m}$ é a força medida e $r_{2}$ é a distância da linha de carga até o centro de rotação após a rotação do espécime. Da Fig. 16 é obtida a seguinte relação

$$
r_{2}=r_{1} \cos \theta-\frac{H}{2} \operatorname{sen} \theta
$$

a qual, substituindo na Eq. (25) e simplificando, resulta

$$
\frac{P_{c}}{P_{m}}=\cos \theta-\frac{H}{2 r_{1}} \operatorname{sen} \theta
$$

A Eq. (27) precedente fornece a correção por rotação da carga medida experimentalmente.

A flexibilidade baseada no CMOD medida durante o ensaio é dada por

$$
\mathrm{C}_{m}^{\mathrm{CMOD}}=\frac{V_{m}}{P_{m}}
$$

Portanto, corrigindo o deslocamento $V_{m}$ (CMOD) com a Eq. (24) e a carga $P_{m}$ com a Eq. (27), a expressão para corrigir a flexibilidade medida na curva $P$-CMOD $\left(\mathrm{C}_{m}^{\mathrm{CMOD}}\right)$ devido à rotação do corpo-de-prova resulta

$$
\mathrm{C}_{c}^{\mathrm{CMOD}}=\frac{\mathrm{C}_{m}^{\mathrm{CMOD}}}{\left[\cos \theta-\frac{D \tan \theta}{2\left(R_{C}+z\right)}\right]\left[\cos \theta-\frac{H \sin \theta}{2 r_{2}}\right]} .
$$


Adicionalmente, quando é empregada a curva $P$-LLD para obter a área plástica e, conseqüentemente, $J_{p}$, a flexibilidade medida na linha de carga, $\mathrm{C}_{m}^{\mathrm{LLD}}$, deve ser corrigida para obter valores corretos da área plástica. Na correção da flexibilidade $e_{m}^{L L D}$ somente é empregada a Eq. (27), uma vez que a única medição a ser corrigida é a carga $P_{m}$ e não o deslocamento. Desta forma, a correção para a flexibilidade derivada do LLD é dada por

$$
\mathrm{C}_{c}^{\mathrm{LLD}}=\frac{\mathrm{C}_{m}^{\mathrm{LLD}}}{\left[\cos \theta-\frac{H \sin \theta}{2 r_{2}}\right]}
$$

Para completar as correções por rotação somente falta definir $R_{C}$ (veja. Fig. 17). Para isto é preciso determinar a posição do centro de rotação do espécime. Em trabalhos anteriores [8] foi assumido que o centro de rotação encontra-se na metade do ligamento remanescente do espécime. Isto é consistente com o valor empregado pela ASTM E1820 [12] para corpos-de-provas compactos C(T) com trinca profunda. Entretanto, isto não é exato no caso de corpos-de-prova SE(T). A posição do centro de rotação é definida como a soma do comprimento de trinca mais uma fração do ligamento remanescente na forma

$$
R_{C}=a+r_{p} \cdot(W-a) .
$$

Onde o raio plástico, $r_{p}$, é calculado numericamente como será apresentado no capítulo 7 . 


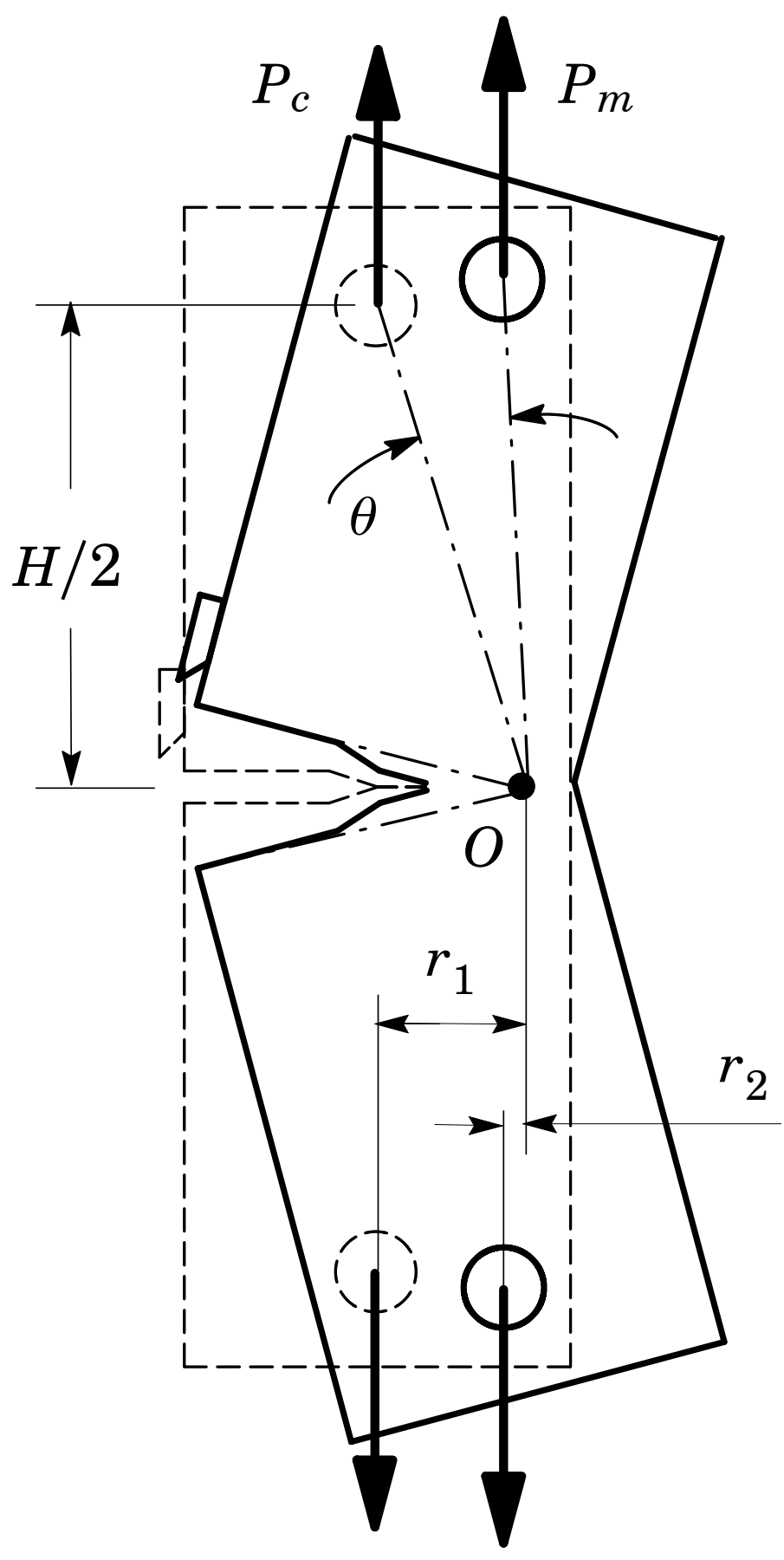

Figura 16 Corpo-de-prova $S E(T)$ carregado por pinos para as configurações não deformada e deformada. 


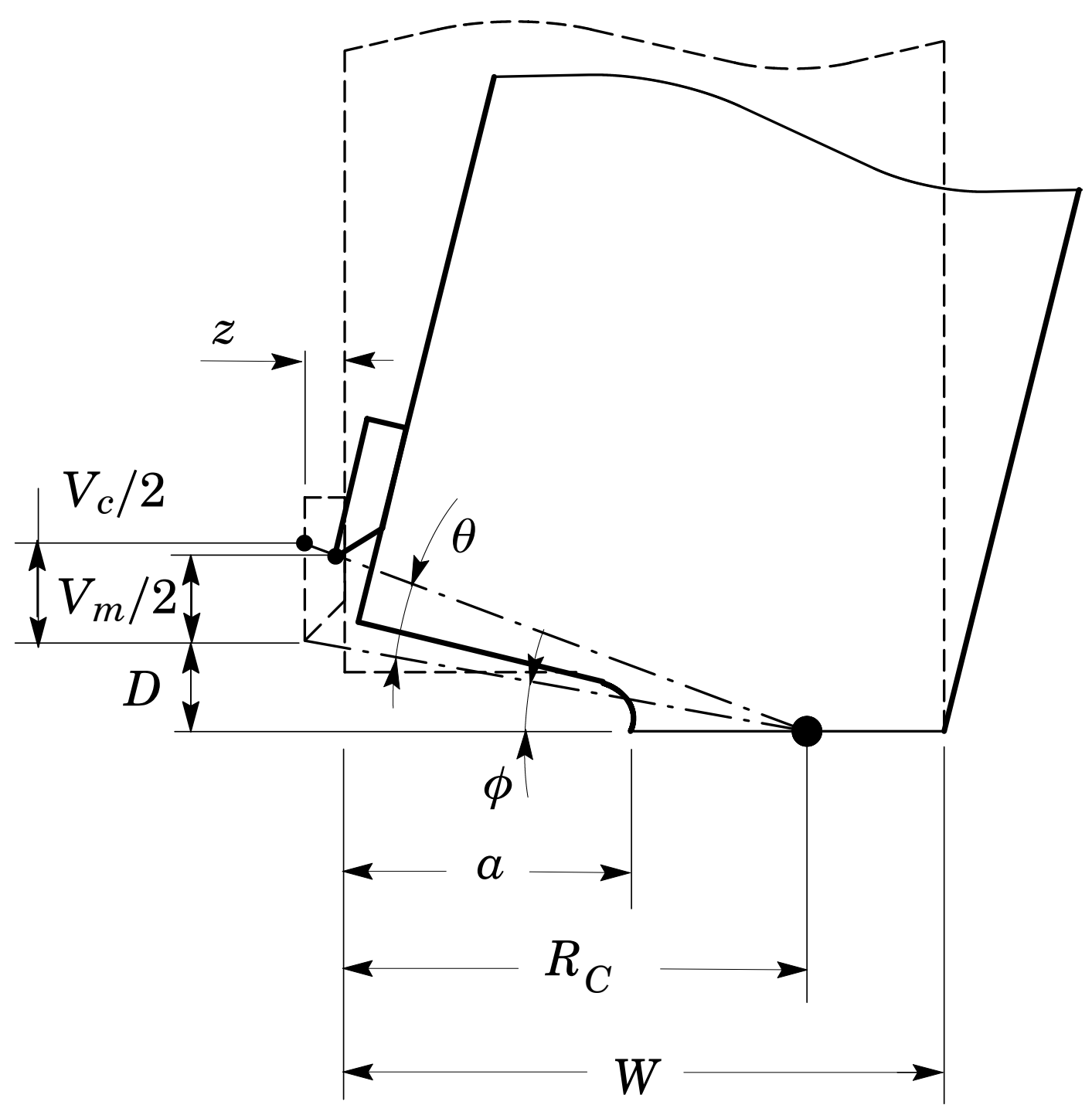

Figura 17 Detalhe da medição do CMOD; neste caso o deslocamento à direita do ponto de medição faz com que o valor medido seja diferente do que seria medido sem rotação. 


\subsection{Medição Experimental de integral $J$ Empregando Múltiplos Corpos-de-Prova}

Durante os primeiros anos após a introdução da integral $J$ [7] havia interesse apenas puramente teórico porque não existia uma metodologia para a sua determinação experimental. Os primeiros a apresentarem uma metodologia para a medição de integral $J$ utilizando ensaios laboratoriais foram Begley e Landes (B\&L) $[45,46]$. A partir de extenso trabalho experimental, eles estabeleceram uma metodologia para a medição do valor da integral $J$ correspondente à iniciação de crescimento estável de trinca $\left(J_{\mathrm{Ic}}\right)$. Esta metodologia não é mais empregada na atualidade; entretanto, ela forneceu as bases para um procedimento padronizado mais preciso [55]. De modo ilustrativo, apresenta-se a seguir uma descrição da metodologia utilizada por B\&L.

No capítulo 2 foram apresentadas as interpretações de integral $J$ como parâmetro de intensidade de tensões e, também, como uma taxa de liberação de energia. Destas interpretações, a última foi a empregada na derivação de um procedimento experimental para a medição de $J$. Em seu trabalho, B\&L [45, 46] obtiveram uma série de curvas de carga vs. deslocamento da linha de carga $(P$-LLD) para corpos-de-prova com geometria e material (A533) similares e diferentes comprimentos iniciais de trinca $\left(a_{0}\right)$. Considerando que a área debaixo da curva $P$-LLD (anterior à propagação da trinca) é a energia de deformação imposta ao sistema, é possível calcular a energia de deformação como função do comprimento de trinca do espécime. Entretanto, B\&L ainda tiveram que resolver o problema de determinação do ponto de carregamento aplicado durante o ensaio em que a trinca começava a propagar. Tal procedimento é necessário para determinar a energia aplicada que produz a iniciação de crescimento de trinca. Para determinar este ponto, B\&L definiram, arbitrariamente, o ponto de carga máxima como o ponto de iniciação (atualmente, é empregado um procedimento mais preciso que aquele empregado por Begley e Landes [12]).

Uma vez obtidas curvas carga vs. deslocamento da linha de carga $(P$-LLD) para diferentes profundidades de defeito e, também, um critério para determinar o início 
de crescimento de trinca, B\&L usaram a interpretação da integral $J$ como a variação da energia de deformação $(U)$ com o comprimento de trinca para determinar o valor de $J$ aplicado. Utilizando o valor da energia de deformação para diferentes dimensões de trincas (conhecida para um corpo-de-prova préespecificado), é possível calcular a variação de $U$ com a profundidade da mesma e, conseqüentemente, determinar o valor de integral $J$. A seguir apresenta-se um exemplo ilustrativo do procedimento seguido por B\&L.

\subsubsection{Exemplo Ilustrativo}

O exemplo apresentado a seguir reproduz o procedimento empregado por Begley e Landes para uma geometria correspondente a espécimes $\mathrm{SE}(\mathrm{T})$ carregados por pinos. As curvas carga vs. deslocamento da linha de carga (LLD) são obtidas de modelos numéricos similares aos descritos a seguir no capítulo 4. Com isto, é possível comparar os valores de integral $J$ obtidos do procedimento empregado pelos autores já mencionados com os valores acurados de $J$ dados pelo método de integral de domínio empregado pelo código de elementos finitos (veja capítulo 4).

Foram construídos 7 modelos elasto-plásticos SE(T) 1-T com geometria idêntica e relações comprimento de trinca - largura de espécime, $a / W$, de 0,1 a 0,7 com incrementos de 0,1 . Destes modelos, foram obtidas as curvas $P$-LLD apresentadas na Fig. 18; uma integração numérica convencional fornece as áreas debaixo destas curvas para deslocamentos $L L D=1.0,1.75$ e $2.5 \mathrm{~mm}$. Estas área representam as energias de deformação , $U$, impostas aos corpos-de-provas para cada um dos deslocamentos já mencionados. Tendo as diferentes energias de deformação $U$ para as diferentes profundidades de trincas, estas energias podem ser ajustadas por um polinômio de quarto grau como apresentado na Fig. 19. Com este polinômio e considerando que

$$
J=-\left(\frac{\partial U}{\partial A}\right)_{\Delta}
$$


pode ser obtido o valor de integral $J$. Na Eq. (32), $U$ é a energia absorvida pelo espécime durante a aplicação da carga e $\partial A$ é o incremento na área da trinca. $\mathrm{O}$ símbolo $\Delta$ indica que o carregamento é controlado por deslocamento. No caso de espécime com espessura constante, $\partial A=B \cdot \partial a$ onde $d a$ é o incremento na profundidade da trinca e $B$ é a espessura do espécime, portanto, a Eq. 32 pode adotar a seguinte forma

$$
J=-\frac{1}{B}\left(\frac{\partial U}{\partial a}\right)_{\Delta}
$$

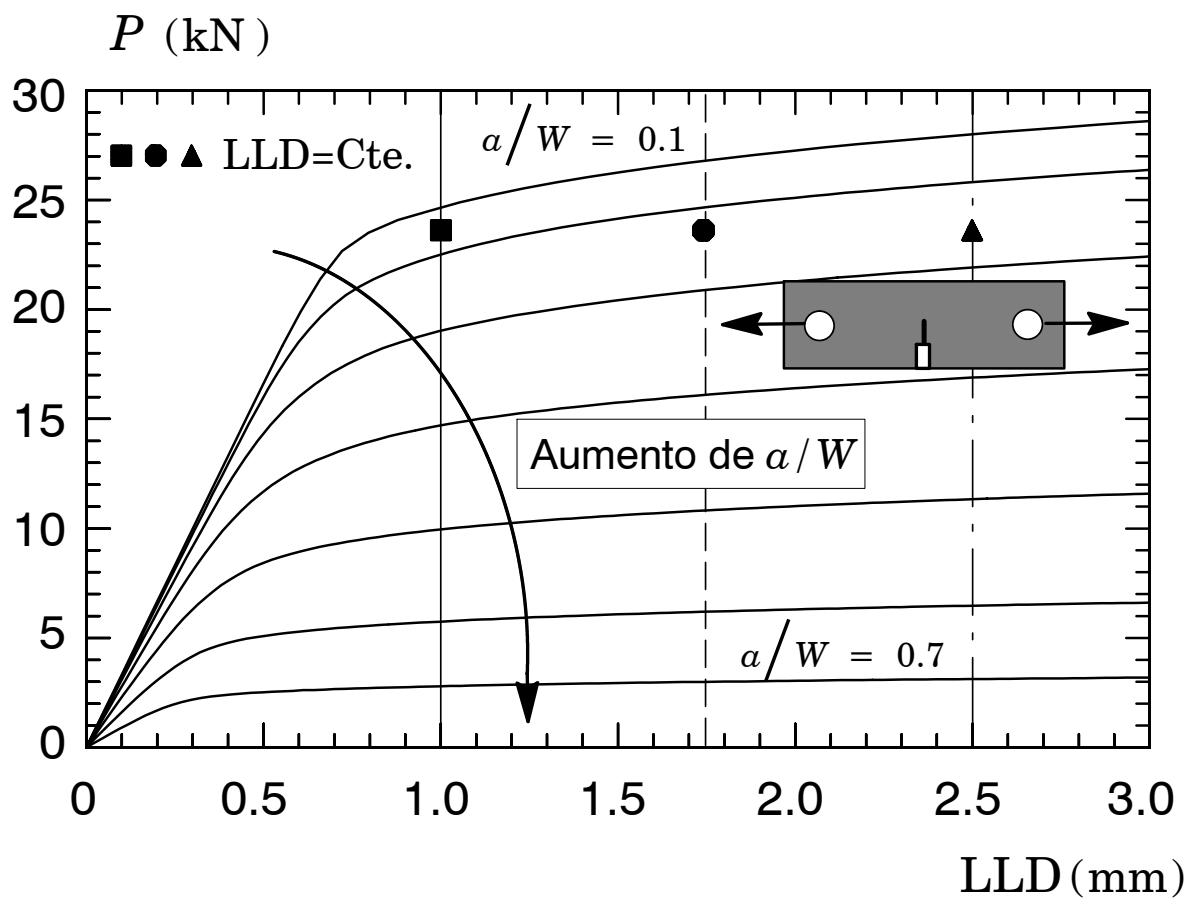

Figura 18 Curvas carga vs. deslocamento da linha de carga obtidas de modelos de elementos finitos para corpos-de-prova $S E(T)$ com diferentes profundidades de trinca.

Da derivação do polinômio de ajuste da energia de deformação (Fig. 19) em relação ao comprimento de trinca $a$, são obtidos os valores de $J$ apresentados na Fig. 20 e na Tabela 1 . A mesma tabela apresenta os valores de integral $J$ calculados pelo método de elementos finitos usando um procedimento de integração de domínio [56] como será descrito no capítulo seguinte. Nesta tabela, pode ser observado que ambos os valores obtidos são muito próximos com diferenças menores a 10\%. A diferencia 




Figura 19 Energias de deformação dos corpos-de-prova $S E(T)$ como função da profundidade de trinca para três níveis de deslocamento da linha de carga.

percentual é definida como o desvio do valor dado pela Eq. (33) em relação ao resultado numérico, o qual é considerado como exato. É importante mencionar que são apresentados valores de $J$ para relações profundidade de trinca - largura de espécime entre 0,2 e 0,6; porque o ajuste polinomial não descreve de forma acurada a variação da energia de deformação $U$ com a profundidade de trinca nos extremos da faixa de ajuste, $a / W=0,1$ e 0,7 .

É evidente que o grau de precisão obtido neste exemplo é devido, em boa medida, aos dados utilizados, os quais, foram obtidos de modelos numéricos onde as profundidades de trinca são conhecidas de forma precisa e os dados de carga e deslocamento não têm erros de medição. Entretanto, isto demonstra que o procedimento é válido e facilmente aplicável quando se dispõe de suficientes dados experimentais. 


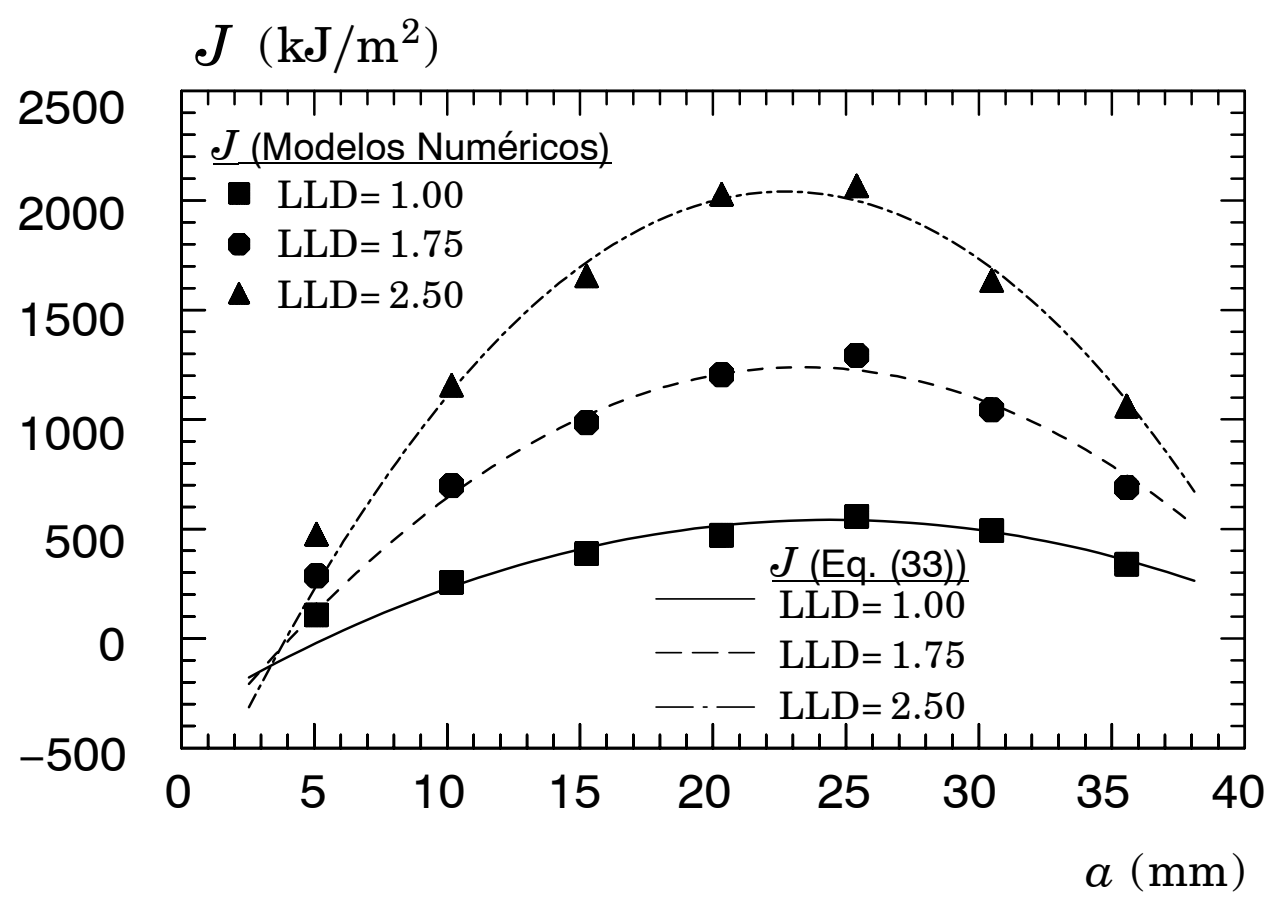

Figura 20 Comparação dos valores de integral J obtidos dos modelos numéricos com os valores obtidos empregando a Eq. 33 para três níveis de deslocamento da linha de carga.

Tabela 1: Comparação dos valores de $\mathrm{J}$ obtidos da derivada da energia de deformação com os valores obtidos por elementos finitos.

\begin{tabular}{|c|c|c|c|c|c|}
\hline$a / W$ & 0,2 & $\mathbf{0 , 3}$ & $\mathbf{0 , 4}$ & $\mathbf{0 , 5}$ & $\mathbf{0 , 6}$ \\
\hline \multicolumn{6}{|l|}{$\mathrm{LLD}=\mathbf{1 , 0 0} \mathrm{mm}$} \\
\hline$J($ Eq. (33)) & 235,38 & 414,22 & 515,81 & 540,14 & 487,20 \\
\hline$J$ (Modelo Numérico) & 256,20 & 387,50 & 471,20 & 558,00 & 492,70 \\
\hline Diferença percentual & $-8 \%$ & $7 \%$ & $9 \%$ & $-3 \%$ & $-1 \%$ \\
\hline \multicolumn{6}{|l|}{ LLD = 1,75 mm } \\
\hline$J$ (Eq. (33)) & 656,73 & 1018,20 & 1207,70 & 1225,20 & 1070,70 \\
\hline$J$ (Modelo Numérico) & 697,30 & 984,80 & 1204,00 & 1293,00 & 1044,00 \\
\hline Diferença percentual & $-6 \%$ & $3 \%$ & $1 \%$ & $-5 \%$ & $3 \%$ \\
\hline \multicolumn{6}{|l|}{$\mathrm{LLD}=\mathbf{2 , 5 0} \mathrm{mm}$} \\
\hline$J$ (Eq. (33)) & 1129,00 & 1717,50 & 2007,50 & 1998,80 & 1691,50 \\
\hline$J$ (Modelo Numérico) & 1156,00 & 1655,00 & 2028,00 & 2066,00 & 1634,00 \\
\hline Diferença percentual & $-2 \%$ & $4 \%$ & $-1 \%$ & $-3 \%$ & $4 \%$ \\
\hline
\end{tabular}




\section{MATRIZ DE ANÁLISE E PROCEDIMENTOS NUMÉRICOS}

Neste capítulo são descritos os modelos de elementos finitos construídos para a obtenção de equações de flexibilidade e fatores $\eta_{J}$ e $\gamma$ para diferentes geometrias de corpos-de-prova. No presente trabalho, ênfase particular é dada ao estudo de espécimes à tração com entalhe lateral $(\mathrm{SE}(\mathrm{T}))$ sendo, portanto a geometria com maior número de modelos executados. Entretanto, também foram estudados espécimes padronizados à flexão de três pontos $(\mathrm{SE}(\mathrm{B}))$ como forma de verificação adicional dos procedimentos utilizados. Para o caso de corpos-de-prova SE(T) foram construídos tanto espécimes $2 D$ como $3 D$ descritos na seção seguinte.

\subsection{Corpos-de-Prova à Fratura}

\subsubsection{Corpos-de-Prova em Estado Plano de Deformações}

Para obter um bom mapeamento do comportamento geral de espécimes SE(T) com diferentes proporções geométricas, modos de carregamento e materiais foi gerada uma grande quantidade de modelos $2 D$ em estado plano de deformações. Entretanto, também foram construídos alguns modelos à flexão $\mathrm{SE}(\mathrm{B})$ para verificação adicional dos procedimentos e comparação com dados disponíveis na literatura. A Fig. 21 apresenta a geometria e dimensões principais dos espécimes. Os materiais considerados são apresentados na subseção 4.2.2. A matriz de análises inclui diversas configurações de espécimes submetidos à tração e à flexão com diferentes geometrias e tamanhos de trinca. Os modelos considerados foram: i) $\mathrm{SE}$ (B) com $a / W=0,1$ a 0,7 com incrementos de 0,05 , ii) $\mathrm{SE}(\mathrm{T})$ com $a / W=0,1$ a 0,7 com incrementos de 0,1 e $H / W=4,6$ e 10. Para estes espécimes, $a$ é a profundidade da trinca, $H$ é a distância entre os pontos de aplicação do carregamento em espécimes SE(T) ou a distância entre apoios no caso de espécimes $\mathrm{SE}(\mathrm{B})$ e $W$ é a largura do espécime. As dimensões e proporções geométricas dos espécimes correspondem àqueles corpos-deprova padrão $1-\mathrm{T}(B=25,4 \mathrm{~mm}, W=2 B$ e $H=8 B)$ exceto os espécimes $\mathrm{SE}(\mathrm{T})$ nos quais 
a distância de aplicação da carga foi alterada. As dimensões dos espécimes 1-T estão detalhadas na Tabela 2. Adicionalmente, foram considerados espécimes $\mathrm{SE}$ (B) 0,5-T e 2-T com comprimento relativo $H / W=4$ para estudar os efeitos das dimensões absolutas. No caso de espécimes $\mathrm{SE}(\mathrm{T})$ 1-T, as análises também consideram diferentes condições de carregamento: carregamento por pinos e carregamento por garras; estes espécimes são identificados como $\mathrm{SE}(\mathrm{T})_{P}$ e $\mathrm{SE}(\mathrm{T})_{C}$.
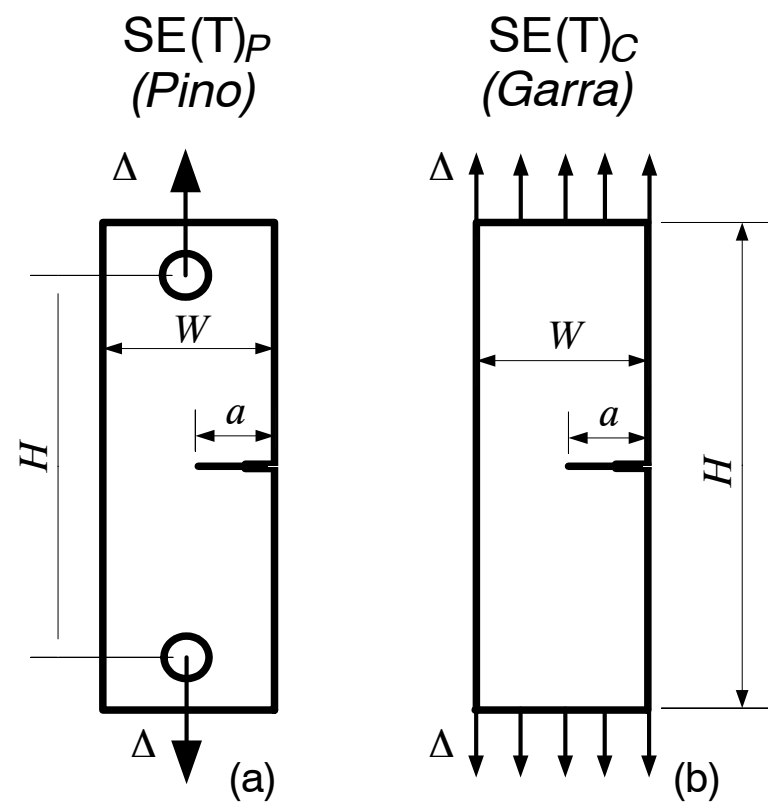

\section{SE(B)}

(a)

Figura 21 Geometrias dos Corpos-de-Prova; a) SE(T) carregado por pino; b) $S E(T)$ fixado por garras; c) $S E(B)$.

Tabela 2: Dimensões dos espécimes 1-T estudados.

\begin{tabular}{ccc}
\hline Espécime & $a / W[\mathrm{~mm}]$ & $H / W$ \\
\hline \multirow{2}{*}{$\mathrm{SE}(\mathrm{B})$} & 0,$1 ; 0,15 ; 0,20 ; 0,25 ; 0,30 ; 0,35 ;$ & 4 \\
& 0,$40 ; 0,45 ; 0,50 ; 0,55 ; 0,60 ;$ \\
0,$65 ; 0,70$ & \\
\hline $\mathrm{SE}(\mathrm{T})_{P}$ e $\mathrm{SE}(\mathrm{T})_{C}$ & $\begin{array}{c}0,1 ; 0,20 ; 0,30 ; 0,40 ; 0,50 ; 0,60 ; \\
0,70\end{array}$ & $4 ; 6 ; 10$ \\
\hline
\end{tabular}




\subsubsection{Modelos de Corpos-de-Prova em Contexto 3D}

Os modelos $2 D$ indicados anteriormente têm as características de serem simples e fornecerem resultados acurados. Entretanto, para confirmar a precisão dos resultados $2 D$, também foram conduzidas análises $3 D$ para algumas geometrias selecionadas de espécimes à fratura $\mathrm{SE}(\mathrm{T})$. Estas análises correspondem a espécimes $\mathrm{SE}(\mathrm{T})$ com $H / W=6$ e relação profundidade de trinca largura do espécime, $a / W=0,1$ a 0,7 com incrementos de 0,1 . A Seção 4.3 apresenta maiores detalhes sobre a construção dos modelos e refinamento de malha dos mesmos.

\subsection{Procedimentos Numéricos}

\subsubsection{Código de Elementos Finitos}

As soluções numéricas apresentadas neste trabalho são obtidas através do código de elementos finitos WARP3D [57]. O programa permite análises elásticas lineares e, também, análises elasto-plásticas. O procedimento para o cálculo das deformações e deslocamentos segue uma teoria linear (pequenas deformações) ou não linear incorporando grandes deslocamentos e deformações. O procedimento para o cálculo das deformações finitas é o empregado pela maioria dos códigos de elementos finitos comerciais tais como ABAQUS [58, 59] e DYNA [60] o qual faz uma decomposição polar das dilatações e rotações. Para maiores detalhes sobre a implementação do procedimento o leitor pode-se referir ao trabalho de Simo e Hughes [61] ou ao manual do software WARP3D [57]. Os modelos de fratura são construídos com elementos isoparamétricos de 8 nós. Desta forma, WARP3D incorpora a modificação da matriz deslocamento-deformação $(B)$ sugerida por Hughes [56] para reduzir o travamento característico deste tipo de elementos com integração completa; este procedimento é denominado método $\overline{\boldsymbol{B}}$. Os termos volumétricos da matriz que relaciona as deformações com os deslocamentos nos pontos de integração gaussianos são substituídos por um grupo de termos volumétricos que produzem tensões médias uniformes no elemento (veja Nagtegaal, e colaboradores [62]). 
O valor local da taxa de liberação de energia mecânica, expressa pela integral $J$ (veja capítulo 2), em pontos ao longo da frente de trinca é dada por

$$
J=\int_{\Gamma}\left[W n_{1}-P_{j i} \frac{\partial u_{i}}{\partial X_{1}} n_{j}\right] d \Gamma
$$

onde $\Gamma$ denota um contorno fechado definido sobre um plano normal à frente da trinca, iniciando na face inferior da trinca e terminando na sua face superior, $n_{j}$ é o vetor normal exterior ao contorno $\Gamma$, $W$ denota a energia de deformação por unidade de volume indeformado, $P_{i j}$ e $u_{i}$ são as componentes cartesianas do tensor de tensões (assimétricas) de Piola-Kirchoff e dos deslocamentos no sistema de coordenadas localizado na frente da trinca. O código WARP3D também tem a capacidade de calcular de forma numérica o valor de integral $J$ apresentada na Eq. (34) por meio de um procedimento de integração de domínio proposto por Moran e Shih [63, 64]. Mesmo utilizando teoria incremental de deformações, o procedimento fornece valores de integral $J$ aproximadamente constantes para diferentes domínios de integração, em regiões suficientemente afastadas da zona com grande plastificação. Os valores de $J$ também são corrigidos para extensão dúctil e concordam, em geral, com os valores obtidos por esquemas de avaliação experimental (e.g., método $\eta$ da ASTM E1820 [12]). Conseqüentemente, a Integral $J$ numérica fornece um parâmetro conveniente e robusto para caracterizar localmente a intensidade do carregamento remoto sobre a frente da trinca.

\subsubsection{Modelo Constitutivo}

O modelo constitutivo utilizado no presente trabalho segue uma teoria de pequenas deformações e algoritmo de plasticidade de Von Mises $\left(J_{2}\right)$. O procedimento para a modelagem da superfícies de escoamento segue uma lei isotrópica a qual é acurada quando os carregamentos são monotônicos como é o caso dos modelos considerados. As soluções numéricas dos modelos utilizam uma lei de potência para caracterizar a resposta a tração uniaxial real do material na forma 


$$
\begin{aligned}
& \frac{\varepsilon}{\varepsilon_{0}}=\frac{\sigma}{\sigma_{0}}, \quad \varepsilon \leq \varepsilon_{0} \\
& \frac{\varepsilon}{\varepsilon_{0}}=\left(\frac{\sigma}{\sigma_{0}}\right)^{n}, \quad \varepsilon>\varepsilon_{0}
\end{aligned}
$$

$\mathrm{Na}$ Eq. (35), $n$ denota o expoente que caracteriza o encruamento do material, $\sigma_{0}$ e $\varepsilon_{0}$ são as tensões e deformações de referência (escoamento) respectivamente. As análises de elementos finitos conduzidas neste trabalho, consideram propriedades de materiais representativas de uma faixa bastante abrangente de materiais estruturais e para vasos de pressão: $n=5\left(E / \sigma_{0}=800\right), n=10\left(E / \sigma_{0}=500\right), n=20$ $\left(E / \sigma_{0}=300\right)$ com $E=206000 M P a$ e $v=0,3$. As respostas tensão-deformação (verdadeiras) destes materiais estão representadas na Fig. 22. Esta faixa de propriedades também reflete a tendência à diminuição no encruamento com o aumento da tensão de escoamento no material (comportamento característico de aços ferríticos).

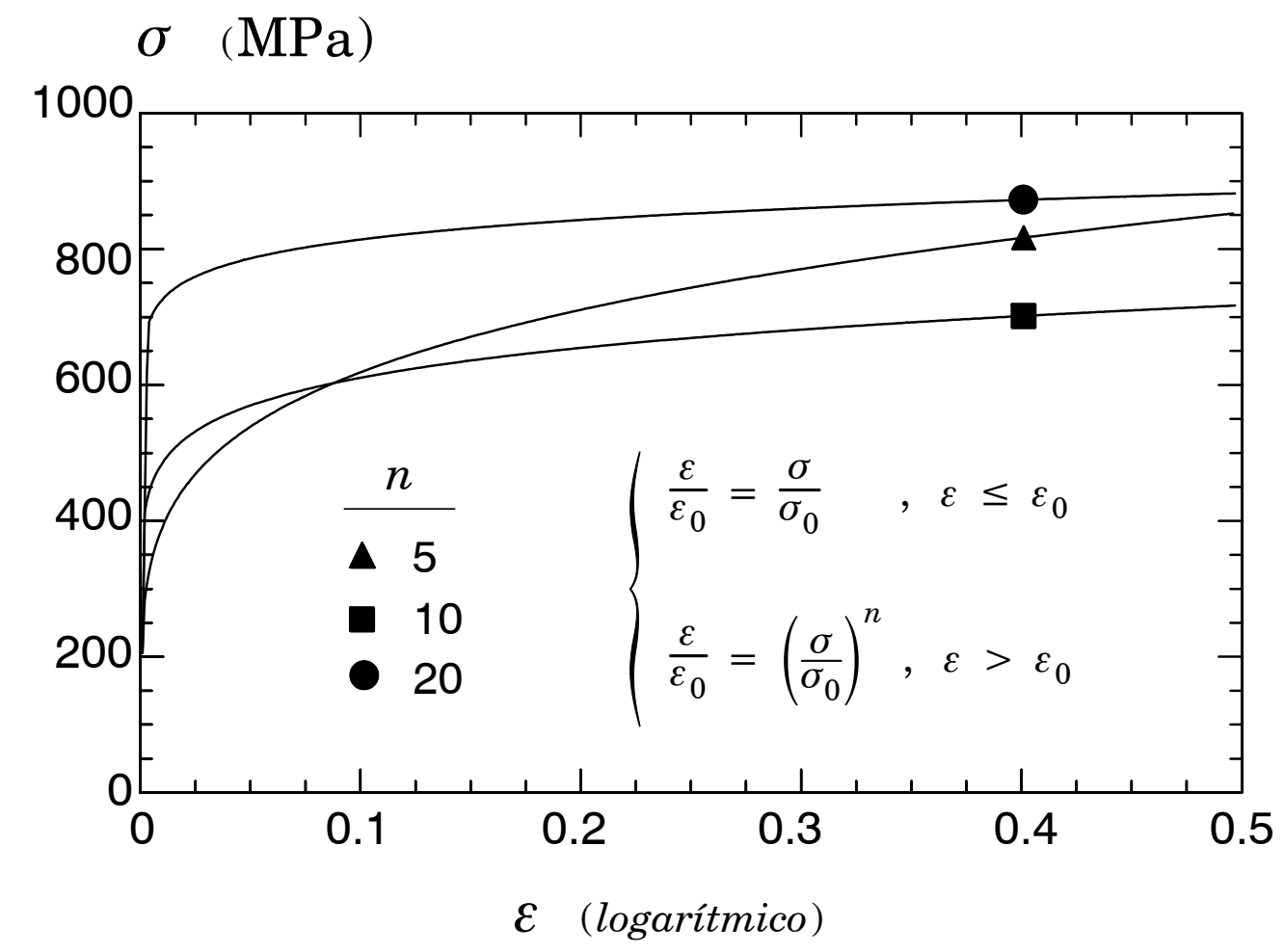

Figura 22 Curvas tensão-deformação verdadeira dos diferentes materiais considerados. 


\subsection{Modelos de Elementos Finitos}

O software Patran [65] foi empregado para a construção dos modelos de elementos finitos simulando as diversas geometrias dos espécimes de fratura considerados na matriz de análise da seção 4.1. A Fig. 23 apresenta dois dos modelos de elementos finitos construídos para as análises em estado plano de deformações. Nestas figuras, $H$ é a distância entre os pontos de aplicação do carregamento e $W$ é a largura do espécime (veja Fig. 21). Foram aproveitadas as condições de simetria destes modelos e construiu-se a metade do corpo-de-prova.

Para poder capturar de forma acurada a forte variação dos campos de tensões e deformações na região na frente da trinca, foi usada uma malha muito refinada em todos os modelos constituída de anéis focais centrados na ponta da trinca. Um pequeno raio $(\rho=0,0025 \mathrm{~mm})$ simulando o arredondamento inicial da trinca foi utilizado para modelar a sua ponta (veja Fig. 23-(c)). Este arredondamento inicial na ponta da trinca evita problemas numéricos na computação das tensões e deformações nas vizinhanças e, ao mesmo tempo, acelera a convergência dos algoritmos de plasticidade durante o estágio inicial de arredondamento do defeito.

Para que os campos de tensões e deformações obtidos possam ser comparados, o detalhamento da malha na ponta da trinca é igual em todos os modelos. A malha para o modelo $\mathrm{SE}(\mathrm{T})_{P} \operatorname{com} a / W=0,5$ e $H / W=6$ está composta por 2926 nós e 1349 elementos $3 D$ de 8 nós com restrições impostas em cada nó para impedir os deslocamentos na direção $Z$ e simular o estado plano de deformações. As malhas para os demais espécimes possuem arranjos similares com detalhamento idêntico na região da ponta da trinca. Os modelos de elementos finitos dos espécimes são carregados por imposição de deslocamentos para melhorar a convergência numérica.

Como foi mencionado anteriormente, também foram construídos e estudados modelos de corpos-de-prova em contexto $3 D$ pleno. A Fig. 24 apresenta a malha de elementos finitos para um espécime $\mathrm{SE}(\mathrm{T})_{P}$ com $a / W=0,5$ e $H / W=6$. As 


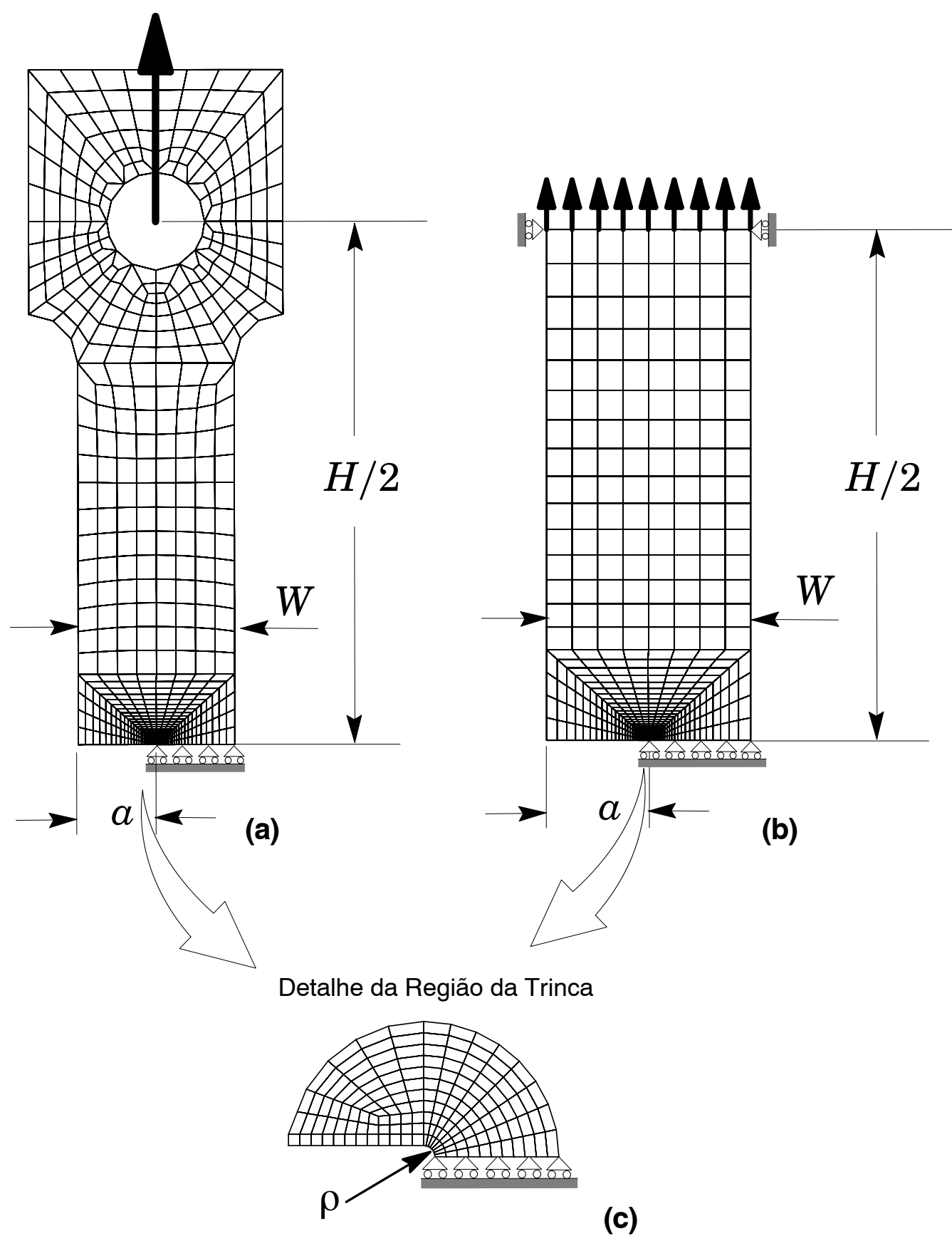

Figura 23 Modelos de elementos finitos empregados nas análises em estado plano de deformações; a) espécime $S E(T)$ carregado por pinos com a/W=0,5e $H / W=6$; b) espécime $S E(T)$ fixado por garras com a / W=0,5 e $H / W=6$; c) Detalhe da ponta da trinca arredondada construída com anéis focais centrados na mesma.

condições de simetria permitem a construção de somente um quarto da geometria por meio da imposição de condições de contorno apropriadas. O refinamento da malha na zona da ponta da trinca é igual ao refinamento da malha dos modelos $2 D$. O modelo apresentado na Fig. 24 tem 23408 nós e 20235 elementos. Estes modelos 
têm 15 camadas de elementos sobre a metade da espessura $(B / 2)$, sendo que a camada de largura maior corresponde ao centro do espécime (coordenada $Z=0$ ) e, à medida que as camadas de elementos aproximam-se da superfície externa do espécime, estas diminuem de espessura para conseguir descrever a maior mudança dos campos de tensões e deformações nesta região. A relação de espessura entre a camada central $(Z=0)$ e a camada exterior $(Z=B / 2)$ é de 10 para 1 . Entretanto, em trabalho prévio [16] foram estudados modelos com 10 e 20 camadas os quais forneceram praticamente a mesma resposta. A razão para a utilização de 15 camadas é devido a trabalhos de outros autores os quais utilizaram malhas similares [66].

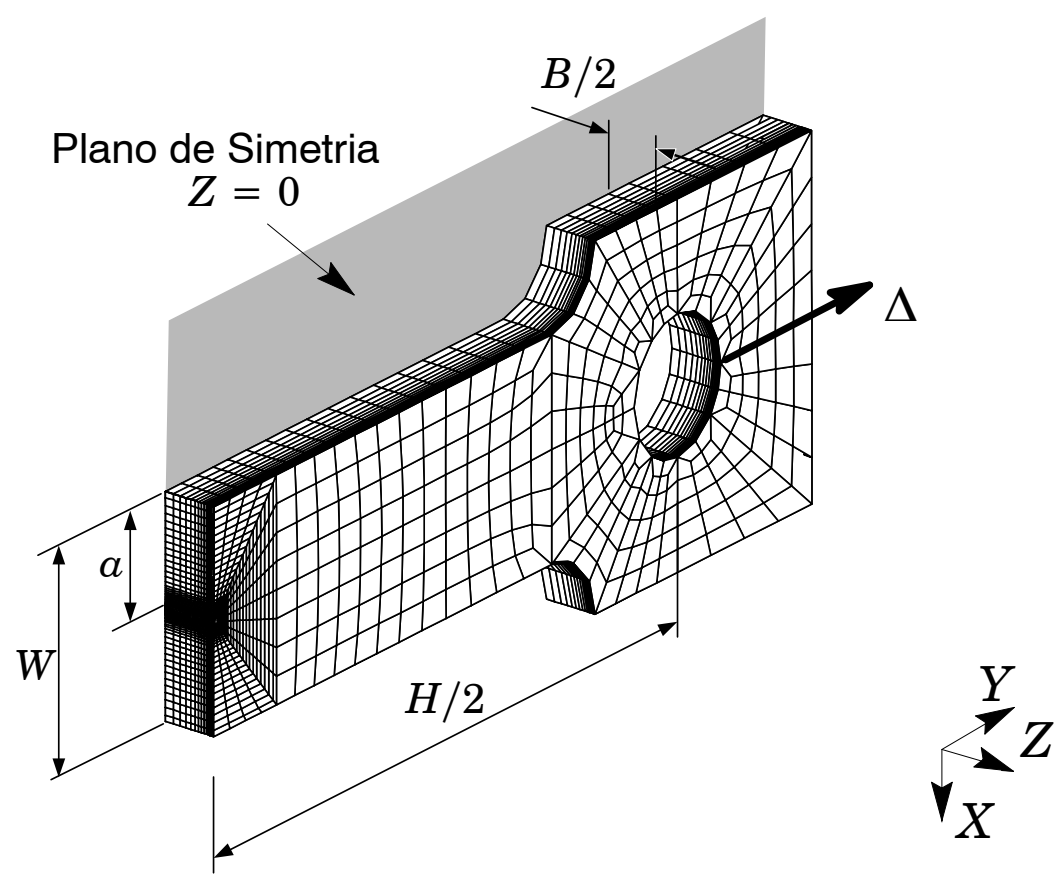

Figura 24 Modelo de elementos finitos $3 D$ para espécime $S E(T)$ carregado por pinos com $a / W=0,5$ e $H / W=6$.

\subsection{Modelagem Numérica do Crescimento Dúctil de Defeitos.}

Esta seção descreve brevemente a modelagem por células computacionais do crescimento estável de defeitos em materiais elasto-plásticos. O objetivo principal é fornecer um procedimento de engenharia que possa ser empregado para verificar 
o método experimental para medição de curvas de resistência proposto neste trabalho.

Xia e Shih (X\&S) [67] propuseram um modelo numérico para descrever o crescimento estável de defeitos em materiais dúcteis. Em sua metodologia, X\&S introduziram o conceito de células computacionais para incluir de forma realista o mecanismo de crescimento de cavidades do material durante o carregamento e representar as dimensões físicas da zona de processo de fratura. $\mathrm{O}$ crescimento de microcavidades permanece confinado a uma faixa de material com espessura $D$, localizada simetricamente no plano de trinca, como ilustrado na Fig. 25(b), onde a dimensão $D$ é associada ao espaçamento médio entre inclusões maiores (veja seção 2.4). Esta faixa de material onde ocorre o crescimento dúctil é composta de células cúbicas; cada célula contém uma cavidade de volume relativo inicial $f_{0}$ (volume inicial dividido pelo volume total da célula). Quando implementado em código de elementos finitos, este modelo define células computacionais associadas à faixa de material onde o crescimento das cavidades ocorre. O material fora das células computacionais (material adjacentes às células) é definido como um material elasto-plástico convencional seguindo uma teoria de plasticidade $J_{2}$ convencional (Von Mises) e permanece, portanto, sem dano durante o crescimento de cavidades nas células. Como uma simplificação adicional, as cavidades são nucleadas apartir de uma inclusão com porosidade relativa $f_{0}$ imediatamente após o início de carregamento. $\mathrm{O}$ crescimento progressivo e o conseqüente dano macroscópico do material (amolecimento) em cada célula é descrito com o modelo constitutivo de Gurson-Tvergaard (GT) para plasticidade dilatacional [68, 69] dado por

$$
g\left(\sigma_{e}, \sigma_{m}, \bar{\sigma}, f\right)=\left(\frac{\sigma_{e}}{\bar{\sigma}}\right)^{2}+2 q_{1} f \cosh \left(\frac{3 q_{2} \sigma_{m}}{2 \bar{\sigma}}\right)-\left(1+q_{3} f^{2}\right)=0
$$

onde $\sigma_{e}$ denota a tensão de Von Mises (macroscópica), $\sigma_{m}$ é a tensão hidrostática (macroscópica), $\bar{\sigma}$ a tensão instantânea de escoamento do material da célula e $f$ define a porosidade relativa no instante considerado. Definindo $f=0$ recupera-se a formulação de plasticidade convencional de Mises para material isotrópico e 


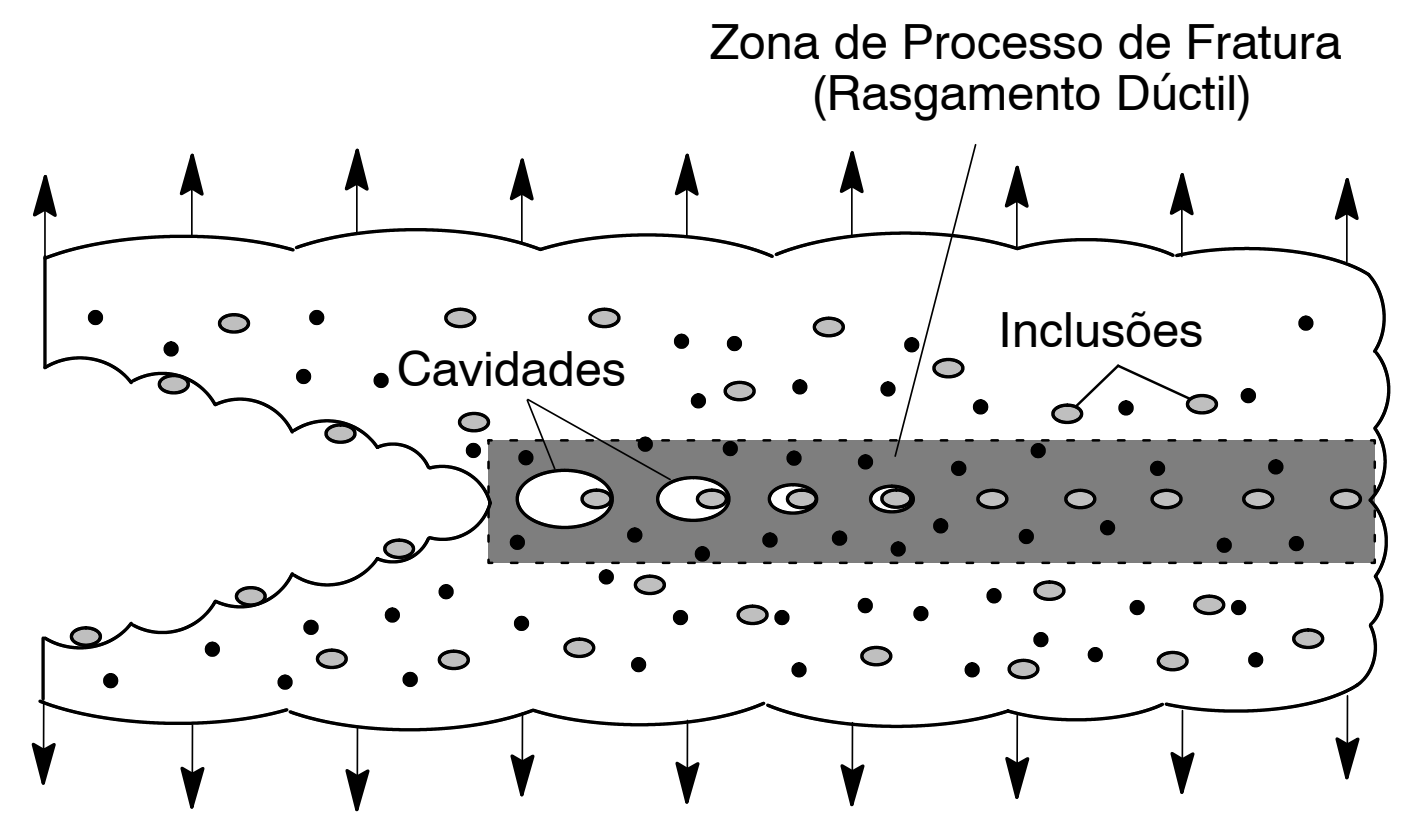

(a)

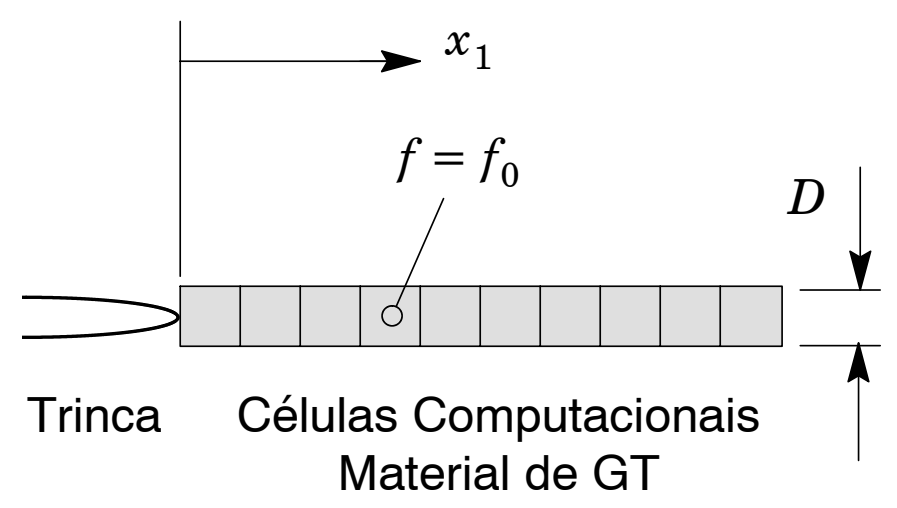

(b)

Figura 25 Modelagem da extensão dúctil de trincas utilizando células computacionais; a) Caminho esquemático de crescimento dúctil sob modo I de fratura.; b) Arranjo de células computacionais para a modelagem [70].

incompressível. Os fatores $q_{1}, q_{2}$ e $q_{3}=q_{1}^{2}$ introduzidos por Tvergaard melhoram as predições do modelo para arranjos periódicos de cavidades cilíndricas e esféricas.

A função de escoamento de Gurson-Tvergaard na Eq. (36) não modela de forma realista a rápida perda de rigidez para grandes porosidades quando as cavidades coalescem e, também, não consegue gerar novas superfícies que determinam o 
crescimento da trinca. No presente trabalho, a evolução de tensões nas células computacionais segue o modelo constitutivo de GT até a porosidade relativa $f$ atingir um valor crítico $f_{E}$. O estágio final de coalescência de cavidades e conseqüente extensão de trinca é representado pela diminuição das tensões nodais até um valor nulo seguindo uma forma previamente estabelecida. Tvergaard [69] refere-se a este processo como técnica de extinção de elemento (vanish technique). O processo de extinção de células segue um modelo linear de separação trativa (para maiores detalhes veja Ruggieri e colaboradores [70]). Quando a porosidade relativa $f$ na célula na ponta da trinca atinge um valor crítico, $f_{E}$, o procedimento computacional elimina a célula e, conseqüentemente, avança a ponta da trinca em um valor discreto dado pela dimensão da célula.

Os parâmetros-chave micromecânicos requeridos para a aplicação da metodologia de células computacionais incluem a espessura da camada de células computacionais, $D$, e a porosidade inicial das células, $f_{0}$. Outros parâmetros importantes (embora de menor relevância) são a porosidade crítica, $f_{E}$, e os fatores $q_{1} \mathrm{e} q_{2}$. Estudos prévios [67, 70] e observações experimentais indicam valores de $f_{E}$ entre 0,15 e 0,25 ; esta faixa de valores de $f_{E}$ não altera o processo de extinção das células nem o avanço de trinca em modelos numéricos. Neste trabalho é adotado um valor de porosidade crítica $f_{E}=0,2$. Os valores para $q_{1}$ e $q_{2}$ generalmente são adotados como $q_{1}=1,5$ e $q_{2}=1$, baseados em estudos de Tvergaard para materiais com baixo encruamento [69]. Entretanto, Faleskog e colaboradores [71] conduziram uma série de análises numéricas para diferentes propriedades de material (encruamento e tensão de escoamento) que resultaram em valores melhorados para os parâmetros $q_{1} \mathrm{e} q_{2}$. A calibração dos parâmetros $D$ e $f_{0}$ é feita por meio de execução de modelos numéricos para a determinação de curvas $R$ que se ajustem a resultados experimentais obtidos de corpos-de-provas convencionais. Estes parâmetros não devem ser vistos como parâmetros metalúrgicos representativos da separação microscópica entre cavidades e de periodicidade relativa das mesmas, mas como parâmetros computacionais fenomenologicamente calibrados. Uma vez que estes parâmetros são calibrados utilizando uma curva $R$ de espécime 
convencional, $f_{0}$ e $D$ devem permanecer fixos em análises de outras configurações geométricas para o mesmo material. O capítulo 10 explora a calibração dos parâmetros micromecânicos para um aço para dutos API X60 baseado em curvas de resistência à fratura obtidas de corpos-de-provas padronizados $\mathrm{C}(\mathrm{T})$.

\subsection{Modelos Numéricos para Crescimento Estável de Trinca}

Ensaios experimentais de corpos-de-prova C(T) construídos em aço API X60 [72] fornecem os dados de resistência ao crescimento dúctil deste material sob condições de alta triaxialidade. Estas curvas $R$ são empregadas para calibrar o modelo de células computacionais descrito previamente e predizer a curva de resistência de corpos-de-prova $\mathrm{SE}(\mathrm{T})$. A calibração do modelo de células computacionais requer uma série de análises de elementos finitos para determinar os parâmetros $D$ e $f_{0}$ que melhor ajustam-se às curvas de resistências de corpos $\mathrm{C}(\mathrm{T})$ medidas experimentalmente.

A Fig. 26 apresenta o modelo de elementos finitos construído para as análises em estado plano de deformações de um espécime $\mathrm{C}(\mathrm{T})$ (espessura $B=13 \mathrm{~mm}$ ) com relação comprimento de trinca-largura do espécime $a / W=0,5$. Novamente, as condições de simetria permitem a modelagem da metade do corpo-de-prova com restrições apropriadas impostas no ligamento remanescente. O modelo tem uma camada de 1078 elementos de 8 nós (hexaédricos) e condições de estado plano de deformações impostas pela restrição dos deslocamentos transversais em cada um dos nós. A imposição de carregamento por meio de controle de deslocamento permite a continuação da análise mesmo após a diminuição da resistência devido ao crescimento de trinca. Para simular o crescimento da trinca o modelo contêm 130 células computacionais dispostas no ligamento remanescente $(b=W-a)$ com arrango similar ao apresentado na Fig. 25(b).

A seguir a Fig. 27 apresenta duas malhas correspondentes a modelos SE(T) carregados por pinos com duas profundidades diferentes de trinca $(a / W=0,2$ e 0,5$)$. 


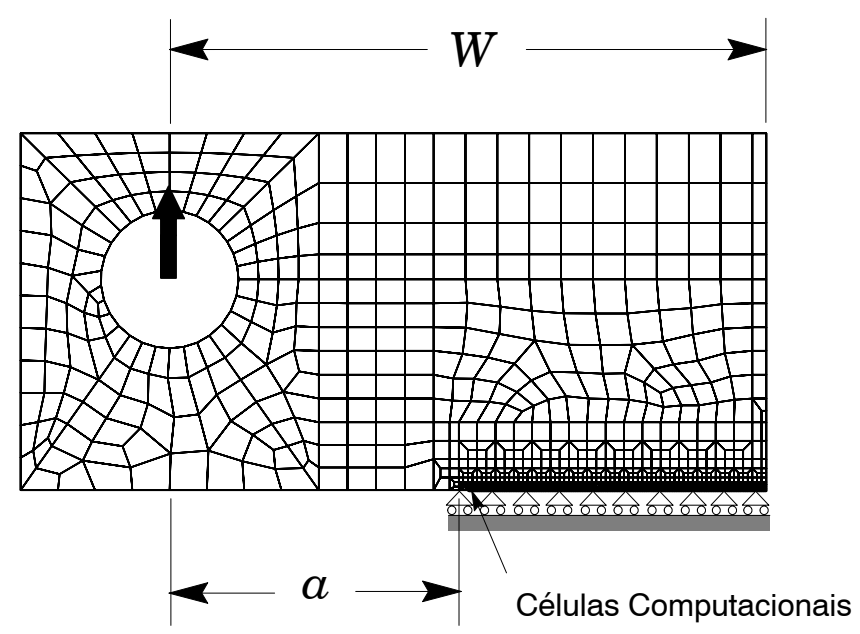

Figura 26 Modelo de elementos finitos de espécime $C(T)$ empregado na calibração dos parâmetros numéricos das células computacionais.

Os modelos têm dimensões geométricas similares às dimensões dos corpos-de-prova ensaiados pelo Núcleo de Ensaios de Materiais e Análises de Falhas (NEMAF) [73] (veja capítulo 10). O modelo com trinca profunda tem uma camada de 2178 elementos de 8 nós e o de trinca rasa tem 3066 elementos de 8 nós. Ambos modelos têm impostas condições de contorno similares às descritas para o modelo de corpo $\mathrm{C}(\mathrm{T})$ no parágrafo anterior. Para simular o crescimento da trinca, o ligamento remanescente foi modelado com células computacionais calibradas com o modelo $\mathrm{C}(\mathrm{T})$ já descrito e os resultados experimentais da mesma geometria. No capítulo 10 é apresentada a calibração das células computacionais e a predição das curvas de resistência em espécimes $\mathrm{SE}(\mathrm{T})$. 


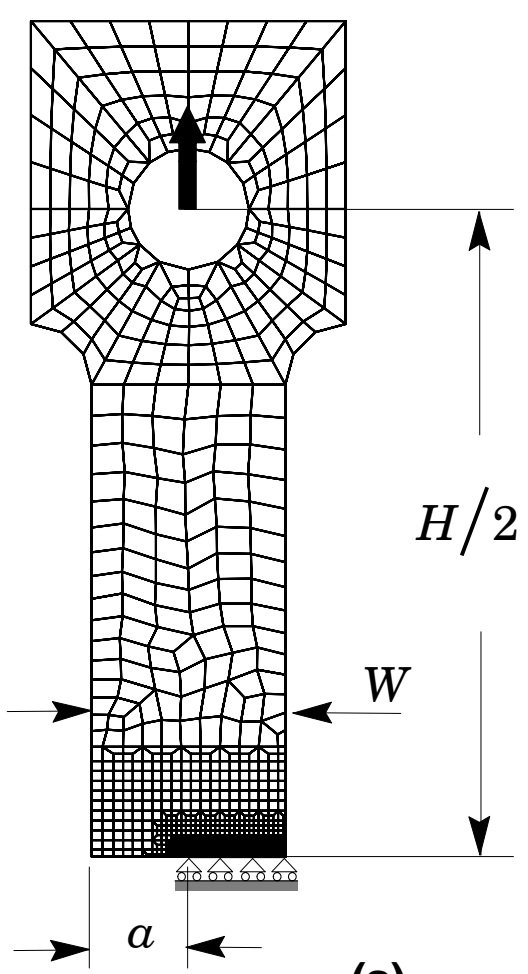

(a)

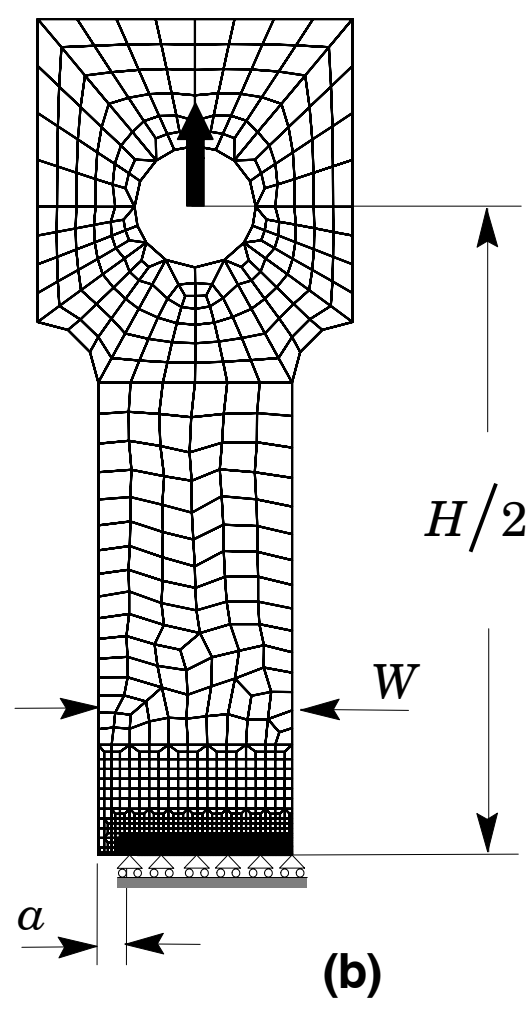

(b)

Figura 27 Modelos de elementos finitos de espécimes $S E(T)$ empregados nas análises de crescimento estável de trinca; a) $a / W=0,5$; b) $a / W=0,2$. 


\section{PROCEDIMENTOS PARA O CÁLCULO DA FLEXIBILIDADE E FATORES $\eta_{J}$ E $\gamma$}

\subsection{Obtenção de Equações de Flexibilidade}

Análises elásticas lineares dos modelos descritos na seção 4.3 fornecem uma medida da relação linear entre o carregamento aplicado e a abertura da boca da trinca CMOD para avaliar a flexibilidade do espécime. Para cada espécime com relação $a / W$ especificada, a evolução do carregamento com o CMOD é uma linha reta com inclinação igual ao inverso da flexibilidade, denotada C. As Figs. 28-30 apresentam curvas $P$-CMOD $e$ para diferentes profundidades relativas de trinca $(a / W)$ de espécimes $\mathrm{SE}(\mathrm{B})$ 1-T, e alguns dos $\mathrm{SE}(\mathrm{T})_{P}$ e $\mathrm{SE}(\mathrm{T})_{C}$ estudados. Executando o mesmo procedimento para diferentes configurações geométricas, é obtida a variação da flexibilidade C para cada uma destas.

A flexibilidade $C$ obtida diretamente dos modelos de elementos finitos depende do módulo de elasticidade do material e proporções geométricas do espécime tais como a espessura, a relação $H / W$ e a profundidade relativa de trinca $a / W$. Por meio de análise dimensional a flexibilidade pode ser normalizada para que seja independente de algumas destas variáveis. Para o caso de espécime à flexão em 3 pontos a normalização da flexibilidade resulta na seguinte expressão [12]

$$
\mu=\frac{1}{\left(\frac{B W E \mathrm{C}}{H / 4}\right)^{1 / 2}+1}
$$

Na expressão acima $B$ é a espessura do corpo-de-prova, $W$ é a largura, $H$ é a distância entre apoios e $E$ é o módulo de elasticidade. 


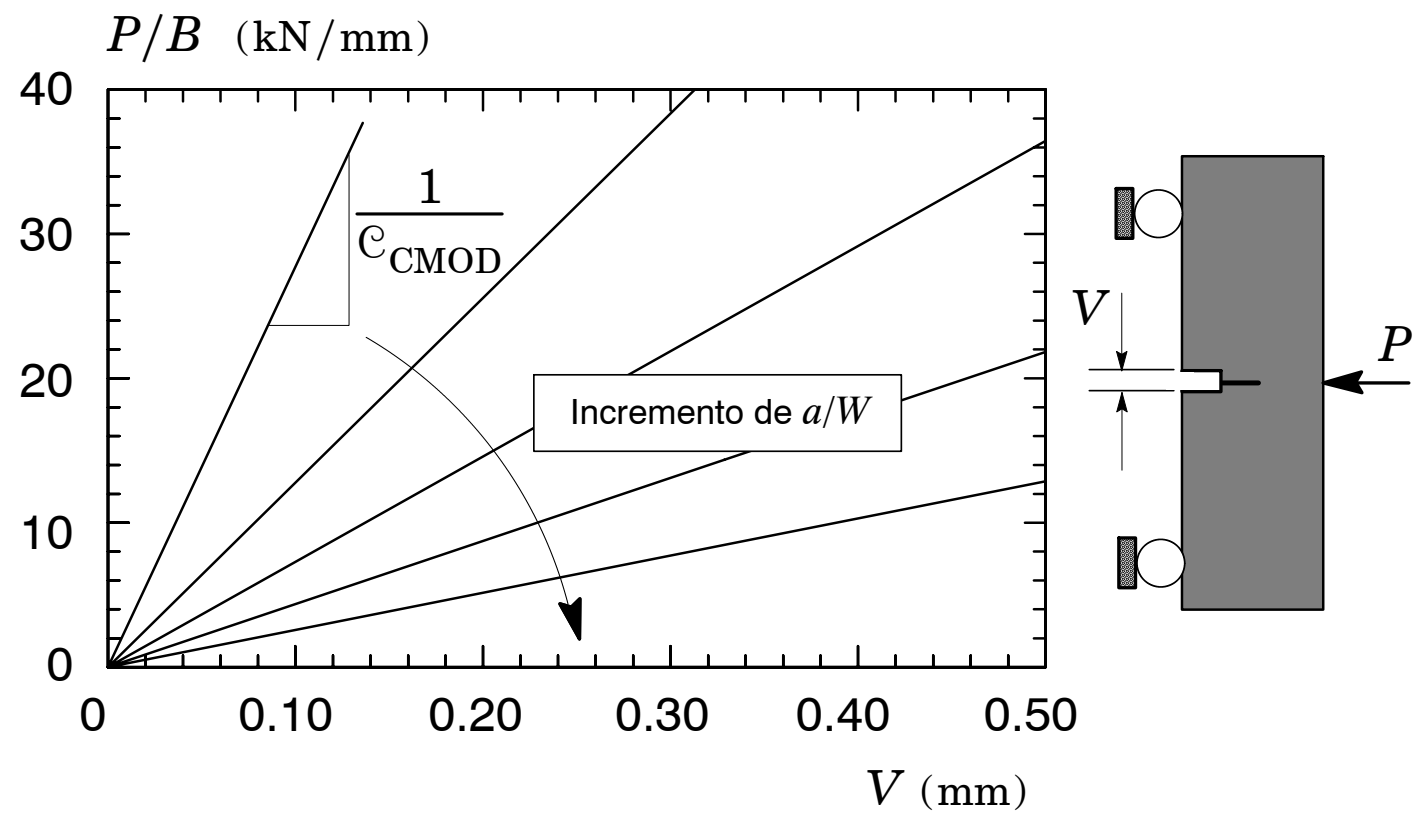

Figura 28 Variação linear da carga por unidade de espessura com a abertura da boca da trinca $(C M O D)$ para espécime $S E(B)-1 T$ e diferentes relações a / W.

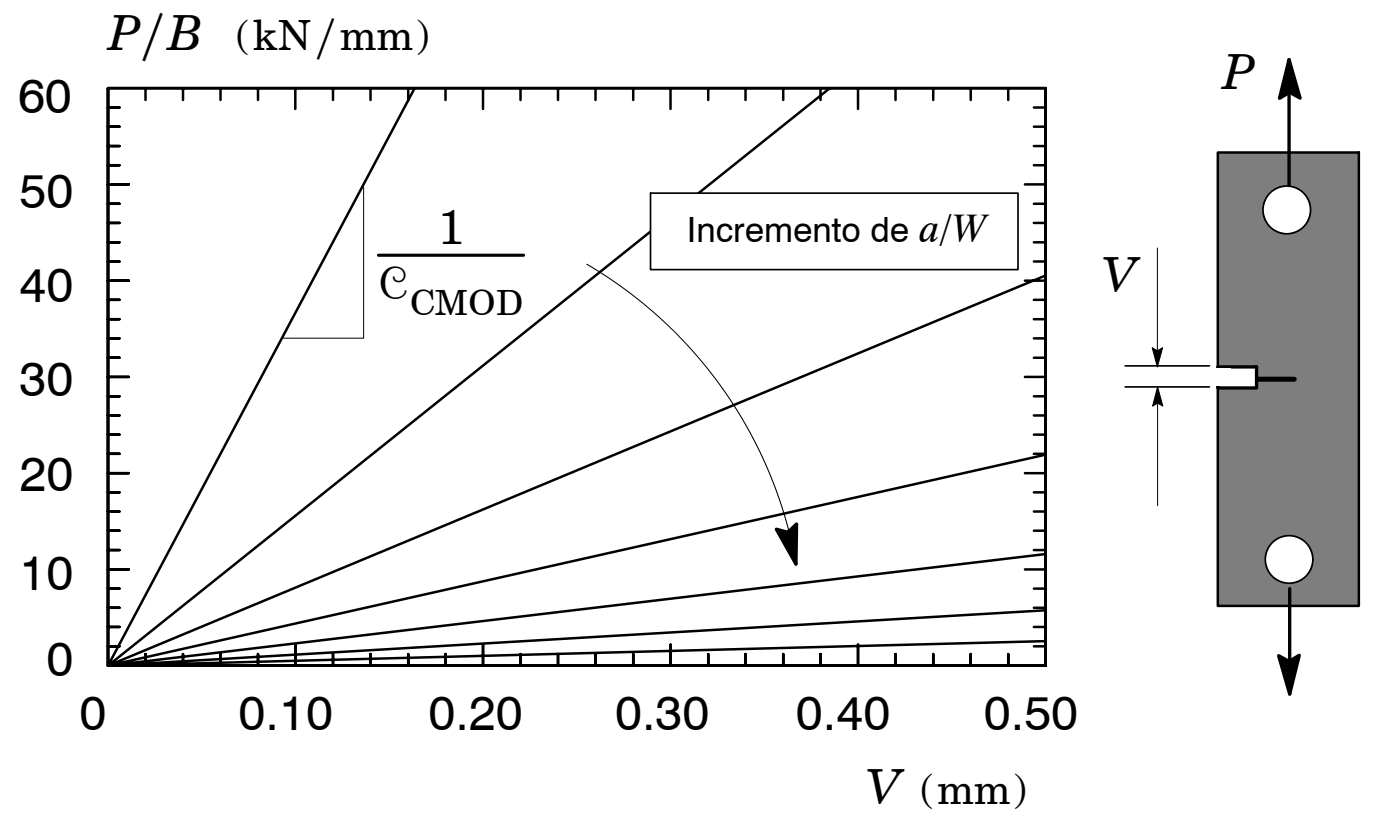

Figura 29 Variação linear da carga por unidade de espessura com a abertura da boca da trinca (CMOD) para espécime $S E(T)$ carregado por pinos com $H / W=6$ e diferentes relações $a / W$. 


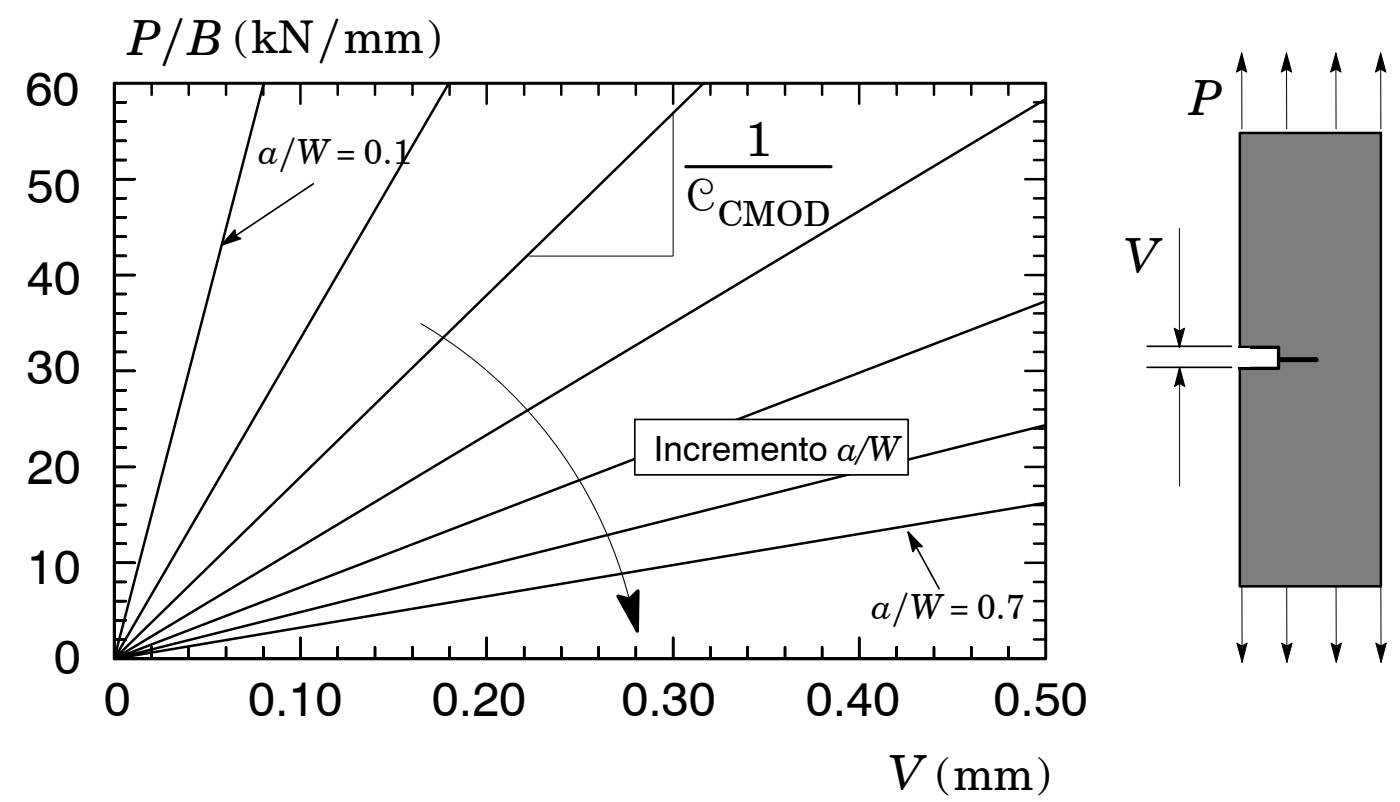

Figura 30 Variação linear da carga por unidade de espessura com a abertura da boca da trinca $(C M O D)$ para espécime $S E(T)$ fixado por garras com $H / W=6$ e diferentes relações a/ W.

Para espécimes submetidos à tração $(\mathrm{SE}(\mathrm{T}))$, a flexibilidade normalizada é dada pela seguinte expressão $[74,75]$

$$
\mu=\frac{1}{1+\sqrt{E^{\prime} B C}}
$$

Para espécimes com espessura reduzida devido a entalhes laterais (side groove), o valor $B$ é substituído pela espessura efetiva $B_{e f}$ dada pela seguinte expressão [76]

$$
B_{e f}=B-\frac{\left(B-B_{N}\right)^{2}}{B} .
$$

onde $B_{N}$ é a espessura do corpo-de-prova considerando a redução causada pelos entalhes laterais.

\subsection{Verificação da Metodologia}

A determinação da flexibilidade para corpos-de-prova à flexão em 3 pontos (SE(B)) permite verificar o procedimento apresentado na seção anterior. Uma vez que este 
corpo-de-prova é uma geometria padronizada, suas expressões para flexibilidade são extensivamente verificadas (inclusive experimentalmente) e incorporam procedimentos normalizados como ASTM E1820 [12]. Desta forma, é possível comparar a flexibilidade obtida com o procedimento descrito anteriormente com dados de flexibilidade padrão. A Fig. 31 apresenta a variação da flexibilidade normalizada, $\mu$, com a relação $a / W$ para espécimes $\mathrm{SE}(\mathrm{B})-1 \mathrm{~T}$ em estado plano de deformações $(2 D)$ e em contexto $3 D$ pleno. Para efeitos de comparação, a Fig. 31 também inclui a variação de flexibilidade com a relação $a / W$ fornecida pela ASTM (linha tracejada). Para trincas médias e profundas $(a / W \geq 0,25)$, os valores de flexibilidade para todos os casos analisados são próximos. Entretanto, para trincas rasas, os resultados $2 D$ e $3 D$ apresentam resultados consideravelmente diferentes quando comparados aos valores de flexibilidade dados pela ASTM E1820. Isto é razoável dado que a norma E1820 é aplicável para relações $0,45 \leq a / W \leq 0,70$. Por outro lado, a diferença para trincas profundas entre flexibilidade de corpos-de-prova SE(B) dada pela ASTM E1820 e resultados $2 D$ da mesma geometría é menor a $5 \%$, valor que diminui a $2 \%$ quando compara-se a norma com os resultados $3 D$. Seria desejável que a diferença entre modelos $2 D$ e $3 D$ fosse menor. Entretanto, no próximo capítulo será observado que os efeitos $3 D$, no caso de espécimes $\mathrm{SE}(\mathrm{T})$, são muito menores o que justifica o emprego dos modelos $2 D$.

Par verificar se a flexibilidade normalizada, $\mu$, efetivamente fornece resultados independentes do tamanho do corpo-de-prova, foram construídos 2 modelos adicionais $\mathrm{SE}(\mathrm{B})$ com dimensões correspondentes a $0.5-\mathrm{T}(B=12,7 \mathrm{~mm}$.) e $2-\mathrm{T}(B=$ $50,8 \mathrm{~mm}$ ) e profundidade relativa de trinca, $a / W=0,5$. Os valores de flexibilidade fornecidos por estes modelos também são apresentados na Fig. 31; e os resultados claramente demonstram que não há essencialmente nenhuma diferença em relação aos modelos $2 D$ com dimensões 1-T sendo que os símbolos se confundem com os símbolos correspondentes aos resultados 1-T.

A equação de flexibilidade dada pela norma ASTM E1820 para espécimes SE(B) à flexão em 3 pontos é, 


$$
\begin{aligned}
\frac{a}{W}=0.999748- & 3.9504 \mu+2.9821 \mu^{2} \\
- & 3.21408 \mu^{3}+51.5156 \mu^{4}-113.031 \mu^{5}
\end{aligned}
$$

E a equação obtida dos resultados de elementos finitos $2 D$ é a seguinte

$$
\begin{aligned}
\frac{a}{W}=0.7590 & +1.2961 \mu-37.9076 \mu^{2} \\
& +154.9671 \mu^{3}-270.3815 \mu^{4}+182.6632 \mu^{5}
\end{aligned} .
$$

$\mathrm{Na}$ equação anterior foi empregado o método dos mínimos quadrados [77] para ajustar um polinômio de grau 5 .

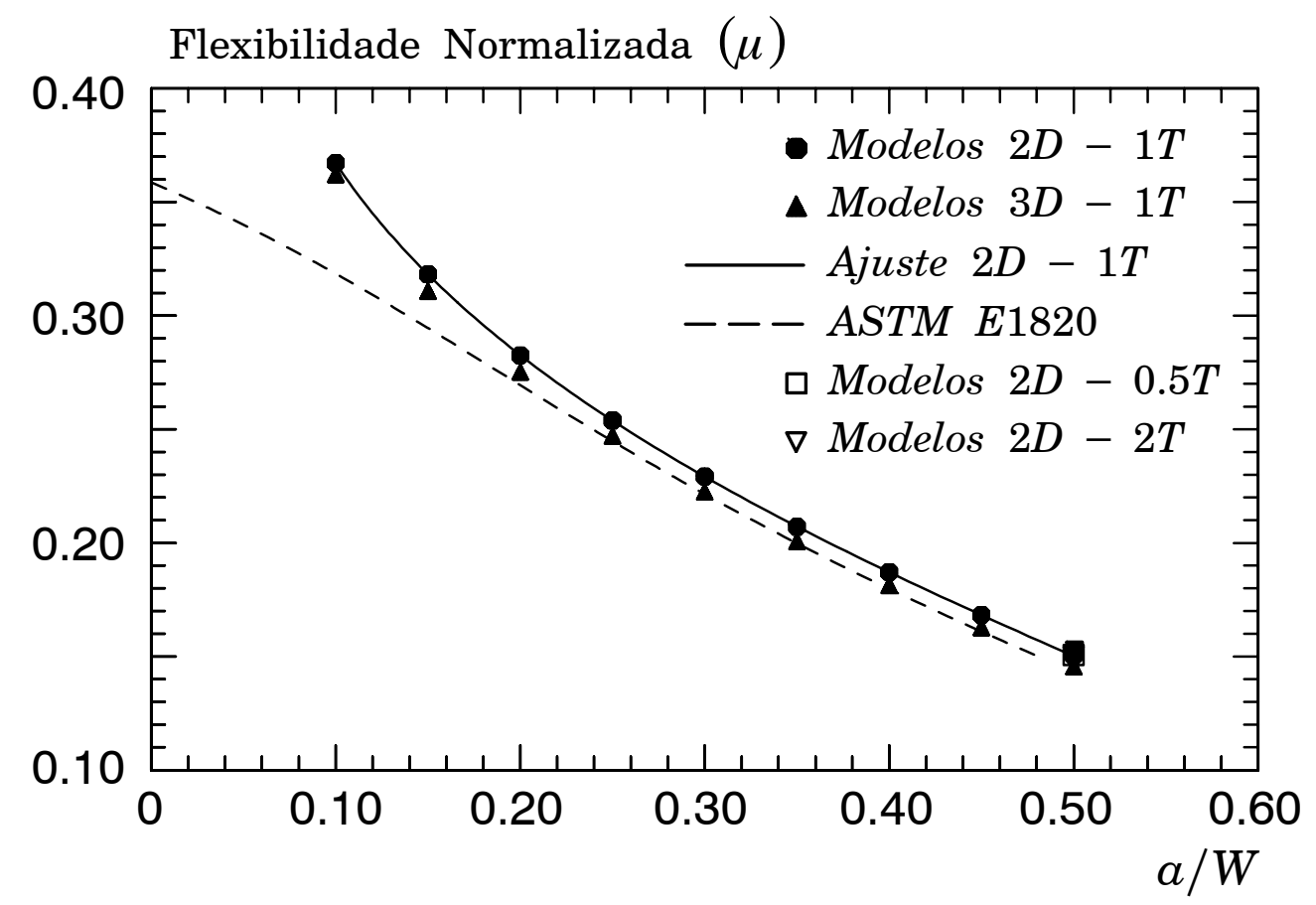

Figura 31 Variação da flexibilidade normalizada, $\mu$, em função de a / W para corpos-de-prova $S E(B)$.

\subsection{Obtenção dos Fatores $\eta_{J}$ Plásticos}

A execução das análises elasto-plásticas, descritas no capítulo 4, fornece valores de integral $J$ aplicada, curvas carga vs. deslocamento da linha de carga ( $P$-LLD) e 
carga vs. deslocamento da boca da trinca (P-CMOD) (veja Fig. 15(b)) para as diferentes configurações consideradas. Com estes dados e empregando a Eq. (9) reescrita a seguir para facilitar a leitura,

$$
J=J_{e}+J_{p}=\frac{K_{\mathrm{I}}^{2}}{E^{\prime}}+\frac{\eta_{J} A_{p}}{B b_{0}}
$$

é possível calcular os fatores $\eta_{J}$ para diferentes geometrias. Da equação acima,

$$
J_{p}=\frac{\eta_{J} A_{p}}{B b}
$$

onde a área plástica é obtida da subtração da área elástica à área total

$$
A_{p}=A-A_{e}
$$

Adicionalmente, a área elástica é dada pela flexibilidade calculada nas análises elásticas lineares,

$$
A_{e}=\frac{\Delta_{e} \cdot P}{2}
$$

onde $\Delta_{e}$ é o deslocamento elástico da linha de carga ou, de forma equivalente,

$$
A_{e}=\frac{\mathrm{eLLD}^{\mathrm{LL}} \cdot \mathrm{P}^{2}}{2}
$$

onde $e^{\text {LLD }}$ é a flexibilidade do espécime medida na linha de carga.

Finalmente, resolvendo a Eq. (43), obtém-se a seguinte relação para o cálculo do fator $\eta_{J}$

$$
\eta_{J}=\frac{J_{p} B b}{A_{p}}
$$

Pode ser seguido o mesmo desenvolvimento para as curvas $P$-CMOD. Entretanto, uma vez que a área plástica obtida usando o deslocamento da linha de carga (LLD) 
difere da área plástica obtida usando a abertura da boca da trinca (CMOD), os fatores $\eta_{J}$ também diferem; estes fatores são designados, $\eta_{J}^{\text {LLD }}$ e $\eta_{J}^{\text {CMOD }}$ respectivamente.

Experimentalmente é mais simples obter maior precisão na medição da abertura da boca da trinca do que na medição do deslocamento da linha de carga. Isto motiva o emprego de curvas $P-C M O D$ e, conseqüentemente, do fator $\eta_{J}^{\mathrm{CMOD}}$ para a obtenção de curvas $R$ quando comparados ao emprego de curvas $P$-LLD e fatores $\eta_{J}^{\mathrm{LLD}}$ convencionais. Outra vantagem do $\eta_{J}^{\mathrm{CMOD}}$ em relação ao $\eta_{J}^{\mathrm{LLD}}$ é apresentar menor variação com o carregamento, propriedades de material e profundidades de trinca, como será discutido nos capítulos 7 e 8 .

Um ponto central a ser resolvido para a avaliação numérica dos fatores $\eta_{J}^{\mathrm{CMOD}}$ e $\eta_{J}^{\mathrm{LLD}}$ é a escolha dos valores de carregamento para os quais serão calculadas as áreas plásticas e, conseqüentemente, $\eta_{J}$. Para níveis baixos de carregamento, a porção elástica da área sob a curva carga-deslocamento é da mesma ordem de grandeza que a porção plástica afetando, conseqüentemente, o valor calculado de $\eta_{J}$. A Fig. 32 (a-d) apresenta a evolução de $\eta_{J}^{\mathrm{CMOD}}$ com o nível de deformação (dado por $J /\left(b \sigma_{0}\right)$ onde $b$ é o ligamento remanescente e $\sigma_{0}$ é a tensão de escoamento) para corpos-de-prova $\mathrm{SE}(\mathrm{T})$ carregados por pinos e fixados por garra com $a / W=0,1 \mathrm{e}$ $a / W=0,7$. Estes gráficos correspondem a espécimes com relação comprimento largura do espécime $H / W=6$ e material com encruamento moderado, $n=10$. Para baixos níveis de deformação, os fatores $\eta_{J}$ plásticos apresentam uma significativa variação até atingir um patamar para valores de deformação de $J /\left(b \sigma_{0}\right) \geq 0.01 \sim 0.02$ para todos os casos analisados exceto para o $\mathrm{SE}(\mathrm{T})$ fixado por garras com máxima profundidade de trinca (Fig. 32 (d)). Comportamento similar foi observado para outros valores de encruamento e relações $H / W$. Com base nas experiências numéricas, $\eta_{J}$ é obtido do valor médio de todos os valores de $\eta_{J}$ encontrados entre a faixa de deformações dada por $0.01 \geq J /\left(b \sigma_{0}\right) \geq 0.1$ (veja Fig. 
32). Este procedimento fornece valores razoavelmente representativos para $\eta_{J}$ que são aplicáveis a valores típicos de $J$ comumente observados em ensaios de fratura (Para dados representativos, veja [8] e [53] e os resultados experimentais apresentados no capítulo 10).

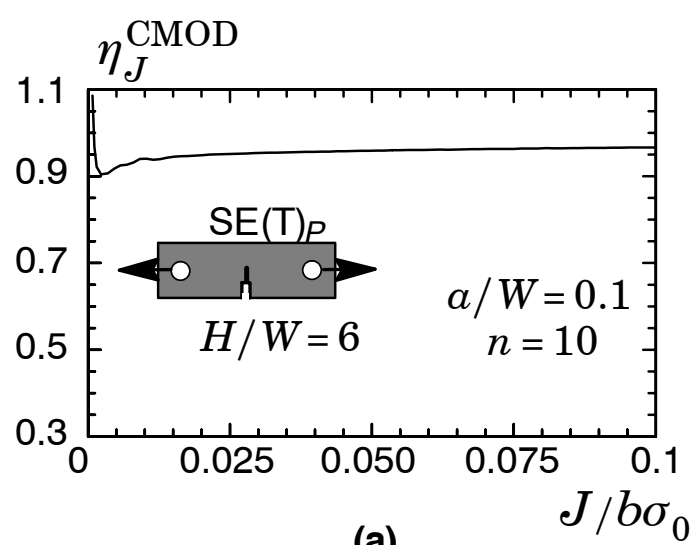

(a)

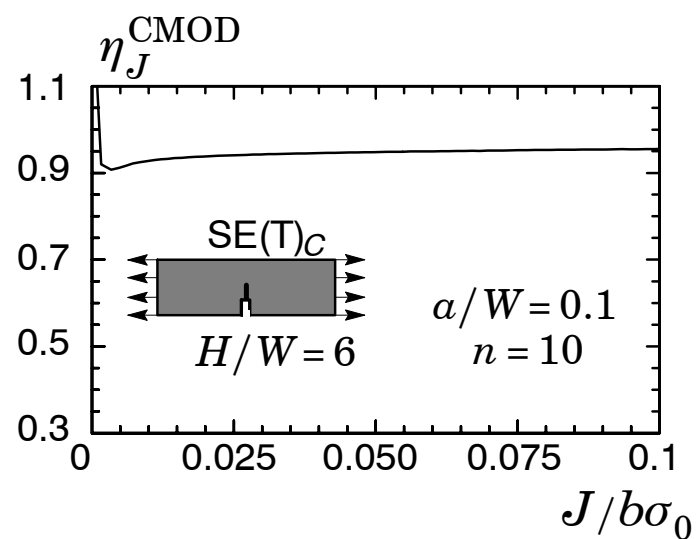

(c)


(d)

Figura 32 Variação do fator $\eta_{J}$ derivado do CMOD com o incremento do carregamento normalizado para espécimes $S E(T)$ com $H / W=6$ e n=10; a) $S E(T)$ carregado por pinos com $a / W=0,1 ; b) S E(T)$ carregado por pinos com $a / W=0,7$; c) $S E(T)$ fixado por garras com $a / W=0,1$; d) $S E(T)$ fixado por garras com $a / W=0,7$.

A seguir, a Fig. 33 (a-d) apresenta a evolução do fator $\eta_{J}^{L L D}$ com o $J$ normalizado por $b \sigma_{0}$ para os mesmos casos apresentados na Fig. 32 (a-d). Em contraste com o comportamento previamente apresentado pelo fator $\eta_{J}^{\mathrm{CMOD}}$, o fator $\eta_{J}^{\mathrm{LLD}}$ apresenta uma maior dependência com o nível de deformação imposto, particularmente para baixos níveis de carregamento. Novamente, os fatores $\eta_{J}^{L L D}$ são obtidos do valor médio dos $\eta_{J}$ calculados para a faixa de deformação entre $0.01 \geq J /\left(b \sigma_{0}\right) \geq 0.1$. 
Observando os resultados apresentados nas Figs. 32 e 33 é possível determinar que os fatores $\eta_{J}^{\mathrm{CMOD}}$ são menos sensíveis ao nível de carregamento do que os fatores $\eta_{J}^{\mathrm{LLD}}$. Os fatores $\eta_{J}^{\mathrm{CMOD}}$ e $\eta_{J}^{\mathrm{LLD}}$ para espécimes $\mathrm{SE}(\mathrm{T})$ com diferentes proporções geométricas, propriedades de material e tipos de carregamento são apresentados nos capítulos 7 e 8 .
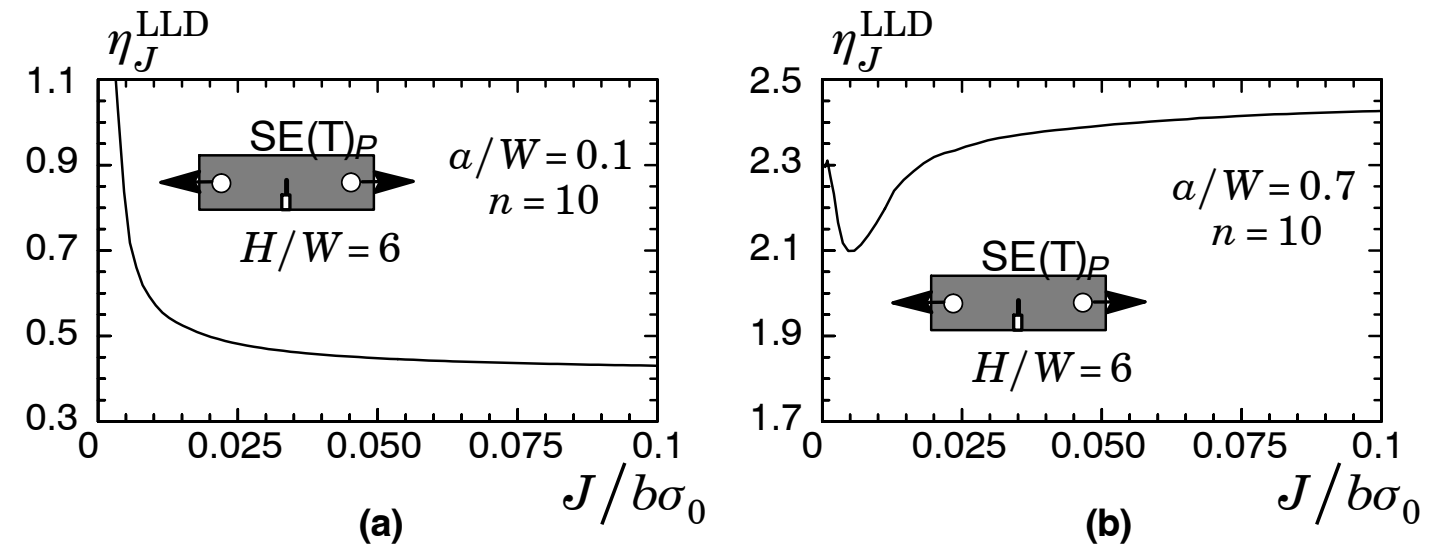

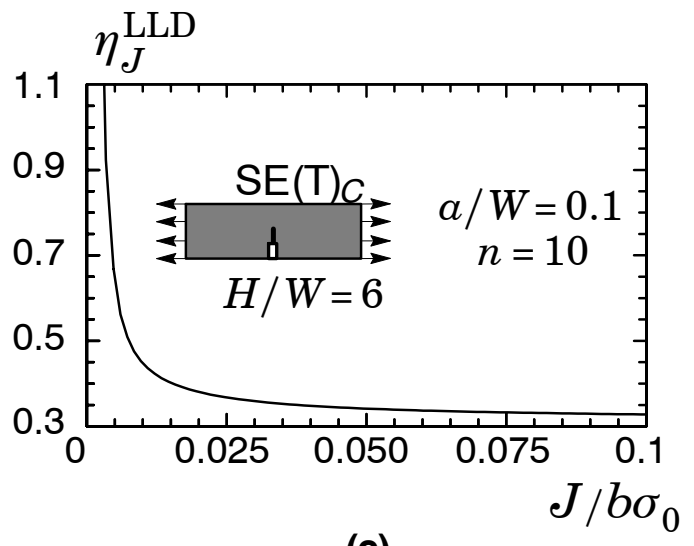

(c)

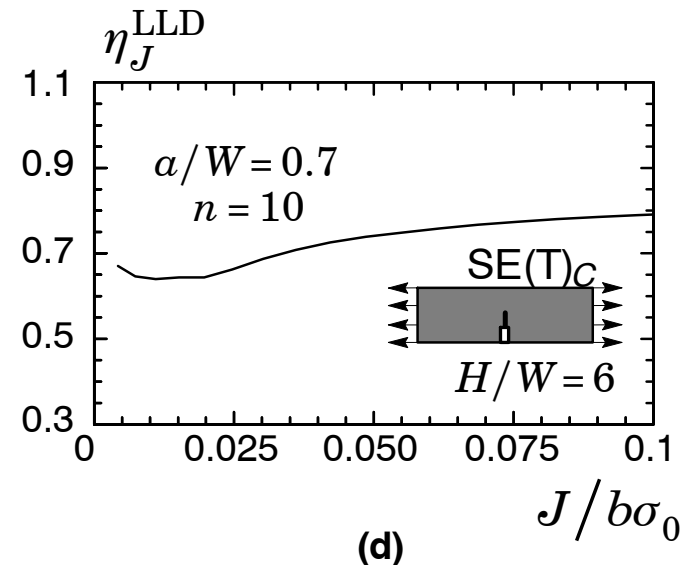

(d)

Figura 33 Variação do fator $\eta_{J}$ derivado do LLD com o incremento do carregamento normalizado para espécimes $S E(T)$ com $H / W=6$ e $n=10$; a) $S E(T)$ carregado por pinos com a / W=0,1; b) $S E(T)$ carregado por pinos com a/W=0,7; c) $S E(T)$ fixado por garras com $a / W=0,1 ; d) S E(T)$ fixado por garras com $a / W=0,7$. 


\subsection{Obtenção do Fator $\gamma$}

Como apresentado no capítulo 3, o fator $\gamma$ é derivado da seguinte forma [51],

$$
\gamma=\eta_{J}-1+\frac{b}{W \eta_{J}} \frac{d \eta_{J}}{d(b / W)}
$$

Com a equação acima e uma expressão para a variação do fator $\eta_{J}$ com a profundidade de trinca, é relativamente simples obter o fator $\gamma$. Expressões polinomiais para fatores $\eta_{J}$ são apresentadas nos capítulos 7 e 8, a partir das quais os fatores $\gamma$ são obtidos empregando a definição da Eq. (48).

É importante notar que, dos modelos de elementos finitos e empregado o procedimento da seção 5.3, são obtidos fatores $\eta_{J}^{\mathrm{LLD}}$ e $\eta_{J}^{\mathrm{CMOD}}$ para diferentes valores de comprimento relativo de trinca $(a / W)$. Com estes valores de $\eta_{J}^{\mathrm{LLD}} \mathrm{e} \eta_{J}^{\mathrm{CMOD}}$, podem ser obtidos polinômios que ajustem os fatores $\eta_{J}$ em função da relação $a / W$. Conseqüentemente, aplicando-se a Eq. (48), os fatores $\gamma$ são facilmente calculados. Entretanto, devido à natureza da sua derivação (veja Anexo A.2), esta equação somente é aplicável quando se empregam dados de curvas carga vs. deslocamento da linha de carga $\left(P\right.$-LLD) e, portanto, fatores $\eta_{J}$ derivados da mesma curva $\left(\eta_{J}^{\mathrm{LLD}}\right)$.

No caso de ser empregada a curva $P$-CMOD para a medição de $J$ com crescimento estável de trinca em ensaio experimental, a definição do fator $\gamma$ não é necessariamente aplicável. Isto porque a área sob a curva $P$-CMOD não representa a energia de deformação do sistema e, adicionalmente, a sua derivada com o comprimento de trinca não representa uma taxa de liberação de energia $(\partial U / \partial a)$. Por conseguinte, a Eq. (48) não é válida para $\eta_{J}^{\mathrm{CMOD}}$. No entanto, na seção seguinte é demonstrado que os fatores $\gamma$ derivados de $\eta_{J}^{\mathrm{LLD}}$ são igualmente aplicáveis para a medição de integral $J$ com crescimento estável de trinca quando são empregados dados $P$-CMOD e fatores $\eta_{J}^{\mathrm{CMOD}}$. 


\subsection{Medição Experimental de Integral $J$ Empregando o Deslocamento da Boca da Trinca}

A Eq. (13) no capítulo 3 para a determinação experimental da integral $J$ emprega dados da curva $P$-LLD. Entretanto, a medição do deslocamento da boca da trinca, CMOD, em espécimes $\mathrm{SE}(\mathrm{B})$ e $\mathrm{SE}(\mathrm{T})$ é mais simples e precisa que a medição do deslocamento da linha de carga, LLD. A razão para isto é que a fixação de um extensômetro (clip gage) na boca do defeito é mais simples do que um extensômetro linear (LVDT) entre os pontos de fixação e carregamento. Desta forma, é útil um procedimento para a medição de $J$ com crescimento estável de trinca empregando dados $P$-CMOD no lugar de dados $P$-LLD.

Trabalhos prévios de Kirk e Dodds [78] e Schibetta [79] propuseram o emprego de medições de CMOD para a determinação de integral $J$ aplicada em espécimes $\mathrm{SE}(\mathrm{B})$. No caso do trabalho de Kirk e Dodds [78], foi proposto um novo fator $\eta_{J}^{\mathrm{CMOD}}$ que correlaciona a componente plástica de $J$ com a área debaixo da curva $P-\mathrm{CMOD}_{p}$ (veja capítulos 7 e 8). Já no trabalho de Schibetta [79], foi proposta a determinação do deslocamento da linha de carga, LLD, partindo de medições da abertura da boca da trinca, CMOD. Com isto é possível o emprego de fatores $\eta_{J}$ convencionais derivados de LLD, $\eta_{J}^{\mathrm{LLD}}$. É importante mencionar que, recentemente, Piovatto [80] também propôs a determinação do deslocamento LLD partindo de dados CMOD para o caso de corpos-de-prova $\mathrm{SE}(\mathrm{T})$.

Entretanto, com exceção da tese de Piovatto [80], estes trabalhos foram focalizados na medição de $J$ quando o crescimento de trinca é pequeno em comparação às dimensões do corpo-de-prova. Desta forma não sendo necessária uma correção devido ao crescimento da mesma. Porem, a correção de $J$ torna-se importante no caso de considerável crescimento estável do defeito. A seguir apresenta-se uma dedução simples para a medição de integral $J$ com crescimento estável de defeito empregando dados P-CMOD. A dedução assume que o deslocamento da linha de carga e a abertura da boca da trinca estão relacionados da seguinte forma 


$$
\Delta_{p}=h_{(a)} \cdot V_{p}
$$

Onde a função $h_{(a)}$ é independente do carregamento e depende do comprimento de trinca, $a$. Esta relação foi verificada por meio das análises de elementos finitos descritas nos capítulos anteriores e a seguinte seção demonstra está hipótese.

Da Eq. (49), os diferenciais de $\operatorname{LLD}_{p}$ e $\operatorname{CMOD}_{p}\left(d \Delta_{p}\right.$ e $d V_{p}$ respectivamente) estão relacionados pela expressão seguinte

$$
d \Delta_{p}=h_{(a)} \cdot d V_{p}
$$

Adicionalmente, quando há crescimento estável de defeito, a componente plástica de $J$ é dada pela seguinte expressão (veja Ernst e colaboradores [51] e Anexo A.2).

$$
J_{p}=\int_{0}^{\Delta_{p}} \frac{\eta_{J}^{\mathrm{LLD}}}{b} P d \Delta_{p}-\int_{a_{0}}^{a} \frac{\gamma}{b} J_{p} d a
$$

Substituindo a Eq. (50) na Eq. (51),

$$
J_{p}=\frac{\eta_{J}^{\mathrm{LLD}}}{b} h_{(a)} \int_{0}^{V_{p}} P d V_{p}-\int_{0}^{a} \frac{\gamma}{b} J_{p} d a
$$

A primeira integral da Eq. (52) representa a área plástica sob a curva $P$-CMOD $\left(A_{p}^{\mathrm{CMOD}}\right)$. Sendo que para espessura unitária e trinca estacionária (veja Seção 5.3),

$$
\eta_{J}^{\mathrm{LLD}}=\frac{J_{p} b}{A_{p}^{\mathrm{LLD}}}=\frac{J_{p} b}{h_{(a)} A_{p}^{\mathrm{CMOD}}}
$$

$\mathrm{e}$

$$
\eta_{J}^{\mathrm{CMOD}}=\frac{J_{p} b}{A_{p}^{\mathrm{CMOD}}}
$$


Das Eqs. (53) e (54) pode-se estabelecer

$$
\eta_{J}^{\mathrm{CMOD}}=h_{(a)} \eta_{J}^{\mathrm{LLD}}
$$

Substituindo a Eq. (55) na Eq. (52),

$$
J_{p}=\frac{\eta_{J}^{\mathrm{CMOD}}}{b} \int_{0}^{V_{p}} P d V_{p}-\int_{0}^{a} \frac{\gamma}{b} J_{p} d a
$$

Portanto, ainda é possível computar $J_{p}$ com crescimento de trinca usando dados experimentais $P$-CMOD e a Eq. (56). Entretanto, o fator $\gamma$ continua sendo o mesmo que o empregado para calcular $J_{p}$ usando dados experimentais $P$-LLD na Eq. (51) e deve ser derivado do fator $\eta_{J}^{\mathrm{LLD}}$.

Finalmente, seguindo um raciocínio similar ao adotado para obter a Eq. (13) (veja anexo A.2), pode ser empregada a seguinte expressão para a resolução da Eq. (56) de forma aproximada

$$
J_{P}^{i+1}=\left[J_{P}^{i}+\left(\frac{\eta_{J}^{\mathrm{CMOD}}}{b}\right)_{i}\left(A_{p, i+1}^{\mathrm{CMOD}}-A_{p, i}^{\mathrm{CMOD}}\right)\right]\left[1-\left(\frac{\gamma}{b}\right)_{i}\left(a_{i+1}-a_{i}\right)\right] .
$$

\subsection{Relação entre LLD e CMOD}

O raciocínio da seção anterior baseia-se na hipótese que o deslocamento da linha de carga (LLD) e a abertura da boca da trinca (CMOD) estão relacionados por um fator, $h_{(a)}$, que depende somente da profundidade de trinca e é independente do carregamento para uma geometria e material dados,

$$
\Delta_{p}=h_{(a)} \cdot V_{p}
$$

Esta relação já foi corroborada em espécimes $\mathrm{SE}(\mathrm{B})$ [79, 81-82] e nesta seção é comprovada para espécimes $\mathrm{SE}(\mathrm{T})$. 
Dos modelos de elementos finitos de espécimes $\mathrm{SE}(\mathrm{T})$ descritos no capítulo 4, foram obtidos dados de deslocamento da linha de carga (LLD) e de abertura da boca da trinca (CMOD) como função da carga aplicada. Portanto, podendo ser obtida a relação entre ambas quantidades

$$
h_{(a)}=\frac{\Delta_{p}}{V_{p}} .
$$

Desta forma, a função $h_{(a)}$ será independente do carregamento aplicado se a relação da Eq. (59) é constante com o mesmo. Está relação é apresentada nas Figs. 34-39 para espécimes $\mathrm{SE}(\mathrm{T})$ carregados por pinos e fixados por garras com diferentes comprimentos relativos de trinca, $a / W$, propriedades de material e relação $H / W=6$. Pode ser observado que, após um período de transição para $J /\left(b \sigma_{0}\right) \lesssim 0,005 \sim 0,01$, o quociente entre LLD e CMOD plásticos, $\Delta_{p} / V_{p}$, efetivamente atinge um valor constante com o carregamento em todas as configurações $\mathrm{SE}(\mathrm{T})$ consideradas exceto nos casos com trinca muito curta, $a / W=0,1$. Esta relação entre LLD e CMOD plásticos também foi verificada para outros comprimentos relativos de espécimes, $H / W=4$ e 10, não sendo apresentados para evitar repetições e não poluir excessivamente os gráficos. 


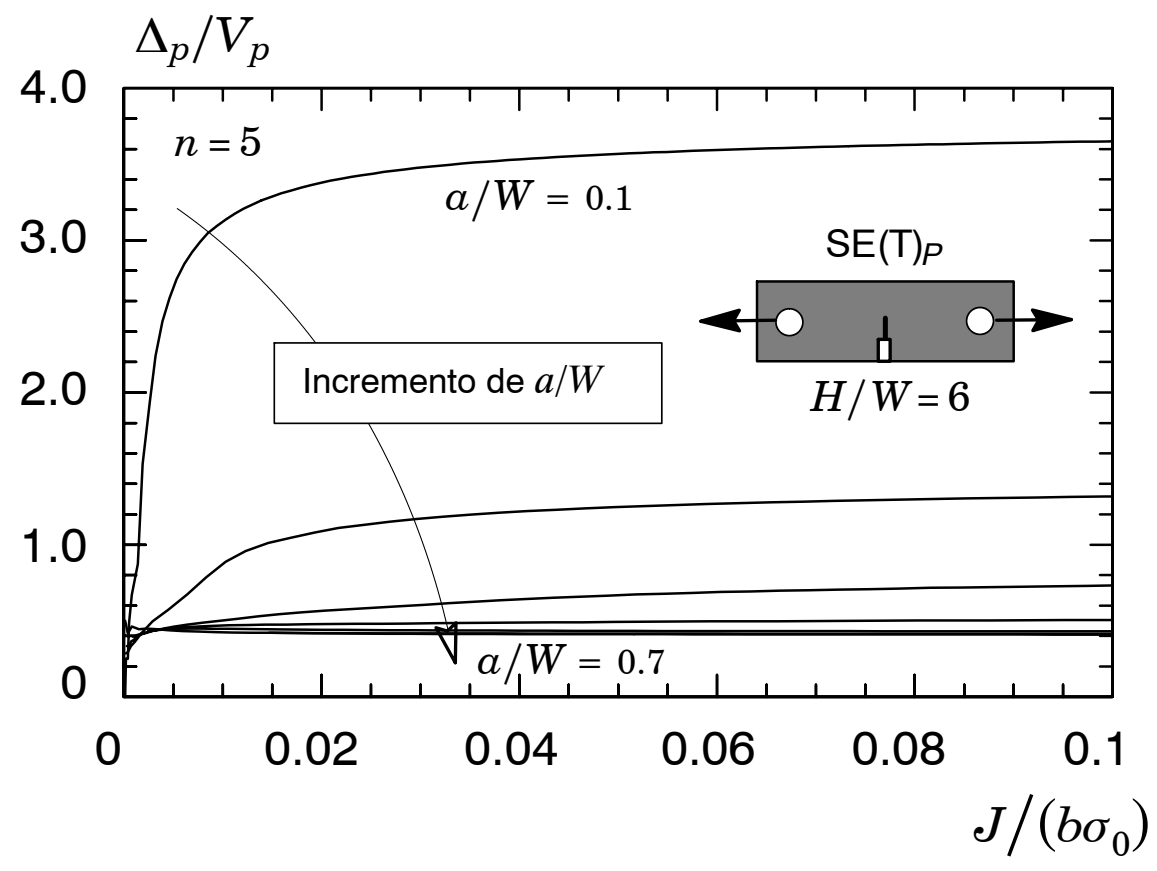

Figura 34 Quociente entre $L L D_{p}$ e $C M O D_{p}$ como função de J normalizado para espécimes $S E(T)$ carregados por pinos com $H / W=6$ e $n=5$.

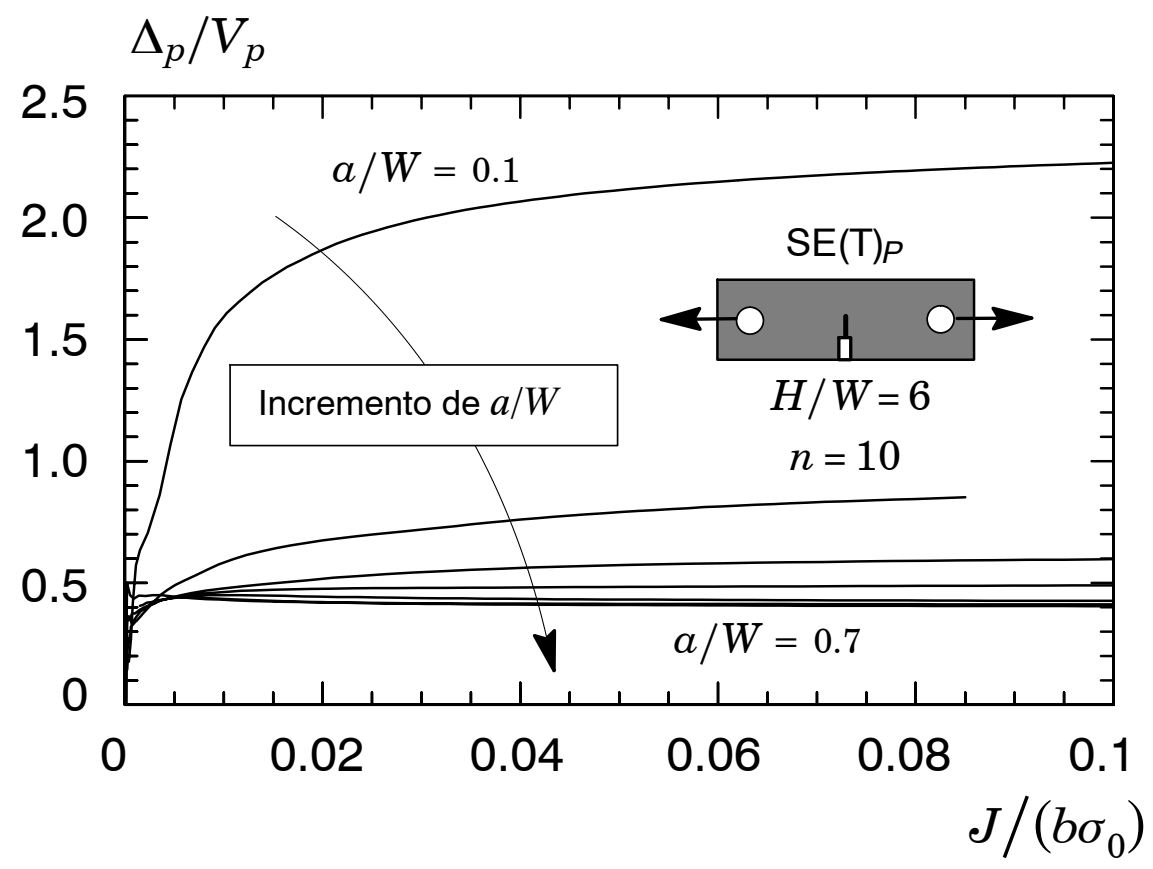

Figura 35 Quociente entre $L L D_{p}$ e $C M O D_{p}$ como função de J normalizado para espécimes $S E(T)$ carregados por pinos com $H / W=6$ e $n=10$. 


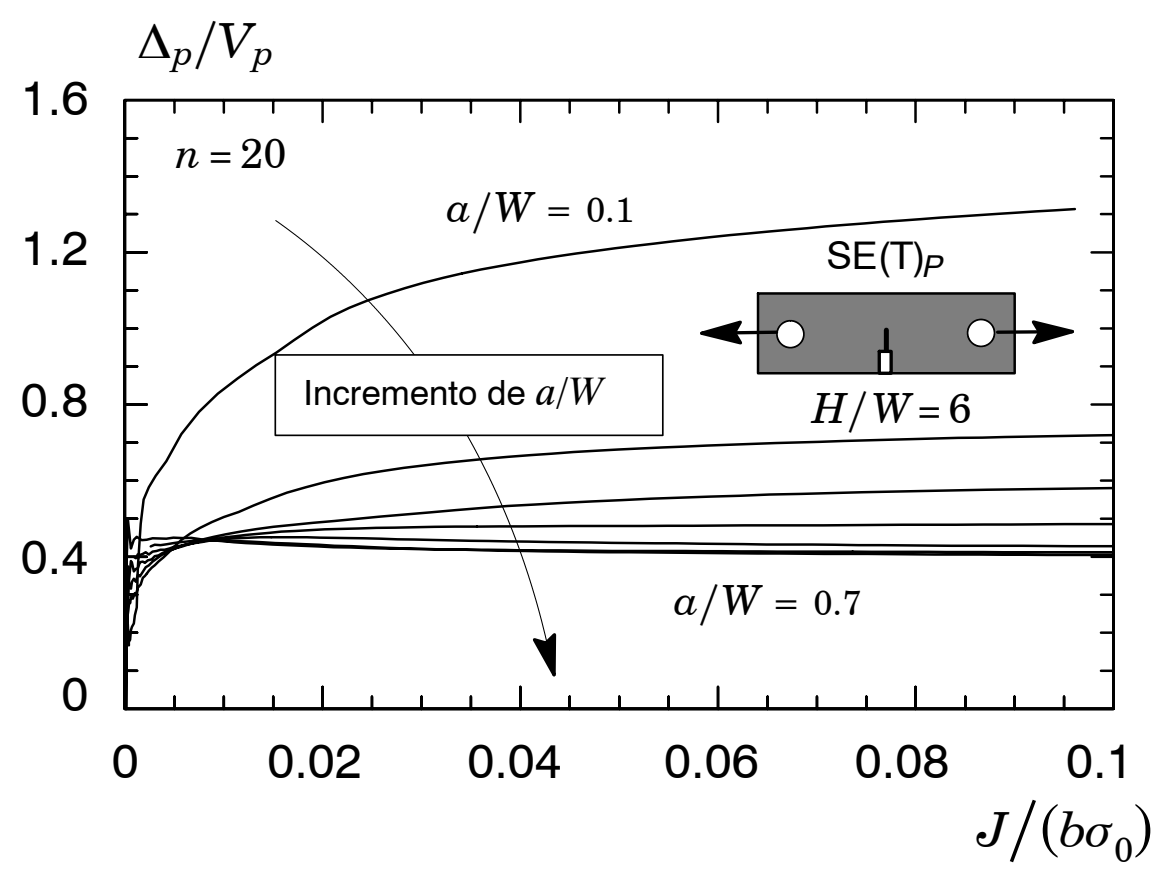

Figura 36 Quociente entre $L L D_{p}$ e $C M O D_{p}$ como função de J normalizado para espécimes $S E(T)$ carregados por pinos com $H / W=6$ e $n=20$.

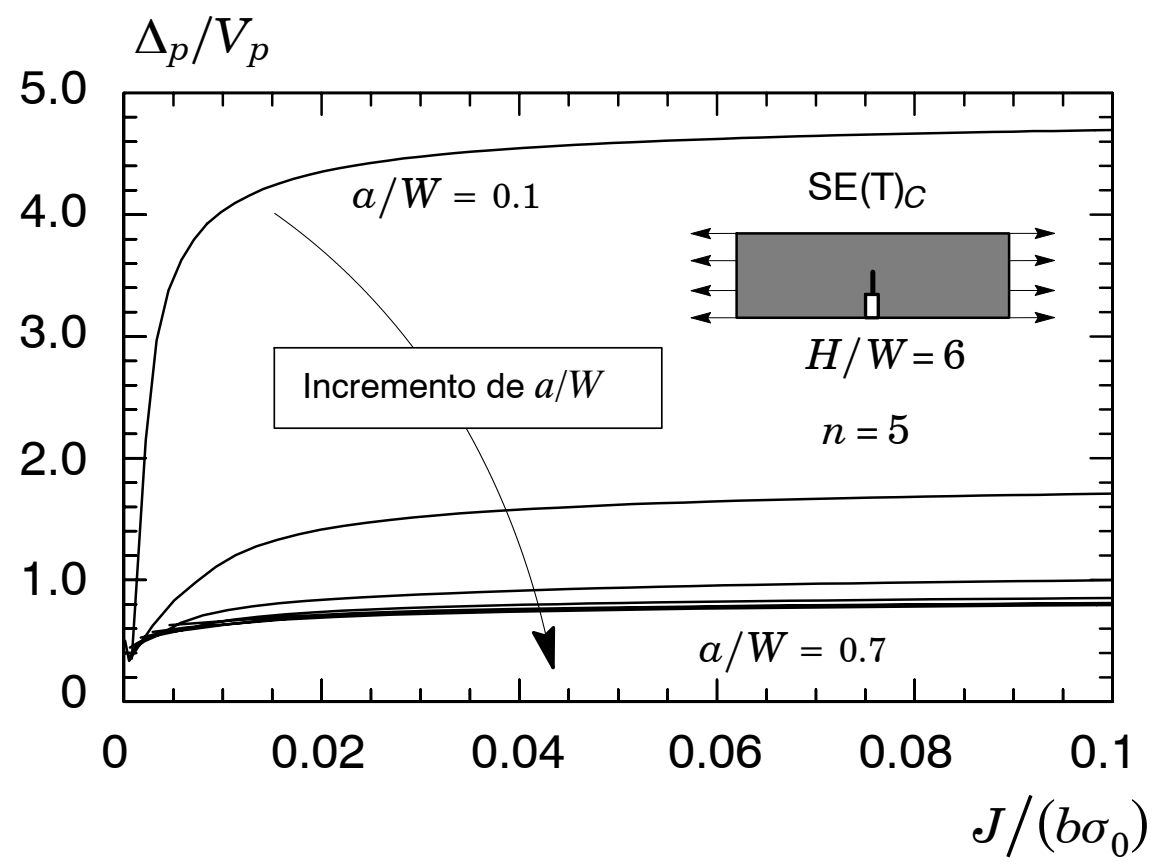

Figura 37 Quociente entre $L L D_{p}$ e $C M O D_{p}$ como função de J normalizado para espécimes $S E(T)$ fixado por garras com $H / W=6$ e $n=5$. 


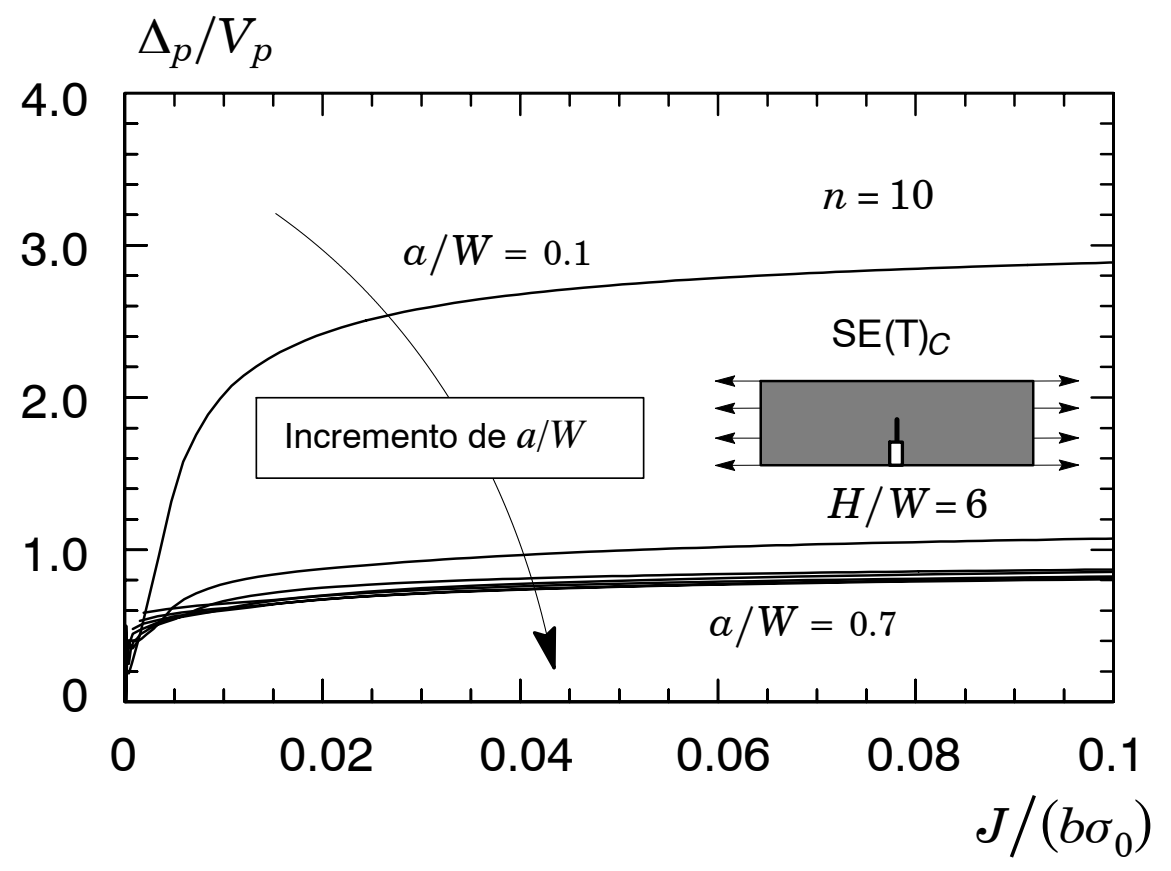

Figura 38 Quociente entre $L L D_{p}$ e $C M O D_{p}$ como função de J normalizado para espécimes $S E(T)$ fixado por garras com $H / W=6$ e $n=10$.

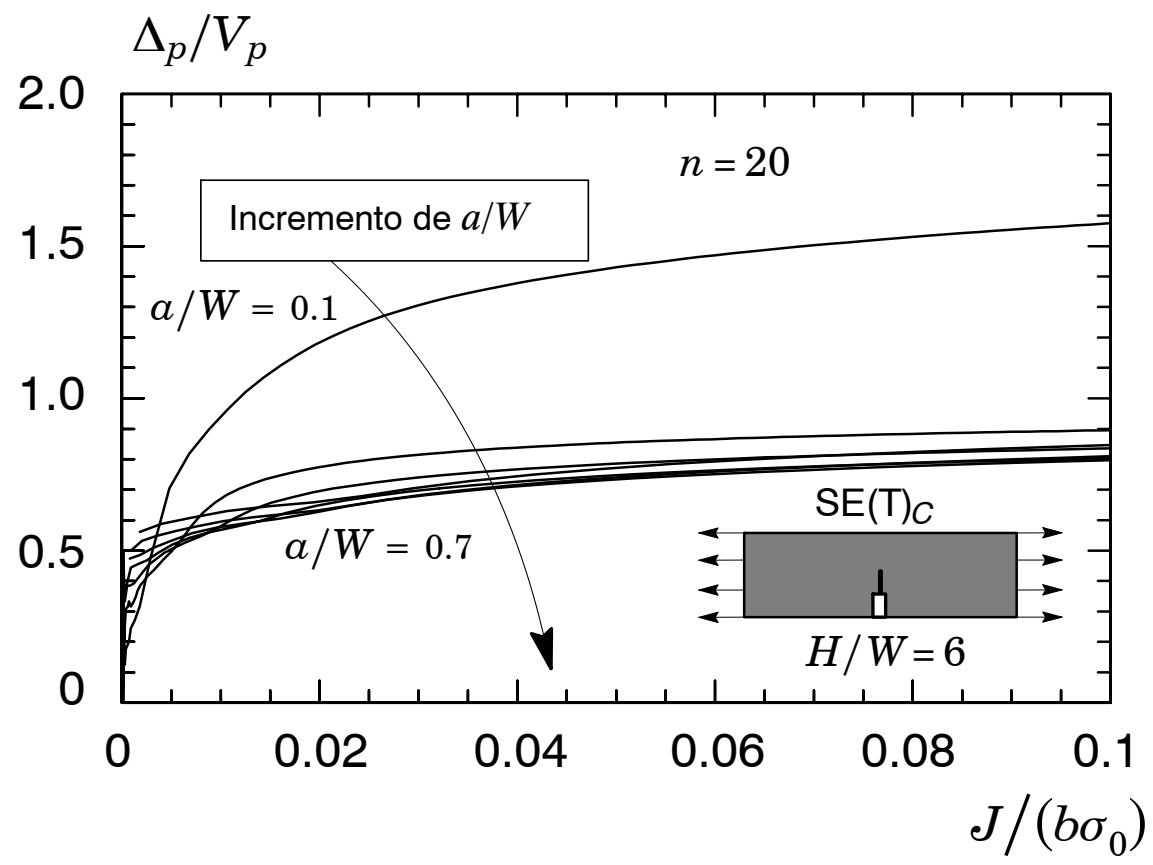

Figura 39 Quociente entre $L L D_{p}$ e $C M O D_{p}$ como função de J normalizado para espécimes $S E(T)$ fixado por garras com $H / W=6$ e $n=20$. 


\section{FLEXIBILIDADE PARA ESPÉCIMES SE(T)}

A flexibilidade normalizada $\mu$ para diferentes configurações de corpos-de-prova $\mathrm{SE}(\mathrm{T})$ é obtida da aplicação do procedimento descrito na seção 5.1 em modelos numéricos elásticos lineares. Desta forma, as Figs. 40 e 41 apresentam a variação da flexibilidade normalizada com a relação comprimento de trinca - largura de espécime, $a / W$, para espécimes carregados por pinos e fixados por garras respectivamente. Nas mesmas figuras, pode ser observado o efeito do comprimento relativo do espécime (relação $H / W$ ). Os resultados apresentados na Fig. 40 mostram que a flexibilidade normalizada é independente da relação $H / W$ para espécimes $\mathrm{SE}(\mathrm{T})$ carregados por pinos; neste caso, todas as curvas colapsam em uma única curva que define a dependência de $\mu$ com a relação $a / W$. Para os espécimes SE(T) fixados por garra, os resultados apresentados na Fig. 41 exibem um comportamento diferente no qual a flexibilidade $\mu$ depende da relação $H / W$, particularmente para relações $a / W \geqslant 0,4$. Entretanto, para relações comprimento de trinca - largura de espécime menores a 0,2 o efeito do comprimento relativo é insignificante.

Utilizando os resultados das Figs. 40 e 41 e empregando o método dos mínimos quadrados [77], foi ajustado um polinômio de grau 5 obtendo-se a seguinte relação entre profundidade de trinca e flexibilidade do espécime

$$
\frac{a}{W}=\beta_{0}+\beta_{1} \mu+\beta_{2} \mu^{2}+\beta_{3} \mu^{3}+\beta_{4} \mu^{4}+\beta_{5} \mu^{5}
$$

onde $\beta_{i}, i=0, \ldots, 5$ representam os coeficientes do polinômio apresentados na Tabela 3. Estes polinômios são representados por linhas cheias nas Figs. 40 e 41 . Com a medição da flexibilidade por meio de descarregamentos parciais durante o ensaio experimental (veja Fig. 15 (a)) e o emprego dos polinômios anteriores, é possível determinar a relação $a / W$ e, conseqüentemente, medir o crescimento de trinca. 
Tabela 3: Coeficientes para o ajuste polinomial da Eq. (60).

\begin{tabular}{|c|c|c|c|c|c|c|c|}
\hline \multicolumn{2}{|c|}{ Espécime } & $\beta_{0}$ & $\beta_{1}$ & $\beta_{2}$ & $\beta_{3}$ & $\beta_{4}$ & $\beta_{5}$ \\
\hline \multirow{2}{*}{$\mathrm{SE}(\mathrm{T})_{P}$} & $\begin{array}{c}\text { Todos os } \\
H / W\end{array}$ & 1.0056 & -2.8744 & 5.4420 & -12.510 & 16.102 & -7.0642 \\
\hline \multirow{3}{*}{$\mathrm{SE}(\mathrm{T})_{C}$} & $H / W=4$ & 2.3928 & -14.074 & 47.881 & -104.58 & 124.20 & -59.423 \\
\cline { 2 - 8 } & $H / W=6$ & 2.1263 & -13.461 & 51.299 & -120.47 & 147.83 & -71.812 \\
\cline { 2 - 8 } & $H / W=10$ & 1.6485 & -9.1005 & 33.025 & -78.467 & 97.344 & -47.227 \\
\hline
\end{tabular}

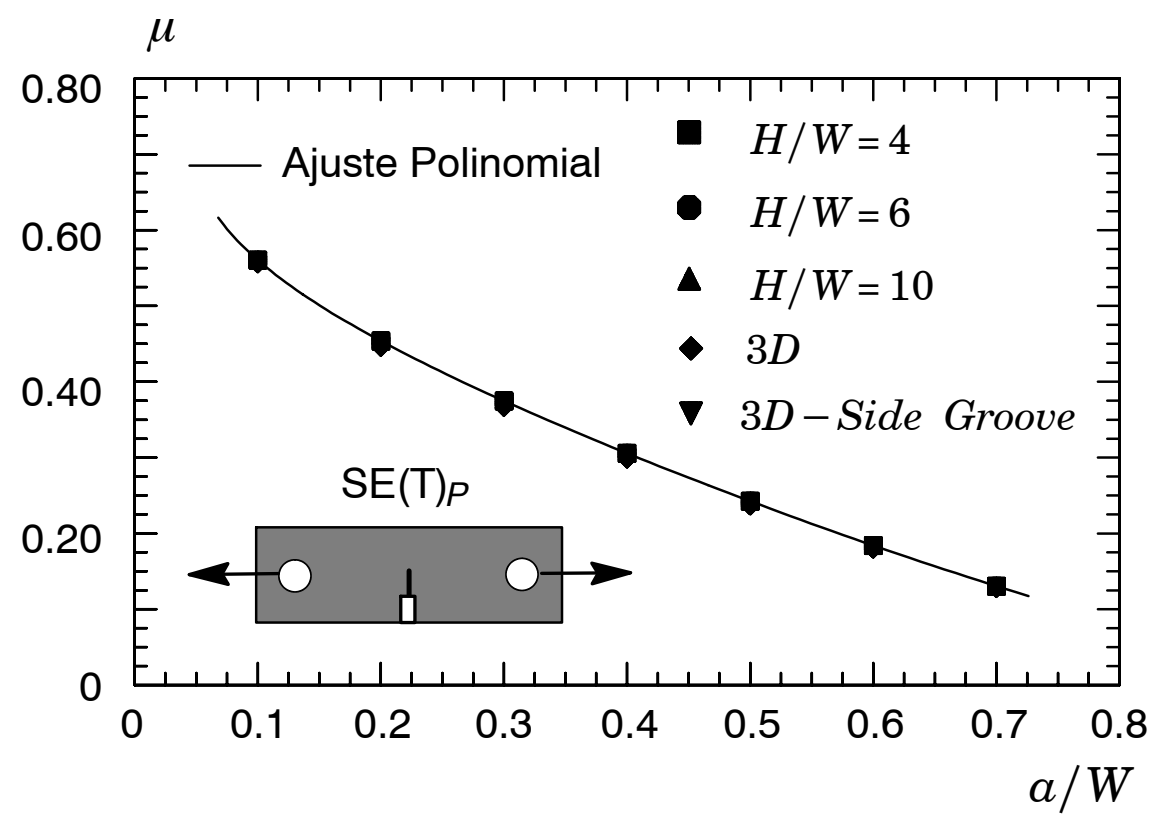

Figura 40 Variação da flexibilidade, $\mu$, com a relação a/Wpara espécimes $S E(T)$ carregados por pino e diferentes relações $H / W$. 




Figura 41 Variação da flexibilidade, $\mu$, com a relação a /W para espécimes $S E(T)$ fixados por garras com diferentes relações $H / W$.

\subsection{Efeitos 3D na Flexibilidade}

As equações de flexibilidade apresentadas anteriormente foram derivadas de análises numéricas $2 D$ em estado plano de deformações as quais resultam em resultados acurados. Entretanto, é de interesse ter conhecimento dos efeitos $3 D$ sobre a variação da flexibilidade $\mu$ com a relação $a / W$. Como, por exemplo, a influência da variação das tensões fora do plano da trinca que não é capturada de forma adequada nos modelos $2 D$. Talvez, mais importante, muitos ensaios experimentais são conduzidos em espécimes com entalhes laterais (side groove) os quais, indiscutivelmente, têm um efeito importante sobre os campos de tensões e deformações na zona da ponta da trinca. Entretanto, não se conhece a priori os efeitos dos entalhes na rigidez global do espécime.

Os pontos destacados no parágrafo anterior motivaram a construção de alguns modelos numéricos $3 D$ (veja capítulo 4) para o estudo dos efeitos de espessura finita sobre a flexibilidade. As geometrias consideradas para o estudo $3 D$ são 
corpos-de-prova $\mathrm{SE}(\mathrm{T}) 1 \mathrm{~T}$ (espessura $B=25,4 \mathrm{~mm}$ ) carregados por pinos com relação $H / W=6$ e profundidades de trinca com relações $a / W=0,1$ até 0,7 com incrementos de 0,1 sem entalhe lateral. Para estudar os efeitos dos entalhes laterais, foram construídos modelos numéricos com $20 \%$ de entalhe (10\% de cada lado) com as mesmas dimensões dos modelos sem entalhes e profundidades de trinca relativa $a / W=0,1$ e 0,5 .

As análises de flexibilidade obtidas por estes modelos $3 D$ são inclusas na Fig. 40. Notar, entretanto, que os resultados confundem-se com os resultados $2 D$ devido à superosição dos símbolos. Desta forma, é evidente que os efeitos $3 D$ são praticamente nulos. Uma vez que as diferenças encontradas entre modelos $2 D$ e $3 D$ são menores a $1.5 \%$ para todos os casos analizados, estes resultados validam o emprego de modelos numéricos $2 D$ no cálculo de flexibilidade de espécimes $\mathrm{SE}(\mathrm{T})$. 


\section{FATORES $\eta_{J}, \gamma$ E RAIOS PLÁSTICOS PARA ESPÉCIMES SE(T) CARREGADOS POR PINOS}

Neste capítulo são apresentados os fatores plásticos $\eta_{J}, \gamma$ e fatores de rotação plástica $r_{p}$ para espécimes $\mathrm{SE}(\mathrm{T})$ carregados por pinos. A metodologia para o cálculo foi apresentada nas seções 5.3 e 5.4. É importante mencionar que os resultados apresentados neste capítulo derivam de análises numéricas em estado plano de deformações. Entretanto, as comparações entre modelos $2 D$ e $3 D$ que serão apresentadas no capítulo 9 demonstram que os modelos em estado plano de deformações fornecem resultados praticamente idénticos aos resultados dos modelos tridimensionais para as geometrias e proporções geométricas consideradas.

\subsection{Fatores $\eta_{J}$ derivados de CMOD}

Nas Figs. 42 a 44 são apresentados os fatores $\eta_{J}$ derivados de CMOD (veja seção 5.3) para espécimes $\mathrm{SE}(\mathrm{T})$ fixados por pinos $\left(\eta_{J, P}^{\mathrm{CMOD}}\right)$ como função da relação profundidade de trinca - largura do espécime $(a / W)$ para diferentes comprimentos relativos de espécime $(H / W)$ e diferentes propriedades de material. Primeiramente, pode ser observado na Fig. 42 que as propriedades do material têm mínima influência sobre os valores de $\eta_{J, P}^{\mathrm{CMOD}}$. Adicionalmente, estes fatores apresentam uma dependência aproximadamente linear com a relação $a / W$, sendo esta quase constante e próxima à unidade. Este comportamento se repete para os casos apresentados nas Figs. 43 e 44 para diferentes relações $H / W$. Consequentemente, uma vez que as diferentes proporções geométricas e propriedades de material não têm grande influencia sobre os fatores $\eta_{J, P}^{\mathrm{CMOD}}$, o seu emprego em procedimentos experimentais é grandemente facilitado. 
Para uma manipulação mais simples dos resultados apresentados nas Figs. $42-44$, foi obtido um polinômios de ajuste para os diferentes fatores $\eta_{J, P}^{\text {CMOD }}$,

$$
\eta_{J, P}^{\mathrm{CMOD}}=0.9167+0.0837(a / W)
$$

Este polinômio é obtido por mínimos quadrados [77] empregando os resultados numéricos e é representado por linha sólida nas Figs. 42-44. A precisão no ajuste do polinômio da Eq. (61) é adequada para todas as profundidades relativas de trinca consideradas apresentando em todos os casos diferenças menores a $5 \%$ entre resultados numéricos e ajuste.

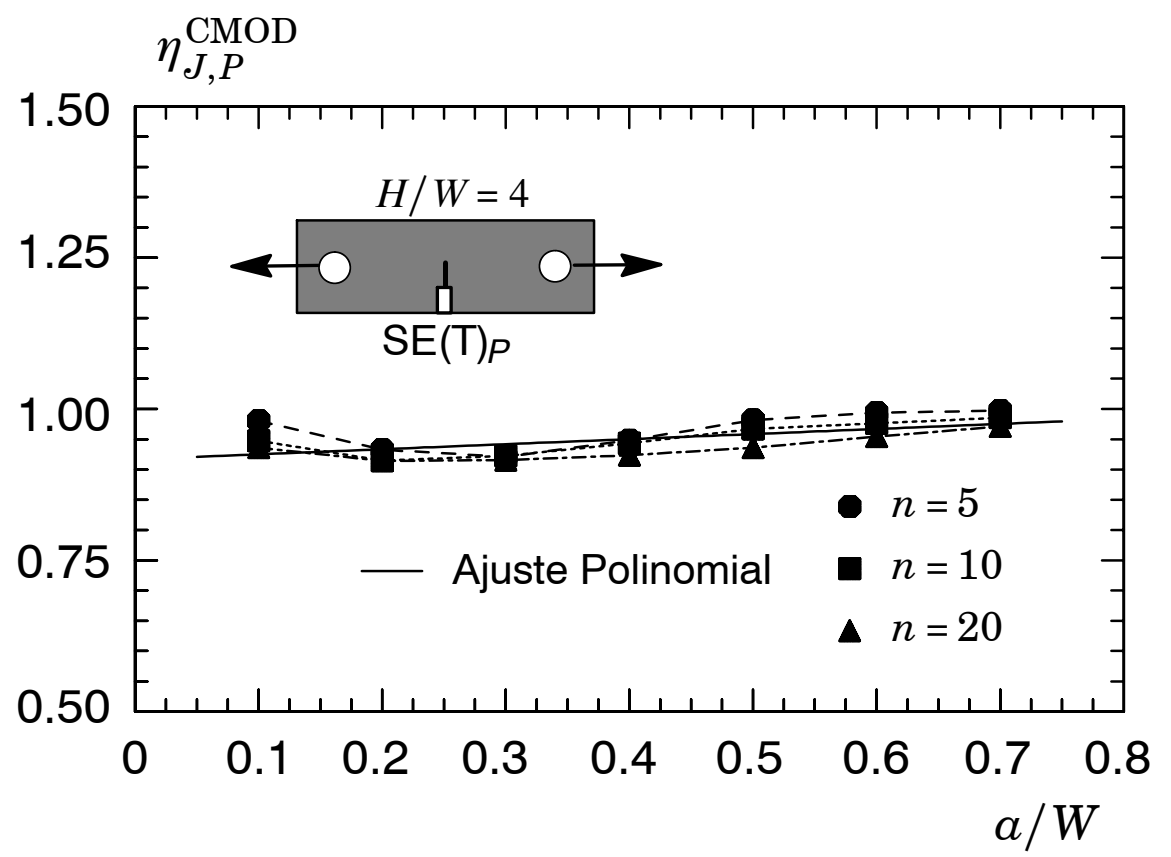

Figura 42 Variação dos fatores $\eta_{J}$ derivados de CMOD com a profundidade de trinca a / W para espécimes $S E(T)$ carregados por pinos e relação $H / W=4$.

\subsection{Fatores $\eta_{J}$ derivados de LLD}

Nas Figs. 45-47 são apresentados os fatores $\eta_{J}$ derivados de LLD para espécimes $\mathrm{SE}(\mathrm{T})$ fixados por pinos como função da relação profundidade de trinca - largura do espécime $(a / W)$, diferentes comprimentos relativos de espécime $(H / W)$ e diferentes 


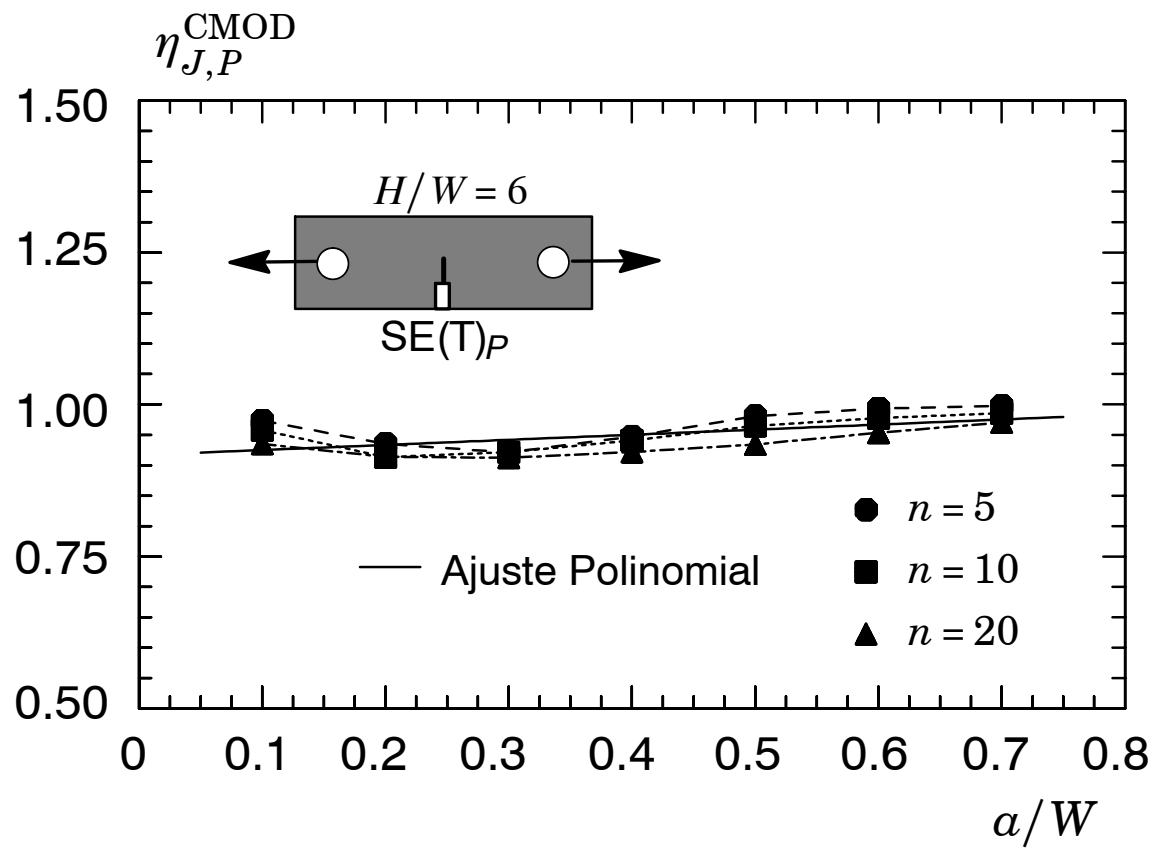

Figura 43 Variação dos fatores $\eta_{J}$ derivados de CMOD com a profundidade de trinca a / W para espécimes $S E(T)$ carregados por pinos e relação $H / W=6$.

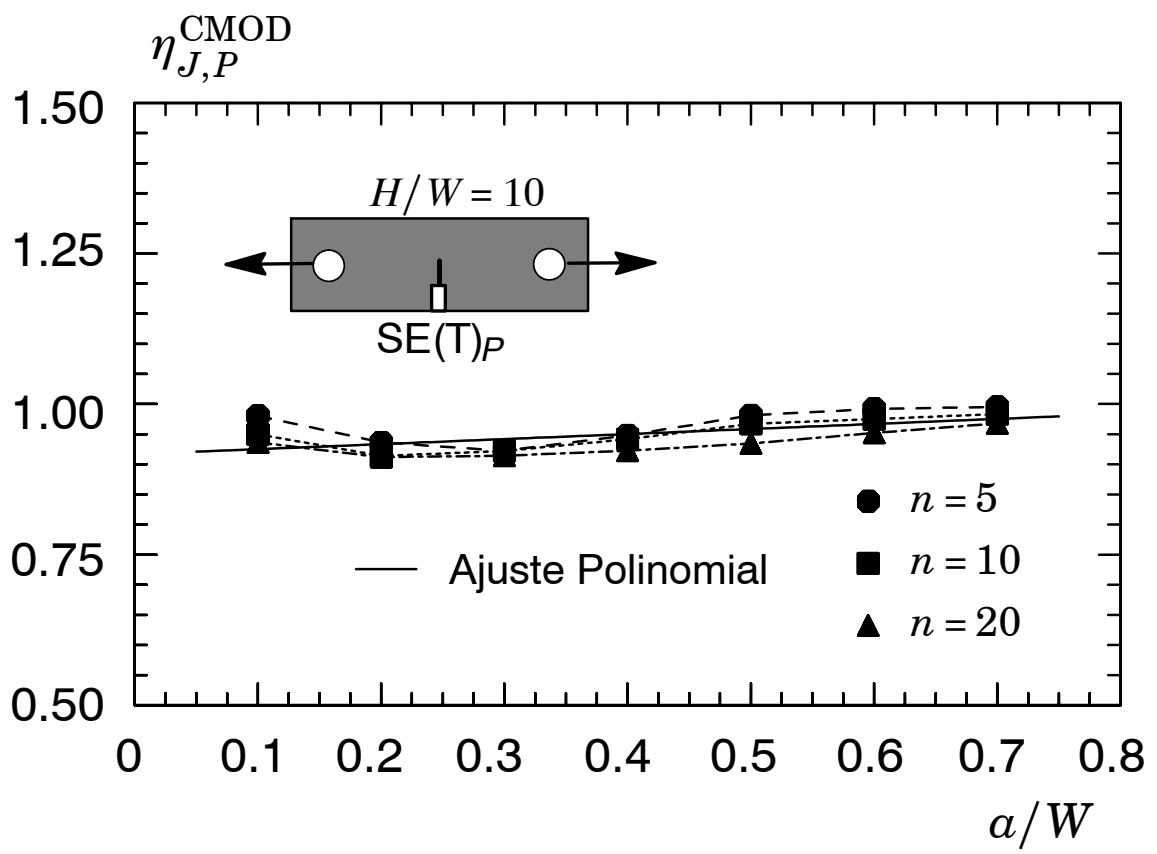

Figura 44 Variação dos fatores $\eta_{J}$ derivados de CMOD com a profundidade de trinca a / W para espécimes $S E(T)$ carregados por pinos e relação $H / W=10$. 
propriedades de material. Observa-se que o comportamento dos fatores $\eta_{J, P}^{\mathrm{LLD}}$ contrasta consideravelmente com o comportamento apresentado pelos fatores plásticos derivados de CMOD. Enquanto os fatores $\eta_{J, P}^{\mathrm{LLD}}$ são relativamente insensíveis ao encruamento do material para valores $a / W \geqslant 0.4$, o efeito do expoente $n$ é considerável para trincas mais rasas. Este efeito é intensificado para comprimentos relativos de corpo-de-prova maiores $(H / W=6,10)$. Adicionalmente, $\eta_{J, P}^{\mathrm{LLD}}$ depende consideravelmente da profundidade relativa de trinca, $a / W$, cujo efeito é mais pronunciado para valores $a / W \leqslant 0,5$.

Como é observado nas Figs. 45-47, as propriedades de material e relação $H / W$ têm efeitos consideráveis sobre os fatores $\eta_{J, P}^{\mathrm{LLD}}$. Desta forma, não é acurado o emprego de somente um polinômio de ajuste para todas as proporções geométricas e propriedades de material considerados como no caso dos fatores $\eta_{J, P}^{\mathrm{CMOD}}$. Portanto, utilizando o método dos mínimos quadrados [77], foram obtidos polinômios de segundo grau para o ajuste de cada uma das propriedades de material e comprimentos relativos dos espécimes estudados. A forma do polinômio de ajuste para $\eta$ derivado de LLD é expresso por

$$
\eta_{J, P}^{\mathrm{LLD}}=A+B(a / W)+C(a / W)^{2}
$$

A Tabela 4 apresenta os coeficientes destes polinômios para as diferentes propriedades de material e comprimentos de espécime.

\subsection{Fatores $\gamma$}

Os fatores $\gamma$ são obtidos a partir da aplicação do procedimento descrito na seção 5.4 utilizando a Eq. (48) em conjunção com a Eq. (62). Esta derivação resulta em uma expressão para o fator $\gamma$ na forma 


$$
\begin{aligned}
\gamma_{P}=(A-1)+B(a / W)+C(a / W)^{2}+ \\
\frac{-B-(2 B+C)(a / W)+2 C(a / W)^{2}}{A+B(a / W)+C(a / W)^{2}} .
\end{aligned}
$$

Onde os coeficientes A, B e C são dados na Tabela 4.

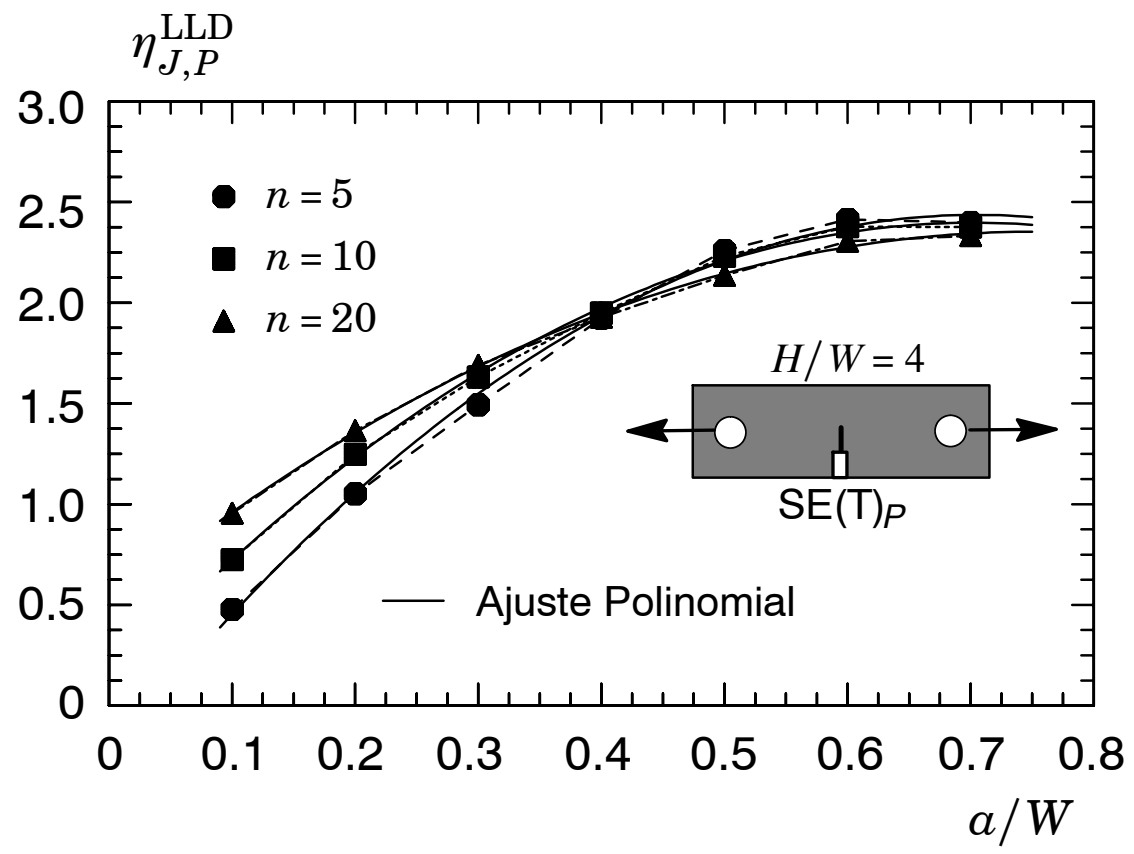

Figura 45 Variação dos fatores $\eta_{J}$ derivados de LLD com a profundidade de trinca a /W para espécimes $S E(T)$ carregados por pinos e relação $H / W=4$.

É importante recordar que os fatores $\gamma$ dados pelos polinômios da Eq. (63) são aplicáveis à obtenção de curvas $R$ em ensaios experimentais tanto quando é empregada a curva $P$-LLD como também a curva $P$-CMOD. Isto é demonstrado na Seção 5.5. De forma ilustrativa, a Fig. 48 apresenta a variação do fator $\gamma$ com a profundidade de trinca e diferentes propriedades de material para espécime SE(T) carregado por pinos e comprimento relativo $H / W=6$. 


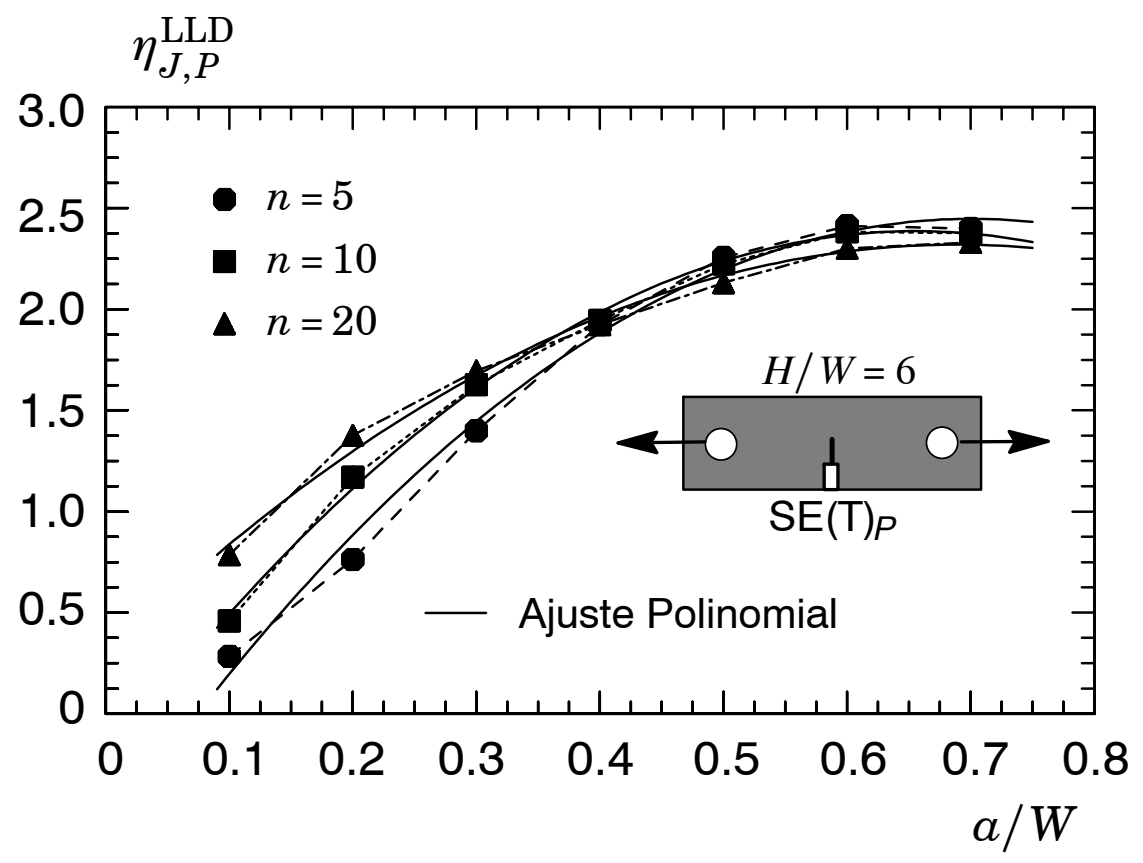

Figura 46 Variação dos fatores $\eta_{J}$ derivados de LLD com a profundidade de trinca a / W para espécimes $S E(T)$ carregados por pinos e relação $H / W=6$.

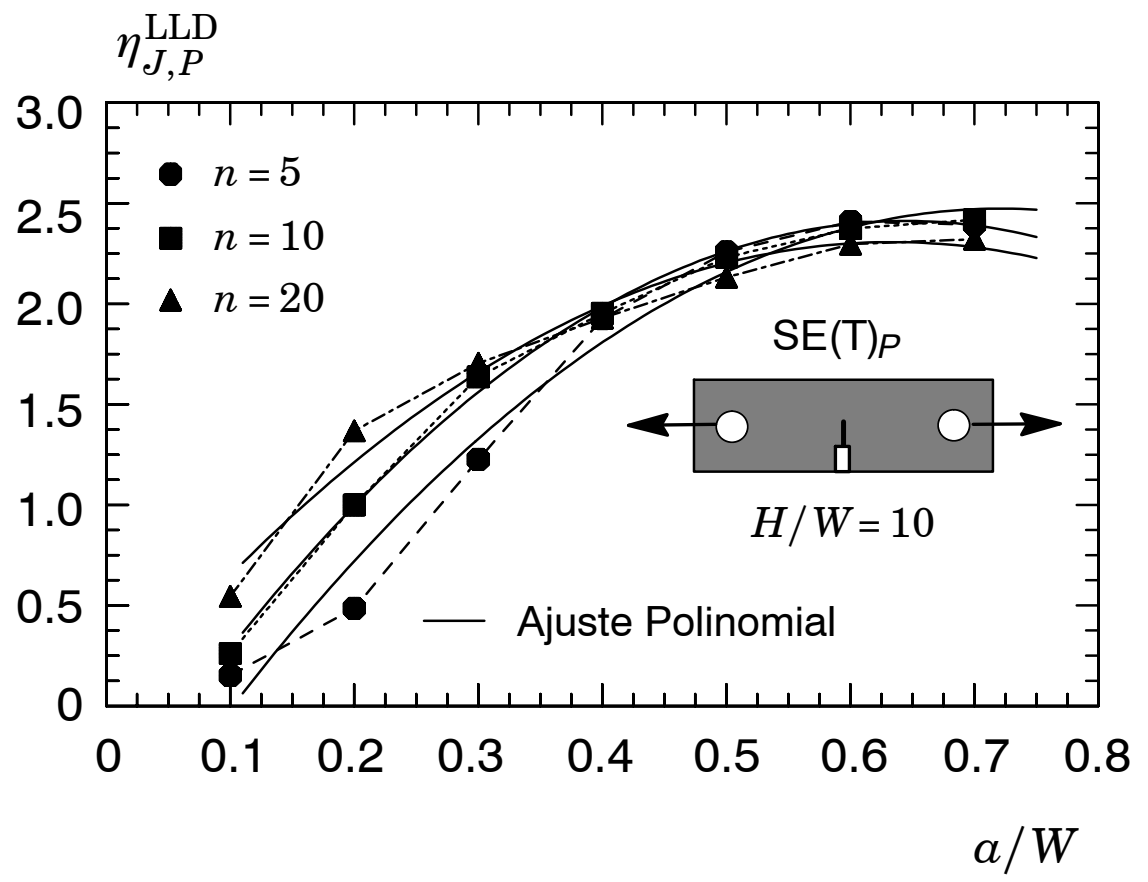

Figura 47 Variação dos fatores $\eta_{J}$ derivados de $L L D$ com a profundidade de trinca a/W para espécimes $S E(T)$ carregados por pinos e relação $H / W=10$. 




Figura 48 Variação do fator $\gamma$ com a relação a / W para espécime $S E(T)$ carregado por pinos com $\mathrm{H} / \mathrm{W}=6$ e diferentes propriedade de material.

\subsection{Comentários Sobre os Resultados do Capítulo}

Os resultados apresentados anteriormente destacam as vantagens do emprego de medições CMOD na determinação de integral $J$ durante ensaios experimentais. Como foi observado, os $\eta_{J, P}^{\mathrm{CMOD}}$ apresentam menor sensibilidade às mudanças de propriedades de material e às proporções geométricas. Sendo que o comportamento apresentado nas Figs. 42-44 permanece essencialmente sem modificação para as relações $H / W$ estudadas, os resultados são considerados representativos de todas as relações $H / W$ para espécimes $\mathrm{SE}(\mathrm{T})$ carregados por pinos com uma ampla faixa de profundidades de trinca e propriedades de material. 
Tabela 4 Coeficientes para os ajustes polinomiais das Eqs. (62) e (63).

\begin{tabular}{|c|c|c|c|c|}
\hline & & \multicolumn{3}{|c|}{ Coeficientes } \\
\hline \multicolumn{2}{|c|}{ Espécime } & $A$ & $B$ & $C$ \\
\hline \multirow{3}{*}{$\mathrm{SE}(\mathrm{T})_{P}-H / W=4$} & $n=5$ & $-0,2571$ & 7,6488 & 47,881 \\
\hline & $n=10$ & 0,1203 & 6,4852 & $-4,6186$ \\
\hline & $n=20$ & 0,5009 & 4,9214 & $-3,2701$ \\
\hline \multirow{3}{*}{$\mathrm{SE}(\mathrm{T})_{P}-H / W=6$} & $n=5$ & $-0,6149$ & 8,7409 & $-6,2381$ \\
\hline & $n=10$ & $-0,2493$ & 8,0430 & $-6,1368$ \\
\hline & $n=20$ & 0,2912 & 5,8895 & $-4,2755$ \\
\hline \multirow{3}{*}{$\mathrm{SE}(\mathrm{T})_{P}-H / W=10$} & $n=5$ & $-0,8832$ & 9,3110 & $-6,4583$ \\
\hline & $n=10$ & $-0,5651$ & 9,2335 & $-7,1608$ \\
\hline & $n=20$ & $-0,0303$ & 7,3783 & $-5,8240$ \\
\hline
\end{tabular}

\subsection{Cálculo do Fator de Rotação Plástica para Espécimes SE(T)}

A correção adequada dos efeitos de rotação dos corpos-de-prova $\mathrm{SE}(\mathrm{T})$ fixados por pinos (ver Seção 3.3) requer a correta determinação do centro de rotação do corpo-de-prova. Para isto, por meio das análises numéricas, foram determinados os valores dos fatores de rotação plástica ou raios plásticos $\left(r_{p}\right)$ em espécimes $\mathrm{SE}(\mathrm{T})$ com diferentes profundidades de trinca, relações comprimento-largura do espécime e propriedades de material. 
As Figs. 49-54 apresentam a variação do fator $r_{p}$ com a abertura da boca da trinca normalizada pelo ligamento remanescente $b$ para corpos-de-prova $\mathrm{SE}(\mathrm{T})$ carregados por pinos e diferentes propriedades de material. Particularmente, nas Figs. 49 e 52 pode ser observado o fator de rotação plástica para diferentes comprimentos relativos de espécimes onde é evidente que a relação $H / W$ não tem efeito apreciável (dentro dos limites estudados) sobre os fatores $r_{p}$ tanto para trincas rasas como para trincas profundas. Desta forma, nos gráficos correspondentes às outras profundidades de trinca $(a / W=0,3 ; 0,4 ; 0,6$ e 0,7$)$, somente são inclusos resultados para relações $H / W=6$.

Nestas figuras, os fatores $r_{p}$ apresentam uma transição para valores $\mathrm{CMOD} / b \lesssim 0,03 \sim 0,04$ até atingir valores estáveis na maioria dos casos estudados. Entretanto, a estabilização não é muito evidente para encruamento muito baixo $(n=20)$ e trincas rasas. Nas Figs. 49 a 51 pode ser observado que as propriedades de material têm efeito considerável no fator $r_{p}$ em espécimes com trincas médias e rasas $(a / W \leq 0,4)$. Por outro lado, a situação muda nos casos de trinca profunda $(\alpha / W \geq 0,5)$, sendo que nas Figs. 52 a 54 as propriedades de material praticamente têm efeito nulo sobre os valores de $r_{p}$. Desta forma, pode-se estabelecer que para profundidades de trinca relativa $a / W=0,5 ; 0,6$ e 0,7 o raio plástico é aproximadamente 0,65; 0,55 e 0,35 respectivamente. Entretanto, para relações de trinca $a / W \leq 0,4$, não pode ser estabelecido um único valor para o fator $r_{p}$ já que este muda consideravelmente com as propriedades de material.Um procedimento adequado para determinar o valor de $r_{p}$ em trincas curtas é proposto no capítulo 10. 


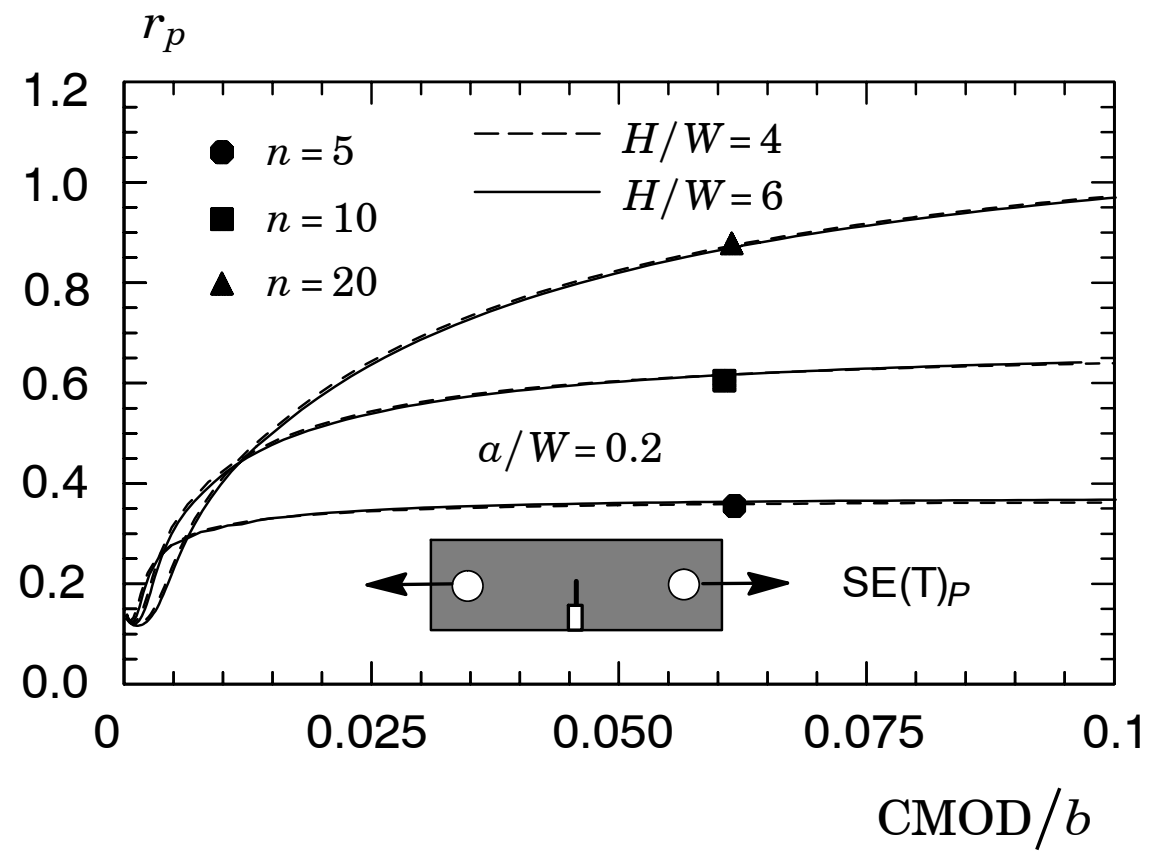

Figura 49 Variação do fator de rotação plástico com o CMOD normalizado para espécimes $S E(T)_{P}$ com a / W=0,2, diferentes propriedades de material e $H / W=4$ e 6 .



Figura 50 Variação do fator de rotação plástico com o CMOD para espécime $S E(T)_{P}$ com a/W=0,3; H/W=6 e diferentes propriedades de material. 


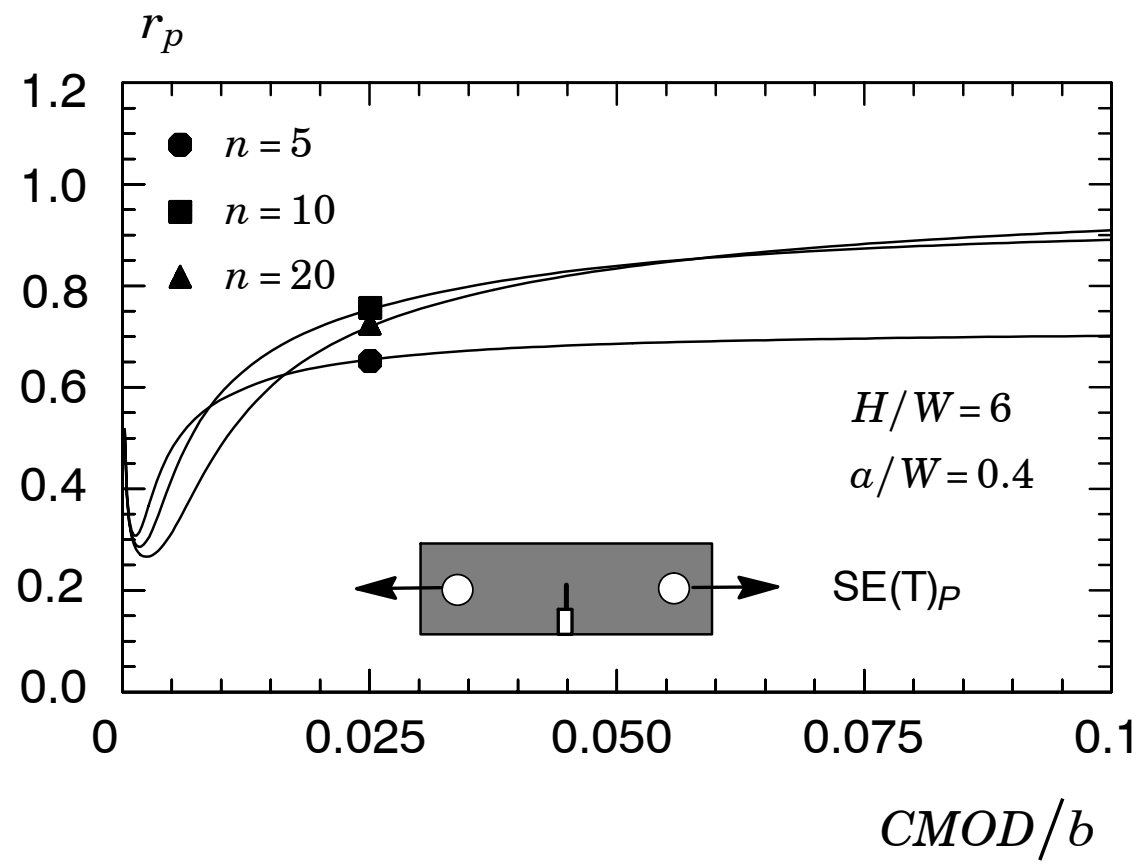

Figura 51 Variação do fator de rotação plástico com o CMOD para espécime $S E(T)_{P}$ com a $/ W=0,4 ; H / W=6$ e diferentes propriedades de material.

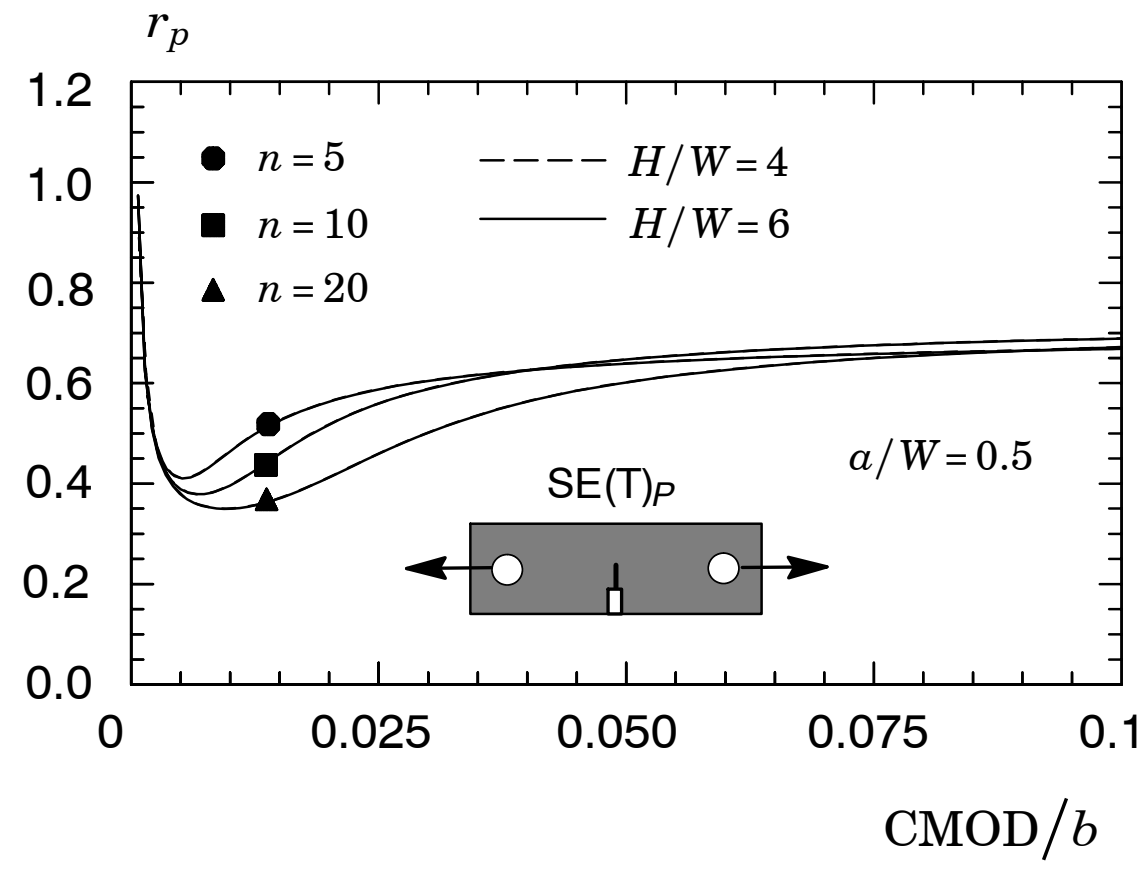

Figura 52 Variação do fator de rotação plástico com o CMOD normalizado para espécimes $S E(T)_{P}$ com a / W=0,5, diferentes propriedades de material e $H / W=4$ e 6 . 




Figura 53 Variação do fator de rotação plástico com o CMOD para espécime $S E(T)_{P}$ com a / W=0,6; $H / W=6$ e diferentes propriedades de material.

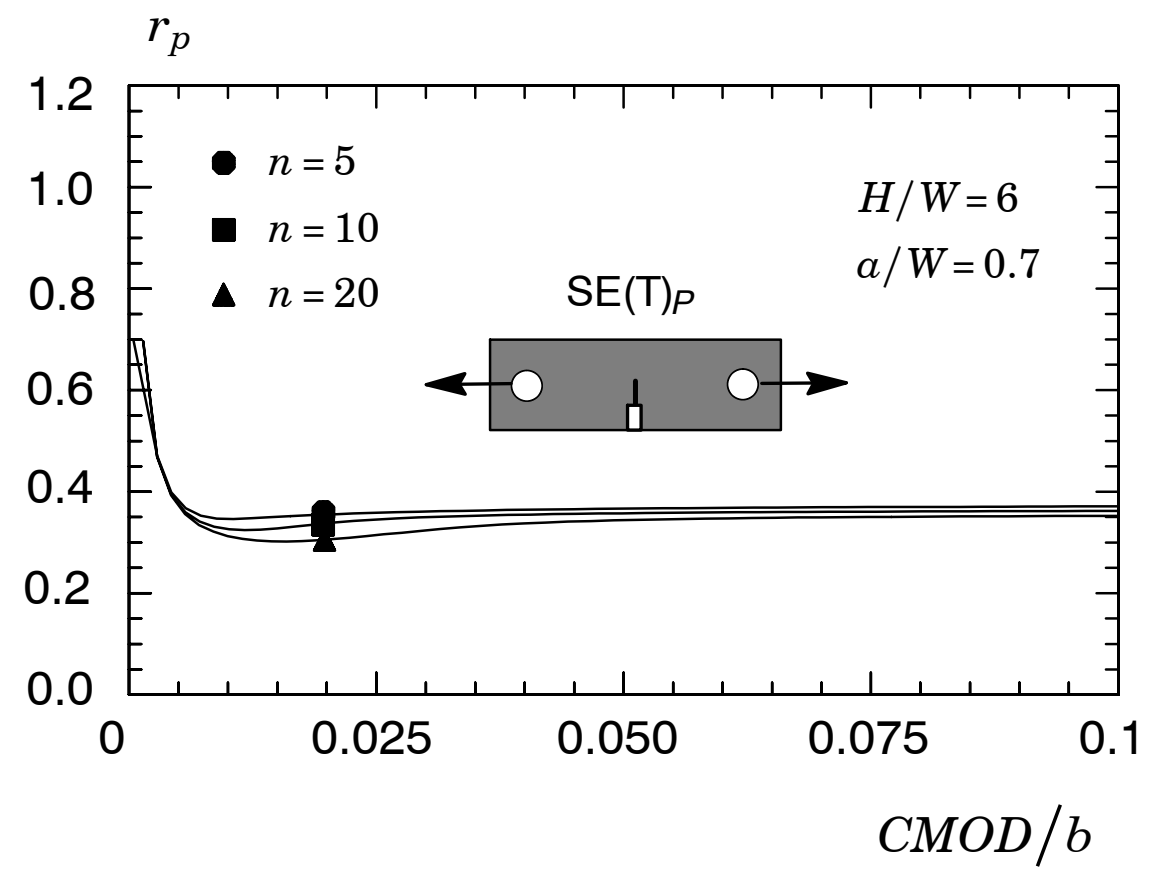

Figura 54 Variação do fator de rotação plástico com o CMOD para espécime $S E(T)_{P}$ com a $/ W=0,7 ; H / W=6$ e diferentes propriedades de material. 


\section{FATORES $\eta_{J}$ E $\gamma$ PARA ESPÉCIMES SE(T) FIXADOS POR GARRAS}

Da mesma forma que no capítulo anterior, neste capítulo são apresentados fatores plásticos $\eta_{J}$ e $\gamma$ para espécimes $\mathrm{SE}(\mathrm{T})$. Entretanto, o modo de fixação considerado é por garras (clamps) as quais não permitem a rotação das extremidades . A metodologia para o cálculo destes fatores plásticos foi apresentada nas seções 5.3 e 5.4. É importante considerar que os resultados apresentados neste capítulo derivam de análises numéricas em estado plano de deformações. Entretanto, as comparações que serão apresentadas no capítulo 9 entre modelos $2 D$ e $3 D$ demonstrarão que os modelos em estado plano de deformações fornecem resultados acurados para as proporções geométricas consideradas.

\subsection{Fatores $\eta_{J}$ derivados de CMOD}

Nas Figs. 55-57 são apresentados os fatores $\eta_{J}$ derivados de CMOD para espécimes $\mathrm{SE}(\mathrm{T})$ fixados por garras como função da relação profundidade de trinca - largura do espécime $(a / W)$, diferentes comprimentos relativos de espécime $(H / W)$ e diferentes propriedades de material. Em contraste ao comportamento apresentado pelos espécimes carregados por pinos do capítulo 7, observa-se na Fig. 55 que os valores apresentados decrescem de forma estável e quase linear com o aumento da profundidade relativa de trinca na faixa $0,1 \leq a / W \leq 0,6$. Tal comportamento repete-se para os outros comprimentos relativos de corpo-de-prova (Figs. 56 e 57). Entretanto, os fatores $\eta_{J}$ para $a / W=0,7$ apresentam um pequeno desvio em relação ao comportamento linear observado em profundidades de trinca menores; este efeito é mais evidente para corpos-de-prova mais curtos $(H / W=4)$ com encruamento moderado e baixo $(n=10$ e 20$)$. Provavelmente, devido ao pequeno ligamento remanescente para este valor elevado de trinca relativa, os efeitos flexionais influenciam o campo de deformações plásticas na zona à frente da trinca afetando, consequentemente, a área plástica da qual $\eta_{J, C}^{\mathrm{CMOD}}$ é derivado. 
Para uma manipulação mais simples dos resultados apresentados nas Figs. 55-57, foi obtido um polinômio de ajuste dos diferentes fatores $\eta_{J}$ na forma.

$$
\eta_{J, C}^{C M O D}=1.0398-0.6870(a / W)
$$

Este polinômio foi derivado do ajuste por mínimos quadrados dos resultados numéricos e são representados por linha sólida nas figuras. A precisão do polinômio apresentado na Eq. (64) é boa para profundidades relativas de trinca entre 0,1 e 0,5. Entretanto, para $a / W=0,6$ e 0,7 as diferenças entre resultados numéricos e ajuste ultrapassam $25 \%$.

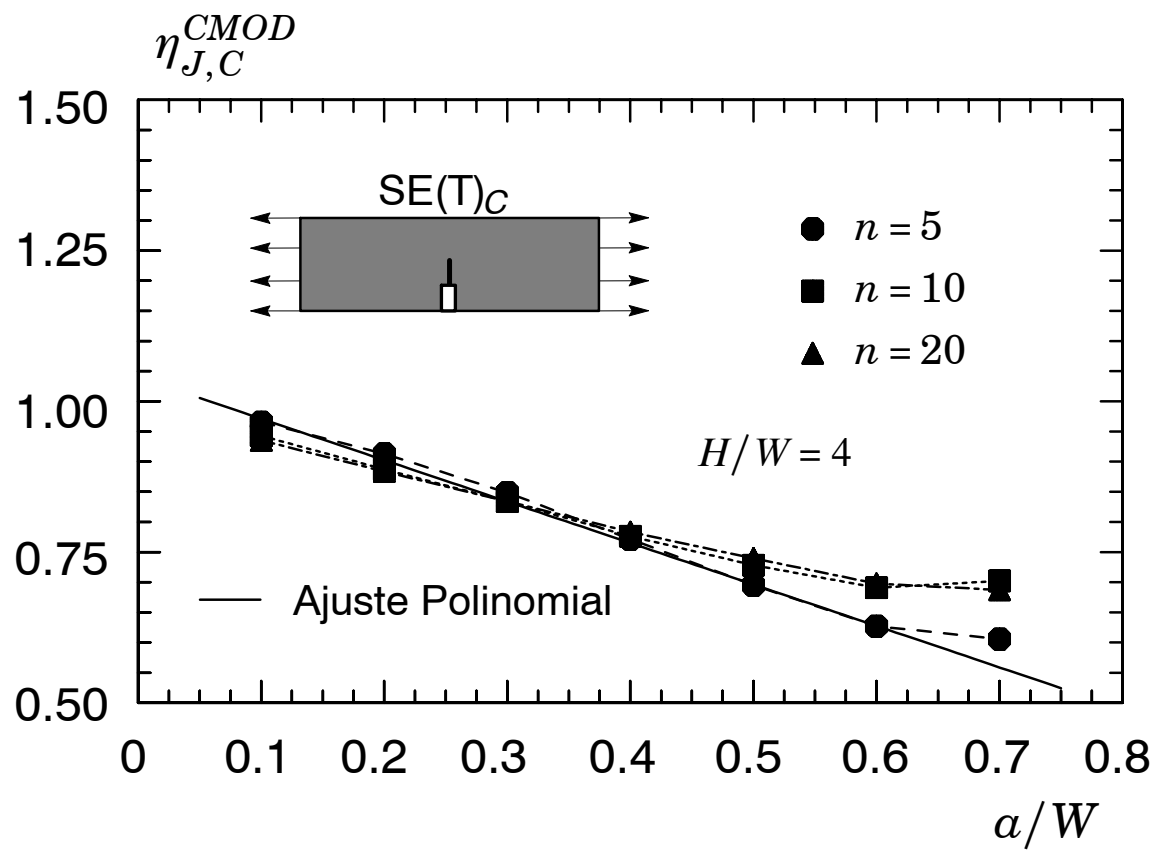

Figura 55 Variação dos fatores $\eta_{J}$ derivados de CMOD com a profundidade de trinca a / W para espécimes $S E(T)$ fixados por garras e relação $H / W=4$.

\subsection{Fatores $\eta_{J}$ derivados de LLD}

A seguir, nas Figs. 58-60 são apresentados os fatores $\eta_{J}$ derivados de LLD. Nestas figuras observa-se que, da mesma forma que nos espécimes SE(T) carregados por pino, os fatores $\eta_{J, C}^{\mathrm{LLD}}$ apresentam uma importante variação com a 


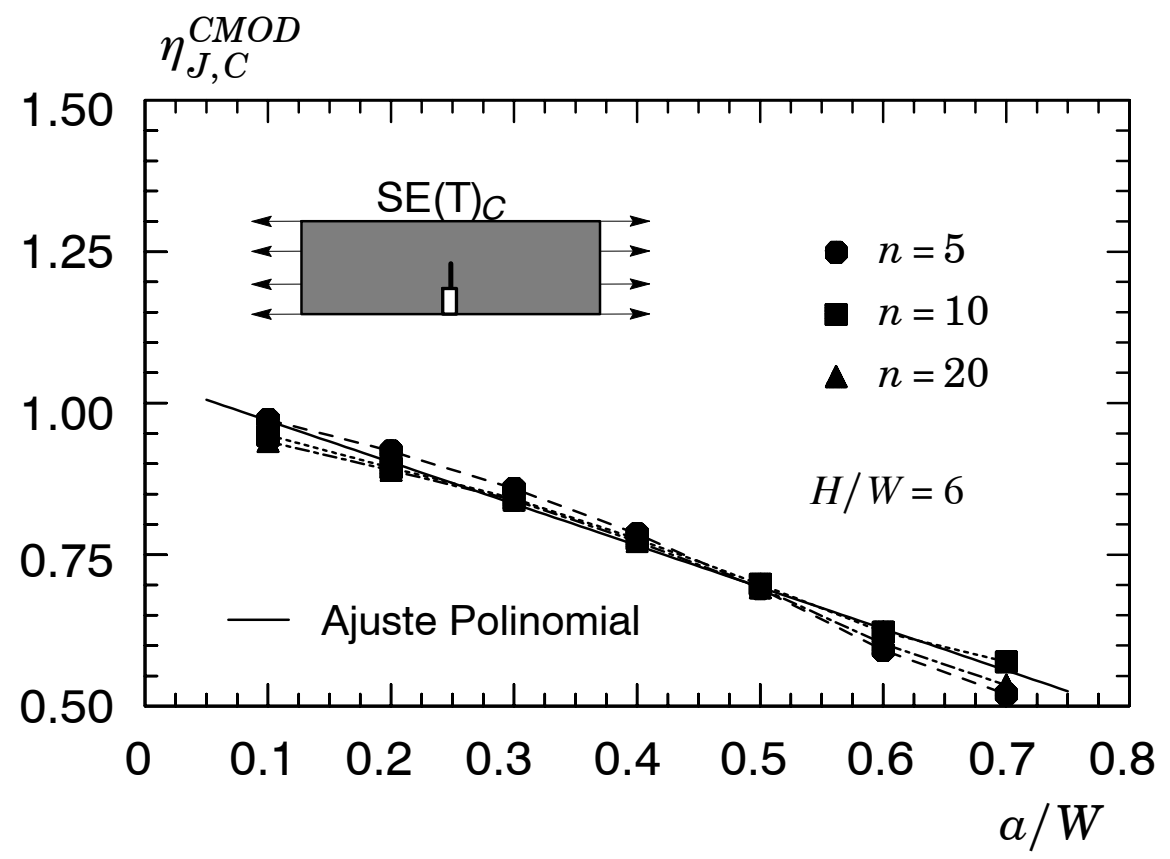

Figura 56 Variação dos fatores $\eta_{J}$ derivados de CMOD com a profundidade de trinca a / W para espécimes $S E(T)$ fixados por garras e relação $H / W=6$.

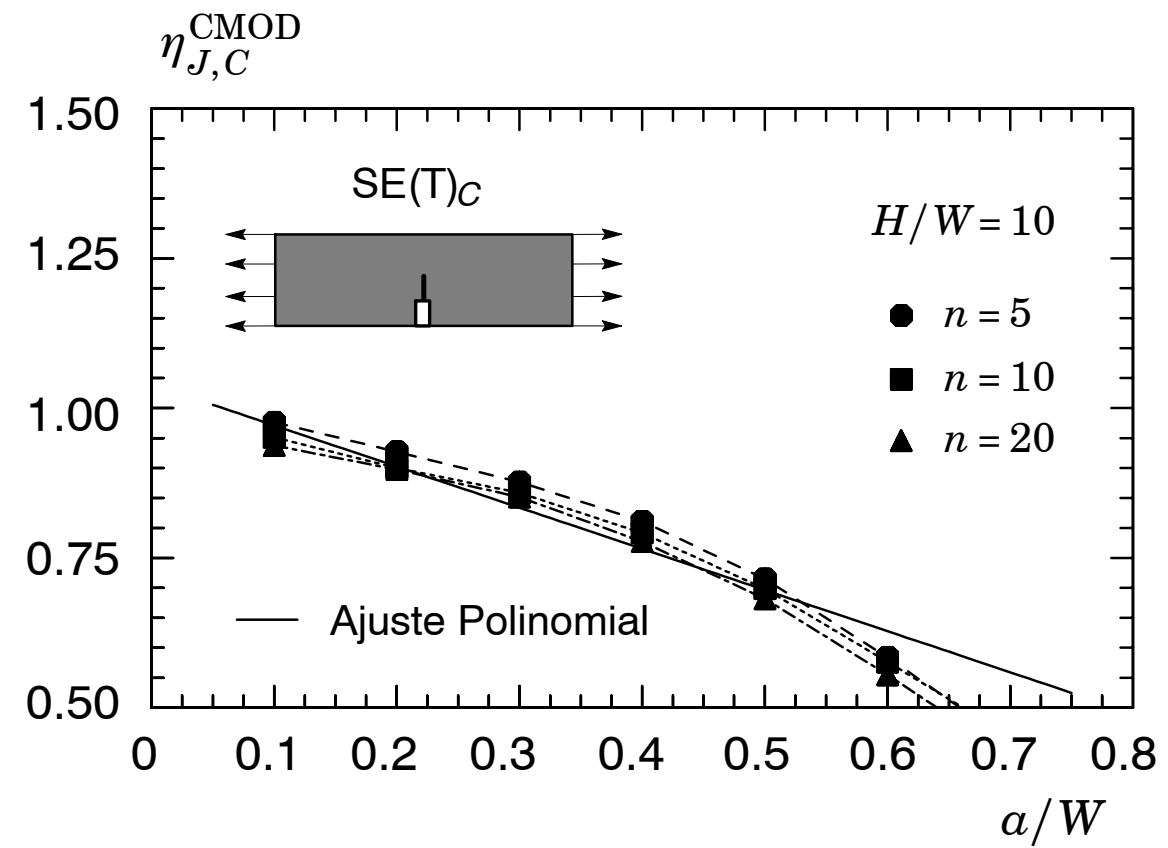

Figura 57 Variação dos fatores $\eta_{J}$ derivados de CMOD com a profundidade de trinca a / W para espécimes $S E(T)$ fixados por garras e relação $H / W=10$.

profundidade relativa de trinca. Adicionalmente, estes fatores acusam um efeito maior das propriedades do material para profundidades de trinca médias e rasas 
$(a / W \lesssim 0.4)$. Este último efeito é mais proeminente em espécimes com comprimentos relativos maiores $(H / W=6$ e 10). Devido à grande influência destas propriedades, foram obtidos polinômios de ajuste por mínimos quadrados para cada uma das propriedades de material e comprimentos relativos dos espécimes estudados. A seguir é apresentada a forma dos polinômios de ajuste para $\eta_{J}$ derivados do LLD.

$$
\eta_{J, P}^{\mathrm{LLD}}=A+B(a / W)+C(a / W)^{2}+D(a / W)^{3}
$$

A Tabela 5 apresenta os coeficientes destes polinômios para as diferentes condições consideradas.



Figura 58 Variação dos fatores $\eta_{J}$ derivados de LLD com a profundidade de trinca a / W para espécimes $S E(T)$ fixados por garras e relação $H / W=4$.

\subsection{Fatores $\gamma$}

Os fatores $\gamma$ são obtidos da aplicação do procedimento descrito na Seção 5.4 utilizando a Eq. (48) em conjunção com a Eq. (65). Esta derivação resulta em uma expressão para o fator $\gamma$ apresentada a seguir, 


$$
\begin{aligned}
\gamma_{C}=(A-1)+B(a / W)+C(a / W)^{2}+D(a / W)^{3}+ \\
\\
\frac{-B+(B-2 C)(a / W)+(2 C-3 D)(a / W)^{2}+3 D(a / W)^{3}}{A+B(a / W)+C(a / W)^{2}+D(a / W)^{3}}
\end{aligned}
$$

Onde os coeficientes A, B, C e D são dados na Tabela 5.

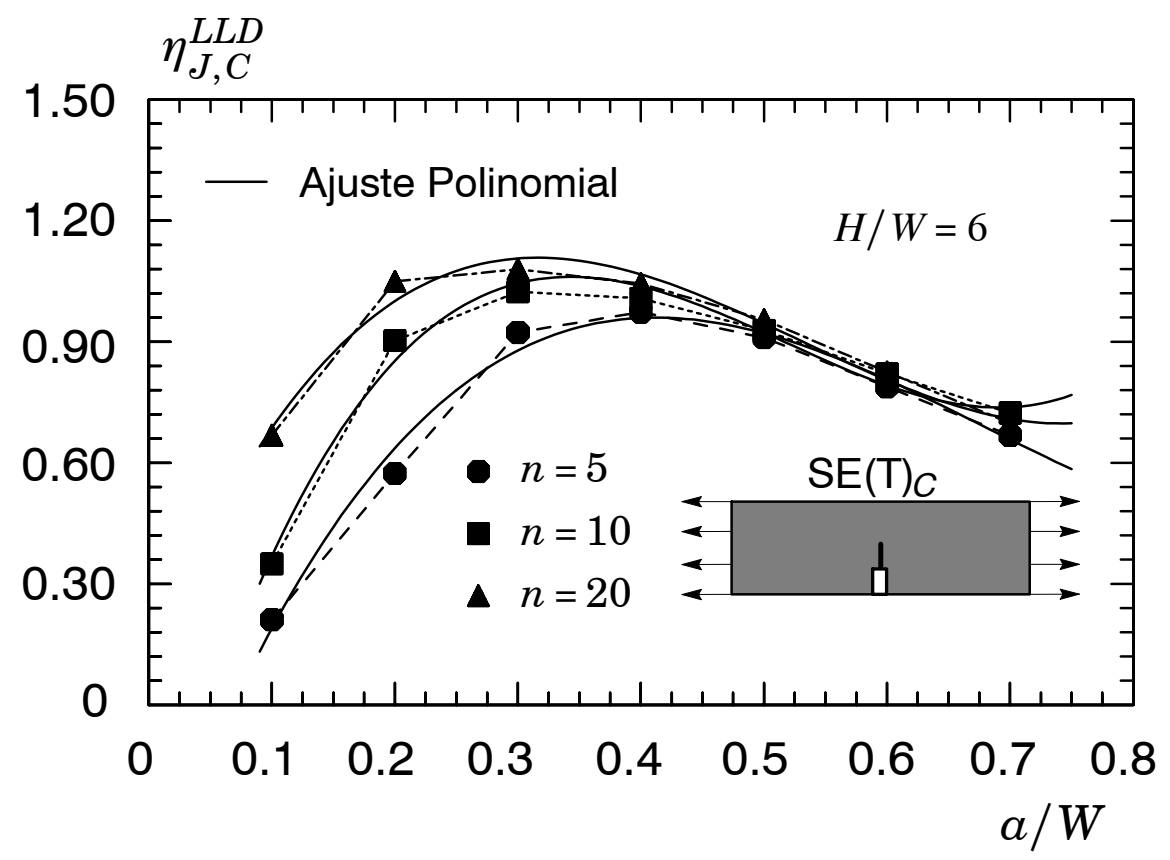

Figura 59 Variação dos fatores $\eta_{J}$ derivados de LLD com a profundidade de trinca a /W para espécimes $S E(T)$ fixados por garras e relação $H / W=6$.

É importante recordar que os fatores $\gamma$ dados pelos polinômios da Eq. (66) são aplicáveis na obtenção de curvas $R$ em ensaios experimentais tanto quando é empregada a curva $P$-LLD como, também, a curva P-CMOD (Como demonstrado no Capítulo 5). De forma ilustrativa, a Fig. 61 apresenta a variação do fator $\gamma$ com a profundidade de trinca e diferentes propriedades de material para espécime $\mathrm{SE}(\mathrm{T})$ fixados por garra e comprimento relativo $H / W=6$. 


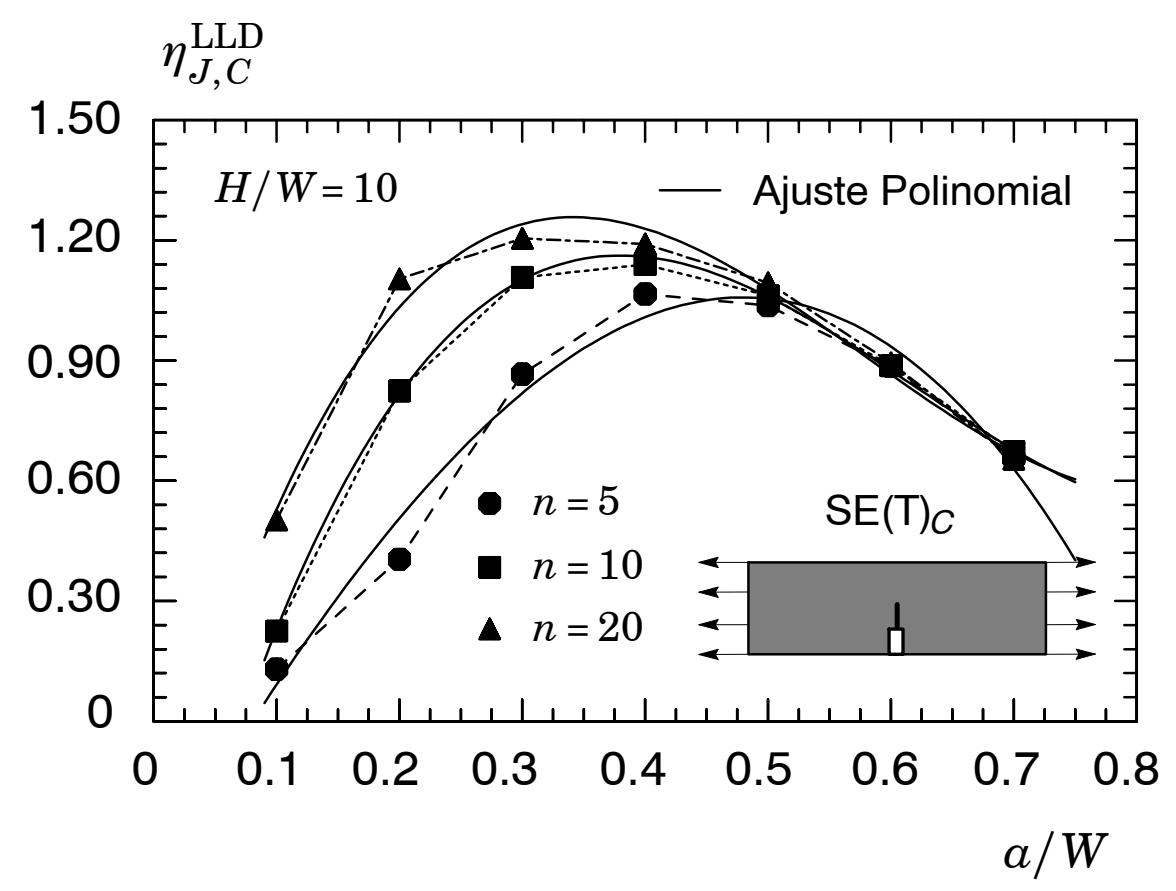

Figura 60 Variação dos fatores $\eta_{J}$ derivados de LLD com a profundidade de trinca a /W para espécimes $S E(T)$ fixados por garras e relação $H / W=10$.

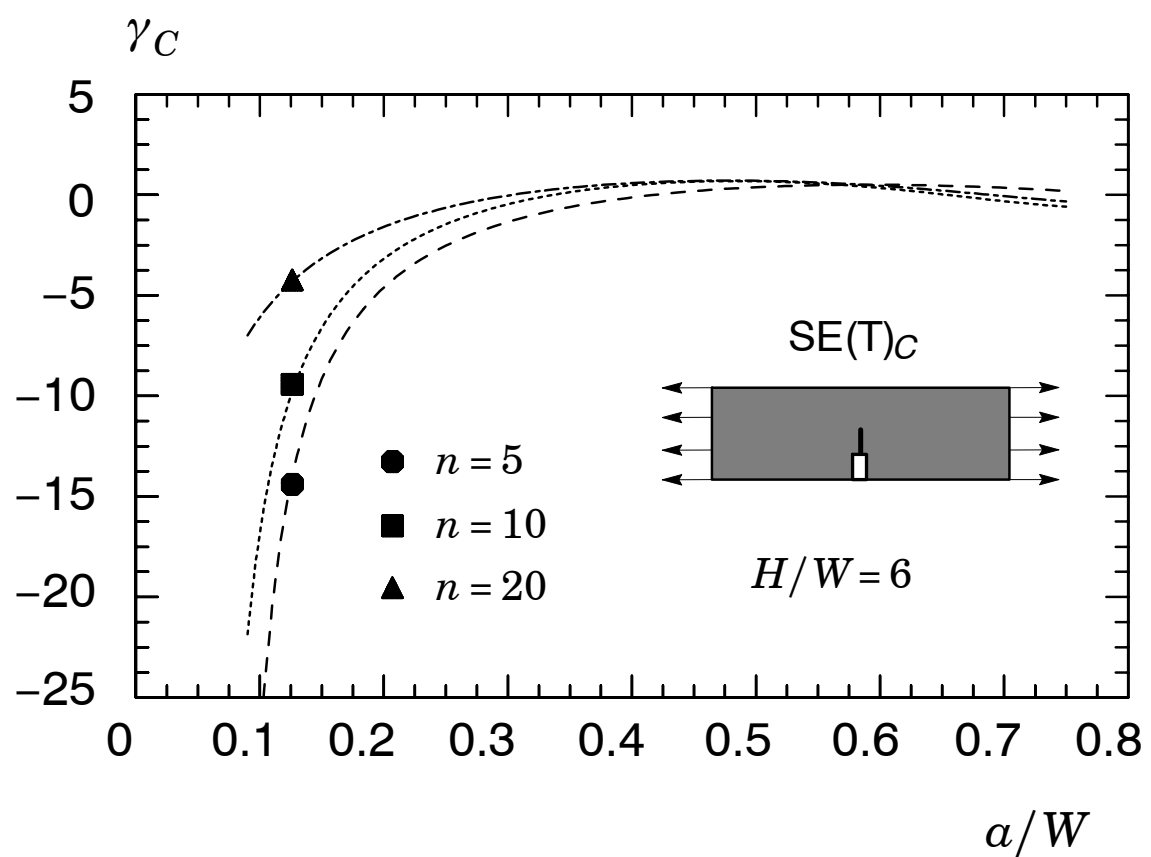

Figura 61 Variação do fator $\gamma$ com a relação a / W derivado do $L L D$ para espécime $S E(T)$ fixado por garras com $H / W=6$ e diferentes propriedade de material. 
Tabela 5 Coeficientes para os ajustes polinomiais das Eqs. (65) e (66).

\begin{tabular}{|c|c|c|c|c|c|}
\hline & & \multicolumn{4}{|c|}{ Coeficientes } \\
\hline \multicolumn{2}{|l|}{ Espécime } & $A$ & $B$ & $C$ & $D$ \\
\hline \multirow{3}{*}{$\mathrm{SE}(\mathrm{T})_{C}-H / W=4$} & $n=5$ & $-0,4367$ & 9,1560 & $-19,1170$ & 11,9920 \\
\hline & $n=10$ & $-0,2200$ & 9,2095 & $-21,4920$ & 14,9280 \\
\hline & $n=20$ & 0,4498 & 4,6561 & $-11,3840$ & 7,7806 \\
\hline \multirow{3}{*}{$\mathrm{SE}(\mathrm{T})_{C}-H / W=6$} & $n=5$ & $-0,5035$ & 8,3061 & $-14,4640$ & 7,0972 \\
\hline & $n=10$ & $-0,4986$ & 10,8960 & $-23,7680$ & 15,3220 \\
\hline & $n=20$ & 0,0998 & 7,4315 & $-16,7530$ & 10,5420 \\
\hline \multirow{3}{*}{$\mathrm{SE}(\mathrm{T})_{C}-H / W=10$} & $n=5$ & $-0,4038$ & 5,2907 & $-3,0060$ & $-3,4889$ \\
\hline & $n=10$ & $-0,7280$ & 11,6740 & $-22,1760$ & 11,9530 \\
\hline & $n=20$ & $-0,3519$ & 10,9460 & $-22,7310$ & 13,1140 \\
\hline
\end{tabular}




\section{COMPARAÇÃO DE RESULTADOS 2D E 3D}

Os fatores $\eta_{J}$ e $\gamma$ apresentados nos capítulos 7 e 8 foram derivados de modelos numéricos em estado plano de deformações. As análises produziram uma extensa matriz de resultados de $\eta_{J}$ e $\gamma$ derivados de CMOD e LLD para diferentes proporções geométricas e propriedades de material para espécimes $\mathrm{SE}(\mathrm{T})$. Entretanto, o caráter $3 D$ dos campos de tensões e deformações pode afetar a energia de deformação plástica do corpo-de-prova da qual o fator $\eta_{J}$ é determinado. Conseqüentemente, a aplicação direta dos fatores $\eta_{J}$ derivados das análises em estado plano de deformações em ensaios de curvas $R$ de espécimes $\mathrm{SE}(\mathrm{T})$ reais pode ser questionada e necessita de verificação adicional.

Para considerar os possíveis efeitos $3 D$ mencionados anteriormente, este capítulo apresenta fatores $\eta_{J}$ obtidos de análises $3 D$ de espécimes $\mathrm{SE}(\mathrm{T})$ carregados por pinos ou fixados por garras com $H / W=6$, diferentes comprimentos relativos de trinca $(a / W)$ e material com encruamento moderado, $n=10$ e $E / \sigma_{0}=500$. Os modelos de elementos finitos empregados nesta seção foram descritos no capítulo 4 . As Fig. 62-65 comparam os fatores $\eta_{J}$ plásticos derivados do CMOD e LLD empregando modelos em estado plano de deformações $(2 D)$ e $3 D$. Como pode ser observado nas figuras, apesar de algumas pequenas diferenças (que dependem da profundidade de trinca e da configuração do espécime), os valores $\eta_{J}$ derivados das análises $3 D$ são essencialmente análogos aos derivados das análises $2 D$. Esta comparação fornece um forte suporte ao emprego da extensa quantidade de resultados para fatores $\eta_{J}$ derivados das análises em estado plano de deformações apresentados anteriormente. 


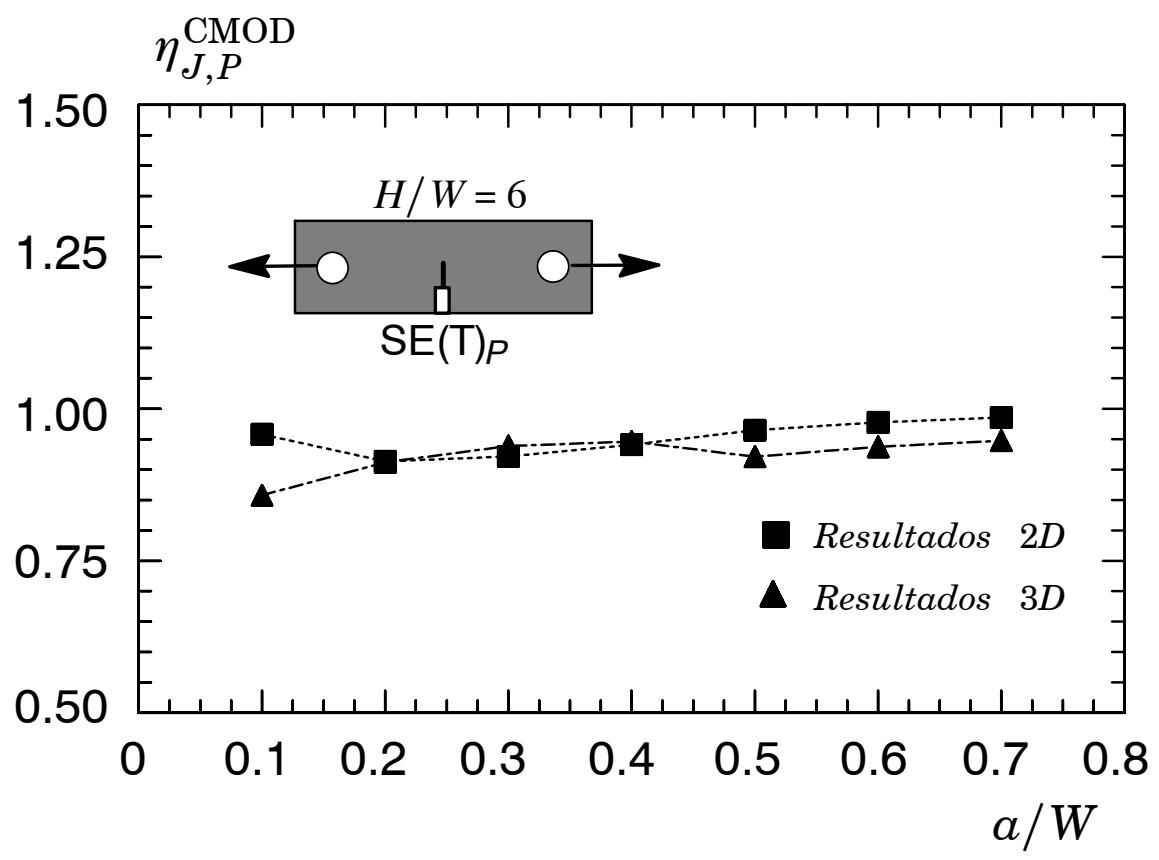

Figura 62 Comparação entre fatores $\eta_{J}$ derivados do CMOD para diferentes relações a / W obtidos de modelos em estado plano de deformações e modelos $3 D$ de corpos-de-prova $S E(T)$ carregados por pinos com $H / W=6$ e $n=10$.

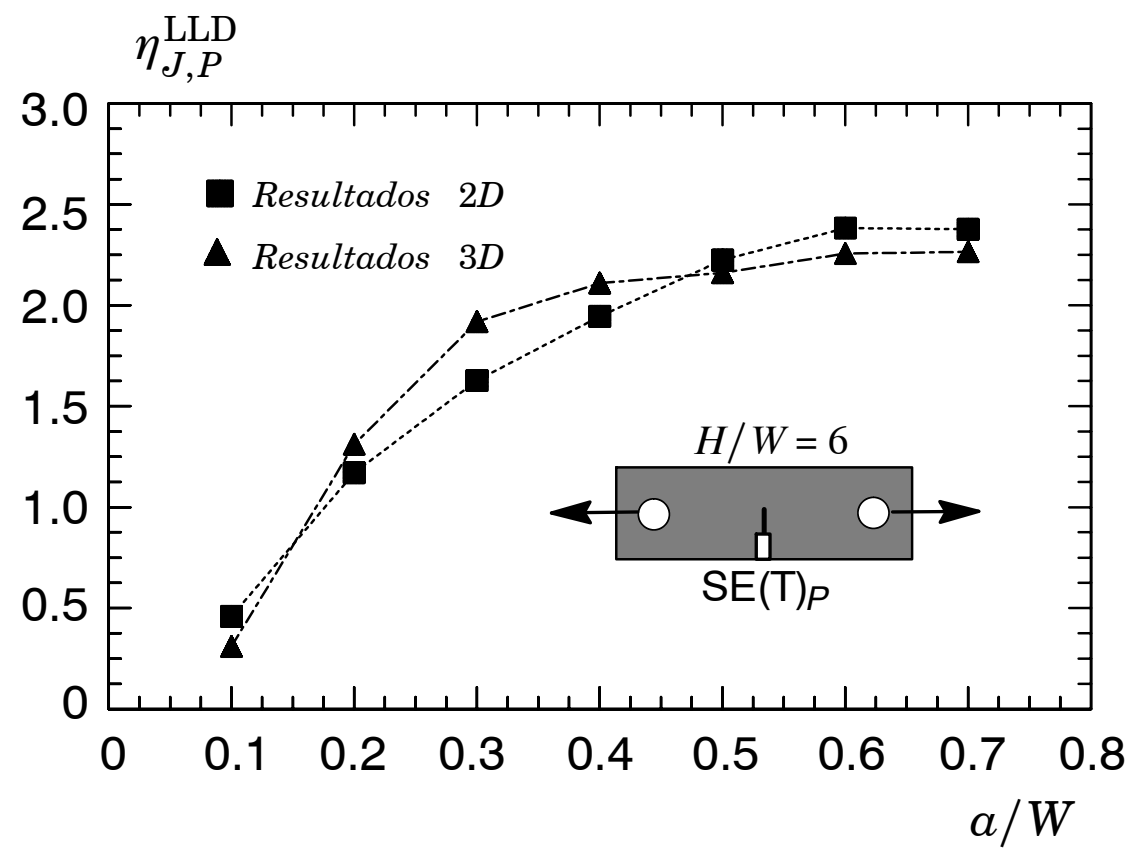

Figura 63 Comparação entre fatores $\eta_{J}$ derivados de LLD para diferentes relações a / W obtidos de modelos em estado plano de deformações e modelos $3 D$ de corposde-prova $S E(T)$ carregados por pinos com $H / W=6$ e $n=10$. 


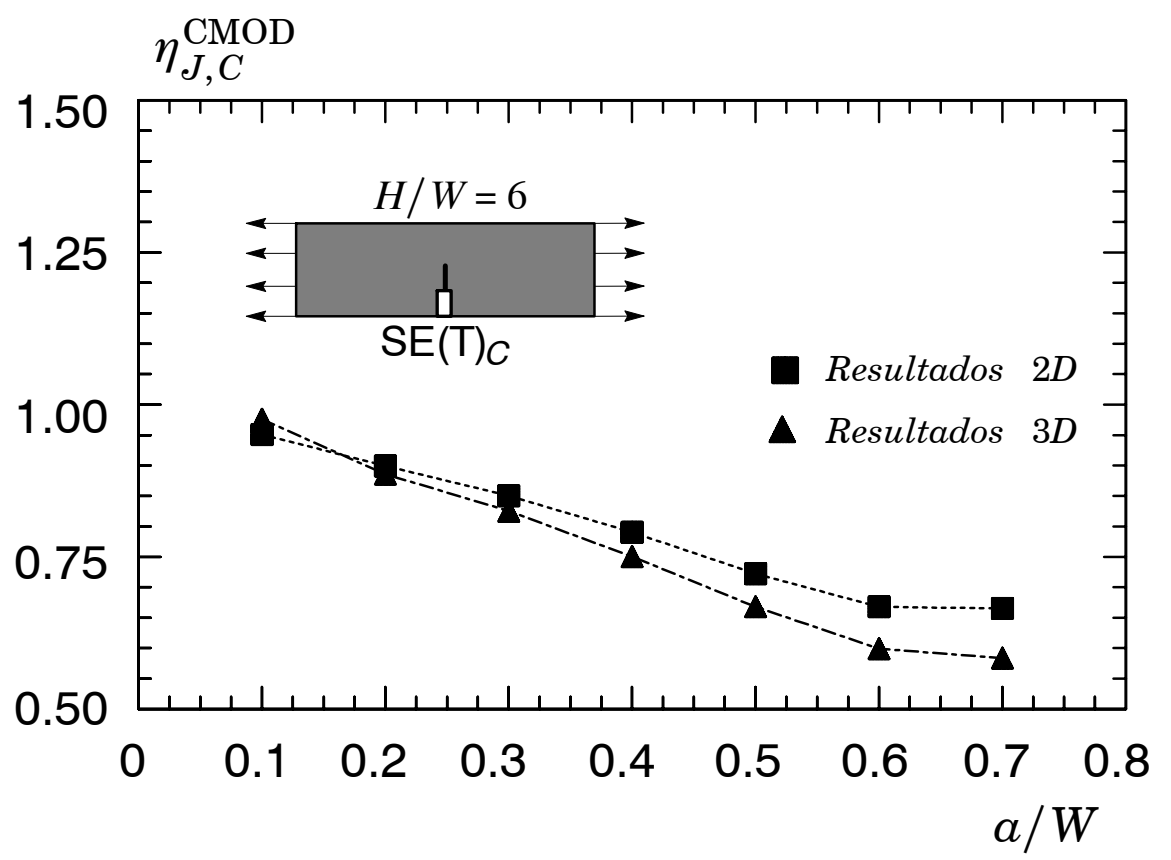

Figura 64 Comparação entre fatores $\eta_{J}$ derivados de CMOD para diferentes relações a / Wobtidos de modelos em estado plano de deformações e modelos $3 D$ de corpos-de-prova $S E(T)$ fixados por garras com $H / W=6$ e $n=10$.

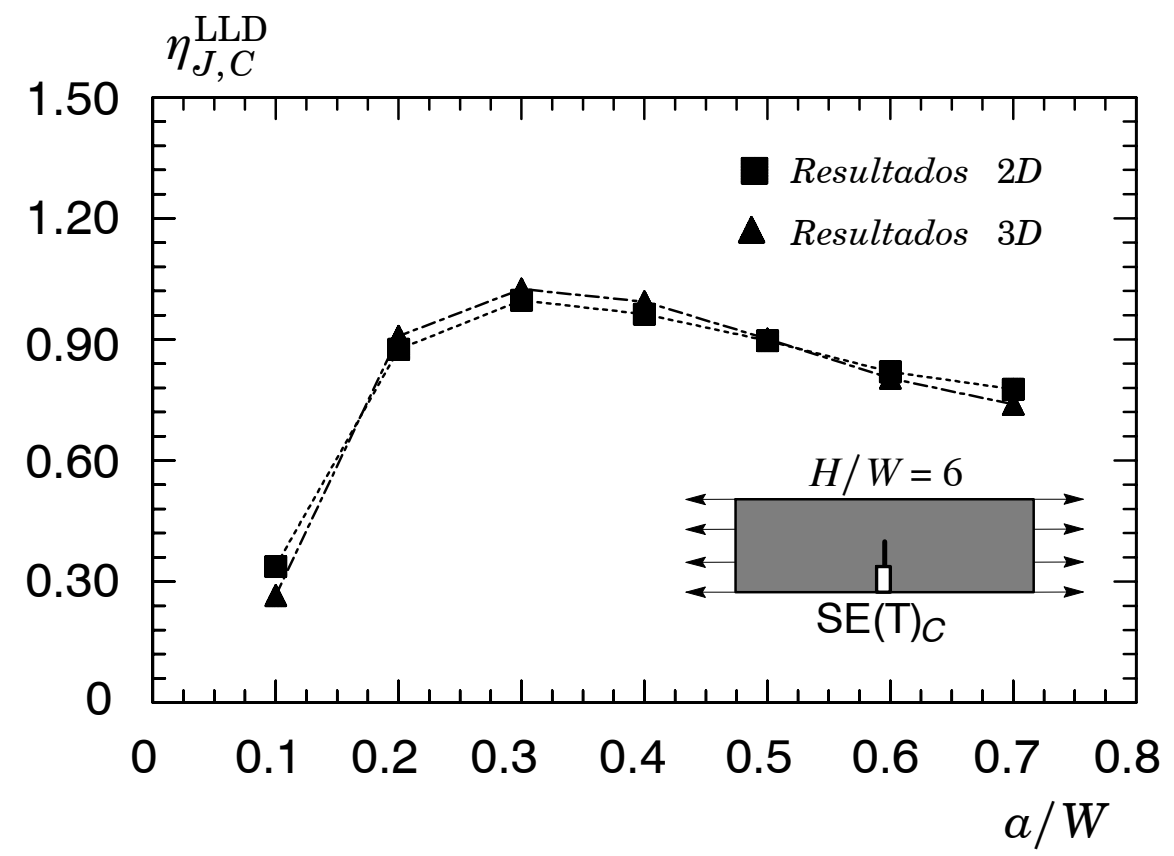

Figura 65 Comparação entre fatores $\eta_{J}$ derivados de LLD para diferentes relações a / W obtidos de modelos em estado plano de deformações e modelos $3 D$ de corposde-prova $S E(T)$ fixados por garras com $H / W=6$ e $n=10$. 


\section{CALIBRAÇÃO DOS MODELOS DE CÉLULAS COMPUTACIONAIS E MEDIÇÕES EXPERIMENTAIS}

\subsection{Calibração dos Parâmetros das Células Computacionais}

Nesta seção é descrito o procedimento para a calibração dos parâmetros das células computacionais para a previção da extensão dúctil de trinca em espécimes $\mathrm{SE}(\mathrm{T})$. No capítulo 4 foram descritos os modelos de espécimes $\mathrm{C}(\mathrm{T})$ e $\mathrm{SE}(\mathrm{T})$ incorporando células computacionais, este último com duas profundidades diferentes de trinca. Os parâmetros calibrados são obtidos a partir do modelo de corpo-de-prova compacto $(\mathrm{C}(\mathrm{T}))$ e subsequentemente os mesmos são empregados para a predição de curvas de resistência em espécimes SE(T). Em trabalho prévio, Dotta [83] apresenta a calibração deste modelo empregando os mesmos resultados experimentais; portanto, esta seção reproduz a sua calibração. Os parâmetros a serem determinados nos modelos de células computacionais são: dimensão da célula, $D$, porosidade inicial, $f_{0}$, porosidade crítica, $f_{E}$ e os fatores $q_{1}, q_{2}$ e $q_{3}=q_{1}^{2}$ (Veja seção 4.4 para maiores detalhes).

De todos os parâmetros mencionados, os dois primeiros ( $D$ e $\left.f_{0}\right)$ são os que realmente têm um papel ativo na calibração. Isto porque a porosidade crítica, $f_{E}$, não tem efeito apreciável sobre a resposta das células computacionais entre valores $f_{E}$ $=0,15$ e 0,25 (Veja capítulo 4 de Dotta [83]). Além disto, os fatores $q_{1}, q_{2}$ e $q_{3}$ podem ser obtidos de calibrações anteriores conduzidas por Faleskog e Shih [84] em função da tensão de escoamento e do expoente de encruamento do material. Por outro lado, a dimensão $D$ da célula computacional é representativa do espaçamento médio entre microcavidades da matriz metálica em estudo. Trabalhos prévios [85-90] estabeleceram valores entre 50 e $200 \mu \mathrm{m}$ desta dimensão para aços ferríticos. Estudos adicionais efetuados por Dotta [83] (pp. 87-91) mostraram que $D=200 \mu \mathrm{m}$ fornece resultados adequados tanto para as previsões de crescimento dúctil como na 
descrição dos campos de tensões e deformações. Desta forma, o parâmetro remanescente que determina a calibração do modelo de células computacionais é a porosidade relativa inicial, $f_{0}$. Embora neste trabalho foram testados diversos valores para $f_{0}$, o valor de porosidade relativa inicial que melhor reproduz os resultados experimentais é $f_{0}=0.020$ [83] . A Fig. 66 apresenta a calibração do parâmetro $f_{0}$ onde pode ser observado o valor que melhor adere aos resultados.

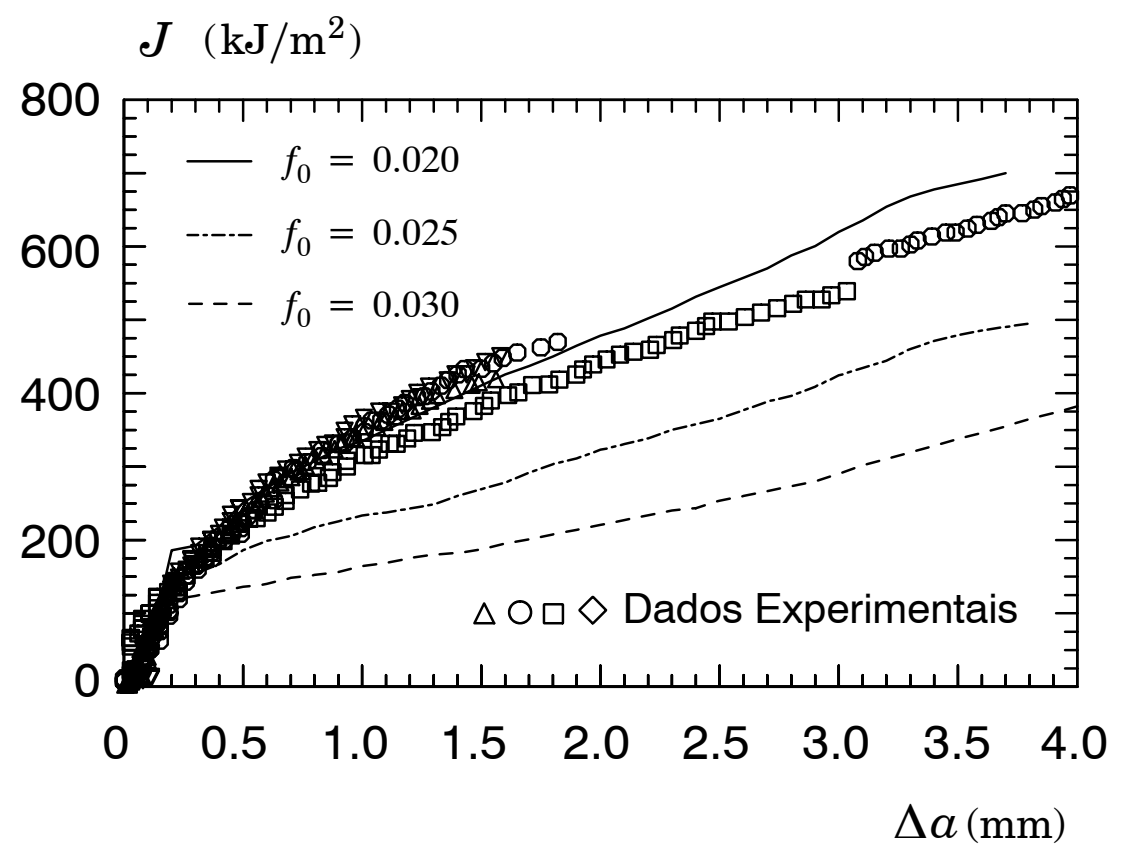

Figura 66 Comparação entre as curvas $R$ medidas experimentalmente em espécimes $C(T)$ e as obtidas numericamente com o modelo de células computacionais (aço API $5 L$ X60).

Uma vez determinados os parâmetros de calibração das células computacionas empregando o modelo de espécime C(T), os mesmos são empregados nos modelos de espécimes $\mathrm{SE}(\mathrm{T})$ com $a / W=0,2$ e 0,5. A Fig. 67 apresenta as curvas obtidas com estes modelos. Nesta figura, pode ser observado como o espécime com trinca curta $(a / W=0,2)$ apresenta uma curva de resistência com inclinação maior indicando uma maior resistência ao crescimento dúctil. Em seção seguinte estas predições de curvas de resistência são comparadas com as curvas $R$ obtidas experimentalmente. 




Figura 67 Comparação entre curvas $R$ obtidas dos modelos de células computacionais de espécimes $S E(T)$ com diferentes profundidades de trinca.

\subsection{Medição Experimental de Curvas de Resistência}

Esta seção descreve a aplicação dos resultados de fatores $\eta_{J}, \gamma$ e $r_{p}$ apresentados nos capítulos 7 e 8 para a determinação experimental de curvas de resistência à fratura de um aço comumente usado em dutos para transporte de óleo e gás. Bose e colaboradores [73] conduziram ensaios experimentais à temperatura ambiente usando o método de flexibilidade no descarregamento [74] em espécimes SE(T) carregados por pinos e com $20 \%$ de entalhe lateral (side groove). O material utilizado foi o aço API 5L X60 na orientação TL. Os espécimes têm espessura $B=12,5 \mathrm{~mm}$, largura de $W=32 \mathrm{~mm}$, distância entre pinos $H=214 \mathrm{~mm}$ e relações nominais de profundidade de trinca-largura, $a / W=0,2$ e 0,5. A Fig. 68 apresenta uma visão geral da máquina de ensaios MTS, detalhes da montagem de um dos corpos-de-prova com trinca profunda $\left(\bar{a}_{0} / W=0.5\right)$ e extensômetro (clip gage) montado. Adicionalmente, na Fig. 68-(c) é observado um dos espécimes no final do carregamento do ensaio de fratura dúctil [73].

Ensaios de tração usando espécimes padronizados forneceram os dados de tensão-deformação para o material testado [72]. A Tabela 6 apresenta os valores de 


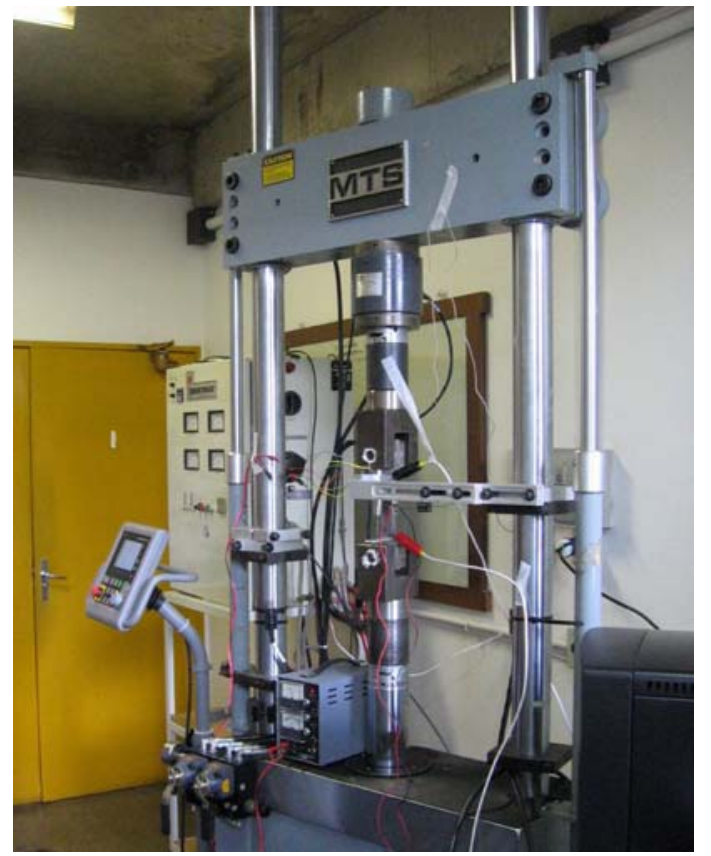

(a)

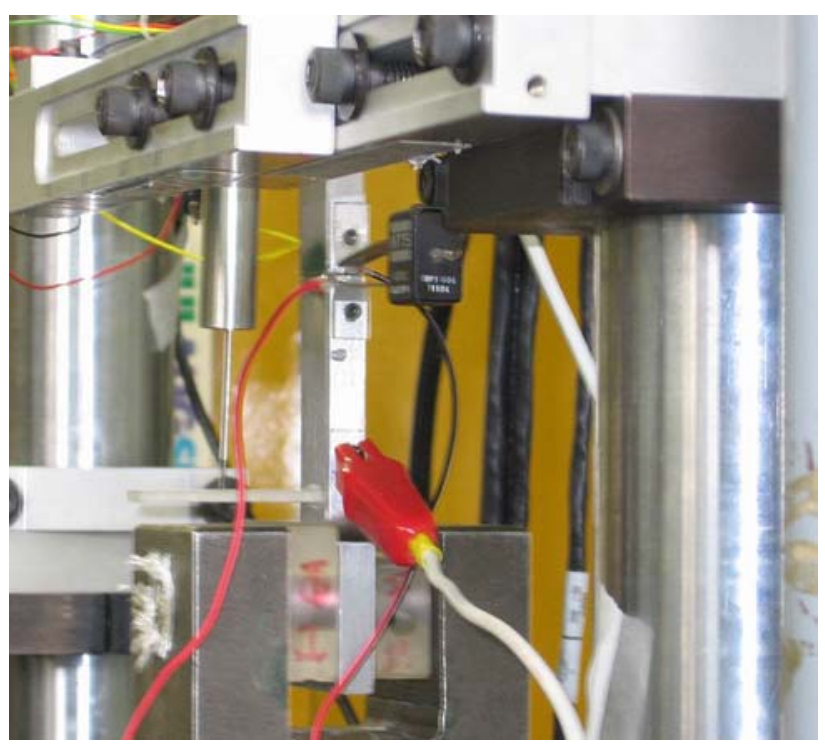

(b)

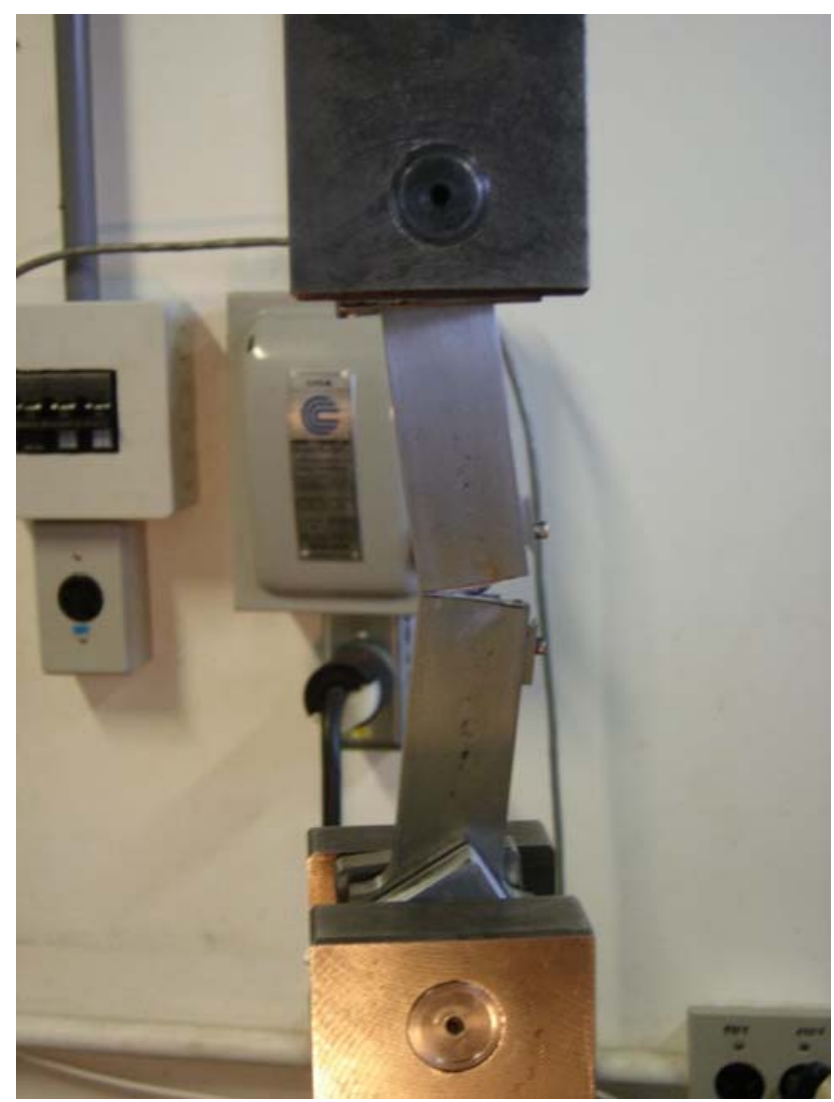

(c)

Figura 68 a) Máquina de ensaios MTS com o corpo-de-prova $S E(T)$ montado; b) Detalhe de montagem do corpo-de-prova com o extensômetro (clip gage); c) Corpode-prova com trinca profunda após o ensaio [73]. 
tensão de escoamento $\left(\sigma_{y s}\right)$, limite de resistência $\left(\sigma_{u}\right)$ e alongamento $\left(\varepsilon_{t}\right)$. Outras propriedades mecânicas deste material são módulo de elasticidade longitudinal $E=210 \mathrm{GPa}$ e coeficiente de Poison, $v=0,3$.

Tabela 6. Propriedades mecânicas do aço API $5 \mathrm{~L}$ X60 usado no ensaio experimental [72].

\begin{tabular}{cccc}
\hline$\sigma_{y s}(\mathrm{MPa})$ & $\sigma_{u}(\mathrm{MPa})$ & $\varepsilon_{t}(\%)$ & $\sigma_{u} / \sigma_{y s}$ \\
\hline 483 & 597 & 29 & 1.24 \\
\hline
\end{tabular}

Foram ensaiados 8 espécimes, 4 com entalhe profundo e 4 com entalhe raso. A Tabela 7 apresenta as principais características dos mesmos tais como comprimentos iniciais e finais de trincas medidos no microscópio após o ensaio. Outro dado importante é a forma de finalização do ensaio. Portanto, na coluna final da tabela, é especificado se o ensaio foi finalizado antes ou depois de apresentar instabilidade por rompimento abrupto. Este dado é adicionado porque, como será observado, o modo de finalização é importante na determinação do comprimento de trinca final. A Fig. 69 apresenta a curva carga vs. CMOD obtida experimentalmente para um dos espécime $\mathrm{SE}(\mathrm{T})$ ensaiados (CTP04) com relação profundidade de trinca-largura de espécime nominal $\bar{a}_{0} / W=0,5$ e a Fig. 70 apresenta os mesmos dados agora para um dos espécime $\mathrm{SE}(\mathrm{T})$ com trinca nominal $\bar{a}_{0} / W=0,2$ (CTR04). 


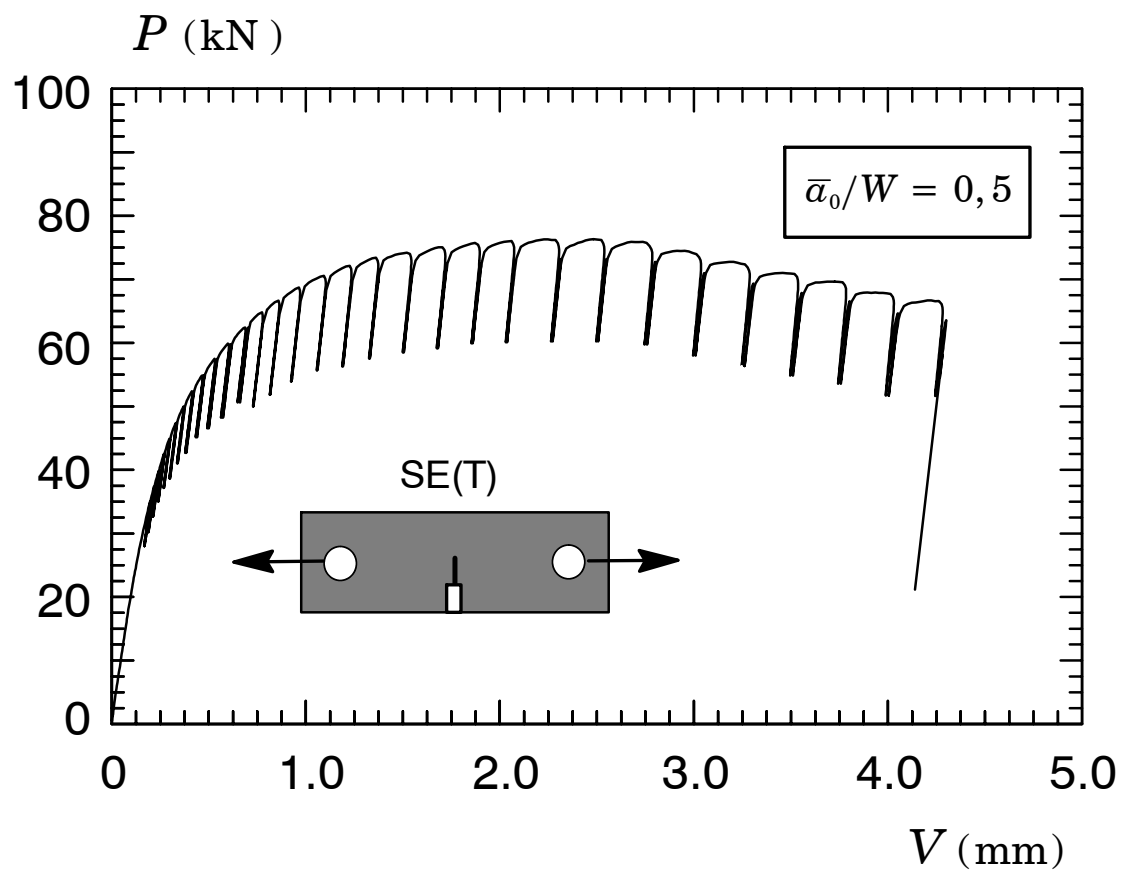

Figura 69 Curva carga vs. CMOD medida experimentalmente correspondente ao espécime CTP04 com relação nominal a $/ W=0,5$.

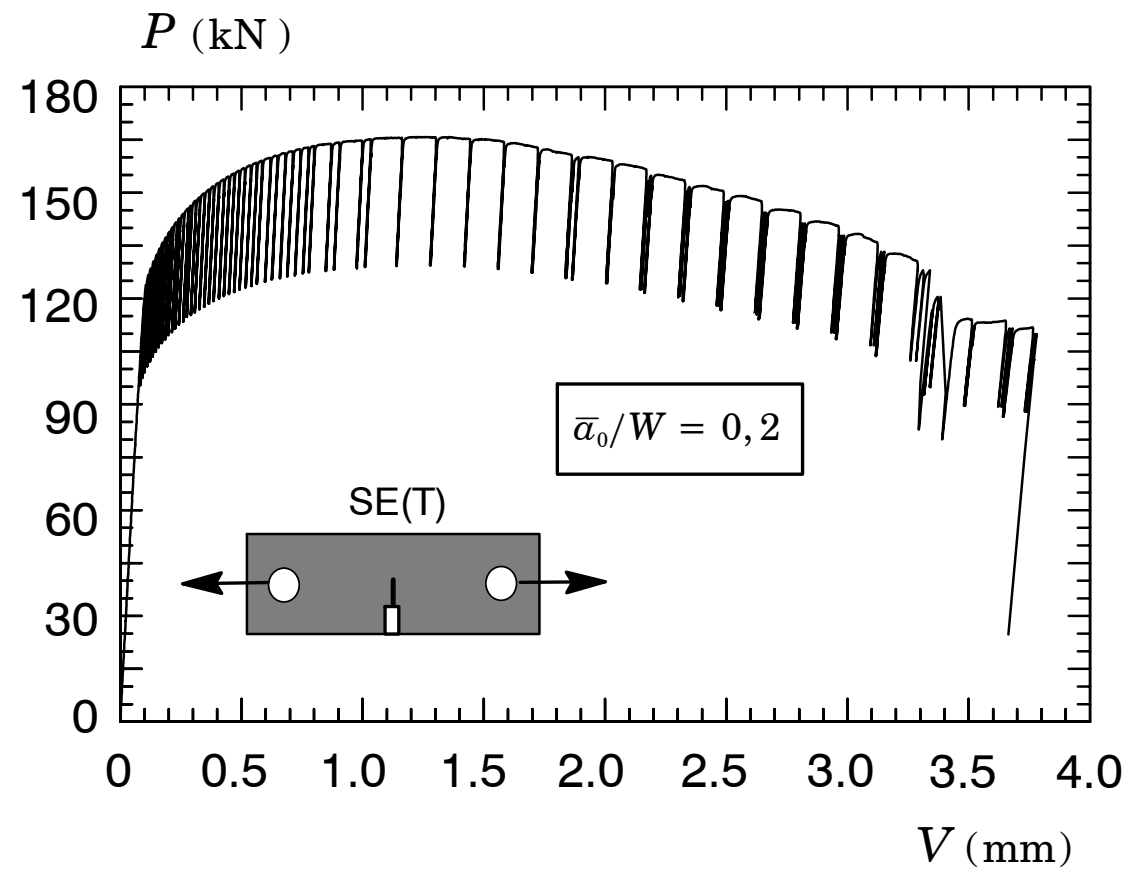

Figura 70 Curva carga vs. CMOD medida experimentalmente correspondente ao espécime CTR04 com relação nominal a / $W=0,2$. 
Tabela 7. Características dos corpos-de-prova ensaiados [73].

\begin{tabular}{ccccc}
\hline Identificação & $a / W$ nominal & $a_{0}[\mathrm{~mm}]$ & $a_{\mathrm{f}}[\mathrm{mm}]$ & Instabilidade \\
\hline CTP01 & 0,5 & 17,44 & 22,88 & $\operatorname{sim}$ \\
\hline CTP02 & 0,5 & 16,83 & 21,64 & não \\
\hline CTP03 & 0,5 & 16,60 & 22,89 & não \\
\hline CTP04 & 0,5 & 17,40 & 21,60 & não \\
\hline CTR01 & 0,2 & 7,24 & 12,44 & sim \\
\hline CTR02 & 0,2 & 6,97 & 17,78 & sim \\
\hline CTR03 & 0,2 & 7,07 & 13,57 & sim \\
\hline CTR04 & 0,2 & 6,97 & 15,38 & não \\
\hline
\end{tabular}

A avaliação da curva de resistência deriva da obtenção do valor de $J$ e $\Delta a$ para cada um dos descarregamentos parciais. Baseada nos resultados apresentados nos capítulos prévios, a analise faz uso dos fatores $\eta_{J, P}^{\mathrm{CMOD}}$ e $\gamma$ para estimar a porção plástica da integral $J$. Adicionalmente, foi aplicada a correção por rotação apresentada no capítulo 3 para corrigir os valores medidos de flexibilidade-CMOD $\left(\mathrm{C}_{m}^{\mathrm{CMOD}}\right)$. Esta correção é necessária para evitar erros na medição do comprimento de trinca e no cálculo das áreas plásticas causados pela rotação do espécime durante o ensaio. Como foi apresentado no capítulo 7, o raio plástico dos modelos $\mathrm{SE}(\mathrm{T})$ carregados por pinos é obtido dos modelos de elementos finitos para diferentes profundidades de trinca e propriedades de material. Para os espécimes com trinca profunda $(a / W>0,5)$, o raio plástico empregado foi de 0,57 e para os espécime com trinca rasa $(a / W>0,2)$ o raio plástico empregado foi de 0,9 . Como foi mencionado no capítulo 7 , o fator de rotação plástica de espécimes com trinca profunda é 
facilmente determinado porque atinge um valor estável após certo nível de carregamento e as propriedades de material não têm efeito sobre o mesmo. Porém, em espécimes com trincas médias e rasas $(a / W<0,4)$, o fator $r_{p}$ muda consideravelmente com as propriedades de material fazendo com que seja difícil a sua determinação. Outro problema presente na determinação do raio plástico, tanto para trincas profundas como rasas, é que o mesmo muda consideravelmente com a relação $a / W$ conforme a trinca avança. Desta forma, para determinar o raio plástico dos espécimes ensaiados foi adotado o procedimento descrito a seguir.

Após o ensaio experimental, são obtidos os comprimentos iniciais e finais de trinca. Com estes dados, pode ser calculado um comprimento de trinca médio dado pelo valor médio entre trinca inicial e final. A seguir, empregando o comprimento médio de trinca e os fatores de rotação plástica apresentados no capítulo 7, pode ser estabelecido um valor médio para o $r_{p}$. Entretanto, no caso de espécimes com trincas médias e rasas, as propriedades de material têm grande efeito sobre o fator de rotação plástica; desta forma, é adotada uma interpolação linear entre valores de $r_{p}$ para as diferentes propriedades de material. Por exemplo, o material ensaiado (X60) tem um expoente de encruamento $n=12,7$ e, dado que se têm os valores de $r_{p}$ para $n=10$ e $n=20$, por intermédio de uma interpolação linear é inferido o valor de $r_{p}$ para $n=12,7$. Este procedimento foi usado por ser simples de implementar e por fornecer valores razoáveis de raio plástico e, conseqüentemente, de curvas de resistência. Além deste procedimento, foi implementado também um método que computa os valores de $r_{p}$ para cada um dos descarregamentos parciais por meio de interpolações e iterações progamadas de forma automática. Entretanto, este procedimento é relativamente complexo e não fornece grandes vantagens em relação ao descrito anteriormente não sendo, portanto, utilizado.

As Figs. 71 e 72 apresentam as curvas de resistência obtidas para os espécimes com trinca funda e rasa, respectivamente. Além de certa dispersão nos resultados, as características essenciais do rasgamento dúctil em metais são capturadas pelo método apresentado. Nestas figuras, as curvas apresentam uma elevação crescente 
da resistência com o crescimento estável do comprimento de trinca. Também, comparando as duas figuras (Figs. 71 e 72), pode ser observada a elevação da resistência ao rasgamento dúctil para os espécimes com trinca curta $\left(\bar{a}_{0} / W=0,2\right) \mathrm{em}$ relação aos corpos-de-prova com trinca profunda. Estes espécimes $\left(\bar{a}_{0} / W=0,2\right)$ apresentam menor restrição plástica e, conseqüentemente, uma resistência aparente maior ao rasgamento dúctil caracterizado pela integral $J$. Este efeito pode ser observado mais claramente na Fig. 73 onde são apresentadas duas faixas representativas da dispersão das curvas obtidas dos espécimes com trinca profunda e rasa. É importante mencionar que, tanto nos espécimes com trinca profunda como com trinca curta, o fenômeno de delaminação apresentou-se de forma importante o que pode ter causado a dispersão nos resultados. Observando a Fig. 73, pode parecer que os corpos-de-prova com trinca profunda apresentaram menor dispersão se comparados aos espécimes com trinca curta. Entretanto, isto é aparente porque a dispersão relativa (calculada como a diferença percentual entre os valores máximos e mínimos de $J$ para um crescimento de trinca dado) é praticamente a mesma para ambas profundidades de defeito. Adicionalmente, os resultados de curvas $R$ estão de acordo com resultados prévios obtidos por Joyce e Link em um aço para vasos de pressão ASTM A533B. Retornando às Figs. 71 e 72, podem ser comparadas as curvas de resistência obtidas dos modelos de células computacionais na seção 10.1 com as curvas dos resultados experimentais. É evidente que a predição é bastante próxima aos resultados experimentais fornecendo, portanto, suporte e validação adicionais às medições experimentais.

Outro ponto a ser comentado é a precisão na medição dos comprimentos de trinca empregando o método de flexibilidade no descarregamento. Após o ensaio, os comprimentos iniciais e finais da trinca são medidos e comparados com os valores calculados pelas equações de flexibilidade (para ajustar o comprimento inicial medido com o comprimento calculado foi mudado o valor do módulo de elasticidade como recomendado pela ASTM E1820 [12]). Com este procedimento foram obtidos valores de trinca inicial com excelente precisão. Os comprimentos de trinca finais para os corpos-de-prova com $\bar{\alpha}_{0} / W=0,5$ são calculados com precisão adequada 


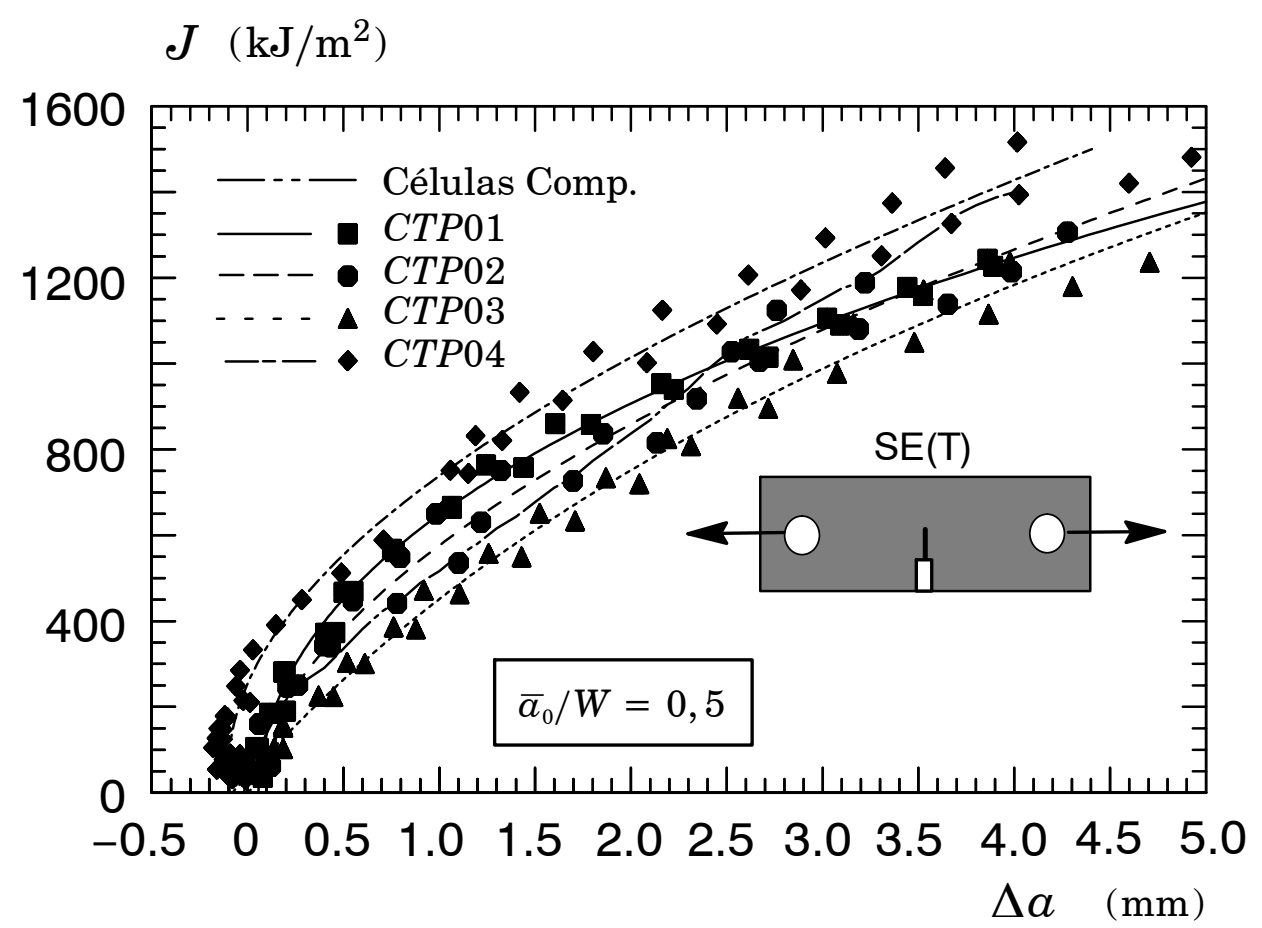

Figura 71 Curvas $R$ correspondentes aos espécimes com relação nominal a/W $=0,5$ obtidas usando os resultados apresentados nos capítulos precedentes.

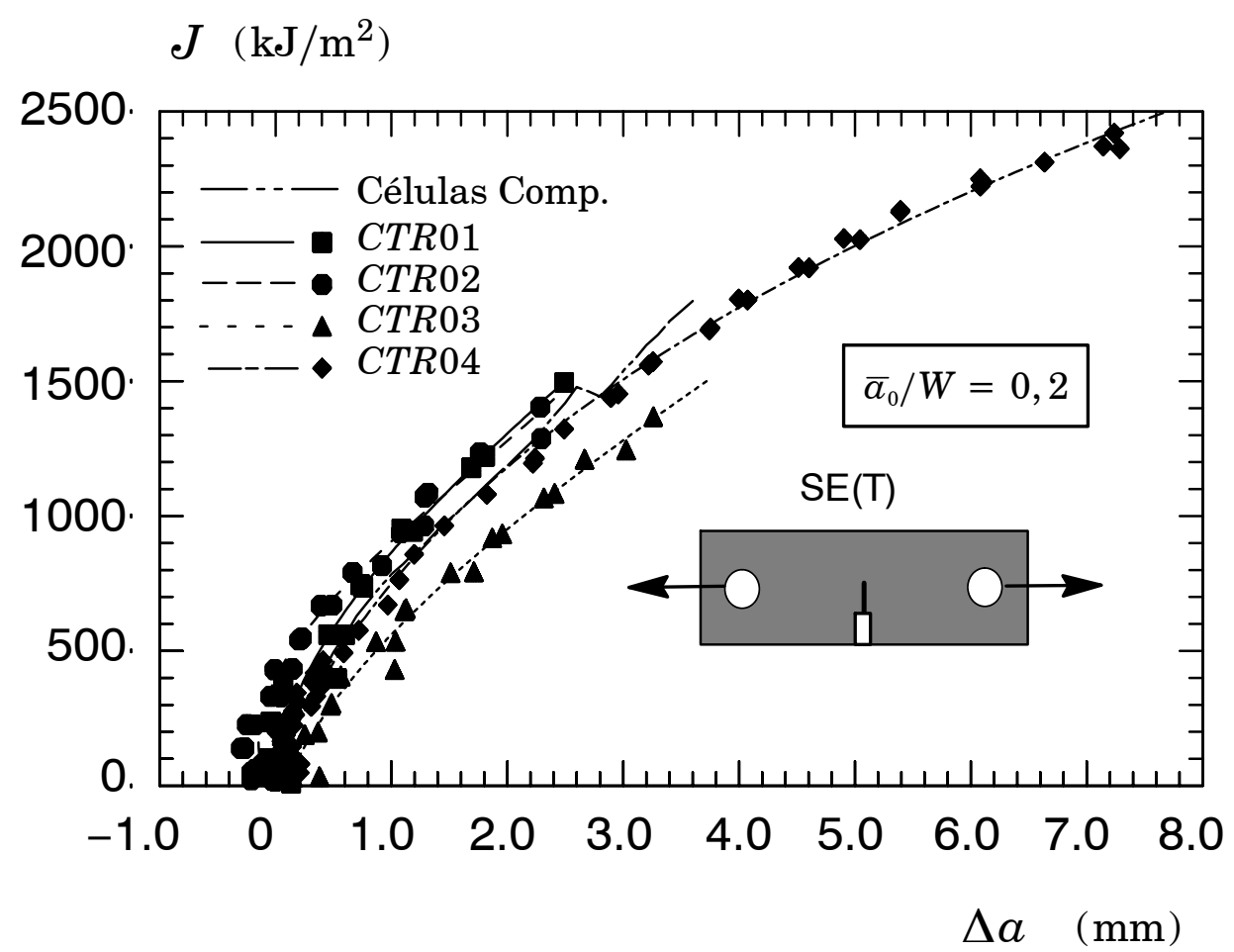

Figura 72 Curvas $R$ correspondentes aos espécimes com relação nominal a/ $W$ =0,2 obtidas usando os resultados apresentados nos capítulos precedentes. 


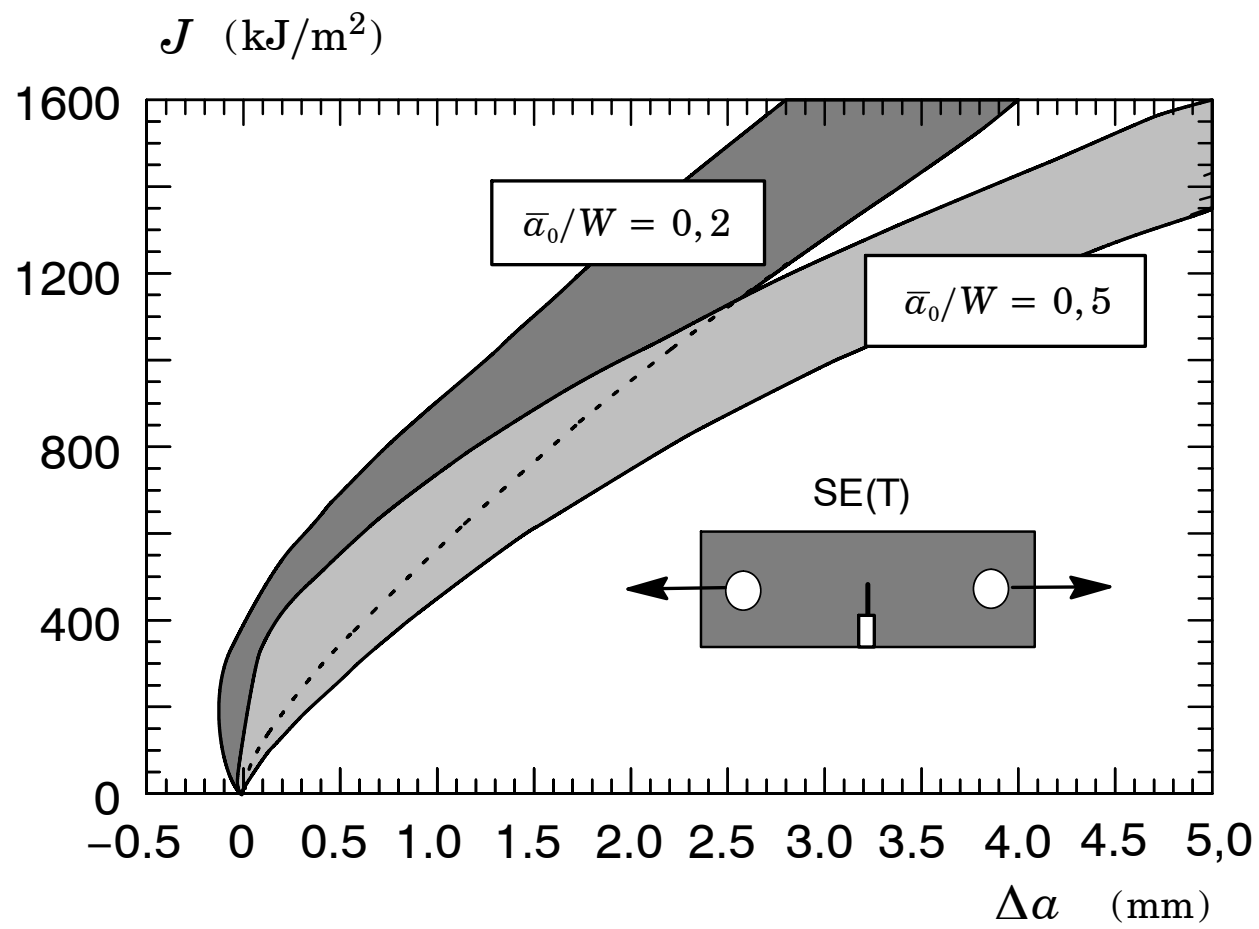

Figura 73 Comparação de faixas de resultados entre espécimes com relação nominal $a / W=0,2$ e 0,5 .

sendo que as diferenças entre valores calculados e medidos não ultrapassaram o 10\% mesmo para o espécime CTP01 que apresentou instabilidade na finalização do ensaio. No entanto, para os corpos-de-prova com entalhe raso, o único que apresentou precisão adequada na medição do comprimento de trinca final foi o CTR04 com um erro percentual de 8\%. É importante lembrar que este espécime foi o único com trinca rasa que não apresentou instabilidade na finalização do ensaio. Uma explicação para este resultado pode ser atribuida ao fato do último descarregamento não coincidir com o final do ensaio; neste caso, a trinca pode continuar a propagar e a flexibilidade medida pode não ser a flexibilidade correspondente ao comprimento final de trinca. 


\section{CONCLUSÕES E SUGESTÕES PARA A CONTINUAÇÃO DO TRABALHO}

\subsection{Comentários}

Esta tese discute a importância do desenvolvimento de procedimentos eficazes aplicados à avaliação acurada de integridade estrutural em dutos. Em particular, a análise realista de criticidade de defeitos representa uma importante ferramenta de engenharia em procedimentos para decisão de reparos e reabilitação de dutos com potencial impacto positivo sobre a segurança operacional e prevenção de acidentes ambientais. Dentro deste contexto, a avaliação das propriedades de tenacidade à fratura e propagação de defeitos utilizando corpos-de-prova mecanicamente similares assume grande relevância e significância.

\subsection{Conclusões}

Este trabalho apresenta extensivos esforços investigativos para o desenvolvimento de ensaios de corpos-de-prova especificamente concebidos para representar as condições de propagação de defeitos em dutos. Os resultados obtidos forneceram um procedimento para a medição de curvas de $J-\Delta a$ usando o método de flexibilidade no descarregamento em espécimes SE(T). A metodologia baseia-se na determinação instantânea da flexibilidade do espécime em cada um dos descarregamentos parciais durante a medição experimental da carga aplicada e a abertura da boca da trinca (CMOD) o que permite uma determinação acurada dos valores de tenacidade, $J$, e crescimento de trinca, $\Delta a$, conforme o carregamento aumenta. As análises numéricas fornecem soluções de equações de flexibilidade e fatores $\eta_{J}$ para uma grande faixa de proporções geométricas, propriedades de material e modos de carregamento em espécimes $\mathrm{SE}(\mathrm{T})$. 
A medição experimental da abertura da boca da trinca (CMOD) apresenta maior simplicidade na sua execução que a medição do deslocamento da linha de carga (LLD). Desta forma, a determinação experimental de integral $J$ baseada em dados $P$-CMOD apresenta grande potencialidade. Entretanto, como foi apresentado no Cap. 5, a definição do fator $\gamma$ não é necessariamente aplicável. Mesmo assim, neste trabalho demonstrou-se que, em espécimes $\mathrm{SE}(\mathrm{T})$, os fatores $\gamma$ derivados de LLD são igualmente aplicáveis à medição de integral $J$ com crescimento estável de trinca quando são empregados dados $P$-CMOD e fatores $\eta_{J}^{\mathrm{CMOD}}$ devido à relação constante encontrada entre o deslocamento da linha de carga e a abertura da boca da trinca.

Para validar os resultados numéricos, foram usadas medições experimentais para a determinação exploratória de curvas de resistência em espécimes SE(T) constituídos de aço API 5L X60 com trinca profunda $\left(\bar{a}_{0} / W=0,5\right)$ e rasa $\left(\bar{a}_{0} / W=0,2\right)$. As curvas $R$ demonstraram a capacidade das equações de flexibilidade e fatores $\eta_{J}$ e $\gamma$ obtidos numericamente para medir o crescimento dúctil de defeitos neste tipo de geometria. As curvas e formulações derivadas das análises numéricas apresentadas nos capítulos precedentes têm grande potencialidade para o estabelecimento de normas e padrões de ensaios de corpos-de-prova SE(T) como alternativa viável às normas ASTM em uso corrente. Evidentemente, há necessidade de estudos experimentais adicionais para validar completamente a metodologia.

\subsection{Sugestões para a Continuação do Trabalho}

A presente tese apresenta uma grande quantidade de soluções para equações de flexibilidade e fatores $\eta_{J}$ e $\gamma$ de espécimes $\mathrm{SE}(\mathrm{T})$. Entretanto, ênfase particular foi dada a corpos-de-prova SE(T) carregados por pinos sendo que não houve verificações experimentais para espécimes fixados por garra. Este último tipo de fixação têm sido grandemente usado na avaliação de defeitos circunferênciais em riser submarinos submetidos ao procedimento de enrolamento (reeling) durante a sua instalação [13, 14, 54]. Desta forma uma verificação experimental das equações de fléxibilidade pa- 
ra este tipo de carregamento é desejável. Também, é provável que sejam necessárias análises numéricas adicionais para a corroboração das equações de flexibilidade e de fatores $\eta_{J} \mathrm{e} \gamma$ para outras propriedades de material e proporções geométricas não estudadas.

Adicionalmente, uma vez que espécimes $\mathrm{SE}(\mathrm{T})$ podem ser empregados na construção Curvas de Avaliação de Falhas (FAD da sigla em inglês), uma contribuição importante ao desenvolvimento desta geometria seria o estabelecimento de equações para determinar a carga limite. Desta forma, seria possível determinar valores de $L_{R \max }[5,6]$ que sejam mais adequados à avaliação de defeitos em dutos.

As sugestões para próximos trabalhos são resumidas a seguir:

- Validação experimental adicional das equações de flexibilidade e de fatores $\eta_{J}$ e $\gamma$.

- Ampliação do estudo para outras proporções geométricas e condições de carregamento. Por exemplo, corpos-de-provas $\mathrm{SE}(\mathrm{T})$ fixados por garras têm sido bastante usados para a avaliação de trincas circunferênciais em risers.

- Cálculo de carga limite de espécimes SE(T) com diferentes configurações, propriedades de material e proporções geométricas.

- Cálculo de equações de flexibilidade e fatores $\eta_{J}$ e $\gamma$ para espécimes $\mathrm{SE}(\mathrm{T})$ com juntas soldadas. 


\section{REFERÊNCIAS}

1. Ministério de Minas e Energia (MME), Disponível em:

<http://www.mme.gov.br/>, Acesso em Novembro de 2006.

2. GASNET - O site do Gás Natural: Entre Projetos realistas e Planos Futuristas, Disponível em: <http://www.gasnet.com.br/artigos/artigos_view2.asp?cod=888>, Acesso em Fevereiro de 2006.

3. Leis B. N. , Eiber R. J., Fracture propagation control in onshore Transmission Pipelines, In: Onshore Pipeline Techonology Conference - Invited paper, p.2.1 - 2.35, 1998, Anais.

4. Kiefner J. F., Maxey W. A., Elber R. J., e Duffy A., R., Failure Stress Levels of Flaws in Pressurized Cylinders, ASTM STP 536 Progress in Flaw Growth and Fracture Toughness Testing, American Society for Testing and Materials, pp. 416-481, 1973.

5. American Petroleum Institute., Recommended Practice for Fitness-forService, API RP-579, 2000.

6. British Standard Institution., Guide on Methods for Assessing the Acceptability of Flaws in Metallic Structures, BS7910, 1999.

7. Rice, J. R., A Path Independent Integral and the Aproximate Analysis of Strain Consentration by Notches and Cracks, Journal of Applied Mechanics, Vol. 35, 1968, pp. 379-386.

8. Joyce, J. A., and Link R. E., Effects of Constraint on Upper Shelf Fracture Toughness, ASTM STP 1256 - Fracture Mechanics, 26th Volume, W. G. Reuter, et al. Eds., American Society for Testing and Materials, Philadelphia, pp. 142-177, 1995.

9. Eiber, R. J. and Kiefner, J. F., Failure of Pipelines, Metals Handbook, $19^{\text {th }}$ Edition, Vol. 11 - Failure Analysis and Prevention, American Society for Metals, pp. 695-706, 1986.

10. American Welding Society, Welding Handbook: Welding Technology, $8^{\text {th }}$ Edition, Vol. 1, Miami, 1987.

11. National Energy Boarding, Stress Corrosion Cracking on Canadian Oil and Gas Pipelines, Report MH-2-95, Calgary, 1996.

12. American Society for Testing and Materials (ASTM), Standard Test Method for Measurement of Fracture Toughness, ASTM E 1820-02, Philadelphia, 2001.

13. Nyhus, B., Oseberg Gas Transportation - OGT Repair Welding, SINTEF Report,STF24 F99277, Norwegian University of Technology (NTNU), 1999. 
14. Nyhus, B. and Ostby, E., SENT Testing of High Strength Steel, In: $2^{\text {nd }}$ International Symposium on High Strength Steel, Verdal, Norway, 2002, Anais.

15. Cravero, S. and Ruggieri, C., Correlation of Fracture Behavior in High Pressure Pipelines with Axial Flaws Using Constraint Designed Test Specimens - Part I: Plane-Strain Analyses, Engineering Fracture Mechanics, Vol. 72, pp. 1344-1360, 2005.

16. Silva L. A. L., Cravero S., e Ruggieri C., Correlation of Fracture Behavior in High Pressure Pipelines with Axial Flaws using Constraint Designed Test Specimens - Part II: 3D Effects on constraint, Engineering Fracture Mechanics, Vol. 73, pp. 2123-2138, 2006.

17. O'Dowd, N.P., and Shih, C.F., Family of Crack-Tip Fields Characterized by a Triaxiality Parameter: Part I -Structure of Fields, Journal of the Mechanics and Physics of Solids, Vol. 39., No. 8, pp. 989-1015, 1991.

18. O'Dowd, N.P., and Shih, C.F., Family of Crack-Tip Fields Characterized by a Triaxiality Parameter: Part II - Fracture Applications, Journal of the Mechanics and Physics of Solids, Vol. 40, pp. 939-963, 1992.

19. Cravero, S., Metodologia Biparamétrica para Análise de Efeitos de Restrição sobre a Fratura de Componentes Estruturais e Aplicações à Avaliação de Defeitos em Dutos., Dissertação de Mestrado, Escola Politécnica da Universidade de São Paulo, 2004.

20. Ruggieri, C., Bose, W. e Spinelli, D., Metodologia Micromecânica e Experimental para Análise de Defeitos e Avaliação de Integridade Estrutural em Dutos para Transporte de Gás e Petróleo, Projeto de Pesquisa FAPESP, Fundação de Amparao à Pesquisa do Estado de São Paulo, 2003

21. Wells, A. A., Unstable Crack Propagation in Metals: Cleavage and fast fracture, Proceedings of the Crack Propagation Symposium, Vol 1, Paper 84, Cranfield, UK, 1961.

22. Rice, J. R. and Rosengren, G. F., Plane Strain Deformation Near a Crack Tip in a Power-Law Hardening Material, Journal of the Mechanics and Physics of Solids, Vol. 16, pp. 1-12, 1968.

23. Hutchinson, J. W., Singular Behavior at the end of a tensile Crack Tip in a Hardening Material, Journal of the Mechanics and Physics of Solids, Vol. 16, pp. 13-31, 1968.

24. Hutchinson, J.W., Fundamentals of the Phenomenological Theory of Nonlinear Fracture Mechanics, Journal of Applied Mechanics, Vol. 50, pp. 1042-1051, 1983.

25. Inglis, C. E., Stresses in a Plate due to a Presence of Cracks and Sharp Corners, Transactions of the Institute of Naval Architects, Vol. 55, 1913, pp. 219-241. 
26. Westergaard, H. M., Bearing Pressures and Cracks, Journal of Applied Mechanics, Vol. 6, 1939, pp. 49-53.

27. Sneddon, I. N., The Distribution of Stress in the Neighbourhood of a Crack in an Elastic Solid, Prossedings, Royal Society of London, Vol. A-187, pp. 229-260, 1946.

28. Williams, M. L., On the Stress Distribution at the Base of a Stationary Crack, Journal of Applied Mechanics, Vol. 24, pp. 109-114, 1957.

29. Irwing, G. R., Analysis of Stresses and Strains near the End of a Crack Traversing a Plate, Journal of Applied Mechanics, Vol. 24, pp. 361-364, 1957.

30. Gomes, P. T., Cruz, J. R. B., Rabelo, E. G., Neto, M. M., Normalizing treatment influence on the forged steel $S A E 8620$ fracture properties. Mat. Res. [online]. 2005, Vol. 8, no. 1, pp. 57-63. Disponível em: <http://www.scielo.br/scielo.php?script=sci_arttext\&pid=S1516-14392005000100011\&lng= en\&nrm=iso>. ISSN 1516-1439. doi: 10.1590/S1516-14392005000100011.

31. Hippert, E. Jr., Investigação Experimental do Comportamento Dúctil de Aços API-X70 e Aplicação de Curvas de Resistência J-Aa para Previsão de Colapso em Dutos., Tese de Doutorado, EPUSP, Universidade de São Paulo, 2004.

32. Anderson, T. L., Fracture Mechanics: Fundaments and Applications 2nd Edition, CRC Press, Boca Raton, 1995.

33. Griffith A. A., The Phenomena of Rupture and Flow in Solids, Philosophical Transactions, Series A, Vol. 221, pp. 163-198, 1920.

34. Kanninen, M., F., e Popelar., C., H., Advanced Fracture Mechanics., Oxford University Press, New York, 1985.

35. Cherepanov, G. P., Crack Propagation in Continuous Media, Applied Mathematics and Mechanics, (trans.P.M.M.), Vol. 31, pp. 476-488, 1967.

36. Shih, C. F., M. D. German, Requirements for a One Parameter Characterization of Crack Tip Fields by the HRR Singularity, International Journal of Fracture, Vol.17, pp. 27-43, 1981.

37. Rice, J. R. , Mechanics of Crack Tip Deformation and Extension by Fatigue, Fatigue Crack Propagation, ASTM STP 415, American Society for Testing and Materials, pp. 247-309, 1967.

38. Tipper, C. F., The Fracture of Metals, Metallurgia, Vol. 39, pp. 133-137, 1949.

39. Puttick, K. E., "Ductile Fracture in Metals", Philosophical Magazine, Vol. 4, pp. 964-969, 1959.

40. Crussard C., Plateau J., Tamhanbar R., Henry G. Lajeunesse D., Fracture, Techology Press of MIT and John Wiley, New York, pp. 524, 1959.

41. Rogers H. C., Trans AIME, Vol. 218, pp. 498, 1960.

42. Garrison, W. M. Jr., Moody, N.R., Ductile Fracture, Journal of the Physics and Chemistry of Solids. v. 48, pp. 1035-1074, 1987. 
43. Isacsson M., Narström T., Microscopic examination of crack growth in a pressure vessel steel, Materials Science and Engineering A, Vol. 241, pp. 189-178, 1998.

44. Paris P. C., Tada H., Zahoor A. e Ernst, H. The theory of Instability of the Tearing Mode of Elastic-Plastic Crack Growth, ASTM STP 668 Elastic-Plastic Fracture, American Society for Testing and Materials, pp. 5-36, 1979.

45. J. A., Begley and J. D., Landes, The J integral as a Fracture Criterion, ASTM STP514, American Society for Testing and Materials, pp. 1-20, 1972.

46. J. D., Landes and J. A., Begley, The Effect of Specimen Geometry on $J_{I c}$, ASTM STP514, American Society for Testing and Material, pp. 24-39, 1972.

47. G. A. Clarke, W. R. Andrews, P. C. Paris and D.W. Schmidt, Single Specimen Tests for $J_{I c}$ Determination, ASTM STP 590 Mechanics of Crack Growth, American Society for Testing and Materials, pp. 27-42, 1976.

48. Joyce, J. A., and Gudas J. P., 1979, Computer interactive $J_{I c}$ Testing of Navy Alloys, ASTM STP 668 Elastic-Plastic Fracture, American Society for Testing and Materials, PA, pp. 451-468.

49. Sumpter, J. D. G. and Turner, C. E., Method for Laboratory Determination of $J_{c}$, ASTM STP 601 Cracks and Fracture, American Society for Testing and Materials, pp 3-18, 1976.

50. Paris P. C., Ernst, H. e Turner, C. E., A J-integral Approach to Development of $\eta$ Factors, ASTM STP 700, American Society for Testing and Materials, pp. 338-351, 1980.

51. Ernst, H., Paris P. C. e Landes, J. D., Estimation on J-integral and Tearing Modulus T from a Single Specimen Test Record, Fracture Mechanics 13th Conference, ASTM STP 743, American Society for Testing and Materials, pp. 476-502, 1981.

52. Chiodo, M. S., Cravero, S. and Ruggieri, C., Stress Intensity Factors for SE(T) Specimens, Reporte Técnico BT-PNV-68, Escola Politécnica da Universidade de São Paulo, 2006.

53. Joyce, J. A., Hackett, E. M. and Roe, C., Effects of Crack Depth and Mode Loading on the $J-R$ Curve Behavior of a High Strength Steel, ASTM STP 1171

Constraint Effects in Fracture, E. M. Hackett, et al. Eds., American Society for Testing and Materials, Philadelphia, pp. 239-263, 1993.

54. Det Norske Veritas, Fracture Control for Pipeline Instalation Methods Introducing Cyclic Plastic Strain, Recomended Practice, DNV-RP-F108, 2006.

55. J. D., Landes and J. A., Begley, Test Results from J-integral Studies: An Attemp to Establish a $J_{I c}$ Procedure, ASTM STP560, American Society for Testing and Materials, West Conshohoken, PA, pp. 170-186, 1974. 
56. Hughes, T. J., Generalization of Selective Integration Procedures to Anisotropic and Nonlinear Media, International Journal for Numerical Methods in Engineering, Vol. 15, pp. 1413-1418, 1980.

57. Koppenhoefer, K., Gullerud, A., Ruggieri, C., Dodds, R. and Healy, B., WARP3D: Dynamic Nonlinear Analysis of Solids Using a Preconditioned Conjugate Gradient Software Architecture, Structural Research Series (SRS) 596, UILU-ENG-94-2017, University of Illinois at Urbana-Champaign, 1994.

58. Hibbit, Karlson \& Sorensen, Inc., ABAQUS Theory Manual, Version 5.3, Providence R.I., 1993.

59. Hibbit, Karlson \& Sorensen, Inc., ABAQUS-Explicit Theory Manual, Version 5.3, Providence R.I., 1992.

60. Gourdeau G. L. and Halliquist J. O., Recent Developments in large-Scale Lagangian Hydrocode Tecnology, Computer Method in Applied mechanics and Engineering, Vol. 33, 725-757, 1982.

61. Simo J. C. and Hughes T. K., Elastoplasticity and viscoplasticity: Computationals aspects, Stanford University, 1988.

62. Nagtegaal, J. C., Parks, D. M., and Rice, J. R., On Numerically Accurate Finite Element Solutions in the Fully Plastic Range, Computer Methods in Applied Mechanics and Engineering, Vol. 4, pp. 153-178, 1974.

63. Moran, B., and Shih, C. F., Crack Tip and Associated Domain Integrals from Momentum and Energy Balance, Engineering Fracture Mechanics, Vol. 27, pp. 615-642, 1978.

64. Moran, B., and Shih, C. F., A General Treatment of Crack Tip Contour Integrals, International Journal of Fracture, Vol. 35, pp. 295-310, 1987.

65. MSC Patran Reference Manual, Disponível em: http://mscsoftware.com.

66. Nevalnien, M. and Dodds, R. H., Numerical Investigation of 3-D Constraint Effects on Brittle Fracture in $S E(B)$ and $C(T)$ Specimens, International Journal of Fracture, Vol 74, pp. 131-161, 1995.

67. Xia, L. and Shih, C. F. Ductile Crack Growth - I. A Numerical Study Using Computational Cells with Microstructurally-Based Length Scales. Journal of the Mechanics and Physics of Solids, Vol. 43 pp. 233-259, 1995,

68. Gurson, A. L., Continuum Theory of Ductile Rupture by Void Nucleation and Growth: Part I - Yield Criteria and Flow Rules for Porous Ductile Media, Journal of Engineering Materials and Technology, Vol. 99, pp. 2-15, 1977.

69. Tvergaard, V., Material Failure by Void Growth to Coalescence., Advances in Applied Mechanics, Vol. 27, pp. 83-151, 1990. 
70. Ruggieri, C., Panontin, T. L. and Dodds, R. H., Numerical Modeling of Ductile Crack Growth in 3-D Using Computational Cells, International Journal of Fracture, Vol. 82 pp. 67-95, 1996.

71. Faleskog, J., and Shih, C.F., Cell Model for Nonlinear Fracture Analysis - I: Micromechanics Calibration, International Journal of Fracture, Vol. 89, pp. 355-373, 1998.

72. Silva, M. S., Determinação da Tenacidade à Fratura de Aços Para Dutos API X60 Utilizando A Metodologia de Integral J com Determinação do Tamanho da Trinca por Queda de Potencial, Tese de Mestrado, COPPE, Universidade Federal de Rio de Janeiro, 2002.

73. Bose, W., Spinelli, D. Carvalho, A. L. M., Cravero, S. and Ruggieri, C., Experimental Evaluation of Crack Growth Resistance Curves for an API X60 Steel Using $S E(T)$ Specimens, Manucrito em Preparação.

74. Joyce, J. A., Manual on Elastic-Plastic Fracture: Laboratory Test procedures, ASTM Manual Series, MNL 27, 1996.

75. Saxena, A., Nonlinear Fracture Mechanics for Engineers, CRC Press, New York, 1998.

76. Shih, C. F. and de Lorenzi, H. G., Elastic Compliances and Stress-Intensity Factors For Side-Grooved Compact Specimens, Intrnational Journal of Fracture, Vol. 45, pp. 544-548, 1977.

77. The MathWorks Inc., Matlab software Version 6.5, 2 CD-ROM, 2002.

78. Kirk M.T. and Dodds R.H.Jr. J and CTOD Estimation Equations for Shallow Cracks in Single Edge Notch Bend Specimens, Journal of Testing and Evaluation, Vol. 21, No. 4, pp. 228-238, 1993.

79. Scibetta, M., 3-D Finite Element Simulation of the PCCv Specimen Statically Loaded in Three-Point Bending, Report BLG-860, SCK*CEN Mol, Bélgica, 2000 .

80. Piovatto, R. R., Desenvolvimento e Aplicação de Espécimes SE(T) Em Aço API X60 para Avaliação de Integridade Estrutural em Dutos Condutores de Gás e Petróleo, Tese de Doutorado, EESC, Universidade de São Paulo, 2007.

81. Underwood J.H., Troiano E.J. and Abbott R.T. Simpler $J_{I c}$ Test and Data Analysis, Procedures for High-Strength Steels, Fracture mechanics: "Twenty-Fourth Volume, ASME STP 1207, American Society for Testing and Materials, Philadelphia, pp. 410-421, 1994

82. American Society for Testing and Materials (ASTM), Test method for the determination of reference temperature, $T_{0}$, for ferritic steels in the transition range, ASTM E1921-05, Philadelphia, 2005. 
83. Dotta, F., Previssão da Pressão de Colápso em Dutos para Transporte de Gás e Petróleo Contendo Defeitos Planares Incorporando Curvas de Resistência J-R: Uma Abordagem Micromecânica Utilizando Critérios Locais, Tese de Doutorado, EPUSP, Universidade de São Paulo, 2006.

84. Faleskog, J. and Shih, C. F., Micromechanics of Coalescence - Synergistic Effects of Elasticity, Plastic Yielding and Multi-Size-Scale Voids, Journal of the Mechanics and Physics of Solids, Vol. 45, pp. 21-50, 1997.

85. Society of Automotive Engineers. High Strength Low Alloy Steel - SAE J410c. SAE Handbook, pp. 46, Estados Unidos, 1972.

86. Ruggieri, C., Modelagem Micromecânica da Fratura Dúctil e Aplicações à Integridade Estrutural, Tese apresentada para a obtenção do título de Professor Livre Docente, Departamento de Engenharia Naval e Oceânica da Escola Politécnica da USP, São Paulo, 2001.

87. Xia, L., and Shih, C. F., Ductile Crack Growth I - A Numerical Study Using Computational Cells with Microstructurally-Based Length Scale., Journal of the Mechanics and Physics of Solids, Vol. 43, pp. 233-259,1995.

88. Xia, L., and Shih, C. F., Ductile Crack Growth II - Void Nucleation and Geometry Effects on Macroscopic Fracture Behaviour., Journal of the Mechanics and Physics of Solids, Vol. 43, pp. 1953-1981,1995.

89. Ruggieri, C. and Dodds, R., H., Numerical Modeling of Ductile Crack Growth in 3-D Using Computational Cell Elements., International Journal of Fracture, Vol. 82, pp. 67-95, 1996.

90. Xia, L., and Shih, C. F., Ductile Crack Growth III - Statistical aspects cleavage fracture after tearing., Journal of the Mechanics and Physics of Solids, Vol. 44, pp. 603-639,1996.

91. Rice, J. R., Paris, P. C. and Merkle, J. G., Some Further Results of J-Integral Analysis and Estimates, ASTM STP 536 Progress in Flaws Growth and Fracture Toughness Testing, American Society for Testing and Materials, pp 231-245, 1973.

92. Dowling, N., E., Mechanical Behavior of Materials: Engineering Methods for Deformation, Fracture, and Fatigue,2nd Ed., West Conshohocken, New York, 1998.

93. Ernst, H. e Paris P. C., Techniques of Analysis of Load-Displacement Records by J-integral Methods, Nuclear Regulatory Commission, NUREG/ CR-1222, 1980.

94. Tada, H., Paris, P. C. and Irwin, G. R., The Stress Analysis of Cracks Handbook, 2nd Ed., 1985. 
95. Blatt, D., John, R. and Coker, D., Stress Intensity Factor and Compliance Solutions for a Single Edge Notched Specimen with Clampd Ends, Engineering Fracture Mechanics, Vol. 47, pp. 521-532, 1994.

96. John, R., Stress Intensity Factor and Compliance Solutions for an Eccentrically Loaded Single Edge Cracked Geometry, Engineering Fracture Mechanics, Vol. 58, pp. 87-96, 1997.

97. John, R. and Rigling, B., Effect of Height to Width Ratio on K and CMOD Solutions for a Single Edge Cracked Geometry with Clamped Ends, Engineering Fracture Mechanics, Vol. 60, pp. 147-156, 1998. 


\section{FATORES $\eta$ E $\gamma$ PARA A MEDIÇÃO EXPERIMENTAL DE INTEGRAL $J$}

\section{A.1 O Fator $\eta_{J}$}

Rice e colaboradores [91] apresentaram a correlação entre a energia de deformação $U$ e a integral $J$ para algumas configurações de corpos-de-prova. Baseados neste trabalho, Sumpter e Turner [49] propuseram o parâmetro $\eta_{J}$ para relacionar a energia de deformação $U$ com a integral $J$. As deduções apresentadas nesta seção são adaptações das seções 3.2.1 e 3.2.5 do livro Fracture Mechanics Fundamentals and Aplications pp. 133-137 [32] e da seção 5.2.2 do livro Nonlinear Fracture Mechanics for Engineers pp. 113-116 [75] apresentando a fundamentação teórica para o fator $\eta_{J}$.

Nas formulações apresentadas a seguir será empregada a seguinte notação, a qual é consistente com os capítulos anteriores. Entretanto, para facilitar a leitura é novamente definida.

$A_{p}^{\mathrm{CMOD}}$ : área plástica sob a curva P-CMOD.

$A_{p}^{\mathrm{LLD}}$ : área plástica sob a curva $P$-LLD.

$b=W-a$ : ligamento Remanescente.

$J$ : integral $J$.

$J_{e}:$ componente elástica da Integral $J$.

$J_{p}$ : componente plástica da Integral $J$.

$M$ : momento aplicado.

$P$ : força aplicada.

$U$ : energia de deformação.

$U_{p}$ : componente plástica da energia de deformação. 
$U^{*}$ : energia de deformação complementar.

$V$ : deslocamento da boca da trinca (CMOD).

$V_{p}$ : deslocamento plástico da boca da trinca $\left(\mathrm{CMOD}_{p l}\right)$.

$\Delta$ : deslocamento da linha de carga (LLD) devido à presença da trinca.

$\Delta_{e}$ : deslocamento elástico da linha de carga $\left(\mathrm{LLD}_{e l}\right)$ devido à presença da trinca.

$\Delta_{p}$ : deslocamento plástico da linha de carga $\left(\operatorname{LLD}_{p l}\right)$ devido à presença da trinca.

$\eta_{J}=\eta_{J}^{\mathrm{LLD}}$ : fator adimensional obtido da curva $P$-LLD. Notar que é suprimido o sobrescrito LLD para simplificar a notação.

$\eta_{J}^{\mathrm{CMOD}}$ : fator adimensional obtido da curva P-CMOD.

$\theta$ : ângulo de rotação.

$\theta_{c}$ : ângulo de rotação devido à presença da trinca.

$\theta_{n c}:$ ângulo de rotação correspondente ao corpo sem trinca.

A integral $J$ pode ser definida como a derivada da energia potencial do sólido em relação à área da trinca

$$
J=-\left(\frac{\partial U}{\partial A}\right)_{\Delta}
$$

onde $U$ é a energia absorvida pelo espécime durante a aplicação da carga e $\partial A$ é o incremento na área da superfície da trinca. $\mathrm{O}$ subscrito $\Delta$ indica que o carregamento é controlado por deslocamento. No caso de espécime com espessura constante, $\partial A=B \cdot \partial a$. Onde $\partial a$ é o incremento na profundidade da trinca e $B$ é a espessura do espécime portanto, a Eq. (A.1) pode adotar a seguinte forma

$$
J=-\frac{1}{B}\left(\frac{\partial U}{\partial a}\right)_{\Delta}
$$

Se é considerado que a trinca avança com carregamento fixo (veja Fig. A.1), 


$$
J=\frac{1}{B}\left(\frac{\partial U^{*}}{\partial a}\right)_{P}
$$

onde $U^{*}$ é a energia de deformação complementar. Ambas quantidades (Eqs (A.2) e (A.3)) diferem em $1 / 2 \cdot(d P \cdot d \Delta)$, valor infinitesimal de ordem superior a $d U$ e pode ser desconsiderado quando o incremento $d a$ é pequeno. Portanto, o $J$ obtido da Eq. (A.2) é igual ao $J$ obtido da Eq. (A.3). Novamente, observando a Fig. A.1 a energia de deformação complementar é definida como ${ }^{1}$

$$
U^{*}=\int_{0}^{P} \Delta d P
$$

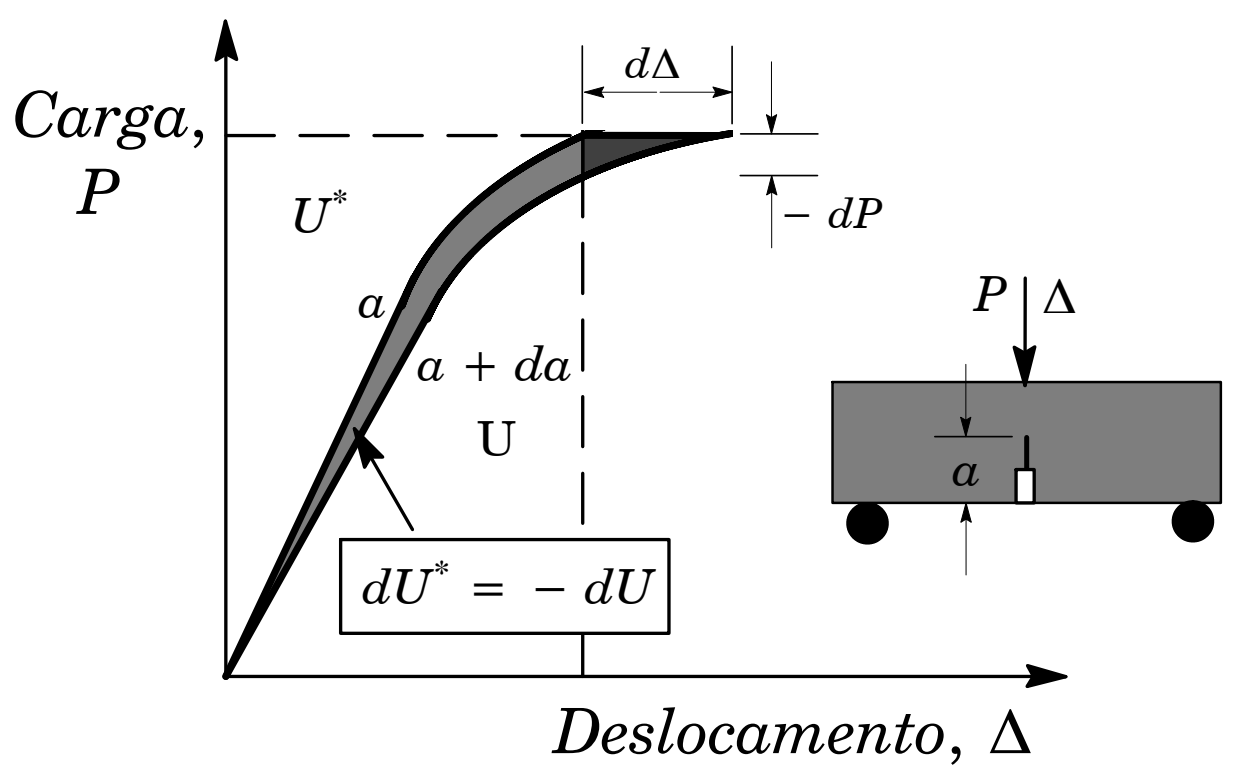

Figura A.1 Curvas carga vs. deslocamento com crescimento de trinca controlado por deslocamento ou por força.

Substituindo a Eq. (A.4) na Eq. (A.3), $J$ pode ser expresso da seguinte forma,

1) A partir deste ponto considera-se que o corpo-de-prova tem espessura unitária $(B=1)$ e, desta forma, elimina-se a constante $B$ das seguintes equações sem prejuízo da dedução. 


$$
J=\left[\frac{\partial}{\partial a} \int_{0}^{P} \Delta d P\right]_{p}=\int_{0}^{P}\left(\frac{\partial \Delta}{\partial a}\right)_{P} d P
$$

A continuação, considera-se uma placa com entalhe lateral de dimensão $a$ e com ligamento remanescente de dimensão $b=(W-a)$ submetida a flexão pura através de momento $M$ (veja Fig. A.2). O deslocamento pode ser medido pelo ângulo $\theta$ o qual é dividido em duas componentes. A primeira delas é o ângulo devido ao esforço aplicado quando não há trinca presente na placa $(\alpha=0)$, o qual denota-se $\theta_{n c}$ a outra componente do ângulo é devido à presença da trinca, $\theta_{c}$. Portanto, o giro total é

$$
\theta=\theta_{n c}+\theta_{c}
$$

No caso da placa ter uma trinca profunda, $\theta_{n c} \ll \theta_{c}$ e pode ser considerado que $\theta=\theta_{c}$.
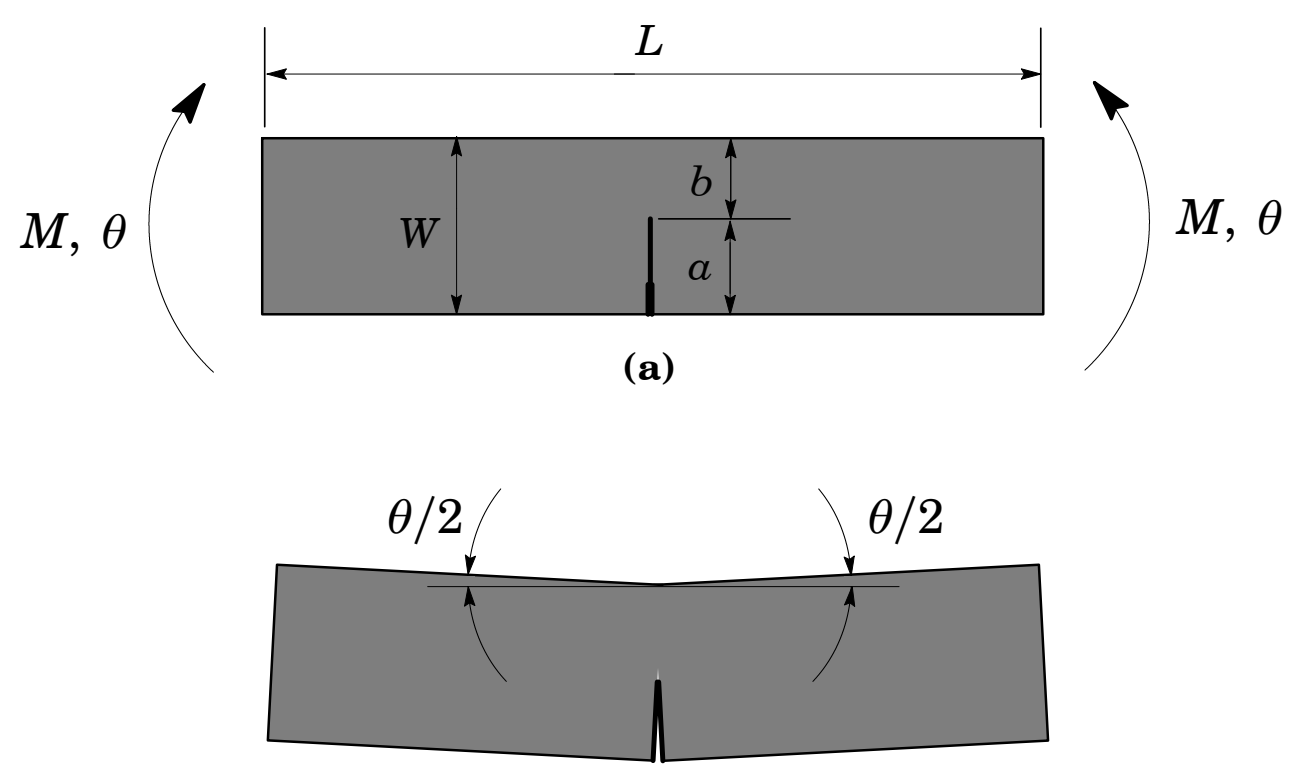

(b)

Figura A.2 Corpo-de-prova com entalhe lateral submetido a flexão pura; a) Sem deformar; b) Deformado. 
A energia absorvida pela placa durante o carregamento pode ser obtida da seguinte forma

$$
U=\int_{0}^{\theta} M d \theta
$$

Quando diferencia-se a energia $U$ em relação à área da trinca para determinar a integral $J$, somente $\theta_{c}$ contribui à taxa de liberação de energia porque $\theta_{n c}$ não é uma função do comprimento da trinca. Por analogia com a Eq. (A.4), $J$ para a placa em flexão pode ser expressa por

$$
J=\int_{0}^{M}\left(\frac{\partial \theta_{c}}{\partial a}\right)_{M} d M
$$

sendo $d a=-d b$,

$$
J=-\int_{0}^{M}\left(\frac{\partial \theta_{c}}{\partial b}\right)_{M} d M
$$

Para calcular a integral $J$ usando a Eq. (A.9) é preciso conhecer a relação carga-deslocamento e as dimensões da placa. Assumindo que as propriedades de tensão-deformação do material constituinte seguem uma lei de Ramberg-Osgood [92], uma análise dimensional fornece a seguinte relação funcional para o ângulo de giro [32]

$$
\theta_{c}=f\left(\frac{M}{b^{2}}\right)
$$

É dizer que o ângulo $\theta_{c}$ depende do momento aplicado e do ligamento remanescente. Esta hipótese é razoável quando a relação comprimento de trinca-largura do espécime é grande $(a / W \geqslant 0,5)$ porque, assume-se, toda a deformação está restrita ao ligamento do corpo-de-prova. 
Para continuar com a dedução é preciso obter a derivada da Eq. (A.10) em relação a $b$ e a $M$. Pela regra da cadeia obtém-se,

$$
\frac{\partial \theta_{c}}{\partial b}=\frac{\partial f}{\partial b}=-\frac{2 M}{b^{3}} \cdot f^{\prime}
$$

$\mathrm{e}$

$$
\frac{\partial \theta_{c}}{\partial M}=\frac{\partial f}{\partial M}=\frac{1}{b^{2}} \cdot f^{\prime}
$$

onde

$$
f^{\prime}=\frac{d f}{d\left(\frac{M}{b^{2}}\right)}
$$

Substituindo a Eq. (A.11) na Eq. (A.9) obtém-se

$$
J=\int_{0}^{M}\left(-\frac{2 M}{b^{2}}\right) \cdot f^{\prime} d M
$$

da Eq. (A.12),

$$
d \theta_{c}=f^{\prime} \cdot \frac{d M}{b^{2}}
$$

Portanto a Eq. (A.14) pode ser expressa como

$$
J=\frac{2}{b} \int_{0}^{\theta_{c}} M d \theta_{c}
$$

A integral da Eq. (A.16), representa o trabalho de deformação $U$ aplicado ao corpo-de-prova. Deve-se notar que o ângulo para a medição da energia de deformação $\theta_{c}$ corresponde à presença da trinca. Entretanto, em termos práticos é 
razoável o emprego do ângulo total quando a trinca é profunda. Uma vez que a contribuição ao ângulo do corpo sem trinca é pequena.

Para o caso mais comum de corpo-de-prova à flexão em 3 pontos com comprimento $H$, carga pontual $P$ e deslocamento da linha de carga medido por $\Delta$ (veja Fig. A.3), pode ser escrito

$$
M=\frac{P H}{2} \quad \text { e } \quad \Delta=\frac{\theta_{c}}{2} H
$$

portanto

$$
d \theta_{c}=\frac{2}{H} d V
$$

assumindo $\theta_{c}=\theta$, (válido para trinca profunda) temos,

$$
\int_{0}^{\theta} M d \theta=\int_{0}^{\Delta} P d \Delta
$$

logo, incluindo a espessura do espécime, $B$

$$
J=\frac{2}{B b} \int_{0}^{\Delta} P d \Delta
$$

A integral acima representa a área sob a curva carga vs. deslocamento da linha de carga $\left(P\right.$-LLD) e o fator 2 que está multiplicando à integral é o conhecido $\eta_{J}^{\mathrm{LLD}}$ para corpos à flexão em 3 pontos empregados pela ASTM 1820 [12].

Para manter concordância com a mecânica da fratura elástica linear, o deslocamento $\Delta$ é separado nas suas componentes elástica e plástica $\left(\Delta=\Delta_{l l}+\Delta_{p l}\right)$ e a Eq. (A.20) é escrita da seguinte forma,

$$
J=\frac{2}{B b}\left[\int_{0}^{\Delta_{e}} P d \Delta_{e}+\int_{0}^{\Delta_{p}} P d \Delta_{p}\right]
$$


Conseqüentemente

$$
J=J_{e}+J_{p}=\frac{K_{\mathrm{I}}^{2}}{E^{\prime}}+\frac{2}{B b} \int_{0}^{\Delta_{p}} P d \Delta_{p} .
$$

Sendo que a integral é a área sob a curva $P-\mathrm{LLD}_{p}$, a Eq. (A.22) pode ser reescrita da seguinte forma,

$$
J=\frac{K_{\mathrm{I}}^{2}}{E^{\prime}}+\frac{\eta_{J} \cdot A_{p}^{\mathrm{LLD}}}{B b}
$$

Esta fórmula é a empregada pela ASTM E1820 [12] para trinca estacionária.

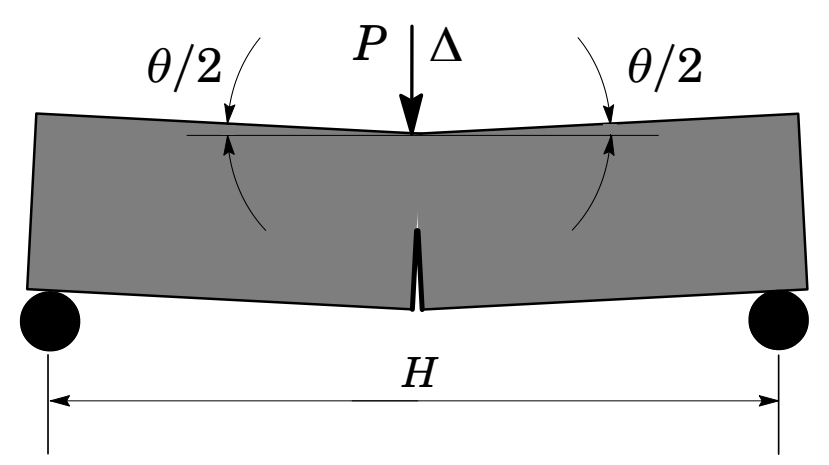

Figura A.3 Corpo-de-prova à flexão em 3 pontos.

As deduções e derivações apresentadas demonstraram a relação proporcional entre a energia de deformação e a integral $J$ para corpo-de-provas à flexão por meio de um fator adimensional $\eta_{J}=2$. Este fator existe para outras configurações. Para maiores detalhes sobre a dedução analítica de $\eta_{J}$ em outras geometrias o leitor pode consultar os trabalhos de e Rice e colaboradores [91] Sumpter e Turner [49], Paris et al. [50] e Kanninen e Popelar [34]. Entretanto, basicamente a condição de existência do fator $\eta_{J}$ é que a relação entre o carregamento e o deslocamento plástico possa ser escrito em variáveis separáveis da seguinte forma [93],

$$
P=f_{(a)} \cdot g_{\left(\Delta_{p}\right)}
$$


Onde a função $f$ depende do comprimento de trinca, $a$, e a função $g$ depende do deslocamento plástico da linha de carga, $\operatorname{LLD}_{p}$.

\section{A.2 Medição Experimental de Integral $J$ com Crescimento Estável de Trinca}

O fator $\eta_{J}$ obtido na seção precedente permite a medição experimental da porção plástica da integral $J$ em trincas estacionárias. Quando se tem uma trinca propagando de forma estável, a não linearidade da curva carga vs. deslocamento não somente é devido à não linearidade do material mas, também, devido ao crescimento de trinca. A Fig. A.4 apresenta esquematicamente uma curva carga vs. deslocamento plástico para um corpo-de-prova com crescimento estável de trinca. Também, podem ser observadas as curvas $P-\Delta_{p}$ correspondentes a diferentes comprimentos de trincas estacionárias. A seguir apresenta-se a dedução de uma formulação para a determinação experimental de $J$ plástico quando há crescimento estável de trinca. Esta formulação é devida a Ernst e colaboradores [51].

Sendo que a integral $J$ é definida para material com comportamento não linear elástico, o cálculo da integral pode ser feito por diferentes caminhos de integração sem mudança no resultado final. Por exemplo, observando a Fig. A.4, para obter o valor de $J$ no ponto $\mathrm{C}$ o caminho poderia ser $\mathrm{OAC}$ ou $\mathrm{OBC}$ resultando no mesmo valor final.

A componente plástica de $J$ pode ser expressa da seguinte forma (Eqs. (A.22) e (A.23))

$$
J_{p}=\frac{\eta_{J}}{B b} \int_{0}^{\Delta_{p}} P d \Delta_{p}=\frac{\eta_{J} \cdot U_{p}}{B b} .
$$

Assumindo espessura unitária,

$$
J_{p}=\frac{\eta_{J} \cdot U_{p}}{b}
$$




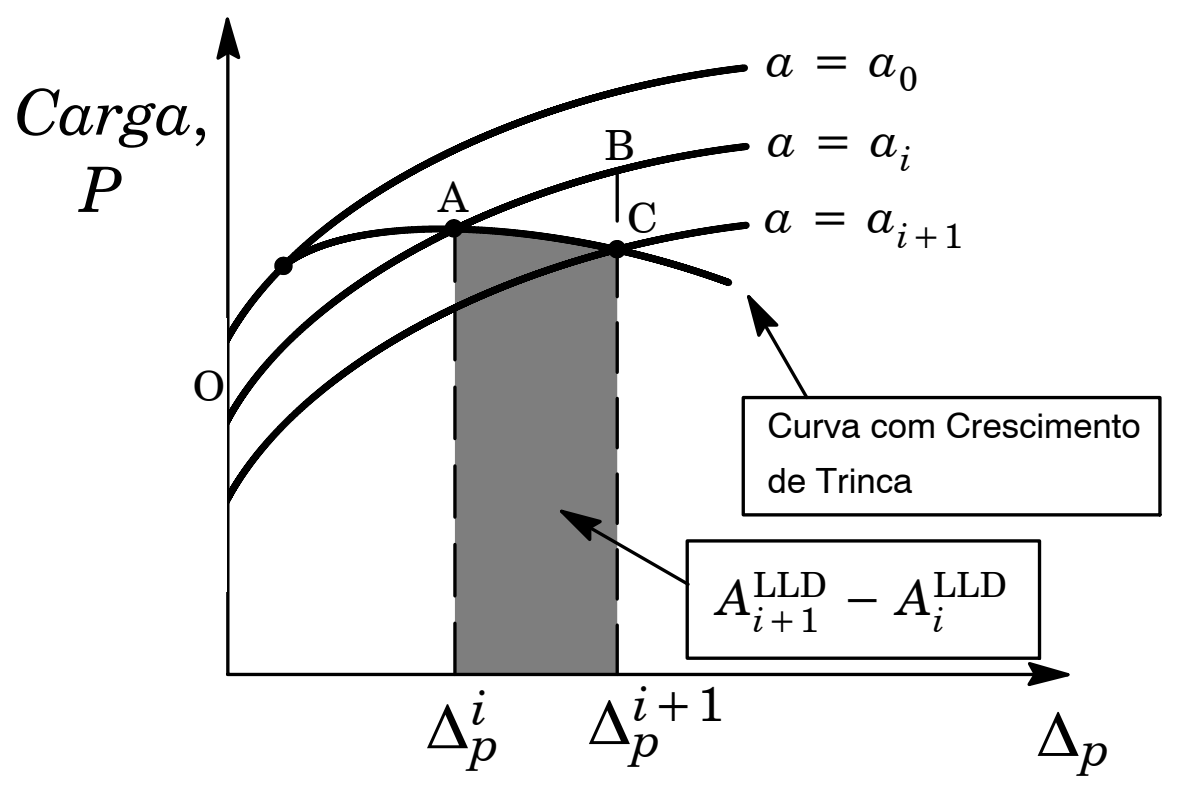

Figura A.4 Curva esquemática carga vs. deslocamento plástico com crescimento estável de trinca.

Da equação acima, $\eta_{J}$ é função da profundidade de trinca, $a$, e $U_{p}$ é função de $a$ e do deslocamento plástico $\Delta_{p}$. Portanto, $J$ é função das mesmas variáveis e o diferencial de $J$ pode ser expresso da seguinte forma,

$$
d J_{p}=\frac{\partial J_{p}}{\partial \Delta_{p}} d \Delta_{p}+\frac{\partial J_{p}}{\partial a} d a
$$

Da Eq. (A.26) e considerando que $b=W-a$, as derivadas parciais da equação anterior são

$$
\begin{aligned}
& \frac{\partial J_{p}}{\partial \Delta_{p}}=\frac{\eta_{J}}{W-a} \frac{\partial U_{p}}{\partial \Delta_{p}} \\
& \frac{\partial J_{p}}{\partial a}=\frac{1}{(W-a)} \frac{d \eta_{J}}{d a} U_{p}+\frac{\eta_{J}}{(W-a)^{2}} U_{p}+\frac{\eta_{J}}{(W-a)} \frac{\partial U_{p}}{\partial a} .
\end{aligned}
$$

Introduzindo as derivadas parciais das Eqs. (A.28) e (A.29) na Eq. (A.27), o diferencial pode ser expresso da seguinte forma 


$$
\begin{aligned}
d J_{p}= & {\left[\frac{\eta_{J}}{(W-a)^{2}} U_{p}+\frac{1}{(W-a)} \frac{d \eta_{J}}{d a} U_{p}+\right.} \\
& \left.\frac{\eta_{J}}{(W-a)} \frac{\partial U_{p}}{\partial a}\right] d a+\left[\frac{\eta_{J}}{W-a} \frac{\partial U_{p}}{\partial \Delta}\right] d \Delta_{p}
\end{aligned}
$$

Reordenando,

$$
\begin{aligned}
d J_{p}= & \frac{\eta_{J}}{(W-a)}\left[\frac{\partial U_{p}}{\partial \Delta_{p}} d \Delta_{p}+\frac{\partial U_{p}}{\partial a} d a\right]+ \\
& \frac{\eta_{J}}{(W-a)^{2}} U_{p}\left[1+\frac{b}{\eta_{J}} \frac{d \eta_{J}}{d a}\right] d a
\end{aligned}
$$

Sendo,

$$
\begin{aligned}
& J_{p}=-\frac{\partial U_{p}}{\partial a} \\
& \frac{J_{p}}{(W-a)}=\frac{\eta_{J} U_{p}}{(W-a)^{2}} \mathrm{e} \\
& P=\frac{\partial U_{p}}{\partial \Delta_{p}}
\end{aligned}
$$

Substituindo na Eq. (A.2) e lembrando novamente que $b=W-a$,

$$
d J_{p}=\frac{\eta_{J}}{b}\left[P d \Delta-J_{p} d a\right]+\frac{J_{p}}{b}\left[1+\frac{b}{\eta_{J}} \frac{d \eta_{J}}{d a}\right] d a
$$

Reordenando novamente e simplificando

$$
d J_{p}=\frac{\eta_{J}}{b} P d \Delta_{p}+\left[-\eta_{J}+1+\frac{b}{\eta_{J}} \frac{d \eta_{J}}{d a}\right] \frac{1}{b} J_{p} d a
$$


O termo entre colchetes é denominado $-\gamma$ [51], portanto

$$
d J_{p}=\frac{\eta_{J}}{b} P d \Delta_{p}-\frac{\gamma}{b} J_{p} d a
$$

Agora integrando para $\Delta_{p}$ e para $a$, obtém-se a seguinte expressão para $J_{p}$

$$
J_{p}=\int_{0}^{\Delta_{p}} \frac{\eta_{J}}{b} P d \Delta_{p}-\int_{a_{0}}^{a} \frac{\gamma}{b} J_{p} d a
$$

No caso de trinca estacionária a segunda integral da Eq. (A.38) é nula retornado-se à expressão da Eq. (A.25) e, no caso de crescimento estável de trinca, também pode ser empregada para a estimação de $J_{p}$.

Observando novamente a Fig. A.4 e lembrando que a integral $J$ é expressa para material com comportamento não linear elástico $J_{p}$ pode ser integrada em diversas etapas. Portanto, $J_{p}$ no ponto A da Fig. A.4 pode ser obtida integrando a Eq. (A.38) e, supondo que até este ponto não há crescimento de trinca,

$$
J_{p}^{A}=J_{p}^{i}=\left(\frac{\eta_{J}}{b}\right)_{i} \int_{0}^{\Delta_{p}^{i}} P d \Delta_{p},
$$

onde a integral representa a área debaixo da curva OA. Também, para o ponto B (ainda sem crescimento de trinca)

$$
J_{p}^{B}=J_{p}^{i}+\left(\frac{\eta_{J}}{b}\right)_{i} \int_{\Delta_{p}^{i}}^{\Delta_{p}^{i+1}} P d \Delta_{p}
$$

Para determinar $J_{p}$ no ponto $\mathrm{C}$ da Fig. A.4 com crescimento de trinca desde $a_{i}$ até $a_{i+1}$ integra-se a Eq. (A.38) no caminho OB e depois no caminho BC. O deslocamento plástico da linha de carga, $\Delta_{p}$, é constante neste último trecho de integração, portanto, 


$$
J_{p}^{i+1}=J_{p}^{B}-\int_{a_{i}}^{a_{i+1}} \frac{\gamma}{b} J_{p} d a
$$

aproximando para incrementos finitos de crescimento de trinca e considerando o fator $\gamma$ constante no incremento,

$$
\int_{a_{i}}^{a_{i+1}} \frac{\gamma}{b} J_{p} d a \cong\left(\frac{\gamma}{b}\right)_{i} J_{p}^{B}\left(a_{i+1}-a_{i}\right)
$$

Desta forma $J_{p}^{i+1}$ pode ser aproximado da seguinte forma

$$
J_{p}^{i+1}=J_{p}^{B}-\left(\frac{\gamma}{b}\right)_{i} J_{p}^{B}\left(a_{i+1}-a_{i}\right)
$$

Agora, recordando que as integrais das Eqs. (A.39) e (A.40) representam as áreas debaixo das curvas carga vs. deslocamento plástico da linha de carga $\left(P-\operatorname{LLD}_{p}\right)$ e empregando a simplificação da Eq. (A.42), pode ser estabelecida a seguinte formulação para a determinação da componente plástica da integral $J$,

$$
J_{p}^{i+1}=\left[J_{p} i+\left(\frac{\eta_{J}^{\mathrm{LLD}}}{b}\right)_{i}\left(A_{p, i+1}^{\mathrm{LLD}}-A_{p, i}^{\mathrm{LLD}}\right)\right]\left[1-\left(\frac{\gamma}{b}\right)_{i}\left(a_{i+1}-a_{i}\right)\right] .
$$

Na expressão acima, $\eta_{J}$ foi trocado por $\eta_{J}^{\mathrm{LLD}}$ para evitar confusão na nomenclatura. Esta equação é a empregada pela norma ASTM E1820 para a determinação de $J_{p}$ com crescimento estável de trinca e é uma aproximação da Eq. (A.38). No caso de corpo-de-prova com espessura diferente da unidade é preciso dividir o lado direito da Eq. (A.44) por $B$.

É importante destacar que o fator $\gamma$ definido na Eq. (A.36)

$$
\gamma=\eta_{J}-1-\frac{b}{\eta_{J}} \frac{d \eta_{J}}{d a}
$$


em muitos casos é expresso da seguinte forma,

$$
\gamma=\eta-1+\frac{b}{W \eta_{J}} \frac{d \eta_{J}}{d(b / W)}
$$

Onde a derivada de $\eta_{J}$ é expressa em relação à relação $b / W$ e deve ser dividida pela largura do espécime para manter a equivalência entre as derivadas das Eqs. (A.45) e (A.46). 


\section{SOLUÇÕES PARA O FATOR DE INTENSIDADE DE TENSÕES $K_{\text {I }}$ EM ESPÉCIMES SE(T)}

A avaliação da componente elástica da integral $J$ em espécimes $\mathrm{SE}(\mathrm{T})$ requer soluções acuradas para o fator de intensidade de tensões $K_{\mathrm{I}}$. Enquanto que alguns estudos prévios [94 - 97] fornecem o fator de intensidade de tensões para esta geometria, as soluções publicadas abrangem uma faixa limitada de proporções geométricas tais como $a / W$ e $H / W$. O presente anexo fornece um detalhado conjunto de soluções $K_{\mathrm{I}}$ para corpos-de-prova $\mathrm{SE}(\mathrm{T})$ carregados por pinos e fixados por garra com diferentes proporções geométricas ( $a / W$ e $H / W$ ) e carregamento excêntrico (como apresentado na Fig B.3, para o caso de carregamento por pinos, o centro do mesmo é deslocado em relação ao centro do espécime). Este anexo reproduz os resultados de Schiodo e colaboradores [52] e são inclusos na presente tese para facilitar a sua leitura.

O fator de intensidade de tensões é definido da seguinte forma

$$
K_{\mathrm{I}}=\frac{P}{B \sqrt{W}} \mathscr{F}(a / W)
$$

onde $\mathcal{F}(a / W)$ representa um fator de intensidade de tensões adimensional que depende da geometria do espécime, profundidade da trinca e condições de carregamento. $P$ é a carga aplicada, $B$ é a espessura do espécime e $W$ é a largura do mesmo. Para $P, B, W$ e condição de carregamento dados, o valor de $K_{\mathrm{I}}$ é obtido da avaliação de $\mathcal{F}(a / W)$ para $a / W$ e $H / W$.

Uma extensa matriz de análise considera espécimes $\mathrm{SE}(\mathrm{T})$ submetidos a diferentes condições de carregamento (pino vs. garra) e relações diversas de tamanho de trinca relativa, $a / W=0,1$ a 0,7 com incrementos de 0,1 e distância do ponto de aplicação da carga sobre largura, $H / W=2,4,6,8,10,20,50$. Adicionalmente, para avaliar os efeitos do deslocamento do ponto de aplicação da 
carga no fator de intensidade de tensões (load point offset ou LPO), denotado por c, análises numéricos adicionas foram conduzidas em espécimes $\mathrm{SE}(\mathrm{T})$ carregados por pinos com comprimento relativo $H / W=6$ para $c= \pm 0,05 W$ e $\pm 0,1 W$.

As análises numéricas lineares 2D sob estado plano de deformações foram conduzidas utilizando-se o programa de elementos finitos WARP3D [57]. Para cada modelo, a avaliação do fator de intensidade de tensões elásticas é feita empregando a relação $J=K_{\mathrm{I}}^{2} / E^{\prime}$ onde $E^{\prime}=E /(1-v)^{2} \operatorname{com} v=0,3$ e $E=206 \mathrm{GPa}$. os modelos de elementos finitos empregados têm similar nível de detalhamento aos descritos no capítulo 4.

A Fig. B.1 apresenta a variação de $\mathscr{F}(a / W)$ com a relação $a / W$ e diversos valores de $H / W$ para espécimes $\mathrm{SE}(\mathrm{T})$ carregados por pinos. O resultado importante associado a este corpo-de-prova é a completa independência de $\mathcal{F}(a / W)$ em relação ao comprimento $H$. Em contraste, a Fig. B.2 revela que o espécime SE(T) fixado por garras exibe grande dependência sobre o valor de $H / W$, particularmente para comprimentos maiores de trinca $(a / W \leq 0,5)$. A Fig. B.3 apresenta a variação de $\mathcal{F}(a / W)$ em função da relação $a / W$ e diversos valores da excentricidade de carga, $c$, para o espécime SE(T) carregado por pinos. Como poderia ser antecipado, valores negativos da excentricidade c aumentam o momento flexor agente sobre a trinca com conseqüente incremento do SIF para um mesmo nível de carga, $P$. Para facilitar o cálculo dos SIFs de espécimes $\mathrm{SE}(\mathrm{T})$, foi realizado um ajuste não linear (por intermédio do método dos mínimos quadrados) de todos os resultados numéricos derivados das análises apresentadas. As curvas foram ajustadas através de funções polinomiais de grau 5 expressas por

$$
\mathscr{F}(a / W)=\xi_{0}+\xi_{1}(a e / W)+\xi_{2}(a / W)^{2}+\xi_{3}(a / W)^{3}+\xi_{4}(a / W)^{4}+\xi_{5}(a / W)^{5}
$$

onde os coeficientes do polinômio são apresentados na Tabela B.1. O caso $\mathrm{SE}(\mathrm{T})_{P}$ $\operatorname{com} c=0$ corresponde aos resultados das análises apresentadas na Fig. B.1. 


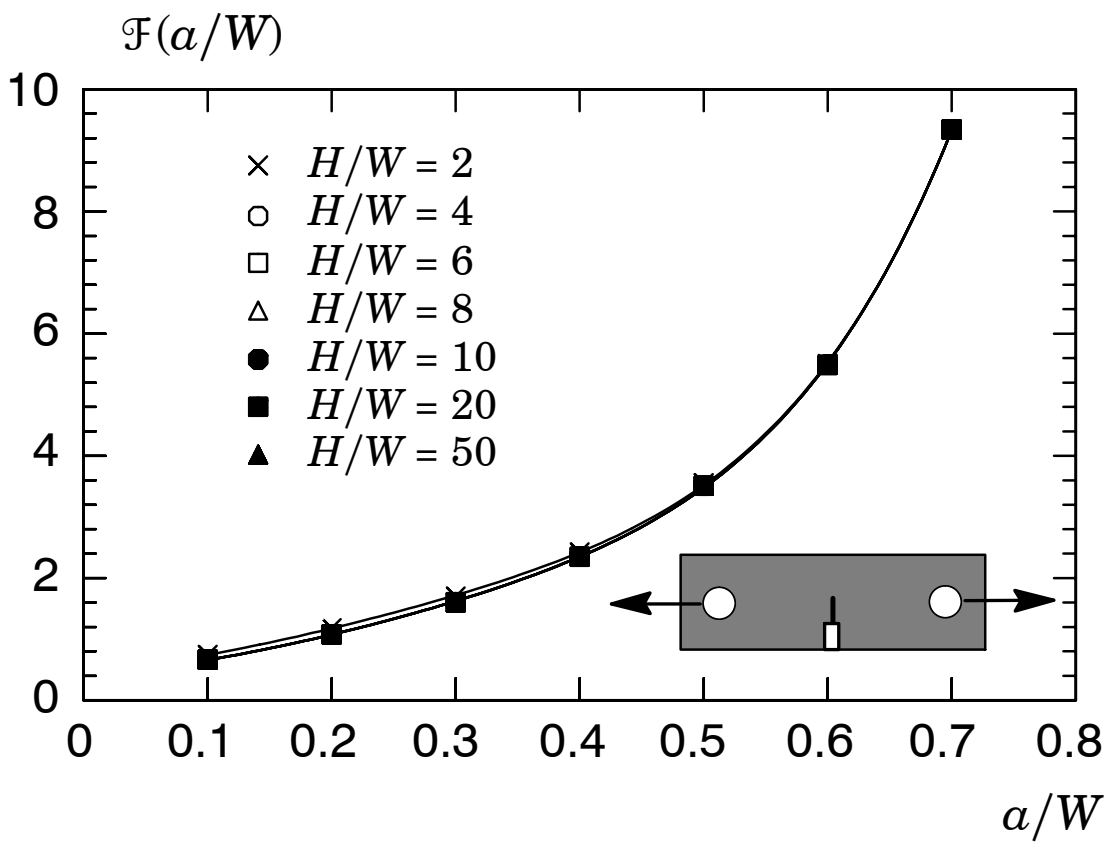

Figura B.1 Variação do fator de intensidade de tensões adimensional em função de a / W e diferentes valores de $H / W$ para o espécime $S E(T)$ carregado por pino.

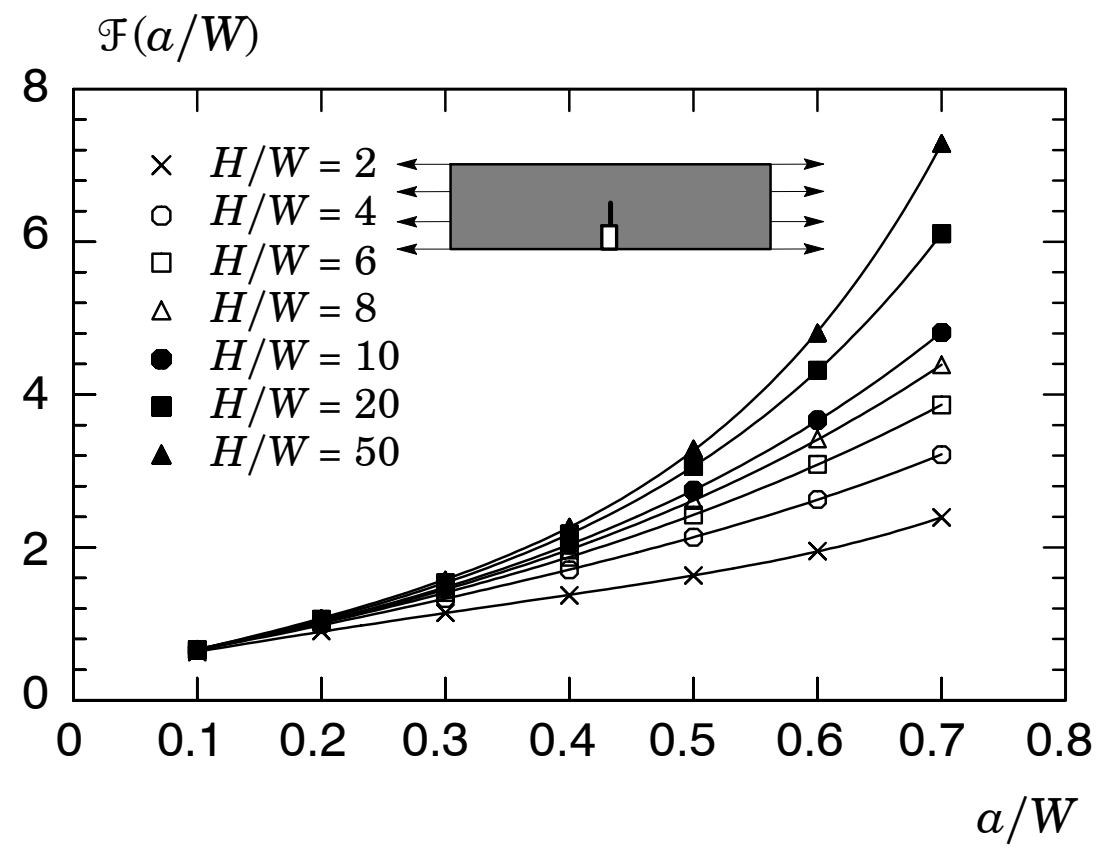

Figura B.2 Variação do fator de intensidade de tensões adimensional em função de a / W e diferentes valores de $H$ / W para o espécime $S E(T)$ carregado por garra. 

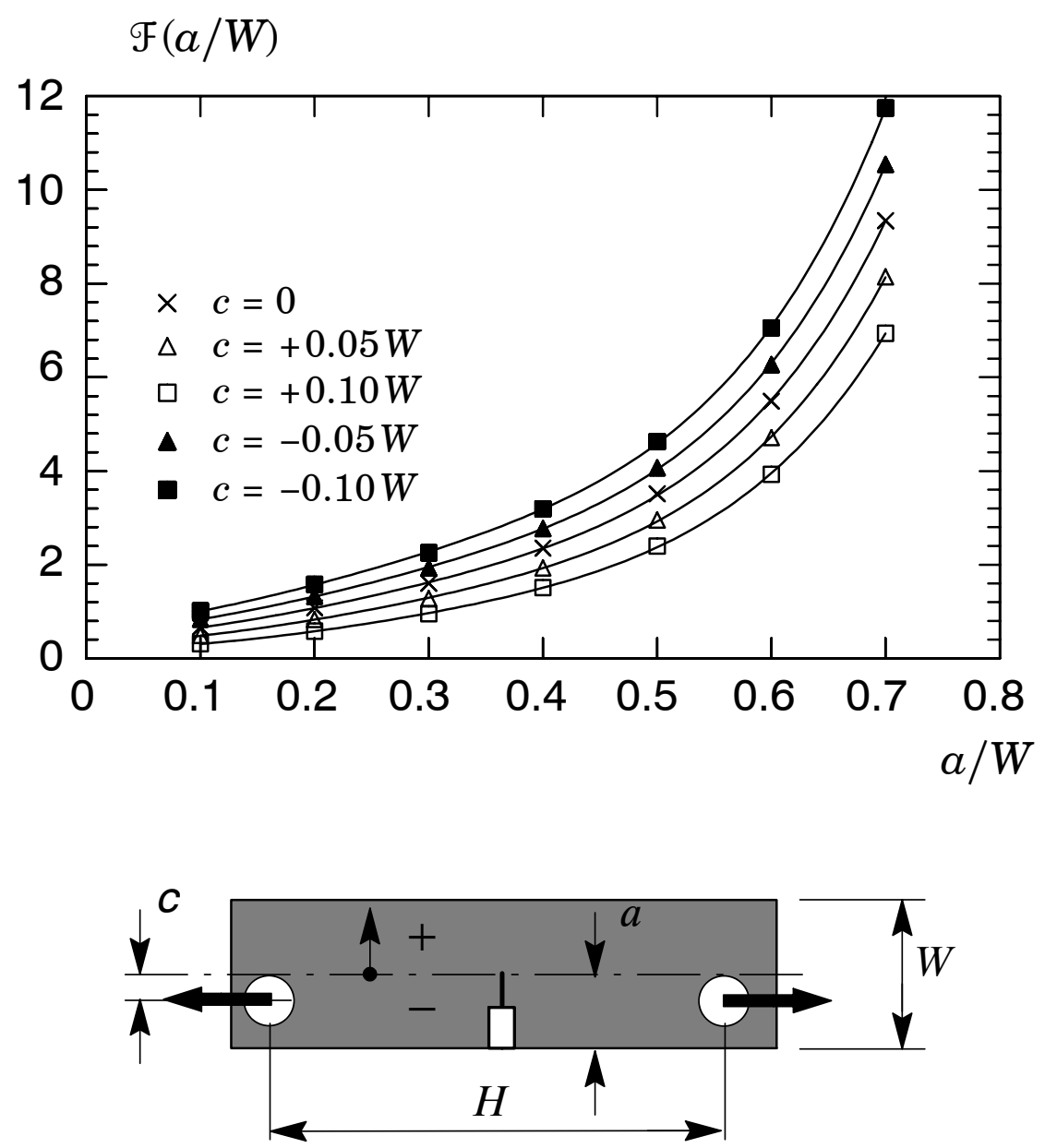

Figura B.3 Variação de $F(a / W)$ em função de a/W e diferentes valores da excentricidade c para o espécime $S E(T)$ carregado por pino 


\begin{tabular}{|c|c|c|c|c|c|c|c|c|c|c|c|c|}
\hline$\mu^{20}$ &  & 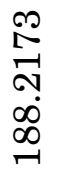 & 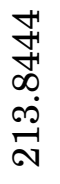 & 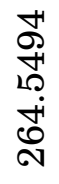 & 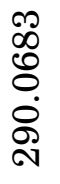 & 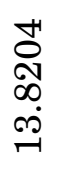 & 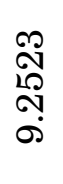 & 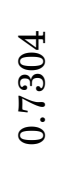 & 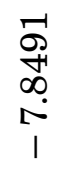 & 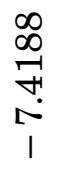 & $\begin{array}{l}\stackrel{9}{+} \\
\stackrel{+}{+} \\
\stackrel{\sigma}{\circ}\end{array}$ & 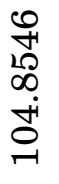 \\
\hline$u^{+}$ & $\begin{array}{l}0 \\
6 \\
10 \\
10 \\
10 \\
00 \\
10\end{array}$ & 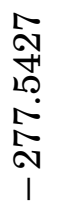 & $\begin{array}{l}\infty \\
\overrightarrow{0} \\
19 \\
0 \\
0 \\
0 \\
0 \\
1\end{array}$ & 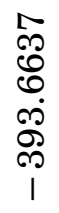 & 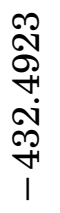 &  & 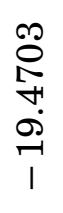 & \begin{tabular}{l}
0 \\
$\stackrel{0}{N}$ \\
\multirow{H}{N}{} \\
0 \\
1
\end{tabular} & 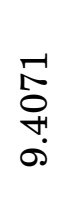 & 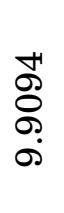 & 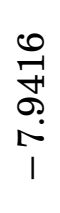 & $\begin{array}{l}0 \\
\mathscr{0} \\
0 \\
\dot{0} \\
10 \\
-1 \\
1\end{array}$ \\
\hline wn & 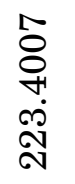 & $\begin{array}{l}\infty \\
2 \\
\infty \\
\infty \\
- \\
\\
\end{array}$ & $\begin{array}{l}-1 \\
\infty \\
10 \\
0 \\
5 \\
0 \\
-1\end{array}$ & 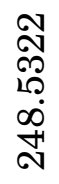 & 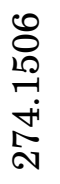 & 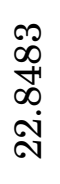 & 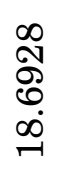 & 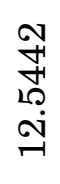 & $\begin{array}{l}\infty \\
5 \\
5 \\
10 \\
0 \\
0\end{array}$ & $\begin{array}{l}\stackrel{0}{二} \\
\stackrel{ }{二} \\
\stackrel{+}{+}\end{array}$ & 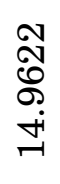 & 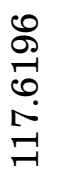 \\
\hline ws & 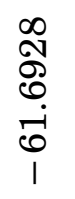 & $\begin{array}{l}\infty \\
\stackrel{2}{\text { N }} \\
\stackrel{10}{10} \\
\stackrel{1}{1} \\
\end{array}$ & $\begin{array}{l}\not 1 \\
\infty \\
0 \\
0 \\
10 \\
10 \\
1\end{array}$ & $\begin{array}{l}\infty \\
10 \\
0 \\
1+ \\
8 \\
0 \\
1\end{array}$ & 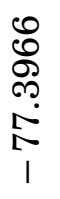 & 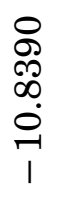 & 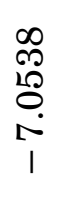 & $\begin{array}{l}\infty \\
8 \\
8 \\
10 \\
+1 \\
1 \\
1\end{array}$ & 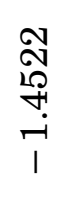 & $\begin{array}{l}10 \\
\infty \\
\infty \\
+ \\
+ \\
\stackrel{1}{1}\end{array}$ & $\begin{array}{l}\text { ని } \\
\ddot{0} \\
\infty \\
\text { ஸे } \\
1\end{array}$ & 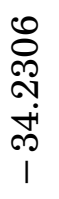 \\
\hline$\mu^{-1}$ & 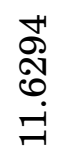 & $\begin{array}{l}10 \\
\emptyset \\
\stackrel{0}{\circ} \\
\stackrel{1}{N}\end{array}$ & \begin{tabular}{l}
10 \\
$\infty$ \\
$\infty$ \\
\multicolumn{1}{c}{} \\
$\infty$
\end{tabular} & $\begin{array}{l}10 \\
\stackrel{10}{+} \\
\stackrel{1}{+} \\
\stackrel{2}{\circ}\end{array}$ & 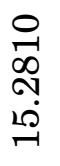 &  & $\begin{array}{l}\text { J } \\
\text { Oे } \\
+1 \\
+\end{array}$ & $\begin{array}{l}0 \\
\stackrel{0}{-} \\
\stackrel{-1}{+} \\
+\end{array}$ & $\begin{array}{l}\infty \\
0 \\
\infty \\
\infty \\
\infty\end{array}$ &  & 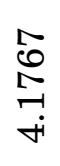 & \begin{tabular}{l}
0 \\
$\notin$ \\
$\infty$ \\
\multirow{2}{0}{} \\
$\infty$
\end{tabular} \\
\hline un & 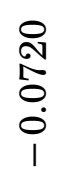 & $\begin{array}{l}0 \\
\infty \\
0 \\
-1 \\
0 \\
1\end{array}$ & \begin{tabular}{l} 
Oे \\
ᄋ \\
\multirow{0}{0}{} \\
$\stackrel{0}{0}$ \\
1
\end{tabular} & 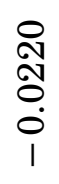 & $\begin{array}{l}\hat{6} \\
\stackrel{1}{ } \\
\text { ô } \\
\stackrel{0}{0}\end{array}$ & $\begin{array}{l}\stackrel{8}{\circ} \\
\text { ๙ิ } \\
\text { ஸิ } \\
0\end{array}$ & $\begin{array}{l}10 \\
60 \\
10 \\
\sim 1 \\
0\end{array}$ & 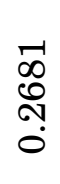 & $\begin{array}{l}N \\
i ̊ \\
\infty \\
\stackrel{\infty}{0} \\
0\end{array}$ & $\begin{array}{l}\text { Nै } \\
\infty \\
\infty \\
\stackrel{D}{0} \\
0\end{array}$ & \begin{tabular}{l}
$N$ \\
$\infty$ \\
0 \\
\multirow{0}{0}{} \\
0 \\
0
\end{tabular} & $\begin{array}{l}\stackrel{0}{+} \\
\stackrel{+}{5} \\
\text { ○ } \\
0\end{array}$ \\
\hline 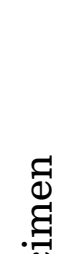 & @! & $\begin{array}{l}3 \\
\\
0 \\
+ \\
\text { II }\end{array}$ & $\begin{array}{l}30 \\
0 \\
0 \\
+ \\
\text { II }\end{array}$ & $\begin{array}{l}10 \\
0 \\
0 \\
0 \\
1 \\
11\end{array}$ & 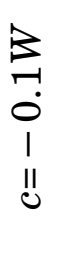 &  & $\underset{⿱ 亠}{\mathbb{I}}$ & $\underset{\Sigma}{11}$ & $\underset{\mathbb{1}}{\stackrel{\infty}{11}}$ & $\begin{array}{l}\stackrel{0}{1} \\
\stackrel{11}{11} \\
\stackrel{1}{1}\end{array}$ & $\frac{\substack{\text { N } \\
\text { II } \\
\stackrel{I}{I}}}{\mathbb{Z}}$ & $\begin{array}{l}\stackrel{0}{10} \\
\mathbb{1 1} \\
\stackrel{1}{11} \\
\mathbb{1}\end{array}$ \\
\hline 至 & \multicolumn{5}{|c|}{  } & \multicolumn{7}{|c|}{ 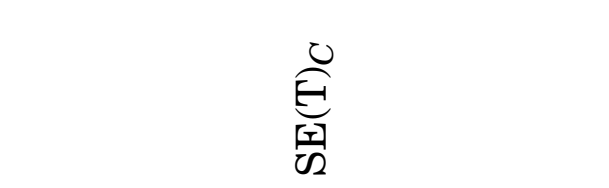 } \\
\hline
\end{tabular}

